\title{
THE MARINE BIOGEOCHEMISTRY OF CHROMIUM ISOTOPES
}

By

Simone Beatrice Moos

B.Sc., Jacobs University, 2011

Submitted in partial fulfillment of the requirements for the degree of

Doctor of Philosophy

at the

MASSACHUSETTS INSTITUTE OF TECHNOLOGY

and the

WOODS HOLE OCEANOGRAPHIC INSTITUTION

February 2018

(C) 2018 Simone B. Moos

All rights reserved.

The author hereby grants to MIT and WHOI permission to reproduce and to distribute publicly paper and electronic copies of this thesis document in whole or in part in any medium now known or hereafter created.

Signature of Author

Joint Program in Oceanography/Applied Ocean Science and Engineering Massachusetts Institute of Technology and Woods Hole Oceanographic Institution October 20, 2017

Certified by

Edward A. Boyle

Professor of Ocean Geochemistry

Thesis Supervisor

Accepted by

Shuhei Ono

Associate Professor

Chair, Joint Committee for Chemical Oceanography

Woods Hole Oceanographic Institution 


\title{
THE MARINE BIOGEOCHEMISTRY OF CHROMIUM ISOTOPES
}

\author{
by \\ Simone Beatrice Moos
Submitted to the MIT/WHOI Joint Program in Oceanography/Applied Ocean Science and Engineering
on October $20^{\text {th }}, 2017$, in partial fulfillment of the
requirements for the degree of
Doctor of Philosophy

In the ocean, chromium $(\mathrm{Cr})$ is a redox-sensitive trace metal. The reduction of $\mathrm{Cr}$ (VI) to $\mathrm{Cr}$ (III) occurs in oxygen deficient zones (ODZs), and $\mathrm{Cr}$ reduction in general has been identified as a significant $\mathrm{Cr}$ isotope fractionation mechanism. This thesis presents the first $\mathrm{Cr}$ isotope variations $\left(\delta^{53} \mathrm{Cr}\right)$ in ODZs of the ocean and adds to the sparse $\mathrm{Cr}$ isotope data published for modern seawater.

I developed a precise and accurate $\mathrm{Cr}$ isotope method for seawater samples. Seawater acidification converts total $\mathrm{Cr}$ to $\mathrm{Cr}(\mathrm{III})$ which is preconcentrated by $\mathrm{Mg}(\mathrm{OH})_{2}$ coprecipitation. A three-column anion exchange chromatography scheme separates $\mathrm{Cr}$ from isobaric and polyatomic interferences present in the seawater and reagent matrixes. Isotope analysis is performed on a MC-ICP-MS IsoProbe. The addition of a ${ }^{50} \mathrm{Cr}-{ }^{54} \mathrm{Cr}$ double spike allows for accurate correction of procedural and instrumental $\mathrm{Cr}$ mass fractionations.

The first $\mathrm{Cr}$ isotope ratio data for a full water column profile in the Pacific Ocean is presented. This station serves as a fully oxic counterpart to stations located within the ODZ of the Eastern Tropical North Pacific. At one station, Cr concentrations are lower and $\delta^{53} \mathrm{Cr}$ values are heavier within the ODZ. This is consistent with $\mathrm{Cr}$ reduction resulting in isotopically lighter, particlereactive $\mathrm{Cr}$ (III), which is scavenged and exported from the water column. A strong correlation of

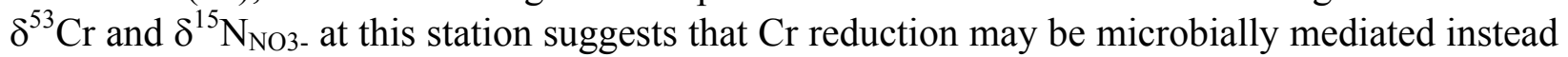
of simply being a product of thermodynamic equilibrium. Alternatively, $\mathrm{Cr}$ may be reduced by $\mathrm{Fe}(\mathrm{II})$. In the anoxic bottom waters of the Santa Barbara Basin a strong Cr reduction signal (lower $[\mathrm{Cr}]$, heavier $\delta^{53} \mathrm{Cr}$ ) is observed, which may result from the same aforementioned $\mathrm{Cr}$ reduction mechanisms. A shift to the heaviest seawater $\mathrm{Cr}$ isotope signatures yet observed was detected in the oxic bottom waters of the shallow Arctic Chukchi shelf, while Cr concentrations decreased. This extreme isotope signal may result from $\mathrm{Cr}$ reduction by a reduced species (e.g. Fe(II)), which was released from the underlying anoxic shelf sediments. $\mathrm{Cr}$ in the Atlantic layer and in the bottom water of a central Arctic station appears to be shaped by a novel, unidentified process.

Thesis Supervisor: Edward A. Boyle

Title: Professor of Ocean Geochemistry 


\section{Acknowledgements}

First and foremost, I would like to thank my advisor, Dr. Edward Boyle. Ed embarked with me into uncharted waters by suggesting I work on the marine chromium isotope system. The $\mathrm{Cr}$ isotope system was new to both of us, but held great promise. He always encouraged me and never lost faith when seemingly intractable obstacles in the method development arose. Oftentimes Ed believed in my capabilities more than I did myself, and he consistently pushed me to become an independent scientist. Beyond his support as a colleague, he has also been a genuine friend who welcomed me into his family for more than one Thanksgiving weekend.

I also would like to thank my PhD committee: Sune Nielsen and Colleen Hansel. Sune brought a great deal of valuable method development experience to the table, and Colleen's extensive background in microbial systems was tremendously appreciated. Whenever I was at a loss for how to proceed, both of them were welcoming, supportive and full of ideas. I would be remiss if I did not also thank Tanja Bosak, who accepted a request to chair my defense on very short notice.

Mark Altabet and Jessica Fitzsimmons helped tremendously by collecting seawater samples for me from the Eastern Tropical North Pacific Ocean and the Santa Barbara Basin, respectively. Frank Stewart was also helpful in streamlining logistics for the ETNP expedition.

I also want to offer my sincere gratitude to members of the Boyle lab. Jess Fitzsimmons, especially, took me under her wing and was a dear friend. Rick Kayser provided much appreciated technical support in the lab. Gonzalo Carrasco, Jong-Mi Lee, Christopher Hayes, Abigail Noble, and Cheryl Zurbrick gave valuable advice and extended their friendship. I would also like to thank Mengli Chen and Tianyi Huang for their support.

Many of my Joint Program and MIT peers became great friends: David Wang, Cara Manning, Christine Chen, Christopher Kingsley, Rene Boiteau, and many more.

The emotional support that my parents and my fiancé provided through all the ups and downs of my method development was invaluable. I love you and could not have done it without you!

This research was supported by the US National Science Foundation (NSF Award No. OCE0926197, OCE-1233749, OCE-1357224), the Singapore National Research Foundation through the Singapore-MIT Alliance for Research and Technology (Award No. WBS 6916070), and the Center for Microbial Research and Education (NSF-OIA Award No. EF-0424599). In the last year of my studies, I was supported by a MIT-WHOI Joint Program Science Fellowship. 


\section{Table of Contents}

\section{Chapter 1: Introduction}

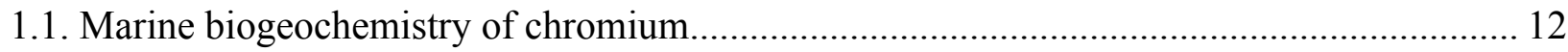

1.2. Notations, natural $\mathrm{Cr}$ isotope abundances, reporting $\mathrm{Cr}$ isotope signatures and fractionation

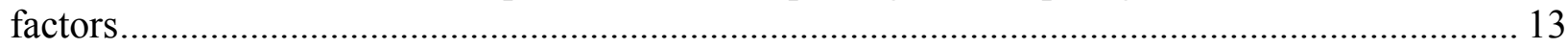

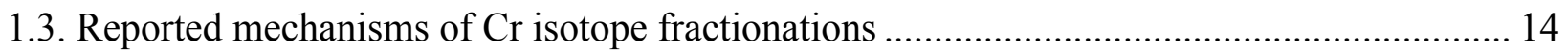

1.4. $\mathrm{Cr}$ isotope signatures reported for different terrestrial reservoirs ...................................... 15

1.5. The $\mathrm{Cr}$ isotope system as a paleo-redox proxy …........................................................ 15

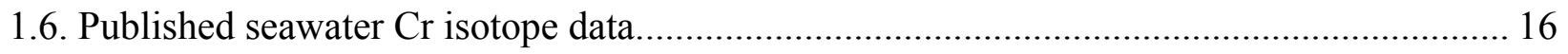

1.7. Cr reduction in oxygen deficient zones of the ocean ..................................................... 17

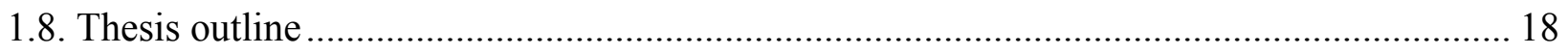

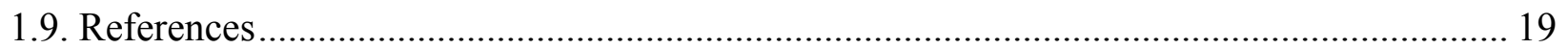

Chapter 2: Determination of Accurate and Precise Chromium Isotope Ratios in Seawater Samples Illustrated by Analysis of SAFe Station in the Pacific Ocean

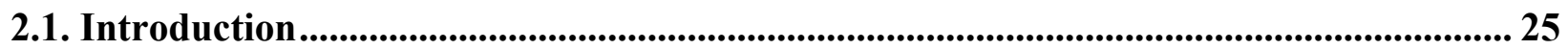

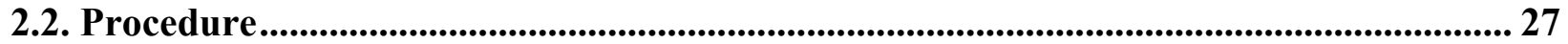

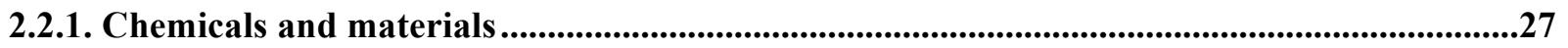

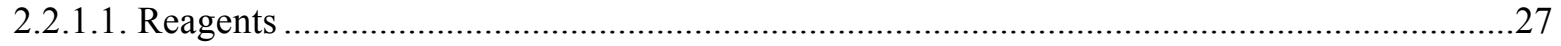

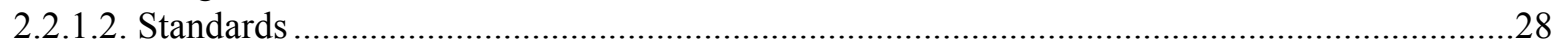

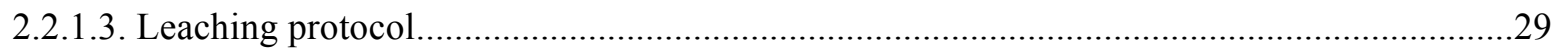

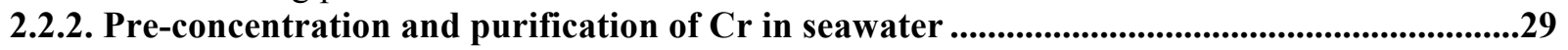

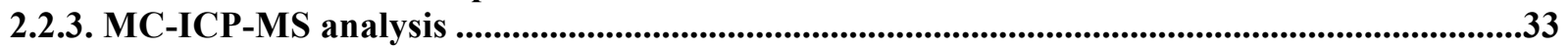

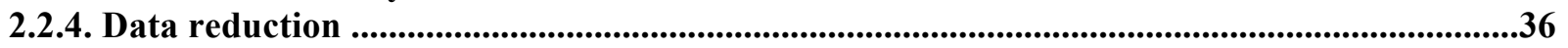

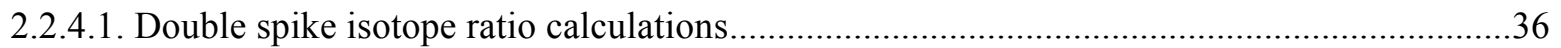

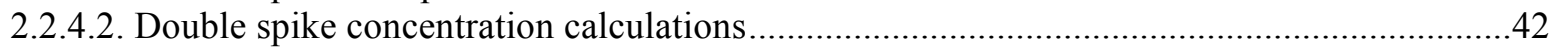

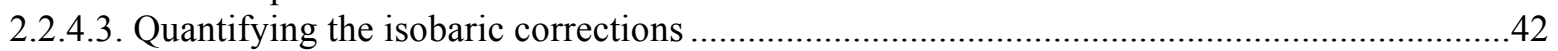

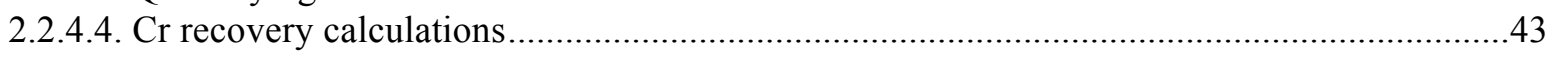

2.3. Results and discussion ............................................................................................. 44

2.3.1. The intricacies of the $\mathrm{Cr}$ oxidation step using ammonium persulfate .....................................44

2.3.2. Accuracy and precision of SRM-DS solutions processed through the oxidation step and

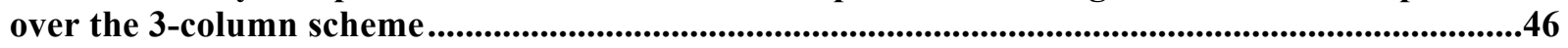

2.3.3. Application of the developed $\mathrm{Cr}$ isotope method to seawater samples.....................................47

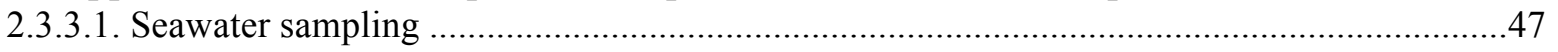

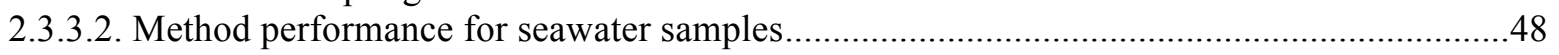

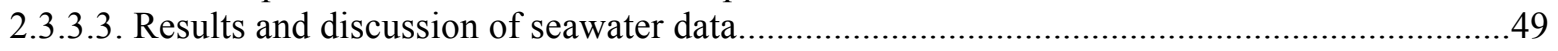

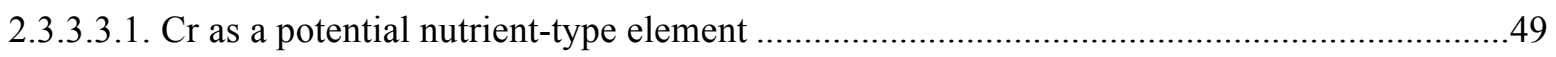

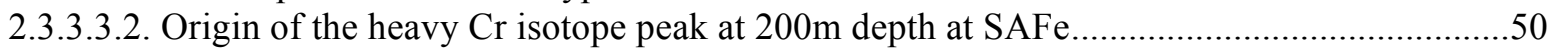

2.3.3.3.3. Position of SAFe samples and the internal reference sample on the global $\mathrm{Cr}$ array .........51

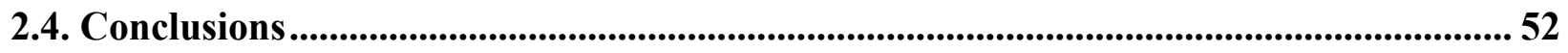




\section{Chapter 3: Investigating chromium cycling in oxygen deficient waters of the Northeast Pacific Ocean using stable Cr isotopes}

3.1. Introduction 67

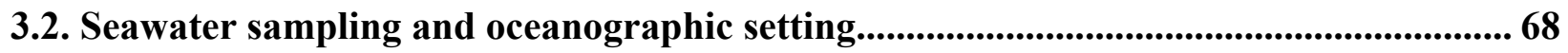

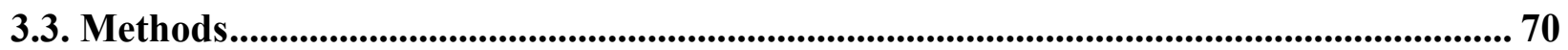

3.3.1. Other oceanographic parameters ................................................................................................71

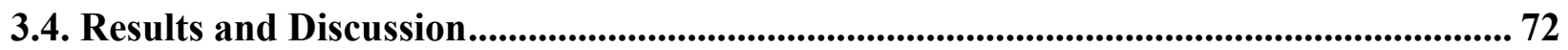

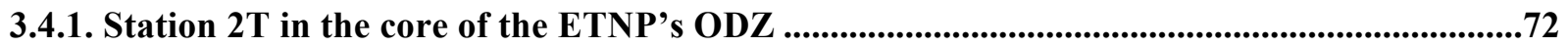

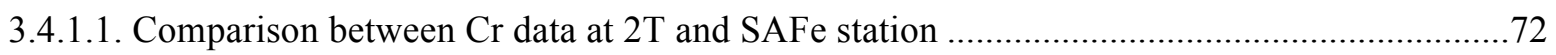

3.4.1.2. Probable effect of analyzing unfiltered ODZ samples versus filtered ODZ samples .............73

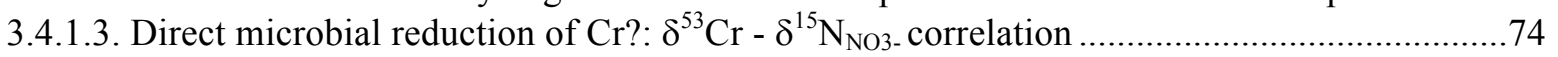

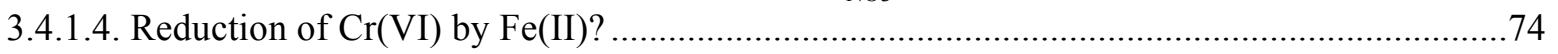

3.4.2. Station 7T in the core of the ETNP's ODZ .....................................................................................75

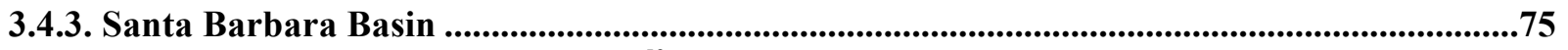

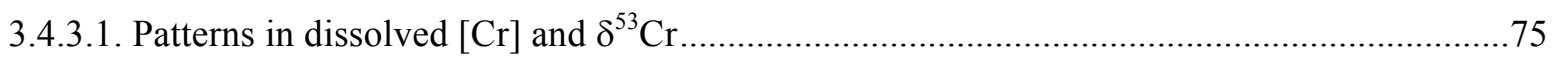

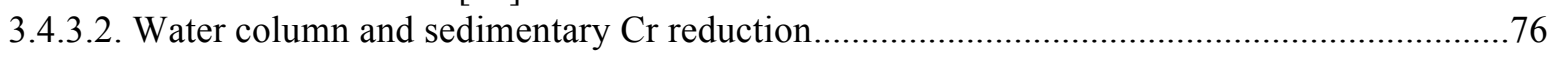

3.4.3.3. Potential mechanisms of $\mathrm{Cr}(\mathrm{VI})$ reduction ................................................................... 77

3.4.3.4. Cr concentration gradient for the possibility of sedimentary $\mathrm{Cr}$ reduction...........................78

3.4.4. Cr data from ETNP (2T, 7T) and the Santa Barbara Basin on the global Cr array ............79

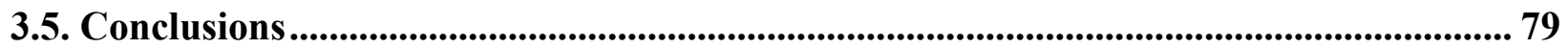

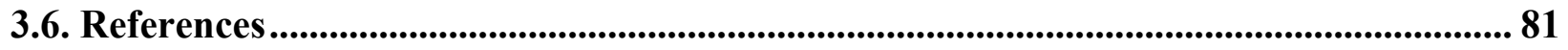

Chapter 4: Investigating Cr Cycling on the Arctic Chukchi Shelf and in the Central Artic Ocean using Cr Stable Isotopes

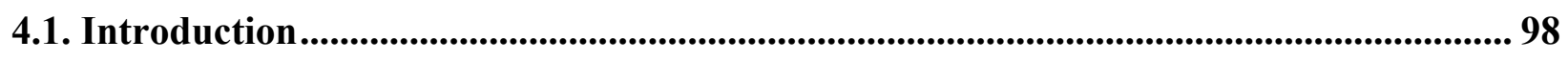

4.2. Seawater sampling and oceanographic setting........................................................... 99

4.3. Methods....................................................................................................................................... 100

4.3.1. Other oceanographic parameters ...............................................................................................101

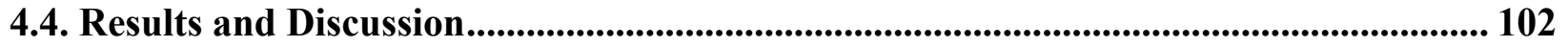

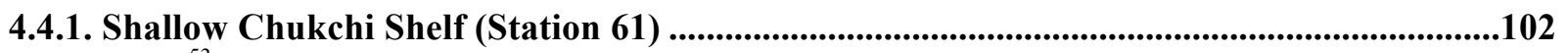

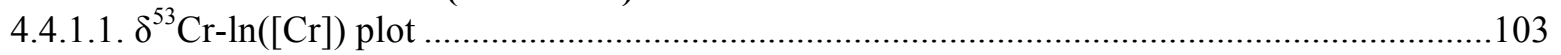

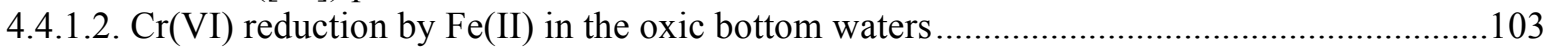

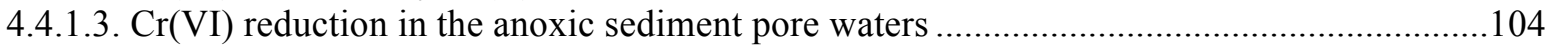

4.4.1.4. Cr(VI) reduction mechanisms in the anoxic sediment pore waters .................................105

4.4.1.5. Pore water $\mathrm{Cr}$ concentration gradient for the possibility of sedimentary $\mathrm{Cr}$ reduction ........106

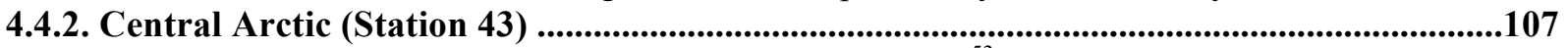

4.4.2.1. Cr data from station 43 above the Alpha Ridge on a $\delta^{53} \mathrm{Cr}-\ln ([\mathrm{Cr}])$ plot...........................109

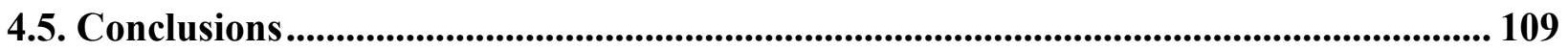

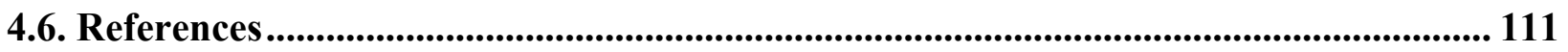


Chapter 5: Summary, Conclusions \& Outlook

5.1. Method for determination of accurate and precise $\mathrm{Cr}$ isotope ratios in seawater....... 125

5.2. Interpretation of $\mathrm{Cr}$ isotope ratio data of analyzed seawater samples ....................... 126

5.3. Recommendations for future research................................................................. 129

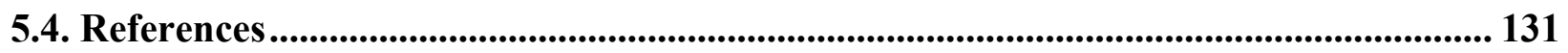

\section{Appendix}

Annual variability of total $\mathrm{Cr}$ concentrations of seawater samples taken at $40 \mathrm{~m}-47 \mathrm{~m}$ depth

off of Bermuda......................................................................132 


\section{List of Tables}

\section{Chapter 2}

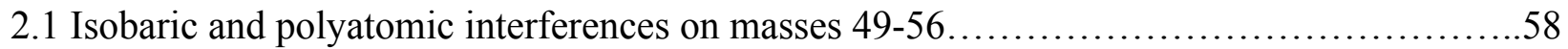

2.2 Faraday cup configuration for the 3 sequences within a MC-ICP-MS detection cycle........58

2.3 Parameters for a typical seawater $\mathrm{Cr}$ isotope run on the MC-ICP-MS ...................59

2.4 $\mathrm{Cr}$ isotope ratio and concentration data table for processed SRM-DS solutions, SAFe samples, and our internal reference sample........................................6

\section{Chapter 3}

3.1 $\mathrm{Cr}$ isotope ratio and concentration data table for Eastern Tropical North Pacific Ocean samples and Santa Barbara Basin samples........................................ 85

\section{Chapter 4}

4.1 $\mathrm{Cr}$ isotope ratio and concentration data table for Arctic Ocean samples..................114

\section{Appendix}

A.1. Total Cr concentration data of seawater samples taken between 40m - 47m depth off of 


\section{List of Figures}

\section{Chapter 1}

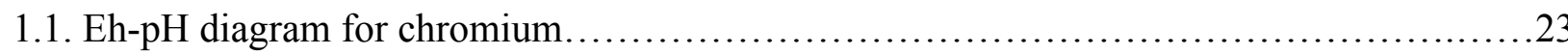

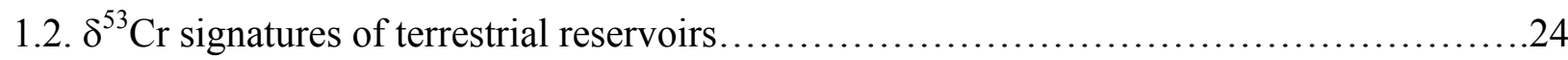

\section{Chapter 2}

2.1 Impact of MC-ICP-MS tuning parameters on the sulfur polyatomic signal (=mass 49) relative to the Cr signal (=mass 52): a) nebulizer gas flow, b) intermediate gas flow, and c) axial torch box position........................................................61

2.2 Variation in $\delta^{53} \mathrm{Cr}$ offset of bracketing SRM-DS solutions with a) concentration of bracketing SRM-DS solutions, and b) run sequence of bracketing SRM-DS solutions................62

2.3 Variation in $\delta^{53} \mathrm{Cr}$ offset of bracketing SRM-DS solutions containing different percentages of

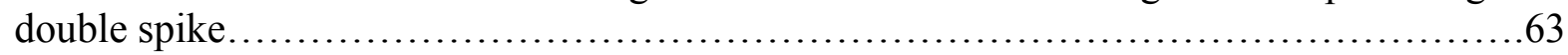

$2.4 \delta^{53} \mathrm{Cr}$ signatures of SRM-DS solutions that were processed through the $\mathrm{Cr}$ (III) oxidation step

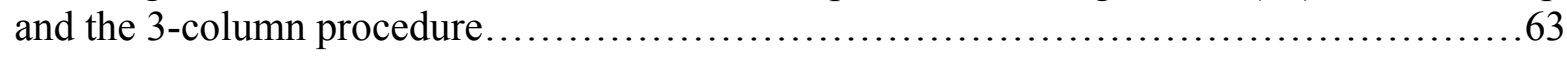

2.5 Map of sampling locations (SAFe station; station from Rue et al., 1997) superimposed onto

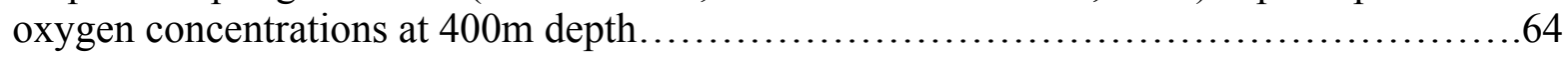

2.6 Profiles of $\mathrm{Cr}$ concentrations, $\mathrm{Cr}$ isotope ratios and other oceanographic parameters at $\mathrm{SAFe}$

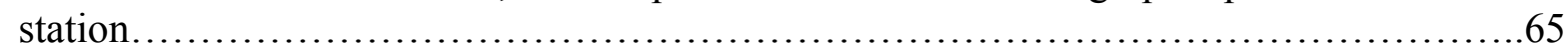

2.7 $\mathrm{Cr}$ data from SAFe station, our internal reference sample and the literature on a $\delta^{53} \mathrm{Cr}$ -

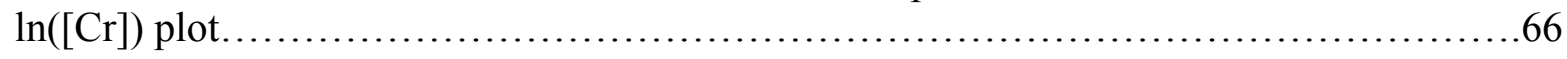

\section{Chapter 3}

3.1 Map of sampling locations (2T, 7T, Santa Barbara Basin, SAFe, Murray et al. (1983), Rue et al. (1997)) in the North Pacific Ocean superimposed onto oxygen concentrations at 400m

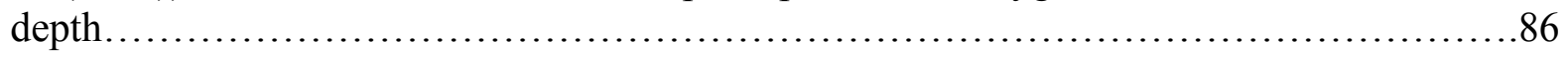

3.2 Bathymetric map of Santa Barbara Basin which indicates our sampling site...............87

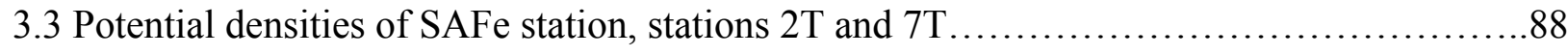


3.4 Approximation of the SAFe station's $[\mathrm{Cr}]-\sigma_{\theta}$ relationship and the $\delta^{53} \mathrm{Cr}-\sigma_{\theta}$ relationship by polynomials.

3.5 Profiles of $\mathrm{Cr}$ concentrations, $\mathrm{Cr}$ isotope ratios and other oceanographic parameters at station $2 \mathrm{~T}$. .90

3.6 Profiles of $\mathrm{Cr}$ concentrations, $\mathrm{Cr}$ isotope ratios and other oceanographic parameters at station 7T. ...

3.7 Profiles of $\mathrm{Cr}$ concentrations, $\mathrm{Cr}$ isotope ratios and other oceanographic parameters at our Santa Barbara Basin sampling site

3.8 Modeling the observed $\mathrm{Cr}$ isotope ratios at station 2T by applying different fractionation factors to the Rayleigh distillation equation.................................... 93

$3.9 \delta^{15} \mathrm{~N}_{\mathrm{NO} 3-}-\delta^{53} \mathrm{Cr}$ plot for station $2 \mathrm{~T}$.

3.10 Modeling the observed $\mathrm{Cr}$ isotope ratios at our Santa Barbara Basin site by applying different fractionation factors to the Rayleigh distillation equation...

3.11 Oxygen concentrations and $N^{*}$ data measured in the Santa Barbara Basin in April and July 2014

3.12 $\mathrm{Cr}$ data from stations 2T, 7T, the Santa Barbara Basin, and the literature on a $\delta^{53} \mathrm{Cr}-\ln ([\mathrm{Cr}])$ plot....

\section{Chapter 4}

4.1 Map of sampling locations of the 2015 US Arctic GEOTRACES expedition

4.2 Phosphate and nitrate concentrations of seawater samples within the Arctic Ocean.........116

4.3 Potential temperature- salinity plot for station 61

4.4 Profiles of $\mathrm{Cr}$ concentrations, $\mathrm{Cr}$ isotope ratios and other oceanographic parameters at station 61 118

4.5 $\mathrm{Cr}$ data from station 61 and the literature on a $\delta^{53} \mathrm{Cr}-\ln ([\mathrm{Cr}])$ plot. .119

4.6 Profiles of $\mathrm{Cr}$ concentrations, $\mathrm{Cr}$ isotope ratios and other oceanographic parameters at station 43.

4.7 Potential temperature- salinity plot for station 43

4.8 $\mathrm{Cr}$ data from station 43 and the literature on a $\delta^{53} \mathrm{Cr}-\ln ([\mathrm{Cr}])$ plot. 


\section{Appendix}

A.1. Total Cr concentrations of seawater samples taken between 40m - 47m depth off of

Bermuda.................................................................... 135 


\section{Chapter 1. Introduction}

\subsection{Marine biogeochemistry of chromium}

In the ocean, chromium $(\mathrm{Cr})$ is a redox-sensitive trace metal with a concentration range of 1.2 $\mathrm{nmol} / \mathrm{kg}-6.5 \mathrm{nmol} / \mathrm{kg}$ (e.g. Bonnand et al., 2013; Scheiderich et al., 2015). The equilibrium between its two stable redox species in aqueous solutions (i.e. $\mathrm{Cr}(\mathrm{III})$ and $\mathrm{Cr}(\mathrm{VI})$ ) is governed by the system's pH and redox potential, Eh (figure 1.1). In oxic seawater, $\mathrm{Cr}(\mathrm{VI})$ is present mainly as the highly soluble oxyanion, $\mathrm{CrO}_{4}{ }^{2-}$ (chromate). In contrast, $\mathrm{Cr}$ (III) occurs as particle-reactive hydroxo complexes $\mathrm{Cr}(\mathrm{OH})_{2}{ }^{+}$and $\mathrm{Cr}(\mathrm{OH})_{3}{ }^{0}$.

Although $\mathrm{Cr}(\mathrm{VI})$ is the dominant oxidation state in the ocean, $\mathrm{Cr}(\mathrm{III})$ can reach significant levels in oxygen deficient zones (Murray et al., 1983; Rue et al., 1997). Due to slow re-oxidation kinetics by $\mathrm{O}_{2}$ (Schroeder and Lee, 1975) and $\mathrm{H}_{2} \mathrm{O}_{2}$ (Pettine and Millero, 1990), $\mathrm{Cr}$ (III) has a residence time of months to years. Particle scavenging of $\mathrm{Cr}$ (III) followed by export to the sediments and chemical precipitation are sinks for $\mathrm{Cr}$ in the ocean. Ultramafic and mafic rocks host $\mathrm{Cr}$ as immobile Cr(III) (Nriagu and Nieboer, 1988). Oxidative weathering catalyzed by manganese oxides (Fendorf and Zasoski, 1992; Oze et al., 2007) releases soluble Cr(VI) which is transported to the ocean via rivers. River input constitutes by far the most important source of Cr to the ocean. In comparison, ground waters are believed to supply only $\sim 0.3 \%$ of the riverine Cr flux (Izbicki et al., 2012; McClain and Maher, 2016; Qin and Wang, 2017). Both hydrothermal inputs (Sander and Koschinsky, 2000) and benthic fluxes (Jeandel and Minster, 1984) may hold local importance. Past estimates of the Cr ocean residence time have varied substantially: 9000 years - 45000 years (Campbell and Yeats, 1984; Reinhard et al., 2013; Van Der Weijden and Reith, 1982). Due to increased flux estimates of the riverine Cr source (McClain and Maher, 2016), the most recent estimate of the Cr ocean residence time is 3000 years (Qin and Wang, 2017; Reinhard et al., 2013). 


\subsection{Notations, natural $\mathrm{Cr}$ isotope abundances, reporting $\mathrm{Cr}$ isotope signatures and fractionation factors}

In this thesis, [Cr] will be used interchangeably with $\mathrm{Cr}$ concentrations.

$\mathrm{Cr}$ has four stable isotopes with the following natural abundances: ${ }^{50} \mathrm{Cr}$ at $4.35 \%,{ }^{52} \mathrm{Cr}$ at $83.79 \%$, ${ }^{53} \mathrm{Cr}$ at $9.50 \%$, and ${ }^{54} \mathrm{Cr}$ at $2.36 \%$ (Holden, 2011; Shields et al., 1966).

When reporting $\mathrm{Cr}$ isotope signatures, the ratio of ${ }^{53} \mathrm{Cr}$ to ${ }^{52} \mathrm{Cr}$ in a sample is compared to the ratio of ${ }^{53} \mathrm{Cr}$ to ${ }^{52} \mathrm{Cr}$ in a standard reference material (equation 1). For $\mathrm{Cr}$ isotope studies, the conventional choice of standard reference material (abbreviated SRM) is SRM 979. Consequently, all sample ratios within this thesis are expressed as relative deviations from SRM 979 in parts per thousand (\%o).

$$
\delta^{53} \operatorname{Cr}(\%)=\left(\frac{\left(\frac{{ }^{53} C r}{{ }^{52} C r}\right)_{\text {Sample }}}{\left(\frac{{ }^{53} C r}{{ }^{52} C r}\right)_{\text {SRM } 979}}-1\right) \times 1000
$$

The fractionation factor $(\alpha)$ expresses the magnitude of a $\mathrm{Cr}$ isotope effect by comparing the ${ }^{53} \mathrm{Cr}$ to ${ }^{52} \mathrm{Cr}$ ratio of the product to that of the reactant (equation 2 ).

$$
\alpha=\frac{\left(\frac{{ }^{53} \mathrm{Cr}}{{ }^{52} \mathrm{Cr}}\right)_{\text {Product }}}{\left(\frac{{ }^{53} \mathrm{Cr}}{{ }^{52} \mathrm{Cr}}\right)_{\text {Reactant }}}
$$

Alternatively, a $\mathrm{Cr}$ isotope effect can be measured by the 'difference fractionation factor' $(\varepsilon)$ as the difference between the $\delta^{53} \mathrm{Cr}$ values of the product and the reactant (equation 3 ).

$$
\varepsilon(\%)=\delta^{53} C r_{\text {Product }}-\delta^{53} C r_{\text {Reactant }}
$$

The fractionation factor expressions $\alpha$ and $\varepsilon$ are related by the approximation given in equation 4 . 


$$
\varepsilon(\% 0) \approx 1000 \times \ln (\alpha) \approx 1000 \times(\alpha-1)
$$

\subsection{Reported mechanisms of $\mathrm{Cr}$ isotope fractionations}

Cr mass fractionations between terrestrial reservoirs have been found to be mass-dependent.

$\mathrm{Cr}$ reduction induces significant kinetic isotope fractionation. The reduction of $\mathrm{Cr}(\mathrm{VI})$ present as $\mathrm{CrO}_{4}{ }^{2-}$ necessitates the breakage of a strong $\mathrm{Cr}$-oxygen bond. The higher vibrational frequencies associated with lighter $\mathrm{Cr}$ isotopes allow their $\mathrm{Cr}$-O bonds to break more readily relative to the $\mathrm{Cr}$ $\mathrm{O}$ bonds of heavier $\mathrm{Cr}$ isotopes. In consequence, the lighter isotopes display greater reaction rates during reduction and the resultant $\mathrm{Cr}(\mathrm{III})$ is isotopically light relative to the original $\mathrm{Cr}(\mathrm{VI})$ (Schauble et al., 2004). As removal of particle reactive Cr(III) generally occurs swiftly, Rayleigh fractionation models (Rayleigh, 1896) are usually employed to derive the fractionation factors of $\mathrm{Cr}$ isotope effects.

Reductants of $\mathrm{Cr}(\mathrm{VI})$ include acid volatile sulfides, ferrous iron ( $\mathrm{Fe}(\mathrm{II})$ ), organic matter and organic acids (Fendorf et al., 2000; Graham and Bouwer, 2010; Kitchen et al., 2012; Patterson et al., 1997; Pettine et al., 1998; Wielinga et al., 2001). Both aerobic and anaerobic microbes have displayed $\mathrm{Cr}$ reducing capabilities (e.g. Basu et al., 2014). Additionally, unintended uptake of $\mathrm{CrO}_{4}{ }^{2-}$ by microbes may occur due to its structural resemblance to $\mathrm{SO}_{4}{ }^{2-}$ (Cervantes et al., 2001). Since the intracellular reduction of chromate is accompanied by the production of free radicals, $\mathrm{Cr}(\mathrm{VI})$ is classified as a toxin (Cervantes et al., 2001). Fractionation factors determined for abiotic and biotic reduction vary widely ( $\varepsilon=0.2 \%$-5\% ; Basu et al., 2014; Basu and Johnson, 2012; Berna et al., 2010; Døssing et al., 2011; Ellis et al., 2002; Han et al., 2012; Kitchen et al., 2012; Sikora et al., 2008; Xu et al., 2015).

In contrast, the isotope effect of $\mathrm{Cr}$ oxidation is more uncertain as studies disagree on both direction and magnitude ( $\varepsilon^{=-2.5 \%}-+1 \%$; Bain and Bullen, 2005; Ellis et al., 2008; Wang et al., 2010; Zink 
et al., 2010). Cr oxidation consists of multiple reactions with intermediate Cr species (Zink et al., 2010).

In natural settings, equilibrium $\mathrm{Cr}$ isotope fractionation appears to be of limited relevance. At isotope equilibrium, heavier isotopes preferentially form stronger bonds such as $\mathrm{CrO}_{4}{ }^{2-}$, whereas light isotopes preferentially form weaker bonds such as $\mathrm{Cr}$ (III) hydroxo complexes (Bigeleisen and Mayer, 1947; Urey, 1947). In practice, the necessity of a simultaneous transfer of three electrons and a shift in coordination environment results in very slow isotope exchange (Schauble et al., 2004; Wang et al., 2015).

\subsection{Cr isotope signatures reported for different terrestrial reservoirs}

Figure 1.2 gives an overview of the $\mathrm{Cr}$ isotope variations observed for terrestrial reservoirs. Schoenberg et al. (2008) characterized bulk silicate earth (BSE) isotopically $\left(\delta^{53} \mathrm{Cr}=0.124 \pm\right.$ $0.101 \%$; average $\delta^{53} \mathrm{Cr}$ of mantle xenoliths, ultramafic rocks, cumulates, oceanic and continental basalts). Soil and weathering profiles tend to be lighter than BSE due to release of isotopically heavy $\mathrm{Cr}$ (VI) during oxidative weathering (e.g. Crowe et al., 2013; Frei et al., 2014; Frei and Polat, 2013). Since rivers receive this isotopically heavy $\mathrm{Cr}(\mathrm{VI})$, they carry heavy $\mathrm{Cr}$ isotope signatures (e.g. Farkaš et al., 2013; Frei et al., 2014; Paulukat et al., 2015). Groundwater can exhibit very heavy $\mathrm{Cr}$ isotope signatures due to intense $\mathrm{Cr}$ reduction along the flow path (e.g. Berna et al., 2010; Ellis et al., 2002; Izbicki et al., 2008). Published seawater $\mathrm{Cr}$ isotope variations are discussed separately (chapter 1.6.).

\subsection{The Cr isotope system as a paleo-redox proxy}

In recent years, the $\mathrm{Cr}$ isotope system has been studied extensively as a geological paleo-redox proxy (e.g. Crowe et al., 2013; Frei et al., 2009; Planavsky et al., 2014). Once a critical amount of oxygen has accumulated in the Earth's atmosphere, $\mathrm{Cr}$ oxidation catalyzed by $\mathrm{MnO}_{2}$ can occur. The mobilized $\mathrm{Cr}(\mathrm{VI})$ is thought to carry a heavier $\mathrm{Cr}$ isotope signature compared to mineral $\mathrm{Cr}$ in 
rocks. Before $\mathrm{Cr}(\mathrm{VI})$ was released by oxidative weathering, unfractionated $\mathrm{Cr}(\mathrm{III})$ was supplied to the ocean as solid detrital minerals or dissolved $\mathrm{Cr}(\mathrm{III})$ after being leached under acidic conditions (Konhauser et al., 2011). The shift from unfractionated $\mathrm{Cr}$ to isotopically heavier $\mathrm{Cr}$ in geological archives of marine precipitation has been used as a record of atmospheric oxygenation (starting with Frei et al., 2009).

\subsection{Published seawater $\mathrm{Cr}$ isotope data}

The first seawater $\mathrm{Cr}$ isotope data was published by Bonnand et al. in 2013. They observed relatively uniform total $\mathrm{Cr}$ concentrations $([\mathrm{Cr}]=5.80 \mathrm{nmol} / \mathrm{kg}-6.50 \mathrm{nmol} / \mathrm{kg}$ ) and total $\mathrm{Cr}$ isotope signatures $\left(\delta^{53} \mathrm{Cr}=0.41 \%\right.$ - 0.66\%) throughout the water column of the Argentine Basin (South Atlantic). The isotope signatures of these seawater samples were heavier relative to those of the mantle and the continental crust $\left(\delta^{53} \mathrm{Cr}=-0.26 \%\right.$ to $-0.04 \%$; Schoenberg et al., 2008). This is consistent with $\mathrm{Cr}$ being subject to isotopic fractionations during weathering and/ or during transport via rivers to the ocean.

Cr isotope signatures and concentrations exhibited a much wider range $([\mathrm{Cr}]=1.23 \mathrm{nmol} / \mathrm{kg}-3.13$ $\mathrm{nmol} / \mathrm{kg}, \delta^{53} \mathrm{Cr}=0.99 \%-1.55 \%$ ) in profiles taken in the Beaufort Sea (Arctic Ocean; Scheiderich et al., 2015). The profiles were interpreted to reflect conservative mixing between a modified Pacific water mass (lower [Cr], higher $\delta^{53} \mathrm{Cr}$ ) and the Atlantic water (higher [Cr], lower $\delta^{53} \mathrm{Cr}$ ). Additionally, Cr data for individual samples from the Pacific and the Atlantic Ocean was reported.

Scheiderich et al. (2015) plotted their data and Bonnand et al. (2013)'s data on a $\delta^{53} \mathrm{Cr}-\ln ([\mathrm{Cr}])$ plot and observed that the data fell onto one Rayleigh-like fractionation line. They hypothesized that this line represented a global seawater relationship with the exception of local effects from freshwater inputs. Furthermore, they suggested that only one process or several processes with the same fractionation factor moved $\mathrm{Cr}$ in seawater samples along the observed Rayleigh-like fractionation line. Processes they proposed were the reduction and removal of $\mathrm{Cr}$ in the surface water, the reduction of $\mathrm{Cr}$ in oxygen minimum zones, and the remineralization of $\mathrm{Cr}$ (III) from particles and sediments. 


\subsection{Cr reduction in oxygen deficient zones of the ocean}

Even though $\mathrm{Cr}$ reduction has been identified as the most important $\mathrm{Cr}$ isotope fractionation mechanism, oxygen deficient zones (ODZs) of the ocean remain unstudied with respect to their $\mathrm{Cr}$ isotope signatures. Filling this gap was the initial motivation of this $\mathrm{PhD}$ thesis.

At seawater $\mathrm{pH}$, the reduction potential of the $\mathrm{Cr}(\mathrm{VI})-\mathrm{Cr}(\mathrm{III})$ redox couple is in the same range than that of $\mathrm{NO}_{3}{ }^{-} \mathrm{NO}_{2}{ }^{-}$redox couple (Stumm and Morgan, 2012). It is conceivable that $\mathrm{Cr}(\mathrm{VI})$ reduction occurs in oxygen deficient zones of the ocean as a product of thermodynamic equilibrium and/ or of microbial mediation. Microbes respire organic matter using the electron acceptor which will yield the highest free energy first, oxygen, before switching to electron acceptors that oxidize carbon with declining free energy yields, such as nitrate (Froelich et al., 1979) and perhaps even chromate.

Indeed, Cr reduction has been observed in the low oxygen zone of the Eastern Tropical North Pacific (ETNP). Murray et al. (1983) analyzed Cr concentrations across an east - west transect off the coast of Baja California, Mexico (Chapter 3, figure 2). Their study found a $\mathrm{Cr}(\mathrm{VI})$ minimum centered between $200 \mathrm{~m}$ and $400 \mathrm{~m}$ depth which is most intense closest to the coast and absent at the station farthest out in the ocean. Dissolved $\mathrm{Cr}$ (III) concentrations reach their maximum $(0.5$ $\mathrm{nmol} / \mathrm{kg}-1.0 \mathrm{nmol} / \mathrm{kg}$ ) at the top of the oxygen minimum zone (OMZ). Within the OMZ particulate $\mathrm{Cr}$ concentrations of up to $\sim 1.1 \mathrm{nmol} / \mathrm{kg}$ are recorded. The transect was located at the northern edge of the ETNP ODZ core where oxygen concentrations at higher than $10 \mu \mathrm{mol} / \mathrm{kg}$ should not support in situ $\mathrm{Cr}(\mathrm{VI})$ reduction. Rue et al. (1997) measured $\mathrm{Cr}(\mathrm{VI})$ and dissolved $\mathrm{Cr}(\mathrm{III})$ concentrations at a site in the ETNP (Chapter 3, figure $2: 15^{\circ} \mathrm{N} 107^{\circ} \mathrm{W}$ ) with oxygen concentrations of $1 \mu \mathrm{mol} / \mathrm{kg}$ to $5 \mu \mathrm{mol} / \mathrm{kg}$ (110 m - $600 \mathrm{~m}$ depth). Comparing $\mathrm{Cr}(\mathrm{VI})$ concentrations within the ODZ to those measured at a nearby station without an ODZ, a deficit of up to $2 \mathrm{nmol} / \mathrm{kg} \mathrm{Cr}(\mathrm{VI})$ was found within the ODZ. Dissolved Cr(III) concentrations peaked at $0.9 \mathrm{nmol} / \mathrm{kg}$ within the suboxic waters and accounted for up to $\sim 50 \%$ of the chromate deficit. The other half of the chromate anomaly was attributed to scavenging and export of particle reactive $\mathrm{Cr}$ (III). It should be noted, that the $\mathrm{Cr}(\mathrm{VI})$ deficit is observed between $\sim 100 \mathrm{~m}$ and $\sim 1000 \mathrm{~m}$ depth, whereas the presence of $\mathrm{dCr}$ (III) is seen over a much narrower depth range $(\sim 100 \mathrm{~m}$ to $\sim 600 \mathrm{~m})$. 


\subsection{Thesis outline}

At the outset of my $\mathrm{PhD}$, no published method for the determination of $\mathrm{Cr}$ isotope signatures in seawater existed. This lead to the development of a novel seawater $\mathrm{Cr}$ isotope method that is presented in detail in chapter 2 . We assess the performance by repeatedly processing pure Cr SRM 979 solution through the procedure. Furthermore, we demonstrate that the method yields oceanographically consistent total $\mathrm{Cr}$ isotope data for a water column profile at the SAFe station $\left(30^{\circ} \mathrm{N} 140^{\circ} \mathrm{W}\right)$ in the Pacific Ocean.

In Chapter 3, we study the signal produced by $\mathrm{Cr}$ reduction in anoxic zones of the ocean. To this end we measured $\mathrm{Cr}$ isotope ratios and concentrations at two stations within the ODZ of the ETNP and at a station in the Santa Barbara Basin which features anoxic bottom waters. Cr profiles are compared to those available at the nearby SAFe station.

$\mathrm{Cr}$ isotope ratio data from the Arctic Ocean is presented in chapter 4. For intercalibration purposes (with respect to Scheiderich et al., 2015), a full water column profile was taken in the Central Arctic Ocean. On the same expedition, the shallow water column on the Chukchi shelf was sampled. The waters of the Chukchi shelf are fully oxic, but intense denitrification has been reported in the underlying anoxic sediments (Brown et al., 2015; Chang and Devol, 2009; Devol et al., 1997).

Chapter 5 gives a summary, conclusions and recommendations for future research.

Results of a side project are presented very briefly in the appendix. In order to evaluate if significant seasonal variability in total $\mathrm{Cr}$ concentrations occurs (as suggested by data reported by Connelly et al., 2006), total $\mathrm{Cr}$ concentrations were measured for weekly samples taken over a year at $\sim 45 \mathrm{~m}$ depth off of Bermuda. 


\subsection{References}

Bain, D.J., Bullen, T.D., 2005. Chromium isotope fractionation during oxidation of Cr (III) by manganese oxides. Geochim.Cosmochim. Acta 69.

Basu, A., Johnson, T.M., 2012. Determination of Hexavalent Chromium Reduction Using Cr Stable Isotopes: Isotopic Fractionation Factors for Permeable Reactive Barrier Materials. Environ. Sci. Technol. 46, 5353-5360. doi:10.1021/es204086y

Basu, A., Johnson, T.M., Sanford, R.A., 2014. Cr isotope fractionation factors for Cr(VI) reduction by a metabolically diverse group of bacteria. Geochim. Cosmochim. Acta 142, 349-361. doi:10.1016/j.gca.2014.07.024

Berna, E.C., Johnson, T.M., Makdisi, R.S., Basu, A., 2010. Cr Stable Isotopes As Indicators of Cr(VI) Reduction in Groundwater: A Detailed Time-Series Study of a Point-Source Plume. Environ. Sci. Technol. 44, 1043-1048. doi:10.1021/es902280s

Bigeleisen, J., Mayer, M.G., 1947. Calculation of Equilibrium Constants for Isotopic Exchange Reactions. J. Chem. Phys. 15, 261-267. doi:10.1063/1.1746492

Bonnand, P., James, R.H., Parkinson, I.J., Connelly, D.P., Fairchild, I.J., 2013. The chromium isotopic composition of seawater and marine carbonates. Earth Planet. Sci. Lett. 382, 10-20. doi:http://dx.doi.org/10.1016/j.epsl.2013.09.001

Brown, Z.W., Casciotti, K.L., Pickart, R.S., Swift, J.H., 2015. Aspects of the marine nitrogen cycle of the Chukchi Sea shelf and Canada Basin. Deep Sea Res. Part II Top. Stud.

Oceanogr. 118, 73-87. doi:10.1016/j.dsr2.2015.02.009

Campbell, J.A., Yeats, P.A., 1984. Dissolved chromium in the St. Lawrence estuary. Estuar. Coast. Shelf Sci. 19, 513-522.

Cervantes, C., Campos-García, J., Devars, S., Gutiérrez-Corona, F., Loza-Tavera, H., TorresGuzmán, J.C., Moreno-Sánchez, R., 2001. Interactions of chromium with microorganisms and plants. FEMS Microbiol. Rev. 25, 335-347. doi:10.1111/j.1574-6976.2001.tb00581.x

Chang, B.X., Devol, A.H., 2009. Seasonal and spatial patterns of sedimentary denitrification rates in the Chukchi sea. Deep Sea Res. Part II Top. Stud. Oceanogr. 56, 1339-1350. doi:10.1016/j.dsr2.2008.10.024

Connelly, D.P., Statham, P.J., Knap, A.H., 2006. Seasonal changes in speciation of dissolved chromium in the surface Sargasso Sea. Deep Sea Res. Part I Oceanogr. Res. Pap. 53, 19751988. doi:http://dx.doi.org/10.1016/j.dsr.2006.09.005

Crowe, S.A., Døssing, L.N., Beukes, N.J., Bau, M., Kruger, S.J., Frei, R., Canfield, D.E., 2013. Atmospheric oxygenation three billion years ago. Nature 501, 535-538.

Devol, A.H., Codispoti, L.A., Christensen, J.P., 1997. Summer and winter denitrification rates in western Arctic shelf sediments. Devol, A.H., Codispoti, L.A., Christ. J.P., 1997. Summer winter denitrification rates West. Arct. shelf sediments. Cont. Shelf Res. 17, 1029-1050. doi10.1016/S0278-4343(97)00003-4Continental Shelf Res. 17, 1029-1050. doi: $10.1016 / \mathrm{S} 0278-4343(97) 00003-4$

Døssing, L.N., Dideriksen, K., Stipp, S.L.S., Frei, R., 2011. Reduction of hexavalent chromium by ferrous iron: A process of chromium isotope fractionation and its relevance to natural environments. Chem. Geol. 285, 157-166. doi:http://dx.doi.org/10.1016/j.chemgeo.2011.04.005

Ellis, A., Johnson, T., Villalobos-Aragon, A., Bullen, T., 2008. Environmental Cycling of Cr Using Stable Isotopes: Kinetic and Equilibrium Effects. Am. Geophys. Union, Fall Meet. 2008, Abstr. \#H53F-08. 
Ellis, A.S., Johnson, T.M., Bullen, T.D., 2002. Chromium isotopes and the fate of hexavalent chromium in the environment. Science (80-. ). 295, 2060-2062.

Farkaš, J., Chrastný, V., Novák, M., Čadkova, E., Pašava, J., Chakrabarti, R., Jacobsen, S.B., Ackerman, L., Bullen, T.D., 2013. Chromium isotope variations $(\delta 53 / 52 \mathrm{Cr})$ in mantlederived sources and their weathering products: Implications for environmental studies and the evolution of $\delta 53 / 52 \mathrm{Cr}$ in the Earth's mantle over geologic time. Geochim. Cosmochim. Acta 123, 74-92. doi:http://dx.doi.org/10.1016/j.gca.2013.08.016

Fendorf, S., Wielinga, B.W., Hansel, C.M., 2000. Chromium Transformations in Natural Environments: The Role of Biological and Abiological Processes in Chromium(VI) Reduction. Int. Geol. Rev. 42, 691-701. doi:10.1080/00206810009465107

Fendorf, S.E., Zasoski, R.J., 1992. Chromium(III) oxidation by .delta.-manganese oxide (MnO2). 1. Characterization. Environ. Sci. Technol. 26, 79-85. doi:10.1021/es00025a006

Frei, R., Gaucher, C., Poulton, S.W., Canfield, D.E., 2009. Fluctuations in Precambrian atmospheric oxygenation recorded by chromium isotopes. Nature 461, 250-253.

Frei, R., Poiré, D., Frei, K.M., 2014. Weathering on land and transport of chromium to the ocean in a subtropical region (Misiones, NW Argentina): A chromium stable isotope perspective. Chem. Geol. 381, 110-124. doi:10.1016/j.chemgeo.2014.05.015

Frei, R., Polat, A., 2013. Chromium isotope fractionation during oxidative weatheringImplications from the study of a Paleoproterozoic (ca. 1.9 Ga) paleosol, Schreiber Beach, Ontario, Canada. Precambrian Res. 224, 434-453. doi:http://dx.doi.org/10.1016/j.precamres.2012.10.008

Froelich, P.N., Klinkhammer, G.P., Bender, M.L., Luedtke, N.A., Heath, G.R., Cullen, D., Dauphin, P., Hammond, D., Hartman, B., Maynard, V., 1979. Early oxidation of organic matter in pelagic sediments of the eastern equatorial Atlantic: suboxic diagenesis. Geochim. Cosmochim. Acta 43, 1075-1090. doi:10.1016/0016-7037(79)90095-4

Graham, A.M., Bouwer, E.J., 2010. Rates of Hexavalent Chromium Reduction in Anoxic Estuarine Sediments: pH Effects and the Role of Acid Volatile Sulfides. Environ. Sci. Technol. 44, 136-142. doi:10.1021/es9013882

Han, R., Qin, L., Brown, S.T., Christensen, J.N., Beller, H.R., 2012. Differential isotopic fractionation during $\mathrm{Cr}(\mathrm{VI})$ reduction by an aquifer-derived bacterium under aerobic versus denitrifying conditions. Appl. Environ. Microbiol. 78, 2462-4. doi:10.1128/AEM.07225-11

Holden, N.E., 2011. Table of the Isotopes (Revised 2010), in: Haynes, W.M. (Ed.), Handbook of Chemistry and Physics 92nd Edition. CRC Press Inc., Boca Raton, FL, pp. 2-174.

Izbicki, J.A., Ball, J.W., Bullen, T.D., Sutley, S.J., 2008. Chromium, chromium isotopes and selected trace elements, western Mojave Desert, USA. Appl. Geochemistry 23, 1325-1352. doi:http://dx.doi.org/10.1016/j.apgeochem.2007.11.015

Izbicki, J.A., Bullen, T.D., Martin, P., Schroth, B., 2012. Delta Chromium-53/52 isotopic composition of native and contaminated groundwater, Mojave Desert, USA. Appl. Geochemistry 27, 841-853. doi:10.1016/j.apgeochem.2011.12.019

Jeandel, C., Minster, J.F., 1984. Isotope dilution measurement of inorganic chromium(III) and total chromium in seawater. Mar. Chem. 14, 347-364. doi:http://dx.doi.org/10.1016/03044203(84)90030-6

Kitchen, J.W., Johnson, T.M., Bullen, T.D., Zhu, J., Raddatz, A., 2012. Chromium isotope fractionation factors for reduction of $\mathrm{Cr}(\mathrm{VI})$ by aqueous $\mathrm{Fe}(\mathrm{II})$ and organic molecules. Geochim. Cosmochim. Acta 89, 190-201. doi:http://dx.doi.org/10.1016/j.gca.2012.04.049 Konhauser, K.O., Lalonde, S. V., Planavsky, N.J., Pecoits, E., Lyons, T.W., Mojzsis, S.J., 
Rouxel, O.J., Barley, M.E., Rosìere, C., Fralick, P.W., Kump, L.R., Bekker, A., 2011. Aerobic bacterial pyrite oxidation and acid rock drainage during the Great Oxidation Event. Nature 478, 369-373. doi:10.1038/nature10511

McClain, C.N., Maher, K., 2016. Chromium fluxes and speciation in ultramafic catchments and global rivers. Chem. Geol. 426, 135-157. doi:10.1016/j.chemgeo.2016.01.021

Murray, J.W., Spell, B., Paul, B., 1983. The Contrasting Geochemistry of Manganese and Chromium in the Eastern Tropical Pacific Ocean, in: Wong, C.S., Boyle, E., Bruland, K.W., Burton, J.D., Goldberg, E.D. (Eds.), Trace Metals in Sea Water, NATO Conference Series. Springer US, pp. 643-669. doi:- 10.1007/978-1-4757-6864-0_37

Nriagu, J.O., Nieboer, E., 1988. Chromium in the natural and human environments. John Wiley \& Sons.

Oze, C., Bird, D.K., Fendorf, S., 2007. Genesis of hexavalent chromium from natural sources in soil and groundwater. Proc. Natl. Acad. Sci. U. S. A. 104, 6544-6549. doi:10.1073/pnas.0701085104

Patterson, R.R., Fendorf, S., Fendorf, M., 1997. Reduction of hexavalent chromium by amorphous iron sulfide. Environ. Sci. Technol. 31, 2039-2044.

Paulukat, C., Døssing, L.N., Mondal, S.K., Voegelin, A.R., Frei, R., 2015. Oxidative release of chromium from Archean ultramafic rocks, its transport and environmental impact? A Cr isotope perspective on the Sukinda valley ore district (Orissa, India). Appl. Geochemistry 59, 125-138. doi:10.1016/j.apgeochem.2015.04.016

Pettine, M., D’Ottone, L., Campanella, L., Millero, F.J., Passino, R., 1998. The reduction of chromium (VI) by iron (II) in aqueous solutions. Geochim. Cosmochim. Acta 62, 15091519. doi:10.1016/S0016-7037(98)00086-6

Pettine, M., Millero, F.J., 1990. Chromium speciation in seawater: the probable role of hydrogen peroxide. Limnol. Oceanogr. 35, 730-736.

Planavsky, N.J., Reinhard, C.T., Wang, X., Thomson, D., McGoldrick, P., Rainbird, R.H., Johnson, T., Fischer, W.W., Lyons, T.W., 2014. Low Mid-Proterozoic atmospheric oxygen levels and the delayed rise of animals. Science (80-. ). 346, 635-638. doi:10.1126/science. 1258410

Qin, L., Wang, X., 2017. Chromium Isotope Geochemistry. Rev. Mineral. Geochemistry 82.

Rayleigh, Lord, 1896. L. Theoretical considerations respecting the separation of gases by diffusion and similar processes. London, Edinburgh, Dublin Philos. Mag. J. Sci. 42, 493 498.

Reinhard, C.T., Planavsky, N.J., Robbins, L.J., Partin, C.A., Gill, B.C., Lalonde, S. V, Bekker, A., Konhauser, K.O., Lyons, T.W., 2013. Proterozoic ocean redox and biogeochemical stasis. Proc. Natl. Acad. Sci. U. S. A. 110, 5357-62. doi:10.1073/pnas.1208622110

Rue, E.L., Smith, G.J., Cutter, G.A., Bruland, K.W., 1997. The response of trace element redox couples to suboxic conditions in the water column. Deep Sea Res. Part I Oceanogr. Res. Pap. 44, 113-134. doi:http://dx.doi.org/10.1016/S0967-0637(96)00088-X

Sander, S., Koschinsky, A., 2000. Onboard-ship redox speciation of chromium in diffuse hydrothermal fluids from the North Fiji Basin. Mar. Chem. 71, 83-102. doi:http://dx.doi.org/10.1016/S0304-4203(00)00042-6

Schauble, E., Rossman, G.R., Taylor Jr., H.P., Taylor Jr, H.P., 2004. Theoretical estimates of equilibrium chromium-isotope fractionations. Chem. Geol. 205, 99-114. doi:http://dx.doi.org/10.1016/j.chemgeo.2003.12.015

Scheiderich, K., Amini, M., Holmden, C., Francois, R., 2015. Global variability of chromium 
isotopes in seawater demonstrated by Pacific, Atlantic, and Arctic Ocean samples. Earth Planet. Sci. Lett. 423, 87-97. doi:10.1016/j.epsl.2015.04.030

Schoenberg, R., Zink, S., Staubwasser, M., von Blanckenburg, F., 2008. The stable Cr isotope inventory of solid Earth reservoirs determined by double spike MC-ICP-MS. Chem. Geol. 249, 294-306. doi:http://dx.doi.org/10.1016/j.chemgeo.2008.01.009

Schroeder, D.C., Lee, G.F., 1975. Potential transformations of chromium in natural waters. Water. Air. Soil Pollut. 4, 355-365.

Shields, W.R., Murphy, T.J., Catanzaro, E.J., Garner, E.L., 1966. Absolute isotopic abundance ratios and the atomic weight of a reference sample of chromium. J. Res. Natl. Bur. Stand. Sect. A Phys. Chem. 70A, 193. doi:10.6028/jres.070A.016

Sikora, E.R., Johnson, T.M., Bullen, T.D., 2008. Microbial mass-dependent fractionation of chromium isotopes. Geochim. Cosmochim. Acta 72, 3631-3641. doi:http://dx.doi.org/10.1016/j.gca.2008.05.051

Stumm, W., Morgan, J.J., 2012. Aquatic chemistry: chemical equilibria and rates in natural waters. Vol. 126. John Wiley \& Sons.

Urey, H.C., 1947. The thermodynamic properties of isotopic substances. J. Chem. Soc. 0, 562. doi:10.1039/jr9470000562

Van Der Weijden, C.H., Reith, M., 1982. Chromium(III) - chromium(VI) interconversions in seawater. Mar. Chem. 11, 565-572. doi:10.1016/0304-4203(82)90003-2

Wang, D., Fregoso, D., Ellis, A., Johnson, T., Bullen, T., 2010. Stable Isotope Fractionation during Chromium (III) Oxidation by delta-MnO2, in: AGU Fall Meeting. p. 1109.

Wang, X., Johnson, T.M., Ellis, A.S., 2015. Equilibrium Isotopic Fractionation and Isotopic Exchange Kinetics between $\mathrm{Cr}(\mathrm{III})$ and $\mathrm{Cr}(\mathrm{VI})$. Geochim. Cosmochim. Acta. doi:10.1016/j.gca.2015.01.003

Wielinga, B., Mizuba, M.M., Hansel, C.M., Fendorf, S., 2001. Iron promoted reduction of chromate by dissimilatory iron-reducing bacteria. Environ. Sci. Technol. 35, 522-527.

Xu, F., Ma, T., Zhou, L., Hu, Z., Shi, L., 2015. Chromium isotopic fractionation during $\mathrm{Cr}$ (VI) reduction by Bacillus sp. under aerobic conditions. Chemosphere 130, 46-51. doi:10.1016/j.chemosphere.2015.02.033

Zink, S., Schoenberg, R., Staubwasser, M., 2010. Isotopic fractionation and reaction kinetics between $\mathrm{Cr}(\mathrm{III})$ and $\mathrm{Cr}(\mathrm{VI})$ in aqueous media. Geochim. Cosmochim. Acta 74, 5729-5745. doi:http://dx.doi.org/10.1016/j.gca.2010.07.015 
Figures for Chapter 1

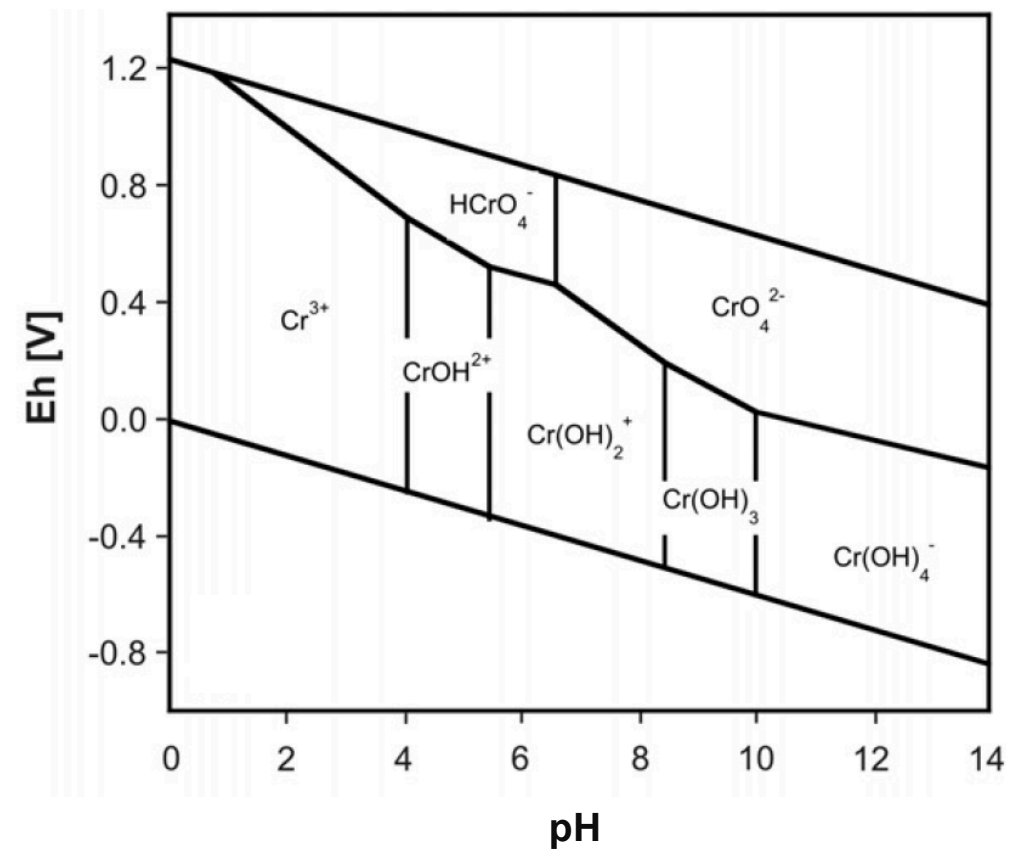

Figure 1.1. This Eh-pH diagram for Cr was adopted from Qin and Wang (2017). 


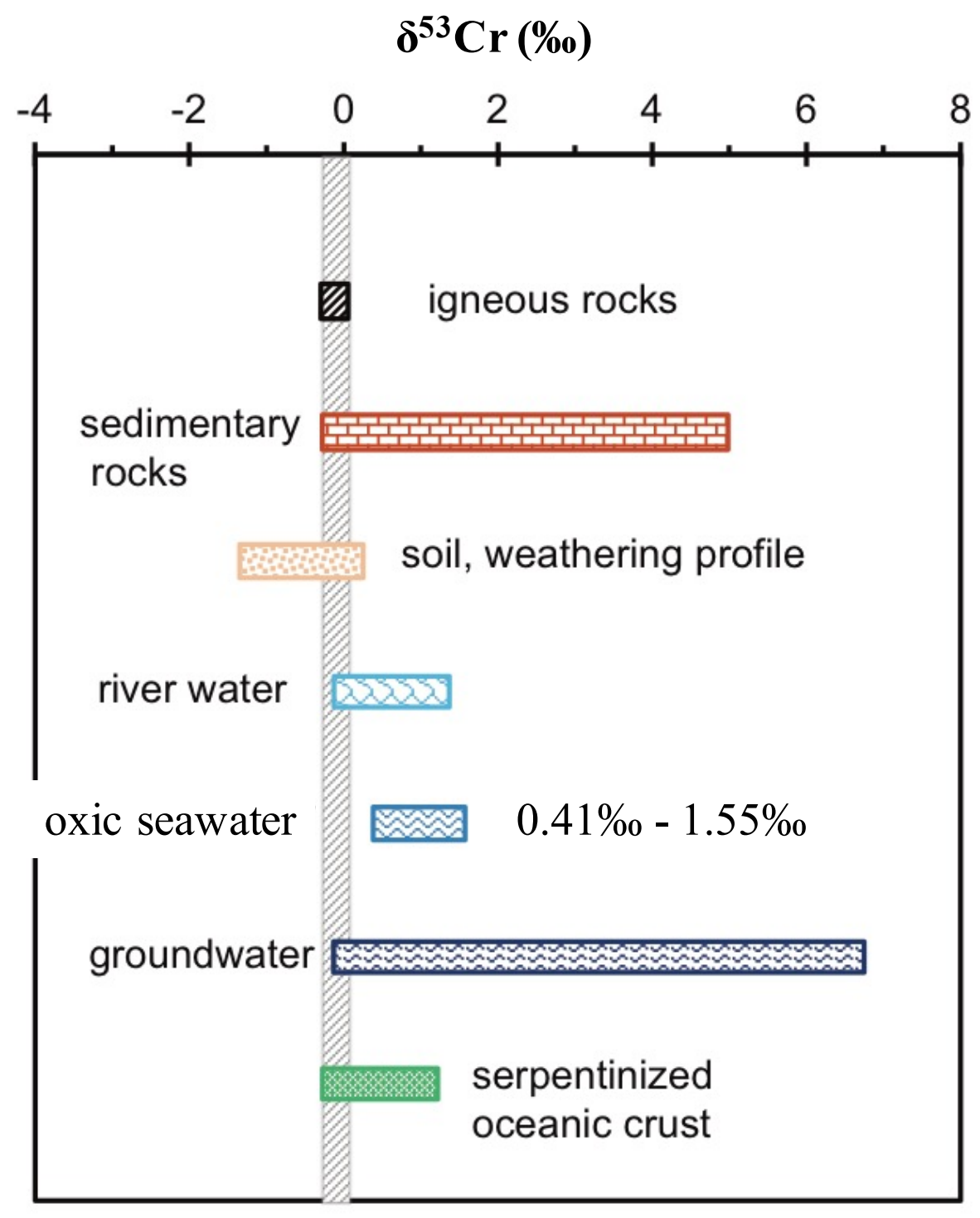

Figure 1.2. Isotope variations observed for different terrestrial reservoirs are given. This figure was adopted from Qin and Wang (2017). 


\section{Chapter 2. Determination of Accurate and Precise Chromium Isotope Ratios in Seawater Samples Illustrated by Analysis of SAFe Station in the Pacific Ocean}

\subsection{Introduction}

Ever since redox transformations between the stable oxidation states of chromium (i.e. Cr(III) and $\mathrm{Cr}(\mathrm{VI})$ ) have been observed to result in significant isotope fractionation (Ball and Bassett, 2000), the terrestrial chromium isotope system has enjoyed considerable interest. Four stable isotopes of chromium exist: ${ }^{50} \mathrm{Cr}(4.345 \%),{ }^{52} \mathrm{Cr}(83.789 \%),{ }^{53} \mathrm{Cr}$ (9.501\%), and ${ }^{54} \mathrm{Cr}$ (2.365\%) (Holden, 2011). Typically, the $\mathrm{Cr}$ isotope signature of a sample $\left(\delta^{53} \mathrm{Cr}\right)$ is reported as the relative deviation of the sample's ${ }^{53} \mathrm{Cr} /{ }^{52} \mathrm{Cr}$ ratio to that of standard reference material (=SRM) 979 in per mil (equation 1).

$$
\delta^{53} C r(\%)=\left(\frac{\left(\frac{{ }^{53} C r}{{ }^{52} C r}\right)_{\text {Sample }}}{\left(\frac{{ }^{53} C r}{{ }^{52} C r}\right)_{S R M}}-1\right) \times 1000
$$

First, the Cr isotope system was used to track the reduction of toxic and soluble Cr(VI) to benign and immobile $\mathrm{Cr}$ (III) in groundwater (Ellis et al., 2004, 2002). These studies observed the preferential reduction of isotopically light chromate $/ \mathrm{CrO}_{4}{ }^{2-}$, which resulted in the remaining $\mathrm{Cr}(\mathrm{VI})$ pool becoming isotopically heavier as the reduction proceeded. Later, shifts in $\mathrm{Cr}$ isotope signatures of marine precipitates were interpreted to reflect the oxidation state of the atmosphere through Earth's history (Frei et al., 2009). This study inspired the wide-spread use of the Cr isotope system as a paleo-redox tracer (e.g. Cole et al., 2016; Crowe et al., 2013; D'Arcy et al., 2017; Planavsky et al., 2014). The basis for this tracer's usage is that a threshold level of atmospheric oxygen is required to form manganese oxides which are a prerequisite for the oxidation of immobile Cr(III) hosted by rock minerals (Bartlett and James, 1979; Fendorf, 1995; Oze et al., 2007). The released hexavalent $\mathrm{Cr}$ is isotopically heavy and is carried to the ocean via rivers. In the absence of oxygen, the ocean receives unfractionated $\mathrm{Cr}$ (III) from detrital minerals and 
bacterially promoted acid leaching (Konhauser et al., 2011). In order to better understand how the $\mathrm{Cr}$ isotopic signal is transferred from $\mathrm{Cr}(\mathrm{III})$ containing rock minerals into marine precipitates, numerous studies have sought to characterize aspects of the terrestrial $\mathrm{Cr}$ cycle such as weathering profiles (e.g. Berger and Frei, 2014; Crowe et al., 2013; Frei et al., 2014; Frei and Polat, 2013; Wang et al., 2016), and rivers (e.g. D’Arcy et al., 2016; Farkaš et al., 2013; Frei et al., 2014; Paulukat et al., 2015; Wu et al., 2017). In contrast, only two studies have presented precise $\mathrm{Cr}$ isotope and concentration data for seawater samples (i.e. Bonnand et al. (2013), and Scheiderich et al. (2015)).

Since $\mathrm{Cr}$ is only present in trace amounts in seawater $(1.23 \mathrm{nmol} / \mathrm{kg}-6.50 \mathrm{nmol} / \mathrm{kg}$; Bonnand et al., 2013; Scheiderich et al., 2015), seawater $\mathrm{Cr}$ isotope methods require high yields, a sensitive detection method and/or big sample volumes. In preparation for sample detection on a mass spectrometer, separation of $\mathrm{Cr}$ from the seawater's salt matrix as well as from isobaric (i.e. Ti, V, $\mathrm{Fe}$ ) and polyatomic (e.g. S) interferences is imperative. Table 2.1 gives an overview of the interferences afflicting masses 49-56. This separation is often achieved by taking advantage of the opposing charges $\mathrm{Cr}$ displays in its trivalent and hexavalent states (e.g. Ball and Bassett, 2000). $\mathrm{Cr}$ loss due to incomplete reduction and oxidation of $\mathrm{Cr}$ during sample processing can lead to significant isotope fractionations. Therefore, $\mathrm{Cr}$ studies commonly rely on double spiking techniques (as opposed to sample-standard bracketing) that enable accurate and precise correction of isotope fractionations occurring during both sample processing and instrumental analysis (Dodson, 1963).

Here, we present a detailed double spike procedure to determine accurate and precise isotope ratios of $\mathrm{Cr}$ in seawater samples which is distinct from those employed by Bonnand et al. (2013) and Scheiderich et al. (2015). We assess the performance by repeatedly processing pure Cr SRM 979 solution through the procedure. Furthermore, we demonstrate that the method yields oceanographically consistent total $\mathrm{Cr}$ isotope data for a water column profile at the SAFe station $\left(30^{\circ} \mathrm{N} 140^{\circ} \mathrm{W}\right)$ in the Pacific Ocean. 


\subsection{Procedure}

\subsubsection{Chemicals and materials}

The handling of chemicals and samples took place under clean conditions (i.e. class 100 clean laminar flow benches, positive-pressure clean labs with recirculating fume hoods) while wearing polyethylene gloves.

\subsubsection{Reagents}

Acids (6 M hydrochloric and $16 \mathrm{M}$ nitric) were secured at reagent grade and distilled four times in a Vycor still. Blank checks for each batch of acid were conducted before use and showed adequately low levels of $\mathrm{Cr}$ and its isobaric interferences.

High purity water was obtained by passing deionized water through two rough ion exchange resin cartridges and one ultrapure ion exchange cartridge followed by re-distillation in a 'Barnstead Mega-Pure' borosilicate glass still (Thermo Scientific).

Reagent grade aqueous ammonia $\left(\mathrm{NH}_{3}\right)$ was purified via isothermal distillation (i.e. a transfer of ammonia from a concentrated $16 \mathrm{M}$ solution into distilled water). Blank checks for each batch of ammonia solution were carried out before use. The titration of a randomly selected batch of distilled $\mathrm{NH}_{3}$ yielded a strength of $\sim 8 \mathrm{M}$.

Suprapur® 30\% (v/v) hydrogen peroxide $\left(\mathrm{H}_{2} \mathrm{O}_{2}\right)$ was acquired from Merck KGaA. Since $\mathrm{H}_{2} \mathrm{O}_{2}$ disintegrates easily, it was stored in a dark cold room when not in use. Light exposure was minimized during use.

Ammonium persulfate (APS) salt was purchased from Sigma-Aldrich (BioXtra, $\geq 98.0 \%$ ). Solutions of APS are unstable; hence they were newly prepared within hours before use.

The anion exchange resin AG 1-X8, 200 - 400 mesh size, was obtained from Eichrom in the chloride form. The resin was transferred into a teflon bottle such that $\sim 1 / 3$ of the bottle was filled 
with beads. After water was added, the bottle was shaken vigorously, suspending the beads in the solution. Degraded beads are lighter and settle more slowly than intact beads, making it possible to decant the degraded beads during this step. The residual beads undergo rinses in the following sequence: methanol ( $\sim 1$ hour), 5 distilled water rinses, $1 \mathrm{M} \mathrm{NaOH}(\sim 1$ hour), 10 distilled water rinses, $6 \mathrm{M} \mathrm{HCl} \mathrm{(} \sim$ days), 5 distilled water rinses, $6 \mathrm{M} \mathrm{HCl}$ ( $\sim 1$ day), 5 distilled water rinses. Omitting this batch cleaning step significantly increases the $\mathrm{Cr}$ resin blank.

\subsubsection{Standards}

All primary standard solutions and all prepared dilutions were stored in plastic bags inside of glass jars, filled with a small amount of water. This avoids the loss of water from the standards and prevents a concentration increase of the standards over time.

The $\mathrm{Cr}$ isotopic reference material, SRM 979, was acquired from the National Institute of Standards and Technology (NIST) in the form of a hydrated chromium (III) nitrate, $\mathrm{Cr}\left(\mathrm{NO}_{3}\right)_{3} \bullet$ $9 \mathrm{H}_{2} \mathrm{O}$. This chromium salt was dissolved in $2 \%(\mathrm{v} / \mathrm{v}) \mathrm{HNO}_{3}$, a medium in which it is readily soluble, and which will preserve $\mathrm{Cr}$ in its trivalent state. The absolute isotopic abundance ratios for SRM 979 were established by Shields et al. (1966).

The ${ }^{50} \mathrm{Cr}^{5}{ }^{54} \mathrm{Cr}$ double spike was derived from $\mathrm{Cr}-50$ and $\mathrm{Cr}-54$ enriched metal powders which were purchased from ISOFLEX USA with a certified isotopic composition of: 1) Cr-50 enriched metal powder: $99.70 \%$ Cr-50, 0.25\% Cr-52, 0.03\% Cr-53, 0.02\% Cr-54, and 2) Cr-54 enriched metal powder: $<0.01 \% \mathrm{Cr}-50,<0.05 \% \mathrm{Cr}-52,0.02 \% \mathrm{Cr}-53,99.8 \% \mathrm{Cr}-54$. Dissolving $\mathrm{Cr}$ metal in an oxidizing acid such as nitric acid, can lead to the formation of a thin surface oxide layer (Haber and Goldschmidt, 1906), effectively passivating the metal and inhibiting its dissolution (Hittorf, 1900; Keir, 1790). Cr shares this passivation property with metals such as aluminum, nickel and iron. Consequently, each $\mathrm{Cr}$ metal powder was first dissolved in $1 \mathrm{M} \mathrm{HCl}$, even though a final double spike matrix of dilute $\mathrm{HNO}_{3}$ was desired. The dissolution took place in a pre-cleaned teflon beaker with a moderate supply of heat facilitating this step. The resulting solution was dried down and brought up in $2 \%(\mathrm{v} / \mathrm{v}) \mathrm{HNO}_{3}$. In this fashion, separate primary solutions for each $\mathrm{Cr}-50$ and $\mathrm{Cr}-54$ were generated which contained $\mathrm{Cr}$ only in the trivalent form. The optimal double spike 
composition to minimize error propagation during ${ }^{50} \mathrm{Cr}-{ }^{54} \mathrm{Cr}$ double spike calculations was determined to be: $57.65 \%$ Cr-50, 0.14\% Cr-52, 0.10\% Cr-53, and $42.10 \%$ Cr-54 (Rudge et al., 2009). The primary solutions were mixed to produce this desired double spike composition.

Two $\mathrm{Cr}$ concentration standards were purchased for concentration calibration of the SRM and the double spike solutions. Both standards have a certified concentration of $1000 \mu \mathrm{g} / \mathrm{mL}$ of $\mathrm{Cr}$ (III) in $2 \%(\mathrm{v} / \mathrm{v}) \mathrm{HNO}_{3}$ with one originating from Inorganic Ventures and one being supplied by SigmaAldrich.

\subsubsection{Leaching protocol}

Various bottles, vials and chromatographic columns made of high density polyethylene as well as teflon containers were used in this work. Acid leaching protocols were followed to ensure that these vessels were devoid of trace metals. Caps and threads of big bottles (volume $\geq 250 \mathrm{~mL}$ ) were first leached overnight in a cold, reagent grade $2 \mathrm{M} \mathrm{HCl}$ bath. After 3 water rinses the bottles were filled with $1 \mathrm{M} \mathrm{HCl}$ (reagent grade), triple bagged and exposed to $60^{\circ} \mathrm{C}$ in an oven. They stayed in the oven for two nights, being inverted after the first night. After 5 water rinses the bottles were filled with clean $0.06 \mathrm{M} \mathrm{HCl}$ and again exposed to $60^{\circ} \mathrm{C}$ in an oven for two days. After decanting the dilute acid, the bottles were considered trace metal clean. For smaller bottles and teflon containers (volume $<250 \mathrm{~mL}$ ) the $2 \mathrm{M} \mathrm{HCl}$ bath was skipped, and bottles were submerged in a 4 L bottle filled with $1 \mathrm{M} \mathrm{HCl}$ (reagent grade). The leaching protocol from this point onwards is identical to the one detailed above. Small vials $(1.5 \mathrm{~mL})$ were similarly submerged in $1 \mathrm{M} \mathrm{HCl}$ and then cleaned individually using squirt bottles of clean water and clean $0.06 \mathrm{M} \mathrm{HCl}$.

\subsubsection{Pre-concentration and purification of $\mathrm{Cr}$ in seawater}

Seawater samples initially contain both trivalent and hexavalent Cr. Upon acidification with $2 \mathrm{~mL}$ $6 \mathrm{M} \mathrm{HCl}$ per liter of seawater the $\mathrm{pH}$ of the samples is lowered to $\sim 2$ and conversion of $\mathrm{Cr}(\mathrm{VI})$ to $\mathrm{Cr}$ (III) begins. Semeniuk et al. (2016) concluded that it takes 3 weeks for complete conversion to

occur at a $\mathrm{pH}$ of $\sim 2$. Erring on the side of caution, all samples within this thesis were acidified for significantly longer time periods ( $\geq 11$ months) before being processed. 
Clean $1 \mathrm{~L}$ separatory funnels are filled with seawater and the weight of this added seawater is recorded. At this point, the trivalent ${ }^{50} \mathrm{Cr}_{-}{ }^{54} \mathrm{Cr}$ double spike is added to the funnels, which are given a manual shake and subsequently transferred onto a shaker table for at least a day. In total three days appear sufficient for effecting complete isotope equilibrium between double spike $\mathrm{Cr}$ and natural $\mathrm{Cr}$.

$\mathrm{Cr}$ is pre-concentrated from seawater samples using $\mathrm{Mg}(\mathrm{OH})_{2}$ (s) coprecipitation. This technique was applied for lead, copper, and cadmium in seawater samples by Wu \& Boyle (1997). Positively charged $\mathrm{Cr}(\mathrm{III})$ ions associate with $\mathrm{Mg}(\mathrm{OH})_{2}$, whereas $\mathrm{Cr}(\mathrm{VI})$ oxyanions do not (Semeniuk et al., 2016). Aqueous $\mathrm{NH}_{3}$ is added to the seawater sample until $\mathrm{Mg}(\mathrm{OH})_{2}$ forms which is allowed to settle overnight. By opening the stopcock, the precipitate is collected into a $50 \mathrm{~mL}$ tube. The supernatant is siphoned off carefully, and the remaining precipitate is neutralized with $\mathrm{HCl}$. It is advisable to keep the precipitate as small as possible in order to minimize the amount of $\mathrm{HCl}$ needed to dissolve it. The size of the $\mathrm{Mg}(\mathrm{OH})_{2}$ pellet is a function of time and the amount of aqueous ammonia added. In this procedure, the formation cannot be significantly shortened as the precipitate settles by gravity to avoid the need for large-volume centrifugation. Therefore, we pay close attention to minimizing the amount of ammonia solution added. For testing purposes, a small sample aliquot receives incremental $\mathrm{NH}_{3}(\mathrm{aq})$ additions, each of which is given $\geq 30$ min to react with the sample, until a visible precipitate is detected after centrifugation. The total volume of ammonia solution used in this test is scaled up to the volume of seawater in the funnel. Typically, seawater samples of $\mathrm{pH} 2.10-\mathrm{pH} 1.97$ require an addition of $5.1 \mathrm{ml}-6.2 \mathrm{ml}$ aqueous $\sim 8 \mathrm{M} \mathrm{NH}_{3}$ per liter of sample. If a given sample contains more than $\sim 10 \mu \mathrm{mol}$ of silicic acid, a fraction of the ammonia solution appears to be consumed by an unidentified byproduct (possibly $\mathrm{SiO}(\mathrm{OH})_{3}{ }^{-}$) and additional $\mathrm{NH}_{3}$ is required to induce the $\mathrm{Mg}(\mathrm{OH})_{2}$ coprecipitation. While minimizing the precipitate size is important, no $\mathrm{Mg}(\mathrm{OH})_{2}$ will form if too little aqueous $\mathrm{NH}_{3}$ is added and $\mathrm{Cr}(\mathrm{III})$ that sits in basic media will be lost to the funnel walls and may be converted back to $\mathrm{Cr}(\mathrm{VI})$.

Once the precipitate has been neutralized, $30 \mu \mathrm{L}$ of $6 \mathrm{M} \mathrm{HCl}$ is added to render the solution acidic. Furthermore, ultrapure $\mathrm{H}_{2} \mathrm{O}$ is added until a total volume of $9 \mathrm{~mL}$ is reached, which optimally results in a $0.02 \mathrm{M} \mathrm{HCl}$ medium. At this point $130 \mu \mathrm{L}$ of solution is being carefully removed for 
$\mathrm{pH}$ testing and if necessary the $\mathrm{pH}$ is adjusted with $\mathrm{HCl}$ or by dilution with $\mathrm{H}_{2} \mathrm{O}$. Each sample receives $1 \mathrm{~mL}$ of $0.2 \mathrm{M}$ APS, capped tightly, shaken, and immediately transferred into a heating block that is set to $110^{\circ} \mathrm{C}$, where it remains for 1 hour. After cooling, the sample is loaded onto the first ion exchange column. Although Cr oxidation using APS has been employed with slight variations by a number of $\mathrm{Cr}$ studies (e.g. Ball and Bassett, 2000; Frei et al., 2009; Götz and Heumann, 1988; Schoenberg et al., 2008), these references do not point out the strong potential for pitfalls during this crucial step. Please refer to section 2.3.1. for information on how small changes in acidic medium and temperature can significantly influence the performance of the oxidation and the amount of sulfate that remains in the sample after this step.

Poly-Prep chromatography columns from Bio-Rad are loaded with $2 \mathrm{~mL}$ of anion exchange resin AG 1-X8 200 - 400 mesh size from Eichrom. The greater a resin's preference for an ion, the greater the corresponding selectivity coefficient will be. This resin has a relative selectivity of 22 for $\mathrm{Cl}^{-}$, 65 for $\mathrm{NO}_{3}{ }^{-}$and 85 for $\mathrm{HSO}_{4}{ }^{-}$(Bio-Rad, 1998a). The $\mathrm{Cr}(\mathrm{VI})$ oxyanion has a similar relative selectivity for $\mathrm{AG} \mathrm{1-X8}$ as $\mathrm{HSO}_{4}{ }^{-}$(Ball and Bassett, 2000). Bearing this information in mind, the

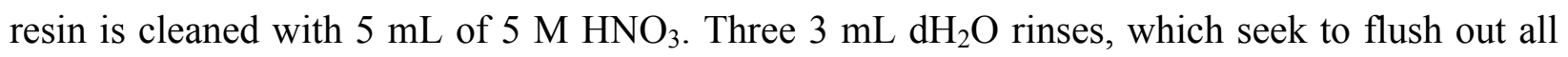
traces of nitric acid, follow. To convert the resin from the $\mathrm{NO}_{3}{ }^{-}$form to the $\mathrm{Cl}^{-}$form, $12 \mathrm{~mL}$ of 1 $\mathrm{M} \mathrm{HCl}$ are added to the column. To adjust the column to the sample's acidic medium, $5 \mathrm{~mL}$ of $0.018 \mathrm{~N} \mathrm{HCl}$ are introduced. At this point, the sample is loaded onto the column. $\mathrm{Cr}(\mathrm{VI})$ oxyanions and as a byproduct, persulfate, sulfate and bisulfate anions will easily exchange with the chloride ions and bind to the resin. Magnesium and other cations have no affinity to the anion exchange resin and are flushed out with a $3 \mathrm{~mL} \mathrm{H}_{2} \mathrm{O}$ rinse, a $5 \mathrm{~mL} 0.2 \mathrm{M} \mathrm{HCl}$ rinse, and another two $3 \mathrm{~mL}$ $\mathrm{H}_{2} \mathrm{O}$ rinses. $\mathrm{Cr}$ is eluted from the column with $10 \mathrm{~mL}$ of $2 \mathrm{M} \mathrm{HNO}_{3}+2 \%(\mathrm{v} / \mathrm{v}) \mathrm{H}_{2} \mathrm{O}_{2}$. Hydrogen peroxide reduces anionic $\mathrm{Cr}(\mathrm{VI})$ to cationic $\mathrm{Cr}(\mathrm{III})$ for which the resin has no affinity. While part of the elution occurs via this reduction, substitution of $\mathrm{Cr}(\mathrm{VI})$ oxyanions with $\mathrm{NO}_{3}{ }^{-}$also takes place. This substitution by $\mathrm{NO}_{3}{ }^{-}$is furthermore responsible for the release of sulfate and bisulfate ions from the binding sites of the resin. Both acid strengths and volumes were generally lowered compared to other studies which used the same column chemistry (e.g. Ball and Bassett, 2000; Frei et al., 2009; Schoenberg et al., 2008). 
After drying down the final eluate, a droplet of sulfuric acid remains. The sulfuric acid digests any resin residue, eliminating the need for an aqua regia digestion. Nevertheless, the presence of sulfur is problematic during MC-ICP-MS analysis since it causes polyatomic interferences (seen as ${ }^{32} \mathrm{~S}^{16} \mathrm{O}^{1} \mathrm{H}^{+}$on mass 49 ), and thereby prevents the measurement of accurate $\mathrm{Cr}$ isotope signatures. To remove sulfur from the sample matrix several $\mathrm{Cr}$ isotope studies rely on the cation exchange resin AG 50W-X8 (e.g. Ball and Bassett, 2000; Halicz et al., 2008). Positively charged Cr(III) ions bind to this resin, whereas the negatively charged sulfur species pass through. While the quantity of sulfur is greatly diminished in this manner, AG $50 \mathrm{~W}-\mathrm{X} 8$ is composed of sulfonic acid functional groups (Bio-Rad, 1998b) which unavoidably contribute a small amount of sulfur to the final $\mathrm{Cr}$ eluate. Taking this into account, we instead repeat column run 1 with the crucial adjustment of $\mathrm{Cr}$ now being present as $\mathrm{Cr}(\mathrm{III})$ and not as $\mathrm{Cr}(\mathrm{VI})$. To ensure the complete conversion to $\mathrm{Cr}(\mathrm{III})$, the sample is brought up in $110 \mu \mathrm{L}$ of $1 \mathrm{M} \mathrm{HCl}$, and $50 \mu \mathrm{L}$ of $30 \%(\mathrm{v} / \mathrm{v}) \mathrm{H}_{2} \mathrm{O}_{2}$ is added. Under these strongly acidic conditions chromate is rapidly reduced by hydrogen peroxide in a first-order reaction (Pettine et al., 2002), whereas a reduction reaction would take longer and be of a higher order in a less acidic medium (Vander Griend et al., 2002). After a short waiting period ( $\sim 1$ hour), water is added to get to a total volume of $11 \mathrm{~mL}$, which results in a $0.018 \mathrm{M} \mathrm{HCl}$ medium. Once 2 $\mathrm{mL}$ of $\mathrm{AG} \mathrm{1-X8}$ resin have been cleaned and preconditioned as previously described, the sample is loaded onto the column. Sulfur is present as negatively charged species which exchange easily with the chloride ions, whereas positively charged $\mathrm{Cr}$ ions pass through the column and are collected in a Savillex vial. Three $1 \mathrm{~mL}$ portions of $0.01 \mathrm{M} \mathrm{HCl}$ are added to push the sample $\mathrm{Cr}^{3+}$ fully through the column. The samples are dried down and resin residue is digested with aqua regia $\left(150 \mu \mathrm{L} 6 \mathrm{M} \mathrm{HCl}, 25 \mu \mathrm{L} 16 \mathrm{M} \mathrm{HNO}_{3}\right)$.

A small fraction of the seawater sample's Fe content still remains after the second ion exchange column. To separate $\mathrm{Cr}$ from the residual $\mathrm{Fe}$, the sample is brought up in $500 \mu \mathrm{L}$ of $6 \mathrm{M} \mathrm{HCl}$. Under these conditions $\mathrm{FeCl}_{4}{ }^{-}$complexes are formed which have a high affinity for the AG 1-X8 resin (Scheiderich et al., 2015). Having ensured that the $\mathrm{Cr}$ is in its trivalent form by adding $10 \mu \mathrm{L}$ of $30 \%(\mathrm{v} / \mathrm{v}) \mathrm{H}_{2} \mathrm{O}_{2}, \mathrm{Cr}$ will pass through the column and is collected. Since the amount of Fe that we seek to bind to the resin is relatively small, and the sample matrix is very pure after two prior column runs, a much smaller amount $(\sim 0.25 \mathrm{~mL})$ of AG 1-X8 resin is loaded into shrink-teflon micro columns. The same process as previously detailed is used to clean and precondition the resin. 
Quantities of $5 \mathrm{M} \mathrm{HNO}_{3}$ are scaled down accordingly. Instead of using $1 \mathrm{M} \mathrm{HCl}$ to convert the resin to the chloride form, $6 \mathrm{M} \mathrm{HCl}$ is used. After the sample is loaded, another three $150 \mu \mathrm{L}$ additions of $6 \mathrm{M} \mathrm{HCl}$ ensure that the sample has been fully rinsed from the column.

The sample is dried down, the resin residue is digested with aqua regia and $\sim 360 \mu \mathrm{L}$ of $2 \%$ (v/v) $\mathrm{HNO}_{3}$ is added (based on an average nebulizer flowrate of $\sim 50 \mu \mathrm{L} / \mathrm{min}$ ). At this point, $\mathrm{Cr}$ is dissolved in a very pure dilute nitric acid matrix, well-suited for MC-ICP-MS analysis.

\subsubsection{MC-ICP-MS analysis}

Isotope ratio analysis took place on an IsoProbe multi-collector inductively coupled plasma mass spectrometer (MC-ICP-MS) originally manufactured by Micromass (later dubbed G/V and partially succeeded by Isotopx). The final analyte solution was converted into an aerosol spray using a $\sim 50 \mu \mathrm{L} / \mathrm{min}$ MicroMist ${ }^{\circledR}$ (Glass Expansion) nebulizer and subsequently passed through a heated Spiro desolvating membrane (Elemental Scientific). In our application, ion extraction from the plasma into the mass analyzer relies on a small positive potential (soft extraction) rather than a strong negative potential (hard extraction). In the soft extraction mode, a more focused ion beam exits the skimmer cone (Archer and Vance, 2004). The IsoProbe is equipped with a hexapole collision cell. Here the ion beam collides with argon gas resulting in a reduction of the kinetic energy and the energy spread of the analyte ions. A smaller range of energies translates into a more accurate mass resolution by the magnetic field. Additionally, hydrogen gas is added in the hexapole and readily releases an electron. This electron combines with positively charged interfering ions which are eliminated from the ion beam. In this manner, polyatomic interferences such as ${ }^{40} \mathrm{Ar}^{12} \mathrm{C}^{+}$on ${ }^{52} \mathrm{Cr},{ }^{40} \mathrm{Ar}^{14} \mathrm{~N}^{+}$on ${ }^{54} \mathrm{Cr}$ and ${ }^{54} \mathrm{Fe}$, and ${ }^{40} \mathrm{Ar}^{16} \mathrm{O}^{+}$on ${ }^{56} \mathrm{Fe}$ are eliminated. After leaving the hexapole region the ion beam enters the lens stack. Here the ion beam gets optimally aligned and accelerated to $\sim 6000 \mathrm{~V}$ before entering the magnetic sector. Analyte ions are detected by an array of Faraday cups with the current measured by the voltage drop across a calibrated resistor.

Data on mass $49\left({ }^{49} \mathrm{Ti}\right)$, mass $50\left({ }^{50} \mathrm{Ti},{ }^{50} \mathrm{~V},{ }^{50} \mathrm{Cr}\right)$, mass $51\left({ }^{51} \mathrm{~V}\right)$, mass $52\left({ }^{52} \mathrm{Cr}\right)$, mass $53\left({ }^{53} \mathrm{Cr}\right)$, mass $54\left({ }^{54} \mathrm{Cr},{ }^{54} \mathrm{Fe}\right)$ and mass $56\left({ }^{56} \mathrm{Fe}\right)$ needs to be collected in order to monitor the four $\mathrm{Cr}$ masses 
and their isobaric interferences. Given that the isobaric interferences are small compared to the $\mathrm{Cr}$ signal, typical abundance ratios (e.g. \%Ti-50/\%Ti-49) can be used to calculate the signal of the isobaric inference. Even though the IsoProbe is equipped with two low mass/axial and seven high mass movable Faraday cups, the mass range of our IsoProbe is not wide enough for simultaneous collection of the required masses, so peak jumping is employed. In total 10 cycles, each consisting of 3 sequences, are recorded. Sequence 1 records masses 49 (L2), 50 (L1), 51 (H1), 52 (H2), 53 (H3) and 54 (H5) simultaneously at an axial magnet mass of 50.5 for a duration of 20 s per cycle. Sequence 2 is a shorter version of sequence 1 (with a duration of only $2 \mathrm{~s}$ per cycle). Sequence 3 is recorded at an axial magnet setting of $\sim 54.42 \mathrm{amu}$ and records mass 56 on detector $\mathrm{H} 2$ for a duration of $2 \mathrm{~s}$ of per cycle. On our instrument, setting the magnet from an axial magnet mass of 50.5 to $\sim 54.42$ produces a peak jump of 4 mass units for detector H2. In practice, this means Faraday cup $\mathrm{H} 2$ which collects ${ }^{52} \mathrm{Cr}$ data during sequence 1 and 2, collects ${ }^{56} \mathrm{Fe}$ data during sequence 3. See table 2.2 for an overview of the cup configuration. Please refer to section 2.2.4.1. for a detailed explanation of the incorporation of the ${ }^{56} \mathrm{Fe}$ signal and of the isobaric interference corrections.

The same operating conditions that maximize $\mathrm{Cr}$ sensitivity also may maximize the signal coming from polyatomic interferences. At this point, only sulfur polyatomic interferences remain a concern (e.g. ${ }^{32} \mathrm{~S}^{16} \mathrm{O}^{1} \mathrm{H}^{+}$on mass $49,{ }^{34} \mathrm{~S}^{16} \mathrm{O}^{+}$on mass $50,{ }^{34} \mathrm{~S}^{16} \mathrm{O}^{1} \mathrm{H}^{+}$on mass 51 ). To fine-tune optimal operating conditions, a $\mathrm{Cr}-\mathrm{S}$ mixture in $2 \%(\mathrm{v} / \mathrm{v}) \mathrm{HNO}_{3}$ is run while monitoring the ratio of mass 49 , the mass most affected by sulfur polyatomic interferences, to mass 52 (=only ${ }^{52} \mathrm{Cr}$ ). Settings that increase the ratio of 'signal mass $49(\mathrm{mV}) /$ signal mass $52(\mathrm{~V})$ ' are unfavorable, since they increase the sulfur signal disproportionately. Figure 2.1 illustrates that tuning can achieve a major decrease in the mass 49 polyatomic $\mathrm{S}$ signal while suffering only a small loss in the $\mathrm{Cr}$ signal by: (a) decreasing the nebulizer gas flow (with our system, a higher $\mathrm{Cr}$ sensitivity is seen at 0.83 $\mathrm{L} / \mathrm{min}$ ), (b) decreasing the intermediate gas flow slightly, and (c) moving the torch box away from the cones (maximum $\mathrm{Cr}$ sensitivity is seen at 2-3 mm). Decreasing the nebulizer flow, increases the sample flow rate and requires dilution of the sample signal by bringing it up in a larger acid volume, so it effectively leads to a larger decrease in $\mathrm{Cr}$ signal than is evident in figure 2.1. In practice, we have chosen a compromise of a nebulizer flow of $\sim 0.73$. Although a nebulizer flow of $\sim 0.73$ is higher than the setting for minimal polyatomic $\mathrm{S}$ signal, it reduces the $\mathrm{S}$ mass 49 
polyatomic signal relative to the $\mathrm{Cr}$ signal. Optimal run parameters varied slightly from day to day and were thus determined at the beginning of every IsoProbe run. The effect of torch power on the sensitivity of S polyatomic interferences was explored but no strong effect was observed.

In low resolution mode under typical operating conditions, which are listed in table $2.3,0.72 \mathrm{~V}$ $1.62 \mathrm{~V}$ for a $2000 \mathrm{nmol} / \mathrm{kg}$ solution of Cr SRM were recorded on mass 52 . Generally, the addition of a small nitrogen gas flow to the desolvator exit increased $\mathrm{Cr}$ sensitivity.

At the beginning of each IsoProbe run, baseline measurements are performed while the analyzer slide valve is shut. This low-level background is automatically subtracted from all subsequent data. Additionally, "on peak zero" (OPZ) acid blanks $\left(2 \%(\mathrm{v} / \mathrm{v}) \mathrm{HNO}_{3}\right)$ are run as frequently as necessary and interpolated values subtracted from sample measurements.

A triplet of solutions are run for double spike (DS) calibration purposes: SRM, SRM-DS and, DS followed by longer washout periods. The 'SRM+DS' solution has the same concentration of SRM and DS as its pure counterparts (e.g. pure SRM, pure DS). The same ratio of SRM/DS used for this calibration is targeted when adding double spike to samples. Please refer to the section 2.2.4.1. for details of the double spike calibration calculations.

As part of the double spike calibration the initial ${ }^{54} \mathrm{Cr} /{ }^{50} \mathrm{Cr}$ value of the SRM-DS solution is set so that $\delta^{53} \mathrm{Cr}$ w.r.t. SRM979 $=0.00 \%$. When further SRM-DS solutions are measured repeatedly over the course of an IsoProbe run, it is evident that the calculated $\delta^{53} \mathrm{Cr}$ of the $\mathrm{Cr}$ SRM drifts slightly with respect to the initial calibration (figure 2.2b). The cause of this drift is not known. While a drift in instrumental mass bias should be corrected for by the DS calculations, a buildup of polyatomic interferences over the course of a run offers another potential explanation. Regardless of the cause of the drift, its small and gradual nature allows a correction to the sample's $\delta$ value with respect to the average $\delta$ value of the sample's bracketing SRM-DS solutions. On average the $\delta^{53} \mathrm{Cr}$ values of bracketing solutions for a given sample are observed to differ by about $0.04 \%$. The largest observed shift in $\delta^{53} \mathrm{Cr}$ values of bracketing solutions for a given sample is $0.11 \%$. This shift contributes an uncertainty of $\pm 0.055 \%$ to the corresponding sample's $\delta^{53} \mathrm{Cr}$ value, which is smaller than the uncertainty of $\pm 0.07 \%$ ( 2 standard deviations) of repeated measurements of SRM-DS solutions processed through the seawater isotope method (see section 2.3.2.). 
For Fe isotope analysis on the IsoProbe, it was observed that the calculated $\delta$ value of standards varied with their concentration (Bergquist, 2004). Erring on the side of caution for our $\mathrm{Cr}$ isotope runs on the IsoProbe, the bracketing SRM-DS solutions are matched in concentration to the samples. Even though some IsoProbe runs suggest a correlation, not all seven IsoProbe runs show such a correlation between the concentration and the delta value of the SRM-DS solutions consistently (figure 2.2a). Instead all seven IsoProbe runs show the aforementioned gradual drift of $\delta^{53} \mathrm{Cr}$ values of SRM-DS solutions with time. Since matching the samples and standards in concentration does not appear to be necessary, a future gain in precision should be obtained by running the SRM+DS solutions at a concentration comparable to the highest concentration samples.

To avoid analytical artifacts the Sample/DS ratio is matched to the SRM/DS ratio of bracketing solutions as closely as possible (i.e. for sample batch 1 a DS : SRM and a DS : sample ratio of 0.76 : 1 was targeted, for sample batch 4 to 5 a DS : SRM and a DS : sample ratio of $1: 1$ was targeted). When SRM-DS solutions of varying ratios (35\%DS - 50\%DS in SRM-DS solutions) were analyzed, a linear correlation between the \%DS in SRM-DS solution and the delta value was observed (figure 2.3). This observation may be coincidental since it could simply reflect the

gradual drift of the $\delta^{53} \mathrm{Cr}$ values of SRM-DS solutions with time. Further experiments featuring a greater number and a broader range of \%DS in SRM-DS solutions being measured in a more random fashion (instead of being lined up by \%DS in SRM-DS) should be conducted.

\subsubsection{Data reduction}

\subsubsection{Double spike isotope ratio calculations}

Subsequent calculations use constants provided by the Cr SRM certificate of analysis (Shields et al., 1966) and the 'Table of the isotopes' by Holden (2011).

The raw data of a given sample, which consists of 10 cycles with 3 sequences each, is imported into an Excel spreadsheet. Plots are generated automatically for every sample. Examining the 
${ }^{53} \mathrm{Cr} /{ }^{52} \mathrm{Cr}$ ratios, ${ }^{54} \mathrm{Cr} /{ }^{50} \mathrm{Cr}$ ratios, and signal intensities of ${ }^{49} \mathrm{Ti},{ }^{51} \mathrm{~V},{ }^{52} \mathrm{Cr},{ }^{56} \mathrm{Fe}$ makes it easy to identify and exclude outliers in the data. An average signal for each mass is calculated from the manually revised 10 cycles.

The OPZ acid background is interpolated linearly between discrete acid blank measurements. Every sample is thus matched with an approximated acid background that is subtracted from the sample signal before any further modifications are made.

As mentioned before, a triplet of samples is run in order to calibrate the double spike: SRM, SRMDS, and DS. The initial instrumental mass fractionation factor, $\beta_{1}$, is calculated from this Cr SRM run using the exponential law (equations 2 and 3, Russell et al., 1978). In the case of the Cr SRM run, the term $\left({ }^{53} \mathrm{Cr} /{ }^{52} \mathrm{Cr}\right.$ ) true refers to the certified ${ }^{53} \mathrm{Cr} /{ }^{52} \mathrm{Cr}$ ratio of the SRM 979 (Shields et al., 1966).

$$
\begin{gathered}
\left(\frac{{ }^{53} \mathrm{Cr}}{{ }^{52} \mathrm{Cr}}\right)_{\text {true }}=\left(\frac{{ }^{53} \mathrm{Cr}}{{ }^{52} \mathrm{Cr}}\right)_{\text {measured }} \times\left(\frac{\text { mass }^{53} \mathrm{Cr}}{\text { mass }^{52} \mathrm{Cr}}\right)^{\beta_{1}} \\
\beta_{1}=\frac{\log \left(\frac{\left(\frac{{ }^{53} \mathrm{Cr}}{{ }^{52} \mathrm{Cr}}\right)_{\text {true }}}{\left(\frac{{ }^{53} \mathrm{Cr}}{{ }^{52} \mathrm{Cr}}\right)_{\text {measured }}}\right)}{\log \left(\frac{\text { mass }{ }^{53} \mathrm{Cr}}{\text { masS }{ }^{52} \mathrm{Cr}}\right)}
\end{gathered}
$$

Assuming ${ }^{52} \mathrm{Cr}_{\text {true }}={ }^{52} \mathrm{Cr}_{\text {measured, }}$, equation 2 is applied to all masses (and all sequences) of the DS. While $\operatorname{mass}_{52} \mathrm{Cr}$ stays constant in the denominator, the numerator is exchanged for the mass of the main isotope of the given mass (e.g. numerator for mass 50 is $\operatorname{mass}{ }_{50} \mathrm{Cr}$ instead of $\operatorname{mass}_{50} \mathrm{~V}$ or $\operatorname{mass}_{50}{ }_{T i}$, numerator for mass 54 is $\operatorname{mass}_{54} \mathrm{Cr}$ instead of $\operatorname{masS}_{54}{ }_{\mathrm{Fe}}$ ). Equation 4 shows the signal on mass 50 being corrected for instrumental mass fractionation: 


$$
\left({ }^{50} \mathrm{Cr}, V, T i_{S 1}\right)_{\text {true }}=\left({ }^{50} \mathrm{Cr}, V, T i_{S 1}\right)_{\text {measured }} \times\left(\frac{\text { mass }^{50} \mathrm{Cr}}{\text { masS } 52^{52} \mathrm{r}}\right)^{\beta_{1}}
$$

Subsequently, known abundance ratios (e.g. ${ }^{50}{ }^{50} \mathrm{Ti} / \%{ }^{49} \mathrm{Ti},{ }^{50}{ }^{50} \mathrm{~V} / \%{ }^{51} \mathrm{~V}$ ) are used to correct for isobaric interferences stemming from $\mathrm{V}, \mathrm{Ti}$, and $\mathrm{Fe}$ (equation 5).

$$
\left({ }^{50} C r_{S 1}\right)_{\text {true }}=\left({ }^{50} \mathrm{Cr}, \mathrm{V}, \mathrm{Ti} i_{S 1}\right)_{\text {true }}-\frac{\%^{50} \mathrm{Ti}}{\%^{49} \mathrm{Ti}} \times\left({ }^{49} \mathrm{Ti} i_{S 1}\right)_{\text {true }}-\frac{\%{ }^{50} \mathrm{~V}}{\%{ }^{51} \mathrm{~V}} \times\left({ }^{51} V_{S 1}\right)_{\text {true }}
$$

As mentioned before, the mass range of the MIT IsoProbe is not big enough to measure ${ }^{56} \mathrm{Fe}$ within the same sequence (i.e. at the same acceleration potential) as masses 49 - 54. Instead, sequence 1 records masses 49 - 54 for $20 \mathrm{~s}$, sequence 2 again records masses 49 - 54 but only for $2 \mathrm{~s}$, and sequence 3 shifts the acceleration potential to record mass 56 for $2 \mathrm{~s}$. Throughout this chapter, sequences 1, 2 and 3 are indicated within equations using subscripts S1, S2 and S3, respectively. While there can be minor changes in sensitivity during the analysis of a sample, sequence 2 and 3 are both short and are assumed to experience no change in sensitivity. Additionally, plotting and comparing the relevant signal intensities (i.e. ${ }^{52} \mathrm{Cr}_{\mathrm{s} 1},{ }^{52} \mathrm{Cr}_{\mathrm{S} 2},{ }^{56} \mathrm{Fe}_{\mathrm{S} 3}$ ) allows us to identify and exclude problematic data points. For example, if the signal intensity of ${ }^{52} \mathrm{Cr}_{\mathrm{S} 2}$ stayed constant over 10 cycles, whereas the ${ }^{56} \mathrm{Fe}_{\mathrm{S} 3}$ signal intensity stayed constant except for a $30 \%$ higher reading in cycle 2 , it makes sense to exclude this data point.

In order to incorporate the ${ }^{56} \mathrm{Fe}_{\mathrm{S} 3}$ signal into the main sequence, $\mathrm{S} 1$, we adjust for changes in sensitivity between $\mathrm{S} 1$ and $\mathrm{S} 2 / \mathrm{S} 3$ using the ratio $\left({ }^{52} \mathrm{Cr}_{\mathrm{S} 1}\right)_{\text {true }} /\left({ }^{52} \mathrm{Cr}_{\mathrm{S} 2}\right)_{\text {true }}$ (equation 6). All 3 measurements $\left({ }^{52} \mathrm{Cr}_{\mathrm{S} 1},{ }^{52} \mathrm{Cr}_{\mathrm{S} 2},{ }^{56} \mathrm{Fe}_{\mathrm{S} 3}\right)$ are made on the same Faraday cup, $\mathrm{H} 2$, thereby avoiding concerns related to differences in cup efficiencies.

$$
\left({ }^{56} \mathrm{Fe}_{S 1}\right)_{\text {true }}=\frac{\left({ }^{52} \mathrm{Cr} r_{S 1}\right)_{\text {true }}}{\left({ }^{52} \mathrm{Cr} r_{S 2}\right)_{\text {true }}} \times\left({ }^{56} \mathrm{Fe} e_{S 3}\right)_{\text {true }}
$$

The newly derived $\left({ }^{56} \mathrm{Fe}_{\mathrm{S} 1}\right)_{\text {true }}$ and the known abundance ratios of $\%{ }^{54} \mathrm{Fe} / \%{ }^{56} \mathrm{Fe}$ are used to correct for isobaric interferences on ${ }^{54} \mathrm{Cr}$ (equation 7). 


$$
\left({ }^{54} C r_{S 1}\right)_{\text {true }}=\left({ }^{54} \mathrm{Cr}, \mathrm{Fe} e_{S 1}\right)_{\text {true }}-\frac{{ }^{54} \mathrm{Fe}}{\%{ }^{56} \mathrm{Fe}} \times\left({ }^{56} \mathrm{Fe} e_{S 1}\right)_{\text {true }}
$$

At this point, we have derived the true ${ }^{50} \mathrm{Cr},{ }^{52} \mathrm{Cr},{ }^{53} \mathrm{Cr}$, and ${ }^{54} \mathrm{Cr}$ signals of the double spike solution. Double spike ratios (i.e. $\left.\left({ }^{52} \mathrm{Cr} /{ }^{50} \mathrm{Cr}\right)_{\mathrm{DS}},\left({ }^{53} \mathrm{Cr} /{ }^{50} \mathrm{Cr}\right)_{\mathrm{DS}},\left({ }^{54} \mathrm{Cr} /{ }^{50} \mathrm{Cr}\right)_{\mathrm{DS}}\right)$ are calculated for later use.

Next, we turn to the SRM-DS run data which will undergo at least 4 iterations and 6 steps within each iteration.

Iteration 1, Step 1: The data is corrected for instrumental mass fractionation using $\beta_{1}$ and for contributions of Ti, $\mathrm{V}$, and Fe isobaric interferences, yielding estimates for the true ${ }^{50} \mathrm{Cr},{ }^{52} \mathrm{Cr},{ }^{53} \mathrm{Cr}$, and ${ }^{54} \mathrm{Cr}$ signals of the SRM-DS solution.

Iteration 1, Step 2: Since the ${ }^{50} \mathrm{Cr}-{ }^{54} \mathrm{Cr}$ double spike is very pure $\left({ }^{52} \mathrm{Cr} /{ }^{50} \mathrm{Cr}\right.$ and $\left.{ }^{52} \mathrm{Cr} /{ }^{54} \mathrm{Cr}<0.003\right)$ we assume that all ${ }^{52} \mathrm{Cr}$ and all ${ }^{53} \mathrm{Cr}$ derives from the SRM. Using the certified $\left({ }^{50} \mathrm{Cr} /{ }^{52} \mathrm{Cr}\right)_{\mathrm{SRM}}$ we can calculate the contribution of ${ }^{50} \mathrm{Cr}$ from the SRM. Subtracting this contribution from the ${ }^{50} \mathrm{Cr}_{\text {SRM-DS }}$ signal we derive the DS contribution to the ${ }^{50} \mathrm{Cr}_{\text {SRM-DS }}$ signal (equation 10). Similarly, we use the certified $\left({ }^{54} \mathrm{Cr} /{ }^{52} \mathrm{Cr}\right)_{\mathrm{SRM}}$ ratio to arrive at the DS contribution to the ${ }^{54} \mathrm{Cr}_{\text {SRM-DS }}$ signal (equation 11).

$$
\begin{gathered}
{ }^{50} C r_{S R M-D S}={ }^{50} C r_{D S \text { in SRM } D S}+{ }^{50} C r_{S R M} \text { in SRM-DS } \\
{ }^{50} C r_{D S \text { in SRM }-D S}={ }^{50} C r_{S R M-D S}-{ }^{50} C r_{S R M} \text { in SRM-DS } \\
{ }^{50} C r_{D S \text { in SRM }-D S}={ }^{50} C r_{S R M-D S}-{ }^{52} C r_{S R M-D S} \times\left(\frac{{ }^{50} C r}{{ }^{52} C r}\right)_{S R M} \\
{ }^{54} C r_{D S \text { in SRM } D S}={ }^{54} C r_{S R M-D S}-{ }^{52} C r_{S R M-D S} \times\left(\frac{{ }^{54} C r}{{ }^{52} C r}\right)_{S R M}
\end{gathered}
$$


Iteration 1, Step 3: In step 2 we calculated the ${ }^{50} \mathrm{Cr}$ and ${ }^{54} \mathrm{Cr}$ signal of the DS within the SRM-DS mixture. Here (equation 12), we derive a correction to the mass fractionation factor, $\beta_{2}$, by

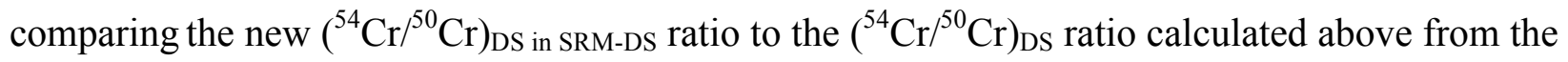
DS run.

$$
\beta_{2}=\frac{\log \left(\frac{\left(\frac{{ }^{54} C r}{{ }^{50} C r}\right)_{D S}}{\left(\frac{{ }^{54} C r}{{ }^{50} C r}\right)_{D S \text { in } S R M-D S}}\right)}{\log \left(\frac{\text { assS }^{54} C r}{\text { masS }^{50} C r}\right)}
$$

Iteration 1, Step 4: We apply the exponential mass fractionation law to the ${ }^{53} \mathrm{Cr}$ signal of the SRMDS mixture, the ${ }^{50} \mathrm{Cr}_{\mathrm{DS}}$ within SRM-DS signal, and the ${ }^{54} \mathrm{Cr}_{\mathrm{DS}}$ within SRM-DS signal using $\beta_{2}$ as the exponent. All of these signals had previously been corrected for instrumental mass fractionation using $\beta_{1}$.

Iteration 1, Step 5: We calculate the SRM ${ }^{52} \mathrm{Cr}$ and $\mathrm{SRM}{ }^{53} \mathrm{Cr}$ signal in the SRM-DS mixture by subtracting DS contributions (see equations 15 and 16, respectively). By assuming all ${ }^{50} \mathrm{Cr}$ and all ${ }^{54} \mathrm{Cr}$ in the SRM-DS mixture stems from the double spike and using $\left({ }^{52} \mathrm{Cr} /{ }^{50} \mathrm{Cr}\right)_{\mathrm{DS}}$ and $\left({ }^{53} \mathrm{Cr} /{ }^{50} \mathrm{Cr}\right)_{\mathrm{DS}}$, we arrive at the DS contribution to the ${ }^{52} \mathrm{Cr}$ and ${ }^{53} \mathrm{Cr}$ signals.

$$
\begin{gathered}
{ }^{52} C r_{S R M-D S}={ }^{52} C r_{D S \text { in SRM } D S}+{ }^{52} C r_{S R M} \text { in SRM-DS } \\
{ }^{52} C r_{S R M \text { in SRM-DS }}={ }^{52} C r_{S R M-D S}-{ }^{52} C r_{D S} \text { in SRM-DS } \\
{ }^{52} C r_{S R M \text { in } S R M-D S}={ }^{52} C r_{S R M-D S}-{ }^{50} C r_{S R M-D S} \times\left(\frac{{ }^{52} C r}{{ }^{50} C r}\right)_{D S} \\
{ }^{53} C r_{S R M \text { in SRM }-D S}={ }^{53} C r_{S R M-D S}-{ }^{50} C r_{S R M-D S} \times\left(\frac{{ }^{53} C r}{{ }^{50} C r}\right)_{D S}
\end{gathered}
$$


Iteration 1, Step 6: Now, we compare the ratio $\left({ }^{53} \mathrm{Cr} /{ }^{52} \mathrm{Cr}\right)_{\mathrm{SRM}}$ within SRM-DS to the certified ratio $\left({ }^{53} \mathrm{Cr} /{ }^{52} \mathrm{Cr}\right)_{\text {SRM }}$ by dividing them. The result should be close to 1.

Iteration 2, Step 1: The original SRM-DS data (same data that served as starting point in iteration 1 , step 1) is corrected for the revised estimate of the instrumental mass fractionation using ' $\beta_{1}+\beta_{2}$ ' as exponents. Subsequently, we correct for contributions of isobaric interferences, yielding the new estimated true ${ }^{50} \mathrm{Cr},{ }^{52} \mathrm{Cr}$, ${ }^{53} \mathrm{Cr}$, and ${ }^{54} \mathrm{Cr}$ signals of the SRM-DS solution.

The subsequent steps repeat themselves with each iteration adding a new $\beta_{\mathrm{n}}$. In the sixth step of the final iteration we again take the ratio of $\left({ }^{53} \mathrm{Cr} /{ }^{52} \mathrm{Cr}\right)_{\mathrm{SRM}}$ within SRM-DS and the certified $\left({ }^{53} \mathrm{Cr} /{ }^{52} \mathrm{Cr}\right)_{\text {SRM. }}$. Using Excel's 'Goal seek' function we force the ratio $\left(\left({ }^{53} \mathrm{Cr} /{ }^{52} \mathrm{Cr}\right)_{\text {SRM within SRM- }}\right.$ $\left.{ }_{\mathrm{DS}} /\left({ }^{53} \mathrm{Cr} /{ }^{52} \mathrm{Cr}\right)_{\mathrm{SRM}}\right)$ to be 1 (exact to at least 6 significant figures behind the decimal point) by changing the original $\left({ }^{54} \mathrm{Cr} /{ }^{50} \mathrm{Cr}\right)_{\mathrm{DS}}$.

This new $\left({ }^{54} \mathrm{Cr} /{ }^{50} \mathrm{Cr}\right)_{\mathrm{DS}}$ is used for all bracketing SRM-DS samples and seawater samples. These samples are taken through the same 4 plus iterations detailed here, except that the 'Goal seek' function is not employed. The final ratio $\left({ }^{53} \mathrm{Cr} /{ }^{52} \mathrm{Cr}\right)$ Sample within Sample-DS is compared to the $\left({ }^{53} \mathrm{Cr} /{ }^{52} \mathrm{Cr}\right)$ SRM to yield the $\delta^{53} \mathrm{Cr}$ value with respect to SRM 979 (equation 17).

$$
\delta^{53} C r(\% 0)=\left(\frac{\left(\frac{{ }^{53} C r}{{ }^{52} C r}\right)_{\text {Sample within Sample-DS }}}{\left(\frac{{ }^{53} C r}{{ }^{52} C r}\right)_{S R M}}-1\right) \times 1000
$$

For a pure SRM+DS mixture, two iterations typically suffice to arrive at a $\left(\left(^{53} \mathrm{Cr} /{ }^{52} \mathrm{Cr}\right)_{\text {SRM within SRM- }}\right.$ $\left.{ }_{\mathrm{DS}} /\left({ }^{53} \mathrm{Cr} /{ }^{52} \mathrm{Cr}\right)_{\mathrm{SRM}}\right)$ ratio that is stable to the 6th digit after the decimal point (i.e. difference between ratio after iteration 2 and after iteration 3 is on the order of $0.0001 \%$ or less). For processed samples, an additional iteration is required to attain a $\left(\left({ }^{53} \mathrm{Cr} /{ }^{52} \mathrm{Cr}\right)_{\text {Sample within Sample-DS }} /\left({ }^{53} \mathrm{Cr} /{ }^{52} \mathrm{Cr}\right)_{\mathrm{SRM}}\right)$ ratio with the same stability. Erring on the side of caution we recommend (the above mentioned) 4 plus iterations regardless of the initial data input. 


\subsubsection{Double spike concentration calculations}

Single isotope dilution, in which one isotope is artificially enriched within the sample-spike mixture, is a commonly employed method to determine sample concentrations. Our ${ }^{50} \mathrm{Cr}-{ }^{54} \mathrm{Cr}$ double spike addition can be viewed as two simultaneous single isotope dilutions as it artificially increases two isotopes within the sample-spike mixture. The same single isotope dilution equations are applied once with respect to ${ }^{50} \mathrm{Cr}$ as the isotope spike and once with respect to ${ }^{54} \mathrm{Cr}$ as the isotope spike. These two single isotope dilution calculations will each yield a sample concentration. The calculated concentrations are typically $0.03 \%$ - $0.08 \%$ apart and are averaged to produce the final sample concentration. The elements of the single isotope dilution equation (equation 18) with respect to ${ }^{50} \mathrm{Cr}$ as the isotope spike are: the concentration of the sample $\left(\mathrm{C}_{\text {sample}}\right)$, the fraction of ${ }^{50} \mathrm{Cr}$ in the double spike ( $\left.\mathrm{f}_{\text {spike }}\right)$, the fraction of ${ }^{50} \mathrm{Cr}$ in $\mathrm{Cr}$ with natural isotopic abundances ( $\left.\mathrm{f}_{\text {natural }}\right)$, the concentration of the spike $\left(\mathrm{C}_{\text {spike }}\right)$, the spike and the sample volume $\left(\mathrm{V}_{\text {Spike }}\right.$ and $\mathrm{V}_{\text {Sample }}$, respectively), the measured ${ }^{52} \mathrm{Cr} /{ }^{50} \mathrm{Cr}$ ratio of the sample-spike mixture corrected for instrumental mass fractionation $\left(\mathrm{R}_{\text {true-sample }}\right)$, the ${ }^{52} \mathrm{Cr} /{ }^{50} \mathrm{Cr}$ ratio of the double spike corrected for instrumental mass fractionation ( $\mathrm{R}_{\text {true-spike}}$ ), and the ${ }^{52} \mathrm{Cr} /{ }^{50} \mathrm{Cr}$ ratio of $\mathrm{Cr}$ with natural isotopic abundances ( $\left.\mathrm{R}_{\text {natural }}\right)$.

$$
C_{\text {sample }}=\frac{f_{\text {spike }}}{f_{\text {natural }}} \times C_{\text {spike }} \times\left(\frac{V_{\text {spike }}}{V_{\text {Sample }}}\right) \times\left[\frac{R_{\text {true-sample }}-R_{\text {true-spike }}}{R_{\text {natural }}-R_{\text {true-sample }}}\right]
$$

First, the double spike concentration was calibrated against certified $\mathrm{Cr}$ concentration standards of natural isotopic composition. The concentration of the SRM dilution and the seawater samples, considered to have a natural isotopic composition, were calibrated against the now known double spike concentration.

\subsubsection{Quantifying the isobaric corrections}

In order to quantify the isobaric corrections made on ${ }^{50} \mathrm{Cr}$ we have to compare the signal on mass 50 to the ${ }^{50} \mathrm{Cr}$ signal after the isobaric corrections with respect to $\mathrm{Ti}$ and $\mathrm{V}$ are performed (equation 19). All signals, which are taken from the final iteration, have previously been corrected for

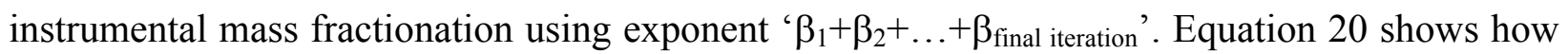


to quantify the isobaric correction on ${ }^{54} \mathrm{Cr}$ by comparing the signal on mass 54 to the ${ }^{54} \mathrm{Cr}$ signal once the ${ }^{54} \mathrm{Fe}$ contribution is subtracted.

$$
\begin{gathered}
\text { Isobaric Correction on }{ }^{50} \operatorname{Cr}(\%)=\left(\frac{\left({ }^{50} C r_{S 1}\right)_{\text {true }}}{\left({ }^{50} C r, V, T i_{S 1}\right)_{\text {true }}}\right) \times 1000 \\
\text { Isobaric Correction on }{ }^{54} \operatorname{Cr}(\%)=\left(\frac{\left({ }^{54} C r_{S 1}\right)_{\text {true }}}{\left({ }^{54} C r, F e_{S 1}\right)_{\text {true }}}\right) \times 1000
\end{gathered}
$$

\subsubsection{Cr recovery calculations}

To calculate the recovery of a sample we compare the ${ }^{52} \mathrm{Cr}$ signal of the sample to the ${ }^{52} \mathrm{Cr}$ signals of the bracketing SRM-DS mixtures. The bracketing SRM-DS mixtures come in different dilutions. The dilution 'SRM-DS 100\%' is set up such that it would match the final analyte concentration of a SRM-DS mixture processed over the column procedure with $100 \%$ recovery. For example, if we choose to process $1.6 \mathrm{nmol}$ of $\mathrm{Cr}$ SRM over the column procedure which we bring up in a final volume of $360 \mu \mathrm{L}$ for IsoProbe analysis, at $100 \%$ recovery we would expect a Cr SRM concentration of $1.6 \mathrm{nmol} / 360 \mu \mathrm{L} \approx 4444 \mathrm{nmol} / \mathrm{L}$ in the final analyte. The bracketing SRM-DS dilutions are set up such that they contain $4444 \mathrm{nmol} / \mathrm{L}$ of $\mathrm{Cr}$ SRM at dilution $100 \%$ ( $=\mathrm{C}_{\text {SRM-DS }}$ $100 \%$ ). Equation 21 returns the recovery of an SRM that was processed like a sample. The equation needs to be adjusted for seawater samples because the final analyte of a seawater sample at $100 \%$ recovery does not necessary match the concentration of the bracketing SRM-DS $100 \%$ dilution. For example, a seawater sample was found to contain $0.8 \mathrm{nmol} / \mathrm{kg}$ of $\mathrm{Cr}\left(=\mathrm{C}_{\mathrm{Sw} \text { Sample }}\right)$ and a weight of $1 \mathrm{~kg}$ was used at the start of the method $\left(=\mathrm{W}_{\mathrm{SW} \text { Sample }}\right)$. If the $\mathrm{Cr}$ in the seawater sample were recovered at $100 \%$ and brought up in $360 \mu \mathrm{L}\left(=\mathrm{V}_{\mathrm{SW}}\right.$ final analyte), the final analyte solution would have a concentration of $0.8 \mathrm{nmol} / 360 \mu \mathrm{L} \approx 2222 \mathrm{nmol} / \mathrm{L}$ natural Cr. Remember that the SRM-DS $100 \%$ dilution contained $4444 \mathrm{nmol} / \mathrm{L}$ of natural Cr. Equation 22 contains an additional scaling factor that accounts for the difference in the initial amount of $\mathrm{Cr}$ present in the seawater sample versus the SRM-DS mixture. Since every sample is bracketed by two SRM-DS mixtures, equations 21 and 22 are applied twice and the resulting recoveries are averaged. 


$$
\text { Recovery of SRM Sample }(\%)=\frac{{ }^{52} C r_{S R M} \text { sample }}{{ }^{52} C r_{S R M-D S}} \times \% S R M-D S
$$

$$
\begin{gathered}
\text { SW Sample Recovery }(\%)= \\
\frac{{ }^{52} C r_{S W \text { Sample }}}{{ }^{52} C r_{S R M-D S}} \times \frac{C_{S R M-D S 100 \%} \times V_{S W \text { final analyte }}}{C_{S W \text { Sample }} \times V_{S W \text { Sample }}} \times \% S R M-D S
\end{gathered}
$$

\subsection{Results and discussion}

\subsubsection{The intricacies of the Cr oxidation step using ammonium persulfate}

The success of the described $\mathrm{Cr}$ oxidation step using APS hinges on carefully controlling the strength of the acidic medium. In strongly acidic solutions APS decomposes to $\mathrm{H}_{2} \mathrm{O}_{2}$ (Elbs and Schönherr, 1895; Palme, 1920). In that case, the initial oxidation of Cr using APS is partially reversed since $\mathrm{H}_{2} \mathrm{O}_{2}$ reduces $\mathrm{Cr}$ under acidic conditions. No hydrogen peroxide is generated when APS decomposes in dilute acidic solutions. In our study, an acidic medium of $\leq 0.02 \mathrm{M} \mathrm{HCl}$ was found to reliably support quantitative $\mathrm{Cr}$ oxidation using APS. A replication of the oxidation in a medium of $0.2 \mathrm{M} \mathrm{HCl}$ (as suggested by Crowe et al. (2013)) using $1 \mathrm{~mL}$ of $0.2 \mathrm{M}$ APS resulted in only $30 \%$ of $\mathrm{Cr}$ being present as $\mathrm{Cr}(\mathrm{VI})$. This is likely due to $\mathrm{Cr}(\mathrm{VI})$ being reduced back to $\mathrm{Cr}$ (III) by generated $\mathrm{H}_{2} \mathrm{O}_{2}$. We must therefore assume Crowe et al. (2013) meant to stipulate a medium of $0.02 \mathrm{M} \mathrm{HCl}$ instead of $0.2 \mathrm{M} \mathrm{HCl}$. Since the generation of $\mathrm{H}_{2} \mathrm{O}_{2}$ is an easy pitfall of $\mathrm{Cr}$ oxidation with APS, it is valuable for Cr studies to address this little-known aspect of APS chemistry.

Additionally, the setup of the APS oxidation step can determine which sulfur species are created and thereby how much sulfur sticks to the first ion exchange column. The presence of sulfur in the final analyte solution is undesirable because sulfur polyatomics interfere with the $\mathrm{Cr}$ isotope analysis; this will be explained in more detail later in this chapter. In dilute acidic media, the decomposition of APS can be described by the following reaction (equation 23):

$$
\mathrm{S}_{2} \mathrm{O}_{8}^{2-}+\mathrm{H}_{2} \mathrm{O} \rightarrow 2 \mathrm{HSO}_{4}^{2-}+\frac{1}{2} \mathrm{O}_{2}
$$


The extent of persulfate decomposition is enhanced by higher temperatures and lower $\mathrm{pH}$ (Kolthoff and Miller, 1951). To evaluate which species $\left(\mathrm{S}_{2} \mathrm{O}_{8}{ }^{2-}\right.$ or $\left.\mathrm{HSO}_{4}{ }^{2-}\right)$ has a higher affinity for the first ion exchange resin, two solutions are passed over the column: (1) $1 \mathrm{~mL} 0.2 \mathrm{M}$ of APS is added to $9 \mathrm{~mL}$ of $0.022 \mathrm{M} \mathrm{HCl}$ and no heat is introduced; (2) $1 \mathrm{~mL} 0.2 \mathrm{M}$ of APS is added to $9 \mathrm{~mL}$ of 0.022 $\mathrm{M} \mathrm{HCl}$, the solution is boiled in a closed Savillex vial at $130^{\circ} \mathrm{C}$ for 1 hour, and loaded onto the column upon cooling. Persulfate in solution 2 will have undergone a much higher degree of decomposition and will contain a larger fraction of $\mathrm{HSO}_{4}{ }^{2-}$ than solution 1. After both solutions are processed over the first column, the final eluate is dried down. Solution 1 (less APS decomposition) results in a much smaller droplet of sulfuric acid. This suggests that the lower the temperature and the weaker the acidic medium during Cr oxidation with APS, the less sulfur will be present after column step 1. Even though APS is a very strong oxidizer (standard reduction potential $\mathrm{E}_{0}=2.123 \mathrm{~V}$, equation 23 , Vanysek (1998)), a certain amount of heat is needed for the $\mathrm{Cr}$ (III) oxidation reaction to occur. Other studies commonly conduct this oxidation step at $130^{\circ} \mathrm{C}$ in a $0.02 \mathrm{M} \mathrm{HCl}$ medium (e.g. Frei et al., 2014; Schoenberg et al., 2008). In our experiments, Cr(III) oxidation remained quantitative over a temperature range of $100^{\circ} \mathrm{C}$ to $130^{\circ} \mathrm{C}$. It is possible that even lower temperatures lead to quantitative $\mathrm{Cr}(\mathrm{III})$ oxidation but $100^{\circ} \mathrm{C}$ was the lowest temperature at which the reaction was studied. Typically, a medium of $0.02 \mathrm{M} \mathrm{HCl}$ is chosen. Here, we settled on a slightly less acidic medium (0.018 M HCl equivalent to a $\mathrm{pH}$ of 1.74). As long as the solution is acidic enough to keep $\mathrm{Cr}$ (III) in solution, it could potentially be even less acidic than the medium we utilized. Another parameter affecting the degree of APS decomposition is boiling time, with shorter time periods of boiling leading to less degradation. This parameter was not examined in our research. Changing the setup of the oxidation step (before: $0.02 \mathrm{M} \mathrm{HCl}, 130^{\circ} \mathrm{C}$, 1 hour; now: $0.018 \mathrm{M} \mathrm{HCl}, 110^{\circ} \mathrm{C}, 1$ hour) resulted in a marked decrease of sulfur in the final analyte. Before this modification, up to $1 / 3$ of samples still contained significant traces of sulfur when analyzed on the MC-ICP-MS; with the revised procedure, only 1 out of 65 processed seawater samples contained significant levels of sulfur (more details in section 2.3.2.). In both scenarios, the $2^{\text {nd }}$ ion exchange column, which is designed to separate $\mathrm{S}$ and $\mathrm{Cr}$, was performed. Due to the adjusted Cr oxidation step, this second column received less sulfur to begin with and was able to separate the remaining $\mathrm{S}$ more reliably from $\mathrm{Cr}$ than previously. 


\subsubsection{Accuracy and precision of SRM-DS solutions processed through the oxidation step}

and over the 3-column scheme

In order to validate the $\mathrm{Cr}$ isotope method, two pure SRM-DS solutions and two acid blanks were processed together with each batch of samples. The SRM-DS solutions were mixed in the same ratio as was targeted for the Sample-DS and bracketing SRM-DS solutions. Furthermore, to mirror the typical $\mathrm{Cr}$ load of the processed seawater samples, a Cr SRM load of $1.6 \mathrm{nmol}$ was chosen. Both pure SRM and DS solutions were present in a $2 \%(\mathrm{v} / \mathrm{v}) \mathrm{HNO}_{3}$ matrix. After the solutions were mixed, they were dried down and brought up in $9 \mathrm{~mL}$ of $0.02 \mathrm{M} \mathrm{HCl}$. In the case of the acid blanks, $9 \mathrm{~mL}$ of $0.02 \mathrm{M} \mathrm{HCl}$ served as the starting solution. From this point forward the SRM-DS and blank solutions were treated the same as the seawater samples. Ammonium persulfate was added, followed by $\mathrm{Cr}$ oxidation and three column runs.

For eight processed SRM-DS solutions an average recovery of $87 \%$ and $\delta^{53} \mathrm{Cr}$ w.r.t. SRM979= $+0.02 \pm 0.07 \%$ ( $\pm 2 \mathrm{SD}$ ) was obtained (figure 2.4$)$. The method blank was deemed negligible since it contributed an average of $1.2 \%(=0.017 \mathrm{nmol}$ of $\mathrm{Cr})$ to the ${ }^{52} \mathrm{Cr}$ signals of the SRM-DS solutions. Average isobaric corrections were $2.17 \%$ on ${ }^{50} \mathrm{Cr}$ and $0.04 \%$ on ${ }^{54} \mathrm{Cr}$.

Even though the column procedure and the operating conditions are designed such that sulfur interferences are minimal, sulfur traces were present in 2 out of a total of 10 processed SRM-DS solutions. Ball and Bassett (2000), who used thermal ionization mass spectrometry (TIMS) instead of MC-ICP-MS to characterize Cr isotope ratios, observed that the presence of sulfur shifted the true ${ }^{53} \mathrm{Cr} /{ }^{52} \mathrm{Cr}$ isotope ratio in unpredictable and mathematically unresolvable ways. In our case, two samples show sulfur traces based on unusually high isobaric corrections on ${ }^{50} \mathrm{Cr}$ if we assume that the signal on mass 49 stems from titanium. Fortunately, the accumulation of significant levels of titanium from reagents or accidental contamination has not been observed. Therefore, for pure starting solutions any calculated isobaric interference correction of Ti on mass 50 exceeding $6 \%$ o suggests the presence of sulfur; the corresponding delta value should be excluded from the data set and the sample rerun. The same criteria should be applied to seawater samples since it is a reasonable assumption that significant levels of titanium will not be present in the final matrix. Seawater contains only trace amounts of Ti (typically $\leq 265 \mathrm{pmol} / \mathrm{L}$; Orians et al., 1990) and our column chemistry does not pre-concentrate Ti from seawater. In figure 2.4 , the $\delta^{53} \mathrm{Cr}$ values of 
processed SRM-DS samples presenting with low levels of sulfur are plotted in brackets $\left(\delta^{53} \mathrm{Cr}\right.$ wrt SRM979 $=+0.04 \%$ o $+0.12 \%$ with a calculated isobaric interference correction of Ti on mass 50 $=10.6 \%$ and $14.1 \%$, respectively).

For this thesis 65 seawater samples were processed (table 2.4; table 3.1; table 4.1). In contrast to the processed SRM+DS solutions, only 1 out of 65 final analyte solutions of processed seawater samples contained sulfur remnants. Why would sulfur remnants be disproportionally present in the processed SRM-DS solutions compared to the processed seawater samples? After the preconcentration of the seawater-DS mixture in a $\mathrm{Mg}(\mathrm{OH})_{2}$ pellet, matrix ions other than $\mathrm{Cr}$ remain. The elevated presence of matrix ions could impact both the oxidation step and the first column run. Ammonium persulfate used in the Cr oxidation step may react to a different extent if more matrix ions are present and thus the nature and/or quantity of the sulfur species being generated in this step may differ for pure Cr SRM-DS and seawater-DS solutions. Furthermore, once the seawater samples are loaded onto the $1^{\text {st }}$ column $\mathrm{Cr}$ and $\mathrm{S}$ oxyanions will have to compete with a higher quantity of matrix anions for resin binding spots, potentially leading to fewer sulfur anions being retained by the resin than would be the case for a pure Cr SRM-DS solution.

\subsubsection{Application of the developed $\mathrm{Cr}$ isotope method to seawater samples}

\subsubsection{Seawater sampling}

In the Eastern Tropical North Pacific (ETNP) Ocean, a 13-depth water column profile was retrieved at $\mathrm{SAFe}\left(30^{\circ} \mathrm{N} 140^{\circ} \mathrm{W}\right.$, figure 2.5) on May 17th 2009 (trace metal isotope cast, GT event 2066). Sampling took place on the R/V Knorr (195-8) during the US GEOTRACES IC2 intercomparison cruise. Surface seawater was pumped into a large volume tank using the Bruland lab's trace metal clean tow-fish (Bruland et al., 2005). Subsurface samples were again taken with the US GEOTRACES rosette. All samples were filtered within hours of collection using pre-cleaned $0.2 \mu \mathrm{m}$ Osmonics capsules. The surface sample was acidified with concentrated $\mathrm{HCl}$ to a $\mathrm{pH}$ of $\sim 1.7$, whereas the subsurface samples were acidified to a $\mathrm{pH}$ of $\sim 2$. While acidification took place shortly after the sample retrieval (May 2009), the samples were processed for total Cr isotope signatures in April 2017. 
A $~ 20 \mathrm{~L}$ seawater sample, that serves as a long-term $\mathrm{Cr}$ isotope reference sample, was collected in the mid-South Pacific Subtropical Gyre (SPSG) near Easter Island $\left(26.2484^{\circ} \mathrm{S} 103.9608^{\circ} \mathrm{W}\right)$ at $100 \mathrm{~m}$ using a DOM pump. The sample was retrieved as part of the BiG RAPA expedition (R/V Melville, MV1015) on 12/12/2010, filtered (0.2 $\mu \mathrm{m}$ AcroPak Supor capsule) and acidified to $\mathrm{pH}$ $\sim 2$ the same day. The sample was first processed through the isotope method in February 2017.

\subsubsection{Method performance for seawater samples}

In order to most accurately report how the developed method performs for seawater samples, the following statistics are based on all seawater samples that were analyzed within this $\mathrm{PhD}$ thesis (table 2.4; table 3.1; table 4.1).

On average, $\mathrm{Cr}$ in seawater samples was recovered at $65 \%$. The $\mathrm{Cr}$ recovery of individual samples ranged from $33 \%$ to $91 \%$. The method blank contributed an average of $1.9 \%$ to the ${ }^{52} \mathrm{Cr}$ signal of the sample and was therefore deemed negligible. For the sample with the lowest final $\mathrm{Cr}$ load, the method blank's contribution rose to $3.5 \%$. For the sample with the highest final $\mathrm{Cr}$ load, a blank contribution of $0.7 \%$ was recorded. Isobaric corrections on ${ }^{54} \mathrm{Cr}$ due to ${ }^{54} \mathrm{Fe}$ and on ${ }^{50} \mathrm{Cr}$ due to ${ }^{50} \mathrm{Ti}$ and ${ }^{50} \mathrm{~V}$ were similarly marginal $\left({ }^{54} \mathrm{Cr}\right.$ : average $=0.12 \%$, range $=0.01 \%-1.50 \%$, ${ }^{50} \mathrm{Cr}$ : average $=1.31 \%$, range $=0.32 \% 0-5.35 \%$ ) .

Up to this date, the aforementioned internal reference seawater sample has only been analyzed three times. As mentioned above, the final sample analyte of 1 out of 65 processed seawater samples contained sulfur remnants. This was noticed due to an abnormally high isobaric correction of Ti on mass $50(10.8 \%)$. Coincidentally, the sample in question is one of the three repeatedly measured internal reference seawater samples. Low-level sulfur remnants like these are not expected to affect the accurate determination of the sample's Cr concentration (no sulfur present: $[\mathrm{Cr}]=3.29 \mathrm{nmol} / \mathrm{kg}, 3.30 \mathrm{nmol} / \mathrm{kg}$; sulfur present: $[\mathrm{Cr}]=3.30 \mathrm{nmol} / \mathrm{kg}$ ). Sulfur polyatomic interferences may however affect the determined $\mathrm{Cr}$ isotope ratio. In this specific case, the $\delta^{53} \mathrm{Cr}$ values were not significantly different (no sulfur present: $\delta^{53} \mathrm{Cr}=0.93 \%$, $0.99 \%$; sulfur present: $\delta^{53} \mathrm{Cr}=1.01 \%$ ), nevertheless the $\delta^{53} \mathrm{Cr}$ value of the affected sample will be excluded from later discussions. 


\subsubsection{Results and discussion of seawater data}

The first full water column profile of $\mathrm{Cr}$ isotope ratios at a station in the Pacific Ocean (SAFe: $30^{\circ} \mathrm{N} 140^{\circ} \mathrm{W}$, Johnson et al., 2007) is presented in figure 2.6. Water mass distributions at this site, which have been reviewed extensively by Talley (2008) and Talley et al. (2011), are shown alongside the Cr data. In the upper $200 \mathrm{~m}$, total $\mathrm{Cr}$ concentrations are stable at $3.16 \mathrm{nmol} / \mathrm{kg}-3.19$ $\mathrm{nmol} / \mathrm{kg}$. Over the same depth range $\delta^{53} \mathrm{Cr}$ values increase gradually from $1.01 \%$ o to $1.11 \%$. North Pacific Intermediate Water (NPIW) is located at $300 \mathrm{~m}$ to $600 \mathrm{~m}$ depth. Between $600 \mathrm{~m}$ and $1300 \mathrm{~m}$, Antarctic Intermediate Water (AAIW) mixes with NPIW. Pacific Deep Water (PDW) and modified Upper Circumpolar Deep Water (UCDW) occupy the depth range between 1300m and $3800 \mathrm{~m}$. Within these 3 layers $(600 \mathrm{~m}-3800 \mathrm{~m}),[\mathrm{Cr}]$ increases gradually with depth and reaches a maximum of $4.77 \mathrm{nmol} / \mathrm{kg}$ at $3000 \mathrm{~m}$. At the same time $\delta^{53} \mathrm{Cr}$ values decrease continuously with depth down to $0.70 \%$ in the deepest sample. Finally, Lower Circumpolar Deep Water (LCDW) resides at depths below $3800 \mathrm{~m}$. Here, Cr concentrations decrease slightly to $4.51 \mathrm{nmol} / \mathrm{kg}$ and $\delta^{53} \mathrm{Cr}$ values range between $0.68 \%$ and $0.74 \%$.

\subsection{Cr as a potential nutrient-type element}

At the SAFe station, the shape of the Cr concentration profile is very similar to that of the silicic acid ( $\mathrm{dSi}$ ) concentration profile (figure 2.6). This nutrient-like shape of the $\mathrm{Cr}$ concentration profile has been observed by other studies, some of which suggested that $\mathrm{Cr}$ distributions in seawater are partially biologically controlled (e.g. Cranston and Murray, 1978; Campbell and Yeats, 1981). Laboratory experiments detected the intracellular accumulation and the extracellular adsorption of (primarily) $\mathrm{Cr}$ (III) by a model diatom species (Semeniuk et al., 2016). Since Cr(VI) reduction typically leads to isotopically light Cr(III) (e.g. Zink et al., 2010), Scheiderich et al. (2015) and Semeniuk et al. (2016) theorize that isotopically light $\mathrm{Cr}(\mathrm{III})$ is removed via biological sequestration from the surface ocean and transported to depth, where the isotopically light $\mathrm{Cr}$ (III) is partially released back into the ocean. At SAFe, we measured lower $[\mathrm{Cr}]$ and higher $\delta^{53} \mathrm{Cr}$ values in the surface ocean consistent with biological removal of isotopically light Cr(III), and we observed higher $[\mathrm{Cr}]$ and lower $\delta^{53} \mathrm{Cr}$ values at depth consistent with remineralization of isotopically light $\mathrm{Cr}(\mathrm{III})$. 
Even though the SAFe profile taken on its own agrees with the proposed biological cycling of $\mathrm{Cr}$, a more general conundrum remains: Contrary to virtually all nutrients or trace metals with nutrienttype distributions, $\mathrm{Cr}$ concentrations in the deep water seemingly do not consistently increase along the water's flow path from the Atlantic to the Pacific Ocean (Scheiderich et al., 2015; Sirinawin et al., 2000). The surface and deep waters of a station in South Atlantic appear to hold substantially higher $\mathrm{Cr}$ concentrations and lighter $\mathrm{Cr}$ isotope ratios $([\mathrm{Cr}]=5.80 \mathrm{nmol} / \mathrm{kg} \mathrm{nmol} / \mathrm{kg}$, $\delta^{53} \mathrm{Cr}=0.52 \%$; Bonnand et al., 2013) compared to the deep waters of the Pacific SAFe station $\left([\mathrm{Cr}]=4.77 \mathrm{nmol} / \mathrm{kg}, \delta^{53} \mathrm{Cr}=0.70 \%\right.$ ). It is also worth noting that Bonnand et al. (2013)'s South Atlantic profile shows very little variation in $\mathrm{Cr}$ concentrations and $\mathrm{Cr}$ isotope ratios down the water column, whereas $[\mathrm{dSi}],\left[\mathrm{NO}_{3}{ }^{-}\right]$and $\left[\mathrm{PO}_{4}{ }^{3-}\right]$ show typical nutrient type profiles at this site. Therefore, this profile as a whole is difficult to reconcile with $\mathrm{Cr}$ being a nutrient-type element. Chromium may still be a nutrient-type element, but further research is needed to resolve these inconsistencies. For now, Scheiderich et al. (2015) suggest that the lower oxygen levels of the Pacific Ocean (relative to the Atlantic Ocean) promote a higher Cr scavenging flux which results in a higher Cr export flux to the sediments.

\subsection{Origin of the heavy $\mathrm{Cr}$ isotope peak at $200 \mathrm{~m}$ depth at $\mathrm{SAFe}$}

Interestingly, the heaviest $\mathrm{Cr}$ isotope signature at $\mathrm{SAFe}$ was not recorded at the surface (as would be expected in a biological Cr uptake scenario) but at $200 \mathrm{~m}$ depth as part of a multiple-point heavy $\mathrm{Cr}$ isotope peak (figure 2.6). The data points that comprise this peak are within a $0.10 \%$ range which is smaller than the uncertainty of $\pm 0.07 \%$ ( $2 \mathrm{SD}$ ) of each individual measurement. Given that the peak is not a one-point but a very smooth six-point feature, we tentatively treat it as real.

Even though dust input could lower the isotopic signature of $\mathrm{Cr}$ in surface waters $\left(\delta^{53} \mathrm{Cr}\right.$ of bulk silicate earth $=-0.124 \pm 0.101 \%$; Schoenberg et al., 2008) and thereby lead to an apparent peak in heavy $\mathrm{Cr}$ at $200 \mathrm{~m}$ depth, this scenario is unlikely. $\mathrm{Cr}$ in dust is generally assumed to be relatively insoluble and estimates of dust input at SAFe are low (0.2-0.5 $\mathrm{g} \mathrm{m}^{-2} \mathrm{yr}^{-1}$; Jickells et al., 2005). Furthermore, $\mathrm{Cr}$ input from dust dissolution should lead to higher $\mathrm{Cr}$ concentrations at the ocean surface which we do not observe at SAFe. 
$\mathrm{SAFe}$ is located in the oligotrophic North Pacific gyre where oxygen levels $\left(\left[\mathrm{O}_{2}\right]>13.2 \mu \mathrm{mol} / \mathrm{kg}\right.$, figure 2.6) are not low enough to favor thermodynamic $\mathrm{Cr}$ reduction. However, $\mathrm{Cr}$ reduction has been observed in the oxygen deficient zone (ODZ) of the Eastern Tropical North Pacific (ETNP) (Murray et al., 1983; Rue et al., 1997). Rue et al. (1997) detected a deficit of up to $2 \mathrm{nmol} / \mathrm{kg} \mathrm{Cr}$ (VI) in the ODZ of the ETNP and a concurrent $\mathrm{Cr}(\mathrm{III})$ peak of up to $0.9 \mathrm{nmol} / \mathrm{kg}$. They reasoned that after soluble $\mathrm{Cr}(\mathrm{VI})$ is reduced to particle-reactive $\mathrm{Cr}(\mathrm{III})$, a fraction of the $\mathrm{Cr}(\mathrm{III})$ is scavenged by particles and exported. Since $\mathrm{Cr}$ reduction typically results in isotopically light $\mathrm{Cr}$ (III) being produced (e.g. Zink et al., 2010), the total Cr remaining after $\mathrm{Cr}$ (III) export should become isotopically heavier. The signal imprinted by $\mathrm{Cr}$ reduction $\left(=\operatorname{lower}[\mathrm{Cr}]\right.$, heavier $\left.\delta^{53} \mathrm{Cr}\right)$ in the ODZ of the ETNP may advect or diffuse to SAFe station and result in the heavy Cr isotope peak that is observed at $200 \mathrm{~m}$ depth. Chapter 3 presents total $\mathrm{Cr}$ concentration and isotope data from the ODZ of the ETNP which supports this scenario.

\subsection{Position of SAFe samples and the internal reference sample on the global $\mathrm{Cr}$ array}

All seawater Cr isotope data published to date (Bonnand et al., 2013; Scheiderich et al., 2015) plot on a Rayleigh-like fractionation on a $\delta^{53} \mathrm{Cr}-\ln ([\mathrm{Cr}])$ plot. Scheiderich et al. (2015) suggested that $\mathrm{Cr}$ in seawater is being moved along this potentially globally applicable line by one or more mechanisms that are characterized by the same fractionation factors. Even though, the Cr samples from SAFe station and our internal reference seawater sample also fall on this Rayleigh-like fractionation line (figure 2.7), too few seawater samples have been analyzed globally to exclude that $\mathrm{Cr}$ undergoes reactions associated with different fractionation factors. In fact, Arctic $\mathrm{Cr}$ isotope data presented in chapter 4 clearly falls off the previously observed Rayleigh-like fractionation line. 


\subsection{Conclusions}

A new $\mathrm{Cr}$ isotope method for seawater samples was presented and shown to be both accurate and precise. Here, we will compare our method to the two other procedures that yielded precise $\mathrm{Cr}$ isotope and concentration data for seawater (Bonnand et al., 2013; Scheiderich et al., 2015).

In our method, quantitative $\mathrm{Cr}$ preconcentration from seawater is achieved using $\mathrm{Mg}(\mathrm{OH})_{2}$ coprecipitation instead of Fe-coprecipitation (Bonnand et al., 2013; Scheiderich et al., 2015), thereby limiting the amount of $\mathrm{Fe}$ that needs to be separated from $\mathrm{Cr}$ to the sample's initial $\mathrm{Fe}$ content. Following the preconcentration, we rely on Cr oxidation using ammonium persulfate and a first anion exchange column step (AG 1-X8), both of which have been used numerous times by Cr isotope studies (Ball and Bassett, 2000; Frei et al., 2009; Schoenberg et al., 2008). We point out previously unmentioned pitfalls and intricacies of this oxidation step and optimize acid usage during the first column step. Overall our 3-ion exchange column scheme demands acids of both significantly lesser strength and smaller volume than that of Bonnand et al. (2013) and avoids the usage of hydrofluoric acid (Scheiderich et al., 2015). Both Bonnand et al. (2013) and Scheiderich et al. (2015) rely on the cation exchange column AG 50W-X8 as their final purification step, whereas our purification scheme solely utilizes anion exchange column AG 1-X8. The usage of AG 50W-X8 resin can be problematic as it features sulfonic acid functional groups, which lead to an unavoidable sulfur residue. This residue is not easily removed by evaporation due to the very high boiling point of sulfuric acid $\left(>300^{\circ} \mathrm{C}\right.$, Nielsen et al., 2011). Especially for MC-ICP-MS analysis the presence of sulfur polyatomics can be detrimental to an accurate $\mathrm{Cr}$ isotope ratio measurement (Ball and Bassett, 2000). The average Cr recovery of our method (65\%) is on par with that of Scheiderich et al. (2015) (Chris Holmden, personal communication). We were unable to ascertain the total recovery of the other Cr seawater isotope method from the literature (Bonnand et al., 2013), but it appears to be $<80 \%$ (Bonnand et al., 2011). The total procedural Cr blank of our method $(0.017 \mathrm{nmol})$ is of the same magnitude than that of Scheiderich et al. (2015) and significantly lower than that of Bonnand et al. (2013) (up to $0.93 \mathrm{nmol}$ ).

The first full water column profile of $\mathrm{Cr}$ isotope ratios in the Pacific Ocean (SAFe station) was generated using the outlined procedure. The profile is oceanographically consistent as $\mathrm{Cr}$ 
concentrations and isotope ratios develop gradually with water masses and the profile shapes are correlated with other oceanographic parameters. The correlation of the $\mathrm{Cr}$ and dissolved $\mathrm{Si}$ data is evident; the SAFe data on its own supports $\mathrm{Cr}$ being a nutrient-type element. However in the context of other published data, inconsistencies remain with regard to the potential biological control on Cr (Bonnand et al., 2013; Scheiderich et al., 2015; Sirinawin et al., 2000). Furthermore, we speculate that a heavy $\mathrm{Cr}$ isotope peak at $200 \mathrm{~m}$ at SAFe may originate from advection and diffusion of a $\mathrm{Cr}$ reduction signal out of the ODZ of the ETNP. In $\delta^{53} \mathrm{Cr}-\ln ([\mathrm{Cr}])$ space, the SAFe data and our internal reference sample (from 100m depth in the SPSG) fall on the same previously observed Rayleigh-like fractionation line (Scheiderich et al., 2015). Even though all $\mathrm{Cr}$ data to date fall on this line, too few seawater samples have been analyzed to assume that $\mathrm{Cr}$ in seawater is only fractionated along this line. 


\subsection{References}

Archer, C., Vance, D., 2004. Mass discrimination correction in multiple-collector plasma source mass spectrometry: an example using $\mathrm{Cu}$ and $\mathrm{Zn}$ isotopes. J. Anal. At. Spectrom. 19, 656665.

Ball, J.W., Bassett, R.L., 2000. Ion exchange separation of chromium from natural water matrix for stable isotope mass spectrometric analysis. Chem. Geol. 168, 123-134. doi:http://dx.doi.org/10.1016/S0009-2541(00)00189-3

Bartlett, R., James, B., 1979. Behavior of chromium in soils: III. Oxidation. J. Environ. Qual. 8, $31-35$.

Berger, A., Frei, R., 2014. The fate of chromium during tropical weathering: A laterite profile from central madagascar. Geoderma 213, 521-532. doi:10.1016/j.geoderma.2013.09.004

Bergquist, B.A., 2004. The marine geochemistry of iron and iron isotopes. Ph.D. thesis Massachusetts Inst. Technol. Woods Hole Oceanogr. Inst. Jt. Progr. Oceanogr. Massachusetts Institute of Technology.

Bio-Rad, 1998a. AG ${ }^{\circledR}$ 1, AG MP-1 and AG 2 Strong Anion Exchange Resin Instruction Manual.

Bio-Rad, 1998b. AG ${ }^{\circledR}$ 50W and AG MP-50 Cation Exchange Resins Instruction Manual.

Bonnand, P., James, R.H., Parkinson, I.J., Connelly, D.P., Fairchild, I.J., 2013. The chromium isotopic composition of seawater and marine carbonates. Earth Planet. Sci. Lett. 382, 10-20. doi:http://dx.doi.org/10.1016/j.epsl.2013.09.001

Bonnand, P., Parkinson, I.J., James, R.H., Karjalainen, A.-M., Fehr, M.A., 2011. Accurate and precise determination of stable $\mathrm{Cr}$ isotope compositions in carbonates by double spike MCICP-MS. J. Anal. At. Spectrom. 26, 528-535.

Bruland, K.W., Rue, E.L., Smith, G.J., DiTullio, G.R., 2005. Iron, macronutrients and diatom blooms in the Peru upwelling regime: brown and blue waters of Peru. Mar. Chem. 93, 81103. doi:10.1016/j.marchem.2004.06.011

Campbell, J.A., Yeats, P.A., 1981. Dissolved chromium in the northwest Atlantic Ocean. Earth Planet. Sci. Lett. 53, 427-433.

Cole, D.B., Reinhard, C.T., Wang, X., Gueguen, B., Halverson, G.P., Gibson, T., Hodgskiss, M.S.W., McKenzie, N.R., Lyons, T.W., Planavsky, N.J., 2016. A shale-hosted Cr isotope record of low atmospheric oxygen during the Proterozoic. Geology 44, 555-558. doi:10.1130/G37787.1

Cranston, R.E., Murray, J.W., 1978. The determination of chromium species in natural waters. Anal. Chim. Acta 99, 275-282. doi:http://dx.doi.org/10.1016/S0003-2670(01)83568-6

Crowe, S.A., Døssing, L.N., Beukes, N.J., Bau, M., Kruger, S.J., Frei, R., Canfield, D.E., 2013. Atmospheric oxygenation three billion years ago. Nature 501, 535-538.

D’Arcy, J., Babechuk, M.G., Døssing, L.N., Gaucher, C., Frei, R., 2016. Processes controlling the chromium isotopic composition of river water: Constrains from basaltic river catchments. Geochim. Cosmochim. Acta 186, 296-315. doi:10.1016/j.gca.2016.04.027

D’Arcy, J., Gilleaudeau, G.J., Peralta, S., Gaucher, C., Frei, R., 2017. Redox fluctuations in the Early Ordovician oceans: An insight from chromium stable isotopes. Chem. Geol. 448, 112. doi:10.1016/j.chemgeo.2016.10.012

Dodson, M.H., 1963. A theoretical study of the use of internal standards for precise isotopic analysis by the surface ionization technique: Part I - General first-order algebraic solutions. J. Sci. Instrum. 40, 289-295. doi:10.1088/0950-7671/40/6/307 
Elbs, K., Schönherr, O., 1895. Studien über die Bildung von Überschwefelsäure. Zeitschrift für Elektrotechnik und Elektrochemie 1, 417-420. doi:10.1002/bbpc.18950011305

Ellis, A.S., Johnson, T.M., Bullen, T.D., 2002. Chromium isotopes and the fate of hexavalent chromium in the environment. Science (80-. ). 295, 2060-2062.

Ellis, A.S., Johnson, T.M., Bullen, T.D., 2004. Using chromium stable isotope ratios to quantify $\mathrm{Cr}(\mathrm{VI})$ reduction: Lack of sorption effects. Environ. Sci. Technol. 38, 3604-3607.

Farkaš, J., Chrastný, V., Novák, M., Cadkova, E., Pašava, J., Chakrabarti, R., Jacobsen, S.B., Ackerman, L., Bullen, T.D., 2013. Chromium isotope variations $(\delta 53 / 52 \mathrm{Cr})$ in mantlederived sources and their weathering products: Implications for environmental studies and the evolution of $\delta 53 / 52 \mathrm{Cr}$ in the Earth's mantle over geologic time. Geochim. Cosmochim. Acta 123, 74-92. doi:http://dx.doi.org/10.1016/j.gca.2013.08.016

Fendorf, S.E., 1995. Surface reactions of chromium in soils and waters. Geoderma 67, 55-71. doi:10.1016/0016-7061(94)00062-F

Frei, R., Gaucher, C., Poulton, S.W., Canfield, D.E., 2009. Fluctuations in Precambrian atmospheric oxygenation recorded by chromium isotopes. Nature 461, 250-253.

Frei, R., Poiré, D., Frei, K.M., 2014. Weathering on land and transport of chromium to the ocean in a subtropical region (Misiones, NW Argentina): A chromium stable isotope perspective. Chem. Geol. 381, 110-124. doi:10.1016/j.chemgeo.2014.05.015

Frei, R., Polat, A., 2013. Chromium isotope fractionation during oxidative weatheringImplications from the study of a Paleoproterozoic (ca. $1.9 \mathrm{Ga}$ ) paleosol, Schreiber Beach, Ontario, Canada. Precambrian Res. 224, 434-453. doi:http://dx.doi.org/10.1016/j.precamres.2012.10.008

Götz, A., Heumann, K.G., 1988. Chromium trace determination in inorganic, organic and aqueous samples with isotope dilution mass spectrometry. Fresenius Zeitschrift für Anal. Chemie 331, 123-128.

Haber, F., Goldschmidt, F., 1906. Der anodische Angriff des Eisens durch vagabundierende Ströme im Erdreich und die Passivität des Eisens. Zeitschrift für Elektrochemie 12, 49-76.

Halicz, L., Yang, L., Teplyakov, N., Burg, A., Sturgeon, R., Kolodny, Y., 2008. High precision determination of chromium isotope ratios in geological samples by MC-ICP-MS. J. Anal. At. Spectrom. 1622-1627. doi:- 10.1039/B808351G

Hittorf, W., 1900. Passivity of metals. Zeitschrift für Phys. Chemie 34, 385-402.

Holden, N.E., 2011. Table of the Isotopes (Revised 2010), in: Haynes, W.M. (Ed.), Handbook of Chemistry and Physics 92nd Edition. CRC Press Inc., Boca Raton, FL, pp. 2-174.

Jickells, T.D., An, Z.S., Andersen, K.K., Baker, A.R., Bergametti, G., Brooks, N., Cao, J.J., Boyd, P.W., Duce, R.A., Hunter, K.A., Kawahata, H., Kubilay, N., LaRoche, J., Liss, P.S., Mahowald, N., Prospero, J.M., Ridgwell, A.J., Tegen, I., Torres, R., 2005. Global Iron Connections Between Desert Dust, Ocean Biogeochemistry, and Climate. Science (80-. ). 308, 67-71.

Johnson, K.S., Boyle, E., Bruland, K., Coale, K., Measures, C., Moffett, J., Aguilar-Islas, A., Barbeau, K., Bergquist, B., Bowie, A., Buck, K., Cai, Y., Chase, Z., Cullen, J., Doi, T., Elrod, V., Fitzwater, S., Gordon, M., King, A., Laan, P., Laglera-Baquer, L., Landing, W., Lohan, M., Mendez, J., Milne, A., Obata, H., Ossiander, L., Plant, J., Sarthou, G., Sedwick, P., Smith, G.J., Sohst, B., Tanner, S., Van den Berg, S., Wu, J., 2007. Developing Standards for Dissolved Iron in Seawater. Eos, Trans. Am. Geophys. Union 88, 131. doi:10.1029/2007EO110003

Keir, J., 1790. Experiments and Observations on the Dissolution of Metals in Acids, and Their 
Precipitations; with an Account of a New Compound Acid Menstruum, Useful in Some Technical Operations of Parting Metals. Philos. Trans. R. Soc. London 80, 359-384.

Kolthoff, I.M., Miller, I.K., 1951. The Chemistry of Persulfate. I. The Kinetics and Mechanism of the Decomposition of the Persulfate Ion in Aqueous Medium. J. Am. Chem. Soc. 73, 3055-3059. doi:10.1021/ja01151a024

Konhauser, K.O., Lalonde, S. V., Planavsky, N.J., Pecoits, E., Lyons, T.W., Mojzsis, S.J., Rouxel, O.J., Barley, M.E., Rosìere, C., Fralick, P.W., Kump, L.R., Bekker, A., 2011. Aerobic bacterial pyrite oxidation and acid rock drainage during the Great Oxidation Event. Nature 478, 369-373. doi:10.1038/nature10511

Murray, J.W., Spell, B., Paul, B., 1983. The Contrasting Geochemistry of Manganese and Chromium in the Eastern Tropical Pacific Ocean, in: Wong, C.S., Boyle, E., Bruland, K.W., Burton, J.D., Goldberg, E.D. (Eds.), Trace Metals in Sea Water, NATO Conference Series. Springer US, pp. 643-669. doi:- 10.1007/978-1-4757-6864-0_37

Nielsen, S.G., Prytulak, J., Halliday, A.N., 2011. Determination of Precise and Accurate 51V/50V Isotope Ratios by MC-ICP-MS, Part 1: Chemical Separation of Vanadium and Mass Spectrometric Protocols. Geostand. Geoanalytical Res. 35, 293-306. doi:10.1111/j.1751-908X.2011.00106.x

Orians, K.J., Boyle, E.A., Bruland, K.W., 1990. Dissolved titanium in the open ocean. Nature 348, 322-325. doi:10.1038/348322a0

Oze, C., Bird, D.K., Fendorf, S., 2007. Genesis of hexavalent chromium from natural sources in soil and groundwater. Proc. Natl. Acad. Sci. U. S. A. 104, 6544-6549. doi:10.1073/pnas.0701085104

Palme, H., 1920. Studien über die Zersetzung der Überschwefelsäure. Zeitschrift für Anorg. und Allg. Chemie 112, 97-130. doi:10.1002/zaac.19201120105

Paulukat, C., Døssing, L.N., Mondal, S.K., Voegelin, A.R., Frei, R., 2015. Oxidative release of chromium from Archean ultramafic rocks, its transport and environmental impact ? A Cr isotope perspective on the Sukinda valley ore district (Orissa, India). Appl. Geochemistry 59, 125-138. doi:10.1016/j.apgeochem.2015.04.016

Pettine, M., Campanella, L., Millero, F., 2002. Reduction of hexavalent chromium by H2O2 in acidic solutions. Environ. Sci. Technol. 36, 901-907.

Planavsky, N.J., Reinhard, C.T., Wang, X., Thomson, D., McGoldrick, P., Rainbird, R.H., Johnson, T., Fischer, W.W., Lyons, T.W., 2014. Low Mid-Proterozoic atmospheric oxygen levels and the delayed rise of animals. Science (80-. ). 346, 635-638. doi: $10.1126 /$ science. 1258410

Rudge, J.F., Reynolds, B.C., Bourdon, B., 2009. The double spike toolbox. Chem. Geol. 265, 420-431. doi:http://dx.doi.org/10.1016/j.chemgeo.2009.05.010

Rue, E.L., Smith, G.J., Cutter, G.A., Bruland, K.W., 1997. The response of trace element redox couples to suboxic conditions in the water column. Deep Sea Res. Part I Oceanogr. Res. Pap. 44, 113-134. doi:http://dx.doi.org/10.1016/S0967-0637(96)00088-X

Russell, W.A., Papanastassiou, D.A., Tombrello, T.A., 1978. Ca isotope fractionation on the Earth and other solar system materials. Geochim. Cosmochim. Acta 42, 1075-1090. doi:10.1016/0016-7037(78)90105-9

Scheiderich, K., Amini, M., Holmden, C., Francois, R., 2015. Global variability of chromium isotopes in seawater demonstrated by Pacific, Atlantic, and Arctic Ocean samples. Earth Planet. Sci. Lett. 423, 87-97. doi:10.1016/j.epsl.2015.04.030

Schoenberg, R., Zink, S., Staubwasser, M., von Blanckenburg, F., 2008. The stable Cr isotope 
inventory of solid Earth reservoirs determined by double spike MC-ICP-MS. Chem. Geol. 249, 294-306. doi:http://dx.doi.org/10.1016/j.chemgeo.2008.01.009

Semeniuk, D.M., Maldonado, M.T., Jaccard, S.L., 2016. Chromium uptake and adsorption in marine phytoplankton - Implications for the marine chromium cycle. Geochim. Cosmochim. Acta 184, 41-54. doi:10.1016/j.gca.2016.04.021

Shields, W.R., Murphy, T.J., Catanzaro, E.J., Garner, E.L., 1966. Absolute isotopic abundance ratios and the atomic weight of a reference sample of chromium. J. Res. Natl. Bur. Stand. Sect. A Phys. Chem. 70A, 193. doi:10.6028/jres.070A.016

Sirinawin, W., Turner, D.R., Westerlund, S., 2000. Chromium (VI) distributions in the Arctic and the Atlantic Oceans and a reassessment of the oceanic Cr cycle. Mar. Chem. 71, 265282.

Talley, L.D., 2008. Freshwater transport estimates and the global overturning circulation: Shallow, deep and throughflow components. Prog. Oceanogr. 78, 257-303. doi:10.1016/j.pocean.2008.05.001

Talley, L.D., Pickard, G.L., Emery, W.J., Swift, J.H., 2011. Descriptive Physical Oceanography. Elsevier.

Vander Griend, D.A., Golden, J.S., Arrington, C.A., 2002. Kinetics and Mechanism of Chromate Reduction with Hydrogen Peroxide in Base. Inorg. Chem. 41, 7042-7048. doi: $10.1021 /$ ic 0257975

Vanysek, P., 1998. Electrochemical series, in: CRC Handbook of Chemistry and Physics 87th Edition.

Wang, X., Planavsky, N., Reinhard, C., Zou, H., Ague, J., Wu, Y., Gill, B., Schwarzenbach, E., Peucker-Ehrenbrink, B., 2016. Chromium isotope fractionation during subduction-related metamorphism, black shale weathering, and hydrothermal alteration. Chem. Geol. 423, 1933.

Wu, J., Boyle, E.A., 1997. Low blank preconcentration technique for the determination of lead, copper, and cadmium in small-volume seawater samples by isotope dilution ICPMS. Anal. Chem. 69, 2464-2470.

Wu, W., Wang, X., Reinhard, C.T., Planavsky, N.J., 2017. Chromium isotope systematics in the Connecticut River. Chem. Geol. 456, 98-111. doi:10.1016/j.chemgeo.2017.03.009

Zink, S., Schoenberg, R., Staubwasser, M., 2010. Isotopic fractionation and reaction kinetics between $\mathrm{Cr}(\mathrm{III})$ and $\mathrm{Cr}(\mathrm{VI})$ in aqueous media. Geochim. Cosmochim. Acta 74, 5729-5745. doi:http://dx.doi.org/10.1016/j.gca.2010.07.015 
Tables for Chapter 2

\begin{tabular}{|c|c|c|c|c|c|c|c|}
\hline & $\begin{array}{l}\text { mass } 49 \\
(\mathrm{amu})\end{array}$ & $\begin{array}{l}\operatorname{mass} 50 \\
(\mathrm{amu})\end{array}$ & $\begin{array}{l}\operatorname{mass} 51 \\
(\mathrm{amu})\end{array}$ & $\begin{array}{l}\text { mass } 52 \\
(\mathrm{amu})\end{array}$ & $\begin{array}{l}\text { mass } 53 \\
(\mathrm{amu})\end{array}$ & $\begin{array}{l}\text { mass } 54 \\
(\mathrm{amu})\end{array}$ & $\begin{array}{l}\operatorname{mass} 56 \\
(\mathrm{amu})\end{array}$ \\
\hline Titanium & $5.410 \%$ & $5.180 \%$ & & & & & \\
\hline Vanadium & & $0.250 \%$ & $99.750 \%$ & & & & \\
\hline Chromium & & $4.345 \%$ & & $83.789 \%$ & $9.501 \%$ & $2.365 \%$ & \\
\hline Iron & & & & & & $5.845 \%$ & $91.754 \%$ \\
\hline $\begin{array}{l}\text { Sulfur- } \\
\text { polyatomics }\end{array}$ & ${ }^{33} \mathrm{~S}^{16} \mathrm{O}^{+}$ & $\begin{array}{l}{ }^{32} \mathrm{~S}^{18} \mathrm{O}^{+} \\
{ }^{34} \mathrm{~S}^{16} 0^{+}\end{array}$ & & & & & \\
\hline $\begin{array}{l}\text { Argon- } \\
\text { polyatomics }\end{array}$ & & $\begin{array}{l}{ }^{36} \mathrm{Ar}^{14} \mathrm{~N}^{+} \\
{ }^{38} \mathrm{Ar}^{12} \mathrm{C}^{+}\end{array}$ & & $\begin{array}{l}{ }^{36} \mathrm{Ar}^{16} \mathrm{O}^{+} \\
{ }^{38} \mathrm{Ar}^{14} \mathrm{~N}^{+} \\
{ }^{40} \mathrm{Ar}^{12} \mathrm{C}^{+}\end{array}$ & ${ }^{40} \mathrm{Ar}^{13} \mathrm{C}^{+}$ & $\begin{array}{l}{ }^{38} \mathrm{Ar}^{16} \mathrm{O}^{+} \\
{ }^{40} \mathrm{Ar}^{14} \mathrm{~N}^{+}\end{array}$ & ${ }^{40} \mathrm{Ar}^{16} \mathrm{O}^{+}$ \\
\hline $\begin{array}{l}\text { Chloride- } \\
\text { polyatomics }\end{array}$ & $\begin{array}{l}{ }^{35} \mathrm{Cl}^{14} \mathrm{~N}^{+} \\
{ }^{37} \mathrm{Cl}^{12} \mathrm{C}^{+}\end{array}$ & $\begin{array}{l}{ }^{35} \mathrm{Cl}^{15} \mathrm{~N}^{+} \\
{ }^{37} \mathrm{Cl}^{13} \mathrm{C}^{+}\end{array}$ & $\begin{array}{l}{ }^{35} \mathrm{Cl}^{16} 0^{+} \\
{ }^{37} \mathrm{Cl}^{14} \mathrm{~N}^{+}\end{array}$ & ${ }^{37} \mathrm{Cl}^{15} \mathrm{~N}^{+}$ & $\begin{array}{l}{ }^{35} \mathrm{Cl}^{18} 0^{+} \\
{ }^{37} \mathrm{Cl}^{16} 0^{+}\end{array}$ & & \\
\hline $\begin{array}{l}\text { Calcium- } \\
\text { polyatomics }\end{array}$ & & & & & & & $\begin{array}{l}{ }^{40} \mathrm{Ca}^{16} \mathrm{O}^{+} \\
{ }^{44} \mathrm{Ca}^{12} \mathrm{C}^{+}\end{array}$ \\
\hline
\end{tabular}

Table 2.1. The abundance percentages of $\mathrm{Cr}$ and its isobaric interferences (i.e. Ti, $\mathrm{V}, \mathrm{Fe}$ ) are listed. Additionally, polyatomic interferences in the mass range 49 - 56 are given. No isotopes with abundances of less than $0.05 \%$ were considered. In order to be listed, one of the isotopes of a polyatomic interference was required to have an abundance greater or equal to $20 \%$. Polyatomic interferences comprised of more than two elements were omitted.

\begin{tabular}{|c|c|c|c|c|c|c|c|c|}
\hline \multirow[b]{2}{*}{ Sequence } & \multirow[b]{2}{*}{ Duration (s) } & \multirow[b]{2}{*}{ Axial mass } & \multicolumn{2}{|c|}{ low mass faraday cups } & \multicolumn{4}{|c|}{ high mass faraday cups } \\
\hline & & & L2 & L1/Axial & H1 & $\mathrm{H} 2$ & $\mathrm{H} 3$ & H5 \\
\hline 1 & 20 & 50.5 & ${ }^{49} \mathrm{Ti}$ & ${ }^{50} \mathrm{Cr},{ }^{50} \mathrm{Ti},{ }^{50} \mathrm{~V}$ & ${ }^{51} \mathrm{~V}$ & ${ }^{52} \mathrm{Cr}$ & ${ }^{53} \mathrm{Cr}$ & ${ }^{54} \mathrm{Cr},{ }^{54} \mathrm{Fe}$ \\
\hline 2 & 2 & 50.5 & & ${ }^{50} \mathrm{Cr},{ }^{50} \mathrm{Ti},{ }^{50} \mathrm{~V}$ & & ${ }^{52} \mathrm{Cr}$ & ${ }^{53} \mathrm{Cr}$ & ${ }^{54} \mathrm{Cr},{ }^{54} \mathrm{Fe}$ \\
\hline 3 & 2 & $\sim 54.42^{*}$ & & & & ${ }^{56} \mathrm{Fe}$ & & \\
\hline
\end{tabular}

Table 2.2. The Faraday cup configuration for detecting $\mathrm{Cr}$ and its isobaric interferences on the IsoProbe is shown. A sample is being measured over 10 cycles each consisting of 3 sequences. *The axial mass setting for sequence 3 is calibrated at the beginning of every IsoProbe run. A CrFe mixture is run to determine the axial mass at which the ${ }^{56} \mathrm{Fe}$ peak is centered on cup $\mathrm{H} 2$ while keeping the HT unchanged over the 3 sequences. 


\begin{tabular}{|l|l|l|}
\hline \multicolumn{4}{|l|}{ IsoProbe Instrumental Parameters } \\
\hline Parameter & Setting & Unit \\
\hline Forward power & $1100-1200$ & $\mathrm{~W}$ \\
\hline Reflected power & $<1$ & $\mathrm{~W}$ \\
\hline Cool gas flow & 13.0 & $\mathrm{~L} / \mathrm{min}$ \\
\hline Intermediate gas flow & $0.95-1.10$ & $\mathrm{~L} / \mathrm{min}$ \\
\hline Nebulizer 1 gas flow gas flow & $0.73-0.75$ & $\mathrm{~L} / \mathrm{min}$ \\
\hline $\begin{array}{l}\text { Nebulizer 2 } \\
\text { (desolvator) }\end{array}$ & 0.7 & $\mathrm{~L} / \mathrm{min}$ \\
\hline Axial torch position* & 2.00 & $\mathrm{~mm}$ \\
\hline Hydrogen hexapole gas flow & 2.50 & $\mathrm{~mL} / \mathrm{min}$ \\
\hline Argon hexapole gas flow & 50 & $\%$ \\
\hline Hexapole RF Amplitude & $5943-5984$ & $\mathrm{~V}$ \\
\hline HT & & \\
\hline
\end{tabular}

Table 2.3. Typical parameters for a Cr isotope run on MIT's IsoProbe MC-ICP-MS are given. * Axial torch position is set to $0 \mathrm{~mm}$ when the outer torch cylinder is $5 \mathrm{~mm}$ from the cone. 


\begin{tabular}{|c|c|c|c|c|c|c|c|c|c|c|c|c|c|c|c|c|c|c|c|c|c|c|c|c|c|c|c|}
\hline 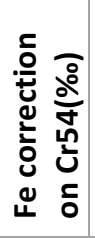 & 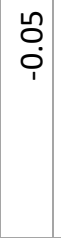 & $\begin{array}{l}0 \\
0 \\
i \\
i\end{array}$ & $\begin{array}{l}0 \\
\text { ọ } \\
\text { în }\end{array}$ & $\begin{array}{l}m \\
0 \\
0 \\
i\end{array}$ & $\begin{array}{l}\text { Õ } \\
\text { ị }\end{array}$ & $\begin{array}{l}-1 \\
0 \\
0\end{array}$ & $\begin{array}{l}\tilde{0} \\
0 \\
0\end{array}$ & $\begin{array}{l}\tilde{o} \\
0 \\
0\end{array}$ & $\begin{array}{l}\tilde{o} \\
0 \\
i\end{array}$ & $\begin{array}{l}-1 \\
0 \\
1\end{array}$ & $\begin{array}{l}\text { nọ } \\
\stackrel{i}{1}\end{array}$ & $\begin{array}{l}0 \\
0 \\
0 \\
1\end{array}$ & $\begin{array}{l}\text { Un } \\
\text { ọ }\end{array}$ & $\begin{array}{l}\text { mọ } \\
\text { ọ }\end{array}$ & $\begin{array}{l}\text { Oे } \\
\text { ơ }\end{array}$ & $\begin{array}{l}0 \\
0 \\
0 \\
0\end{array}$ & $\begin{array}{l}\infty \\
0 \\
0 \\
i\end{array}$ & \begin{tabular}{l}
$\mathscr{0}$ \\
\hdashline \\
\end{tabular} & $\begin{array}{l}m \\
0 \\
0 \\
i\end{array}$ & $\begin{array}{l}m \\
0 \\
0 \\
\end{array}$ & $\begin{array}{l}0 \\
0 \\
0 \\
1\end{array}$ & 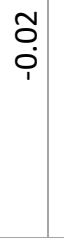 & $\begin{array}{l}\infty \\
0 \\
0 \\
0\end{array}$ & $\begin{array}{l}\tilde{m} \\
\stackrel{0}{0} \\
\dot{\varphi}\end{array}$ & 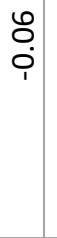 & 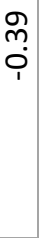 & 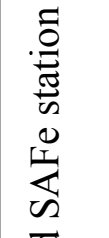 \\
\hline 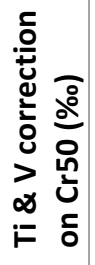 & 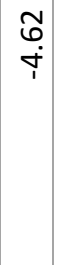 & $\begin{array}{l}\vec{m} \\
\stackrel{i}{\dot{p}}\end{array}$ & 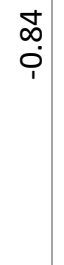 & $\underset{i}{\stackrel{9}{i}}$ & 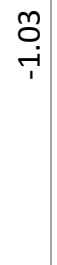 & $\begin{array}{l}0 \\
\ddot{0} \\
0 \\
i\end{array}$ & $\begin{array}{l}\infty \\
\stackrel{0}{0} \\
0 \\
\uparrow \\
1\end{array}$ & $\underset{\mathfrak{i}}{\stackrel{\mathfrak{f}}{i}}$ & $\begin{array}{l}\text { Oे } \\
\stackrel{+}{+}\end{array}$ & $\begin{array}{l}\overrightarrow{0} \\
0 \\
\stackrel{0}{1}\end{array}$ & 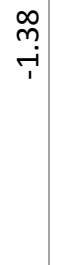 & $\begin{array}{l}\overrightarrow{-} \\
\stackrel{+}{\rightarrow} \\
\rightarrow\end{array}$ & $\begin{array}{l}\text { هి } \\
\text { ధ̣ }\end{array}$ & $\begin{array}{l}\stackrel{\sim}{N} \\
\stackrel{i}{i}\end{array}$ & $\begin{array}{l}\text { ก̊ } \\
\text { ஸ̣ }\end{array}$ & $\begin{array}{c}\tilde{N} \\
0 \\
\grave{1}\end{array}$ & 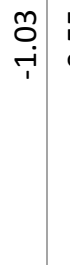 & 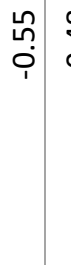 & $\begin{array}{c}\infty \\
\stackrel{0}{0} \\
\stackrel{1}{0}\end{array}$ & 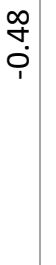 & \begin{tabular}{l}
$\infty$ \\
\multirow{2}{*}{} \\
$\vdots$ \\
1
\end{tabular} & 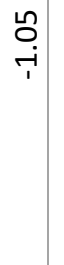 & $\begin{array}{l}\tilde{n} \\
\stackrel{\varphi}{\varphi} \\
\underline{1}\end{array}$ & $\begin{array}{l}\searrow \\
\infty \\
\dot{r} \\
r\end{array}$ & $\begin{array}{l}\hat{\varphi} \\
\dot{\varphi}\end{array}$ & $\begin{array}{l}\text { Oे } \\
\vdots \\
0 \\
1\end{array}$ & 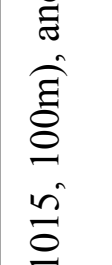 \\
\hline$\frac{\widehat{a}}{\grave{d}}$ & $\ddot{0}$ & $\begin{array}{l}8 \\
0\end{array}$ & $\begin{array}{l}\hat{0} \\
0\end{array}$ & $\begin{array}{l}8 \\
0 \\
0\end{array}$ & $\begin{array}{l}-1 \\
0 \\
0\end{array}$ & $\begin{array}{l}\tilde{O} \\
\text { Oे }\end{array}$ & $\begin{array}{l}\dot{U} \\
\dot{0}\end{array}$ & $\begin{array}{l}\text { Oे } \\
0\end{array}$ & o. & $\begin{array}{l}-1 \\
-i\end{array}$ & $\begin{array}{l}m \\
0 \\
0 \\
i\end{array}$ & $\stackrel{\text { Iี }}{0}$ & $\begin{array}{l}-\overrightarrow{0} \\
-i\end{array}$ & 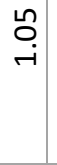 & $\begin{array}{l}\infty \\
\stackrel{\infty}{-} \\
\stackrel{-}{i}\end{array}$ & $\stackrel{\vec{r}}{\overrightarrow{-}}$ & $\begin{array}{l}\infty \\
\stackrel{\infty}{\circ} \\
\sim\end{array}$ & $\begin{array}{l}8 \\
-i\end{array}$ & $\begin{array}{c}2 \\
\infty \\
0 \\
0\end{array}$ & 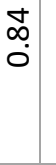 & $\begin{array}{c}n \\
\tilde{0}\end{array}$ & $\stackrel{\overrightarrow{1}}{0}$ & $\begin{array}{l}? \\
0 \\
0\end{array}$ & $\begin{array}{c}\pi \\
\stackrel{0}{*}\end{array}$ & $\begin{array}{l}\infty \\
\stackrel{\infty}{0} \\
0\end{array}$ & 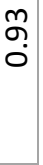 & $\frac{\sum_{0}^{\infty}}{\frac{0}{2}}$ \\
\hline 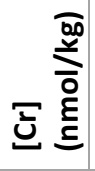 & 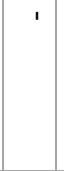 & & ' & & ' & & ' & & $\underset{\text { Nి}}{\stackrel{\text { I }}{2}}$ & $\begin{array}{l}\stackrel{P}{m} \\
m\end{array}$ & 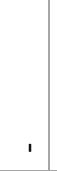 & & $\begin{array}{l}\stackrel{0}{-1} \\
\dot{m}\end{array}$ & $\stackrel{\vec{m}}{m}$ & $\stackrel{\overbrace{}}{\rightarrow}$ & $\stackrel{\vec{m}}{\dot{m}}$ & $\underset{n}{\stackrel{d}{n}}$ & 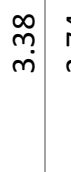 & \begin{tabular}{c}
\multirow{N}{*}{} \\
$m$
\end{tabular} & $\stackrel{m}{\underset{+}{+}}$ & 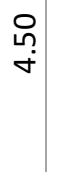 & 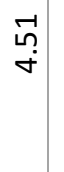 & $\begin{array}{l}\hat{\sim} \\
\dot{\sigma}\end{array}$ & 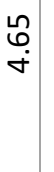 & $\stackrel{\vec{n}}{+}$ & 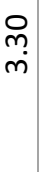 & 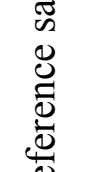 \\
\hline 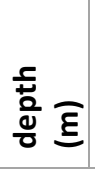 & ' & & ' & & ' & & ' & & ঃ & 암 & 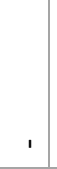 & & 0 & $\stackrel{\llcorner}{\sim}$ & $\underset{\overbrace{}}{\stackrel{-}{-}}$ & ষ্స & 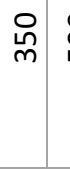 & D & 只 & 各 & $\begin{array}{l}8 \\
\text { 号 }\end{array}$ & ষ্ণ & ষ্ণ & $\begin{array}{l}\text { ঠ } \\
\text { ஒ }\end{array}$ & $\begin{array}{l}8 \\
\text { ดे }\end{array}$ & О्ન & 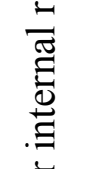 \\
\hline 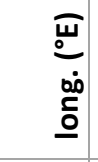 & ' & & ' & & ' & & ' & & 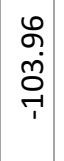 & 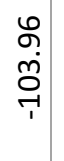 & ' & & $\begin{array}{l}8 \\
\stackrel{0}{0} \\
\stackrel{+}{+} \\
\rightarrow 1\end{array}$ & & & & & & & & & & & & & 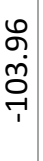 & 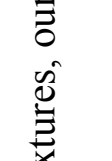 \\
\hline $\begin{array}{l}\bar{z} \\
\dot{0} \\
\tilde{I}\end{array}$ & & & ' & & ' & & ' & & $\begin{array}{l}\stackrel{\sim}{N} \\
\stackrel{\omega}{\sim} \\
\uparrow\end{array}$ & $\begin{array}{l}\stackrel{\mathscr{N}}{\stackrel{\varphi}{\omega}} \\
\stackrel{\sim}{\sim}\end{array}$ & ' & & $\begin{array}{l}\text { \& } \\
\text { on }\end{array}$ & & & & & & & & & & & & & $\begin{array}{l}\stackrel{n}{N} \\
\stackrel{\omega}{\omega} \\
\end{array}$ & $\begin{array}{l}\Xi \\
\mathscr{2} \\
\stackrel{1}{I}\end{array}$ \\
\hline 点 & ' & & ' & & ' & & ' & & N & $r$ & ' & & 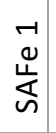 & & & & & & & & & & & & & N & 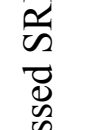 \\
\hline 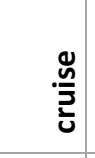 & & & ' & & ' & & ' & & 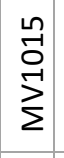 & 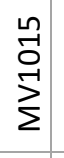 & 1 & & $\frac{\mathfrak{U}}{\mathfrak{v}}$ & & & & & & & & & & & & & 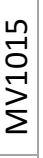 & 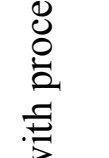 \\
\hline 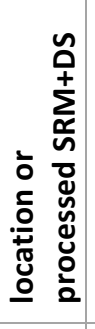 & Non & $\sum_{\substack{n \\
\tilde{n} \\
\tilde{n}}}^{+}$ & $\sum_{\substack{0 \\
\tilde{N}}}^{+}$ & $\sum_{\substack{n \\
N}}^{+}$ & 虽 & $\sum_{\substack{0 \\
N}}^{+}$ & 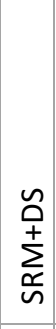 & $\sum_{\substack{+⿱ 亠 䒑\\
}}^{+}$ & 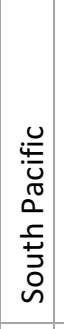 & 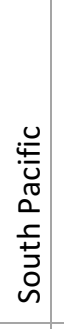 & 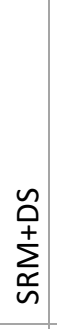 & $\begin{array}{l}\tilde{0} \\
\sum_{0}^{+} \\
\tilde{s}\end{array}$ & 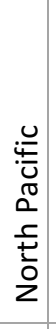 & & & & & & & & & & & & & 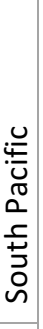 & 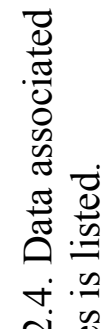 \\
\hline 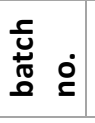 & -1 & & $\sim$ & & $m$ & & $\nabla$ & & $\sigma$ & & Ln & & เn & & & & & & & & & & & & & L & 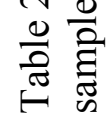 \\
\hline
\end{tabular}


Figures for Chapter 2

a)

intermediate gas flow $=1.00 \mathrm{~L} / \mathrm{min}$, axial position $=1.0 \mathrm{~mm}$

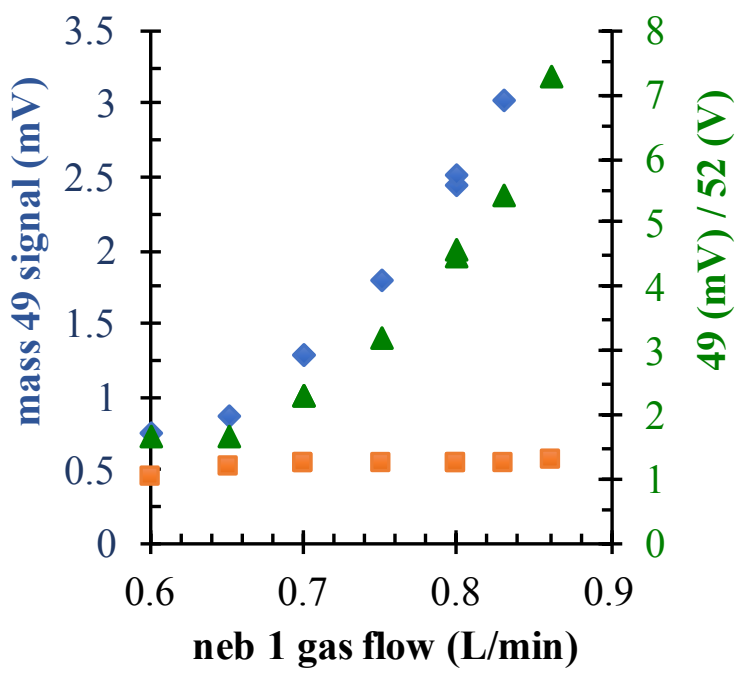

c)

intermediate gas flow $=1.00 \mathrm{~L} / \mathrm{min}$, neb 1 gas flow $=0.83 \mathrm{~L} / \mathrm{min}$

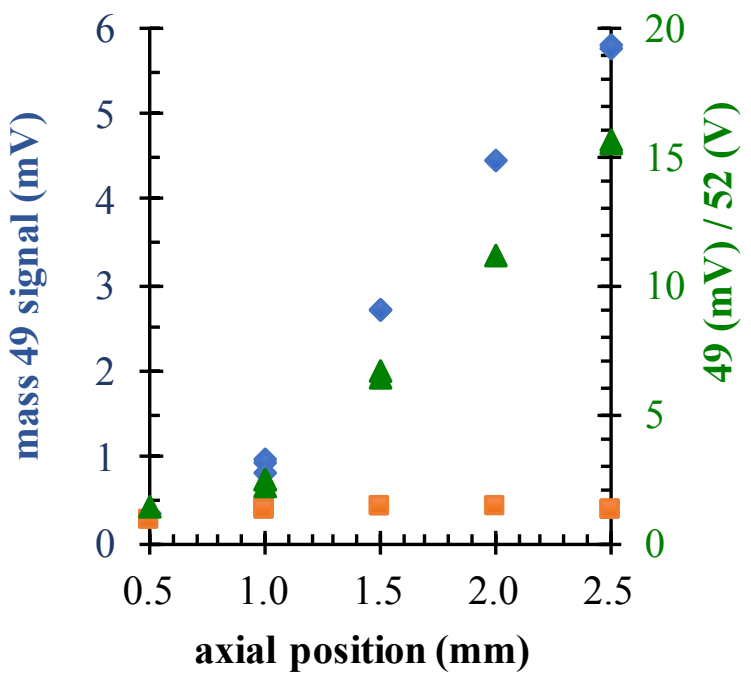

b)

axial position $=1.0 \mathrm{~mm}$, neb 1 gas flow $=0.70 \mathrm{~L} / \mathrm{min}$

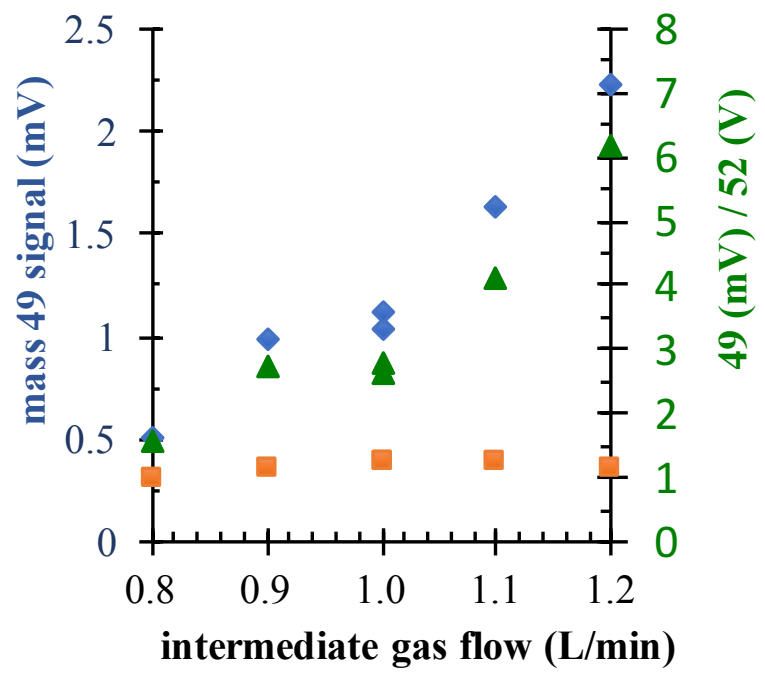

$\diamond$ mass 49 signal, $\mathrm{mV}$

mass 52 signal, $\mathrm{V}$

$\triangle 49 \mathrm{mV} / 52 \mathrm{~V}$

Figure 2.1. Sulfur polyatomic interferences, which affect mass 49 the most, can be significantly decreased relative to chromium (most abundant isotope at mass 52) by changing (a) the neb 1 gas flow, (b) the intermediate gas flow, and (c) the axial position of the torch box. 

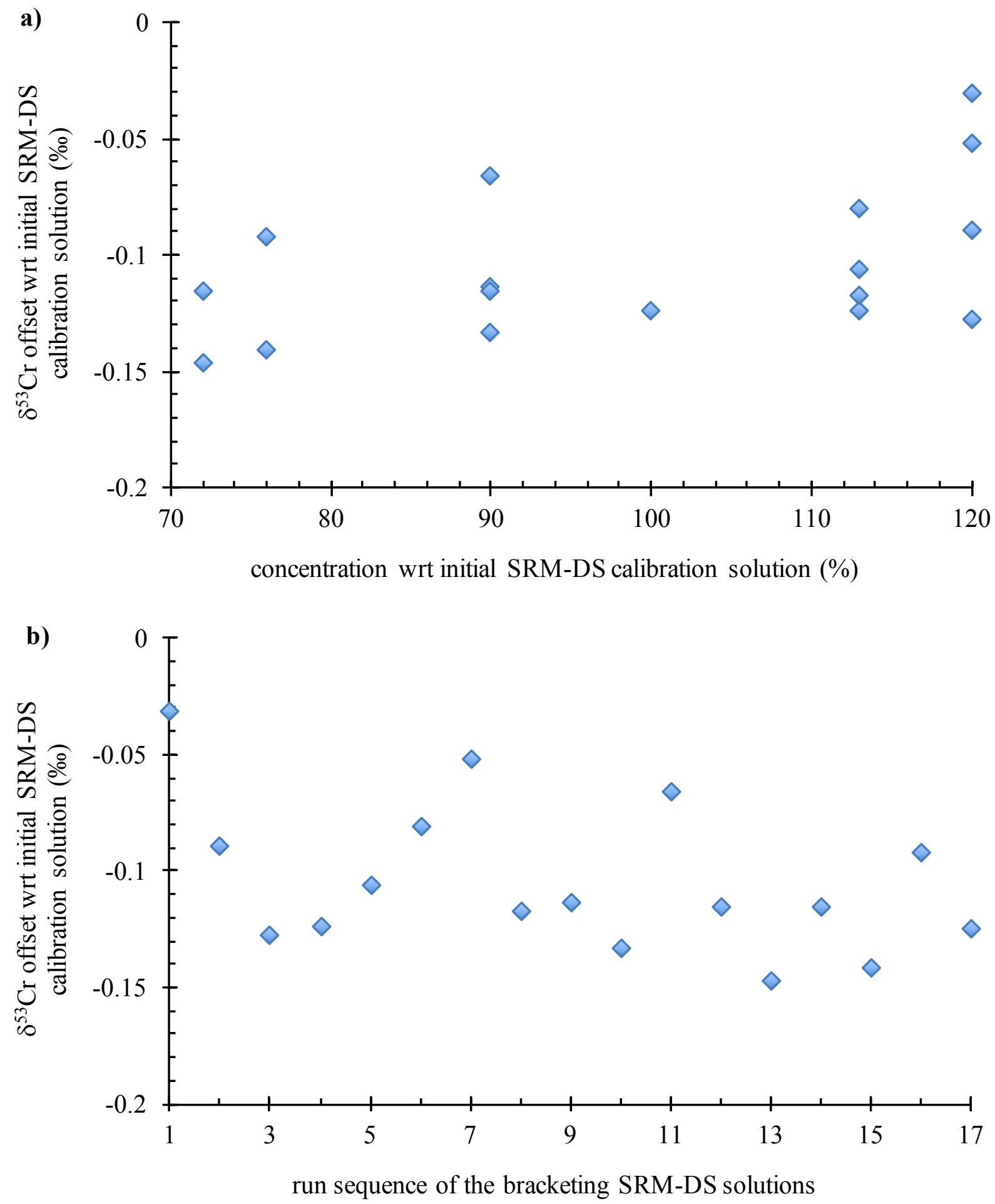

Figure 2.2. The $\delta^{53} \mathrm{Cr}$ values for bracketing SRM-DS solutions of a typical $\mathrm{Cr}$ isotope IsoProbe are plotted a) against the concentration of the bracketing SRM-DS solution and b) against the run sequence of the bracketing SRM-DS solutions. Both the $\delta^{53} \mathrm{Cr}$ values and the concentrations of the bracketing solutions are given relative to those of the initial SRM-DS solution used in the DS calibration. A drift of $\delta^{53} \mathrm{Cr}$ values with time rather than with concentration was identified. 


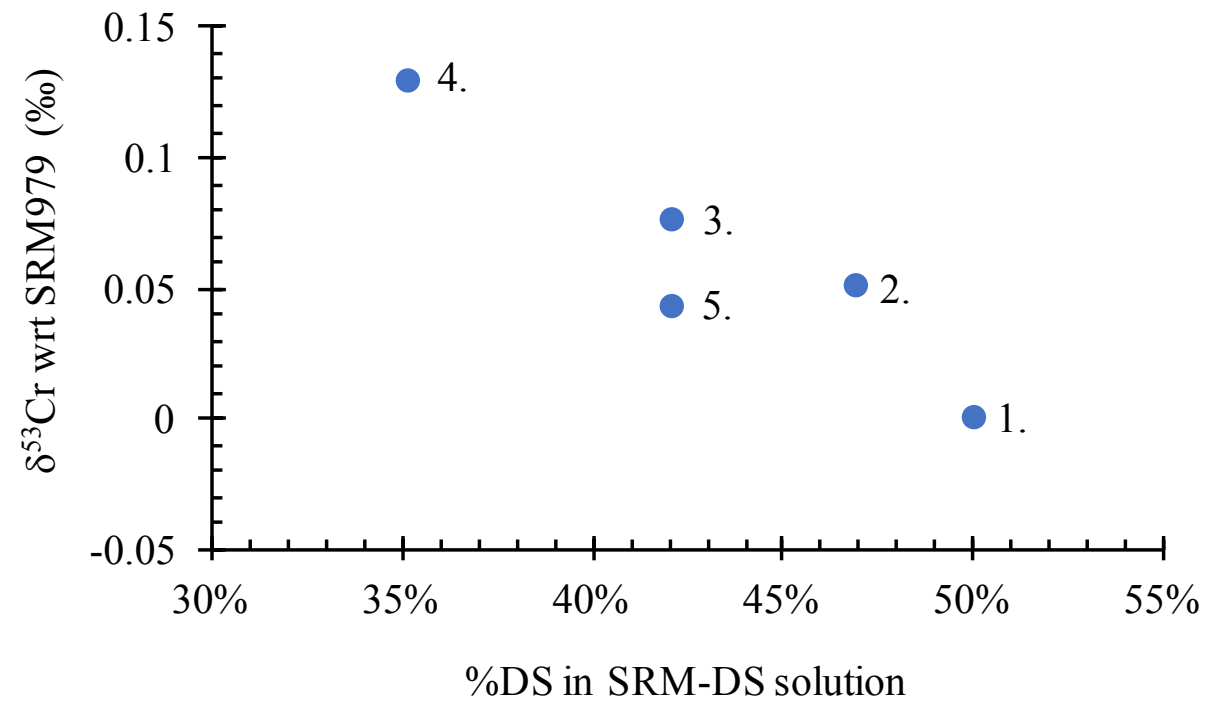

Figure 2.3. SRM-DS solutions containing varying percentages of double spike were analyzed and their $\delta^{53} \mathrm{Cr}$ values are displayed here. The run order is indicated by the numbers next to the data points.

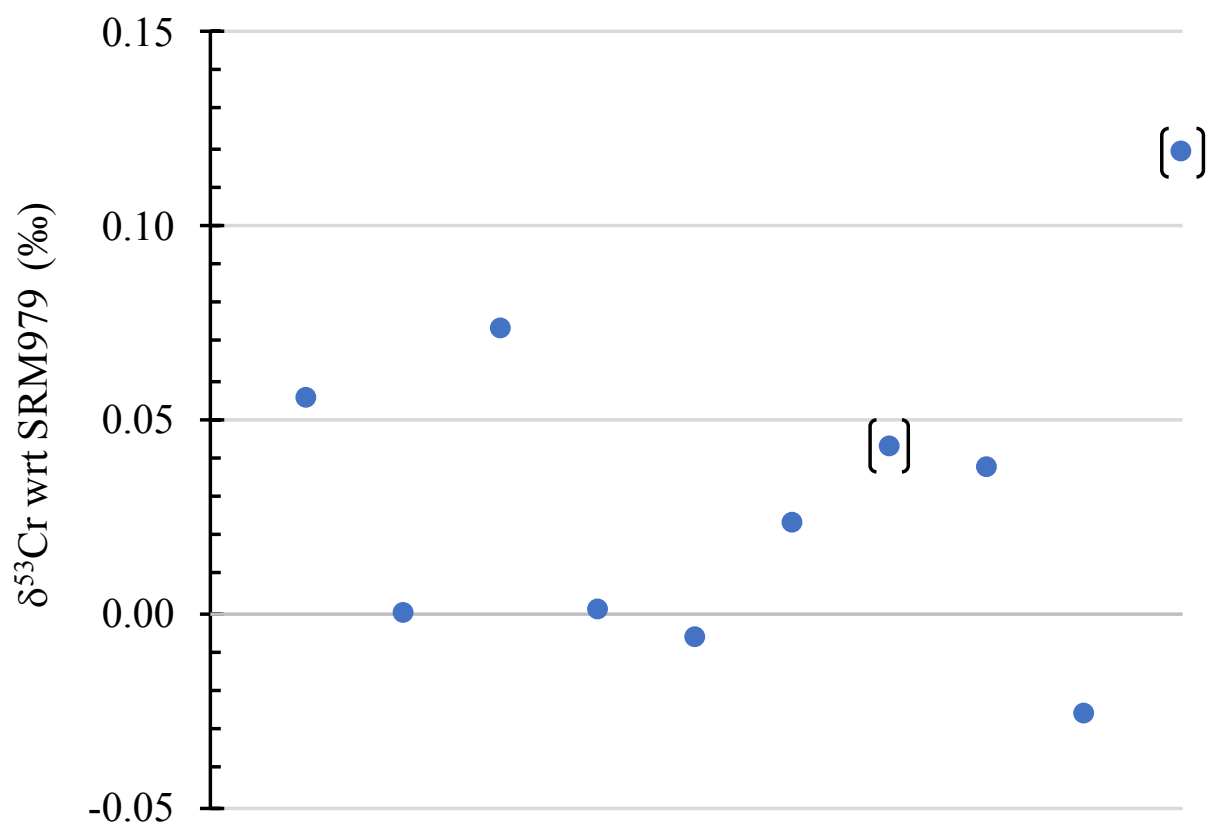

Figure 2.4. Ten pure SRM+DS solutions were processed as samples through the Cr oxidation and the 3-column procedure. Excluding 2 samples (seen here in brackets), which presented with traces of sulfur, the average $\delta^{53} \mathrm{Cr}$ w.r.t. SRM979 $=+0.02 \pm 0.07 \%$ ( $\pm 2 \mathrm{SD}$ ). 


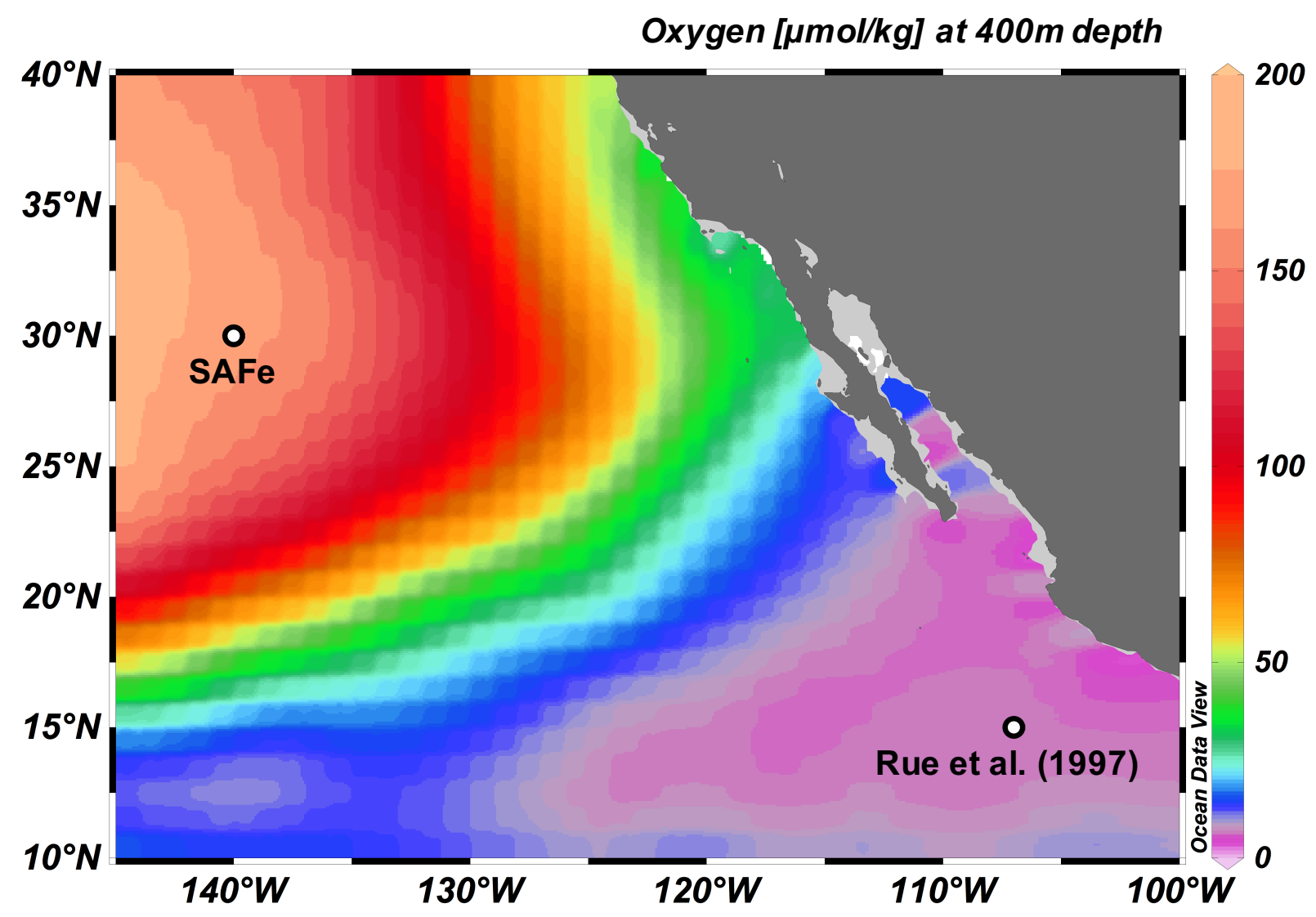

Figure 2.5. Sampling locations are superimposed onto oxygen concentrations $(\mu \mathrm{mol} / \mathrm{kg})$ at $400 \mathrm{~m}$ depth. The displayed annual oxygen data originates from the World Ocean Atlas 2009 (WOA09) (Garcia et al., 2010). For conversion of oxygen data from $\mathrm{ml} / \mathrm{L}$ to $\mu \mathrm{mol} / \mathrm{kg}$ an embedded function of Ocean Data View (ODV) was used (Schlitzer, 2013). ODV was also used to generate this map. 

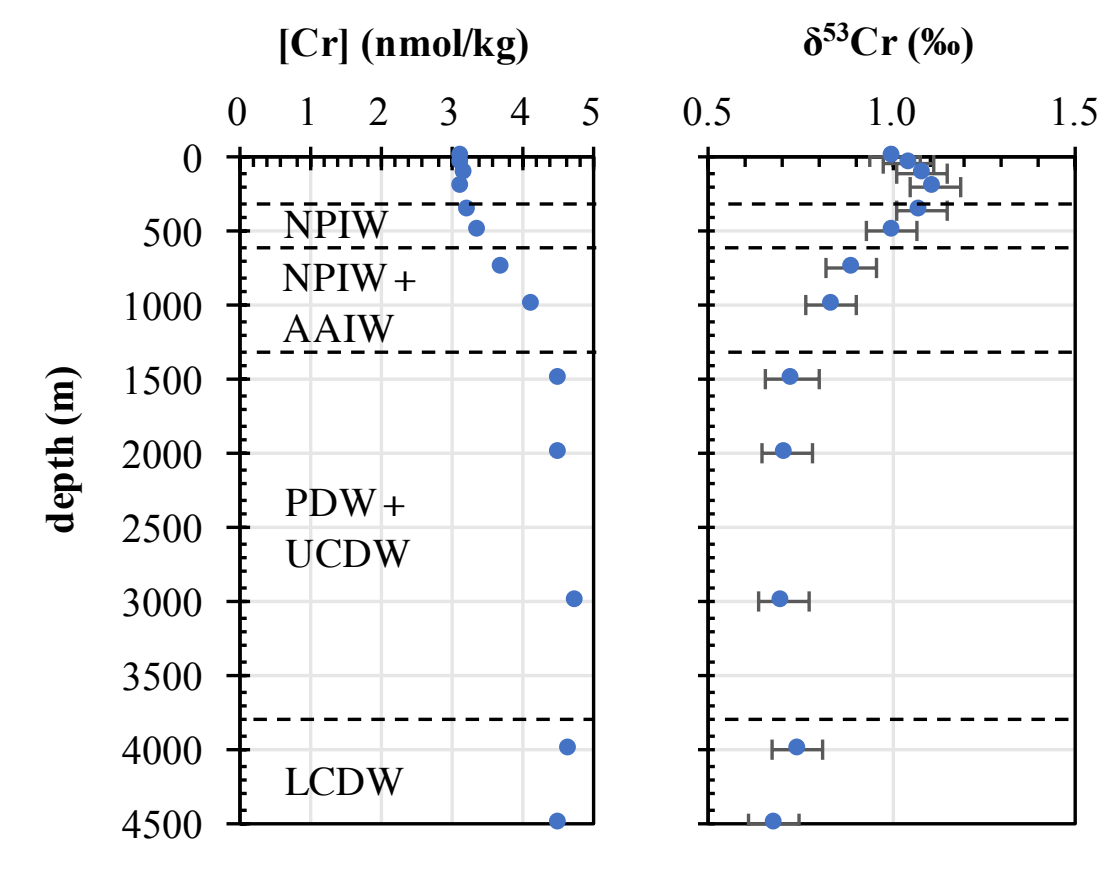

[dSi] $(\mu \mathrm{mol} / \mathbf{k g})$
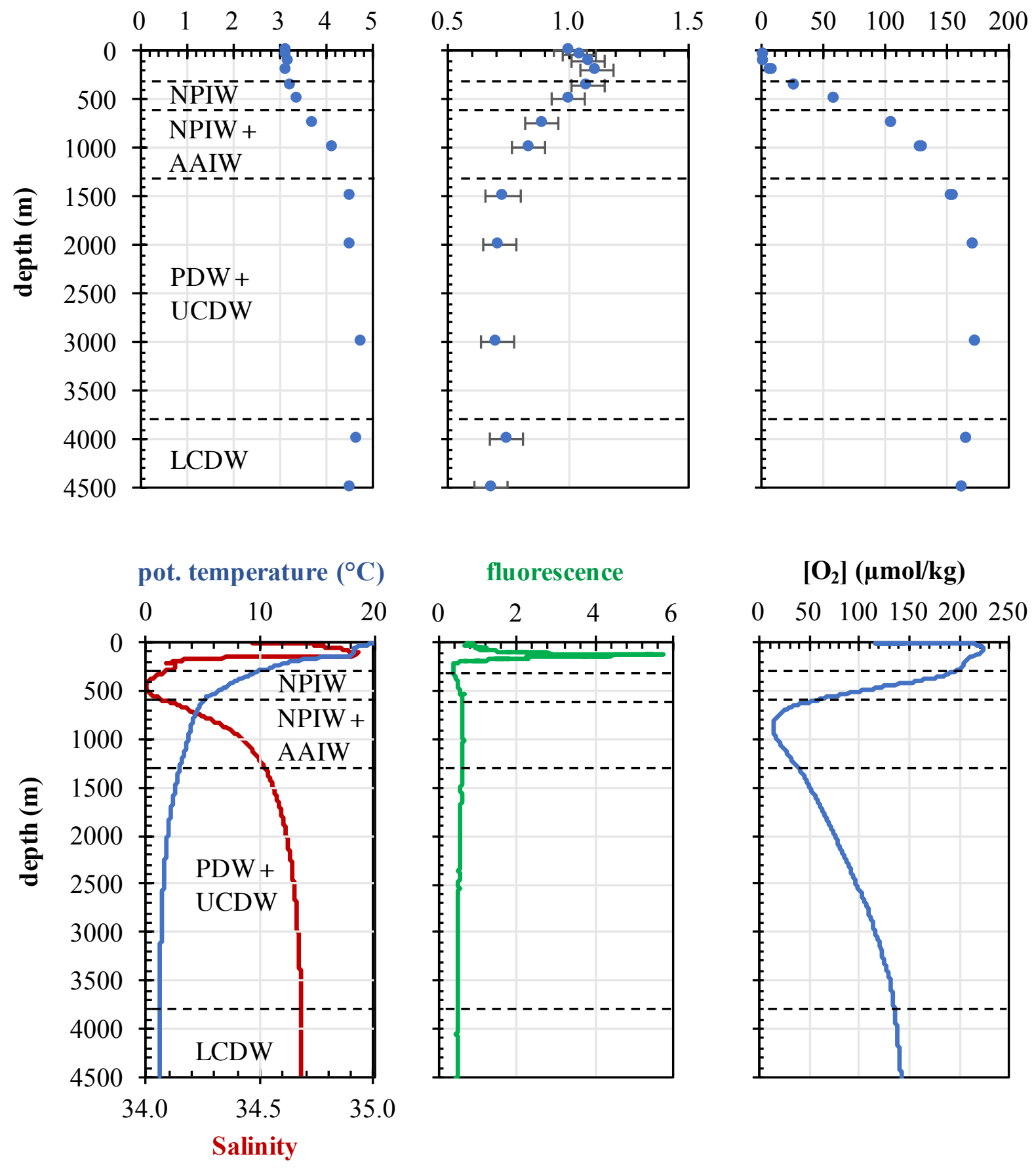

fluorescence

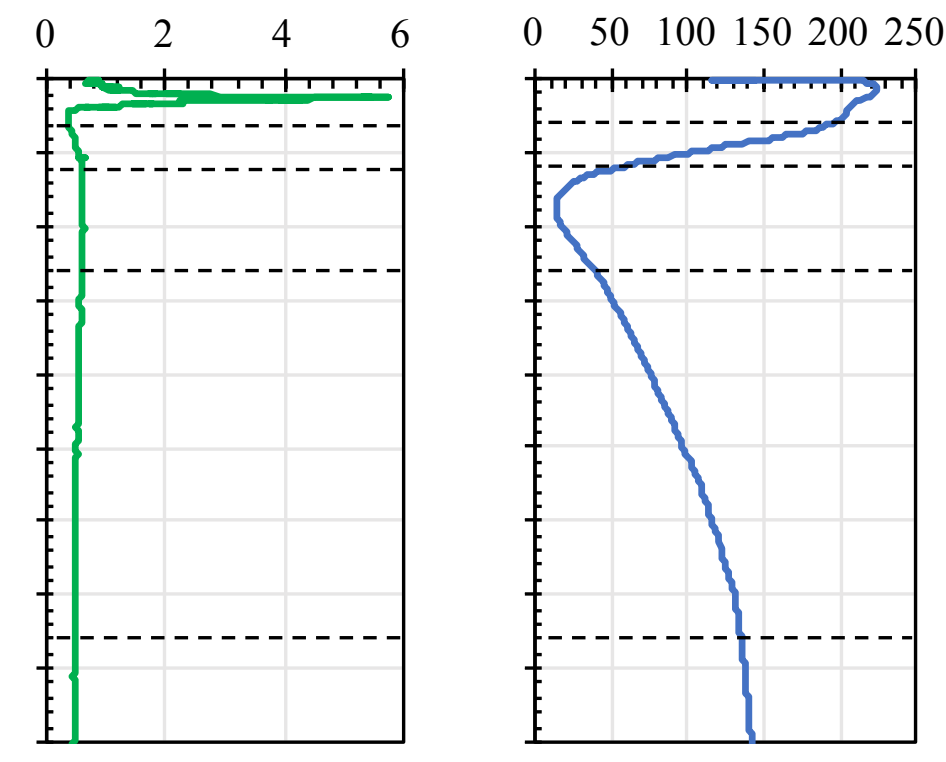

Figure 2.6. Full water column profiles are given for a suite of parameters at SAFe station in the North Pacific Ocean. The error bars on $\mathrm{Cr}$ isotope ratios are 2SD. 


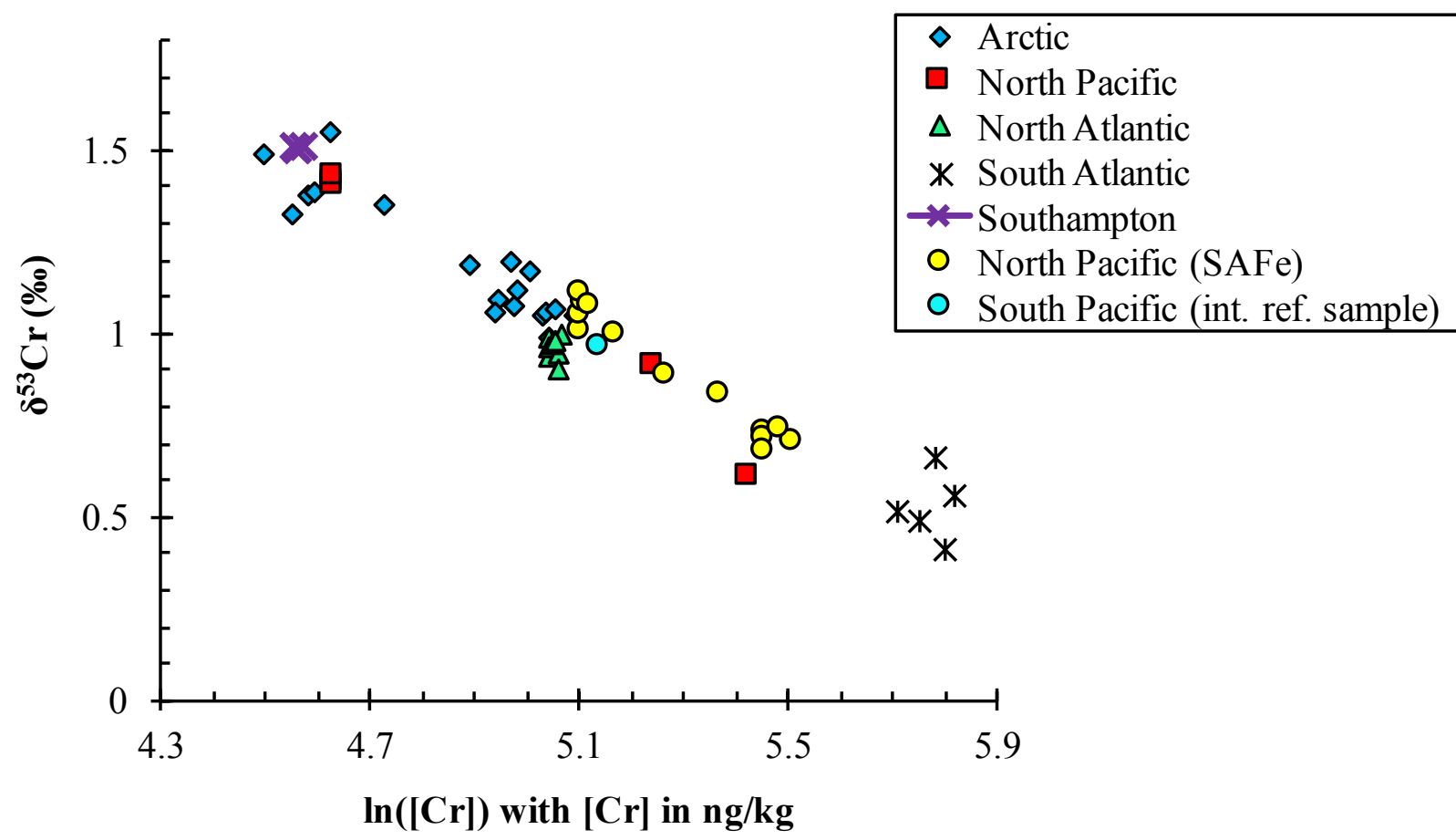

Figure 2.7. Cr data from SAFe and our internal reference sample (MV1015, 100m) is shown alongside published data (Bonnand et al., 2013; Scheiderich et al., 2015) on a $\delta^{53} \mathrm{Cr}-\ln ([\mathrm{Cr}])$ plot. 


\section{Chapter 3. Investigating chromium cycling in oxygen deficient waters of the Northeast Pacific Ocean using stable $\mathrm{Cr}$ isotopes}

\subsection{Introduction}

Redox transformations between the two stable oxidation states of chromium in aqueous solutions (i.e. $\mathrm{Cr}(\mathrm{III})$ and $\mathrm{Cr}(\mathrm{VI})$ ) can result in significant isotope fractionations (e.g. Ellis et al., 2002; Zink et al., 2010). In particular, the reduction of soluble $\mathrm{Cr}(\mathrm{VI})$ results in particle-reactive and easily immobilized $\mathrm{Cr}(\mathrm{III})$, that is isotopically light compared to the initial $\mathrm{Cr}(\mathrm{VI})$ reactant pool. In recent years, the $\mathrm{Cr}$ isotope system has been used extensively to track $\mathrm{Cr}(\mathrm{VI})$ reduction in groundwater (e.g. Berna et al., 2010; Ellis et al., 2002; Izbicki et al., 2012) and to characterize isotope effects of $\mathrm{Cr}(\mathrm{VI})$ reduction in laboratory experiments (e.g. Basu and Johnson, 2012; Døssing et al., 2011; Kitchen et al., 2012; Sikora et al., 2008). However, oxygen deficient waters of the ocean, which appear to be active sites of Cr reduction (Murray et al., 1983; Rue et al., 1997), have not been studied using a stable $\mathrm{Cr}$ isotope approach.

In the ocean, total $\mathrm{Cr}$ exhibits concentrations between $1.2 \mathrm{nmol} / \mathrm{kg}$ and $6.5 \mathrm{nmol} / \mathrm{kg}$, and the first $\mathrm{Cr}$ isotope studies of oxic seawater measured $\delta^{53} \mathrm{Cr}$ signatures that ranged from $0.41 \%$ o to $1.55 \%$ o (chapter 2, Bonnand et al., 2013; Scheiderich et al., 2015). While $\mathrm{Cr}(\mathrm{VI})$ as soluble $\mathrm{CrO}_{4}{ }^{2-}$ prevails in oxygenated seawater, particle-reactive $\mathrm{Cr}(\mathrm{III})$ can reach significant concentrations in anoxic seawater.

$\mathrm{Cr}$ reduction has been observed in the low oxygen zone of the Eastern Tropical North Pacific (ETNP) Ocean (Murray et al., 1983; Rue et al., 1997). Rue et al. (1997) measured Cr(VI) and dissolved $\mathrm{Cr}$ (III) concentrations at a site (figure 3.1) that featured an oxygen-deficient zone (ODZ) between $110 \mathrm{~m}$ and $600 \mathrm{~m}$ depth $\left(\left[\mathrm{O}_{2}\right]=1 \mu \mathrm{mol} / \mathrm{kg}-5 \mu \mathrm{mol} / \mathrm{kg}\right)$. Comparing $\mathrm{Cr}(\mathrm{VI})$ concentrations within the ODZ to those measured at a nearby station without an ODZ, a deficit of up to $2 \mathrm{nmol} / \mathrm{kg}$ $\mathrm{Cr}(\mathrm{VI})$ was found within the ODZ. Dissolved $\mathrm{Cr}(\mathrm{III})$ concentrations peaked at $0.9 \mathrm{nmol} / \mathrm{kg}$ within the suboxic waters and accounted for up to $\sim 50 \%$ of the chromate deficit. The other half of the 
chromate anomaly was attributed to scavenging and export of particle reactive $\mathrm{Cr}(\mathrm{III})$. It should be noted, that the $\mathrm{Cr}(\mathrm{VI})$ deficit is observed between $\sim 100 \mathrm{~m}$ and $\sim 1000 \mathrm{~m}$ depth, whereas the presence of $\mathrm{dCr}(\mathrm{III})$ is seen over a much narrower depth range $(\sim 100 \mathrm{~m}$ to $\sim 600 \mathrm{~m})$. Murray et al. (1983) made similar observations for an east - west transect off the coast of Baja California, Mexico (figure 3.1). Here, oxygen concentrations were as low as $10 \mu \mathrm{mol} / \mathrm{kg}$ but not truly oxygen deficient. This study found a $\mathrm{Cr}(\mathrm{VI})$ minimum centered between $200 \mathrm{~m}$ and $400 \mathrm{~m}$ depth which is most intense closest to the coast and absent at the station farthest out in the ocean. Dissolved Cr(III) concentrations reach their maximum $(0.5 \mathrm{nmol} / \mathrm{kg}-1.0 \mathrm{nmol} / \mathrm{kg})$ at the top of the oxygen minimum zone (OMZ). Within the OMZ, particulate Cr concentrations of up to $\sim 1.1 \mathrm{nmol} / \mathrm{kg}$ are recorded.

Since $\operatorname{Cr}(\mathrm{VI})$ reduction typically produces isotopically light $\mathrm{Cr}(\mathrm{III})$ (e.g. Ellis et al., 2002), a buildup of $\mathrm{Cr}$ (III) in anoxic waters such as that observed by Murray et al. (1983) and Rue et al. (1997) is likely isotopically light relative to the initial $\mathrm{Cr}(\mathrm{VI})$ pool. Furthermore, both studies indirectly suggest that a fraction of the reduced $\mathrm{Cr}$ leaves the $\mathrm{ODZ}$ due to scavenging onto particles. As a whole this implies, that the residual $\mathrm{Cr}$ of the anoxic water becomes isotopically heavier due to $\mathrm{Cr}(\mathrm{VI})$ reduction followed by export of isotopically light $\mathrm{Cr}$ (III). In order to test this hypothesis, we measured $\mathrm{Cr}$ isotope ratios and concentrations at two stations within the ODZ of the ETNP and at a station in the Santa Barbara Basin which features anoxic bottom waters. Cr profiles are compared to those available at the nearby SAFe station (presented in chapter 2), which is characterized by a fully oxygenated water column $\left(\left[\mathrm{O}_{2}\right]>13.2 \mu \mathrm{mol} / \mathrm{kg}\right)$.

\subsection{Seawater sampling and oceanographic setting}

During an expedition of the R/V New Horizon (NH1410) two profiles were taken in the Eastern Tropical North Pacific off of Mexico by Mark Altabet and Frank Stewart (figure 3.1, Stn. 2T: 9 depths, $18.9012^{\circ} \mathrm{N} 108.8002^{\circ} \mathrm{W}$; Stn. $7 \mathrm{~T}$ : 8 depths, $\left.18.2004^{\circ} \mathrm{N} 104.2027^{\circ} \mathrm{W}\right)$. Samples were collected with GO-FLO bottles that were not specifically designed for trace metal sampling (i.e. they featured exterior metal parts). Fortunately, $\mathrm{Cr}$ is not as contamination-prone as other trace metals (e.g. zinc, iron) and $\mathrm{Cr}$ signatures of seawater samples were not compromised. Since this sampling opportunity presented itself at the eleventh hour, seawater samples were not filtered. 
An additional water column profile (8 depths) was collected by Jessica Fitzsimmons within the Santa Barbara Basin (figure 3.1 and 3.2, 34.2304 $\mathrm{N} 120.0255^{\circ} \mathrm{W}$ ) on July 24, 2014 during expedition MV1405 on board the R/V Melville. Teflon coated GO-FLO bottles were used for sampling. Santa Barbara Basin samples were filtered immediately using 0.2 $\mu$ m AcroPak Supor capsules.

All seawater samples presented in this chapter were stored at $\mathrm{pH} \sim 2$ for more than 2 years.

Stations 2T and 7T are located in the ETNP, which constitutes the largest body of oxygen deficient waters on Earth (Paulmier and Ruiz-Pino, 2009). This eastern boundary upwelling area is characterized by high productivity and consequently, high rates of $\mathrm{O}_{2}$ consumption due to remineralization of organic matter (Small et al., 1987). Additionally, the ETNP experiences sluggish ventilation of water masses (Luyten et al., 1983; Reid Jr, 1965). The imbalance between $\mathrm{O}_{2}$ consumption and $\mathrm{O}_{2}$ renewal gives rise to an extensive oxygen deficient zone (ODZ) (Karstensen et al., 2008).

The Santa Barbara Basin (max. depth of $\sim 585 \mathrm{~m}$ ) is one in a series of 14 offshore basins in the continental shelf off of Southern California. With the California coast to the north and the Channel Islands to the south, water can only be exchanged over narrow sills to the east and to the west (figure 3.2). The Santa Monica Basin is located on the other side of the eastern sill (depth of $\sim 200 \mathrm{~m}$ ) and the open Pacific Ocean lies beyond the Santa Barbara Basin's western sill (depth of $\sim 475 \mathrm{~m}$ ).

Wind-driven upwelling of nutrients and cyclonic eddies lead to high primary productivity in the surface waters of the Santa Barbara Basin (Brzezinski and Washburn, 2011). High primary productivity results in enhanced rates of organic carbon export to the underlying waters and sediments. Oxygen is consumed when microbes remineralize organic carbon leading to anoxia in the water column and sediments below the sill depth.

The bottom waters of the Santa Barbara Basin are renewed periodically. The 'new' water originates at depth within the oxygen-minimum zone of the eastern North Pacific and upwells 
north of Point Conception. Subsequently, a strong northwest flow transports the water into the basin over the western sill (Bograd et al., 2002; Reimers et al., 1990; Sholkovitz and Gieskes, 1971). Here, the colder and slightly more oxygenated water spills over the sill and replaces the less dense bottom water. Full or partial bottom water renewal events typically occur in winter or spring when upwelling is strongest (Bograd et al., 2002). Additionally, turbidity currents may transport sediment and oxic seawater from above the redoxcline to the center of the basin without changing salinity or temperature of the bottom waters (Sholkovitz and Soutar, 1975). After bottom waters are disturbed, conditions rapidly (within $\sim 2$ months) return to a normal state (Sholkovitz and Gieskes, 1971).

\subsection{Methods}

Total $\mathrm{Cr}$ isotope signatures of seawater samples were determined using a technique that has been detailed elsewhere (chapter 2), therefore only a brief summary is given here. The acidification of seawater samples to $\mathrm{pH} 2$ prompts the conversion of $\mathrm{Cr}(\mathrm{VI})$ to $\mathrm{Cr}$ (III) over the course of several months (Semeniuk et al., 2016). Once the entirety of $\mathrm{Cr}$ in the sample is present as $\mathrm{Cr}(\mathrm{III})$, a ${ }^{50} \mathrm{Cr}-$ ${ }^{54} \mathrm{Cr}$ double spike (also present in the trivalent form) is equilibrated with the sample for 3 days. This double spike addition enables accurate correction of procedural and instrumental $\mathrm{Cr}$ mass fractionations (Rudge et al., 2009). Preconcentration of $\mathrm{Cr}$ occurs via $\mathrm{Mg}(\mathrm{OH})_{2}$ coprecipitation which is selective for $\mathrm{Cr}(\mathrm{III})$ (Semeniuk et al., 2016). The resulting $\mathrm{Mg}(\mathrm{OH})_{2}$ pellet is neutralized with $\mathrm{HCl}$ and ultimately brought up in $0.02 \mathrm{M} \mathrm{HCl}$. In preparation for the first ion-exchange column step, $\mathrm{Cr}$ is oxidized to $\mathrm{Cr}(\mathrm{VI})$ using ammonium persulfate (Götz and Heumann, 1988). This step demands careful $\mathrm{pH}$, temperature and time control due to pitfalls such as the unwanted generation of $\mathrm{H}_{2} \mathrm{O}_{2}$ (Palme, 1920) leading to subsequent back-reduction of $\mathrm{Cr}(\mathrm{VI})$. Purification of the seawater matrix is achieved with a 3 -anion exchange column scheme (AG 1-X8). The first column separates $\mathrm{Cr}$, which is present as the oxyanion $\mathrm{CrO}_{4}{ }^{2-}$, from the salt matrix (e.g. $\mathrm{Mg}$ ) and from isobaric interferences (i.e. V, Ti, Fe) (Ball and Bassett, 2000). Sulfur species, which form polyatomics that interfere with accurate $\mathrm{Cr}$ analysis, are removed in a second column run for which $\mathrm{Cr}$ is present in the trivalent state. Traces of Fe are eliminated in a third column step with Fe being present as $\mathrm{FeCl}_{4}^{-}$(Yamakawa et al., 2009) and $\mathrm{Cr}$ being present as positively charged $\mathrm{Cr}(\mathrm{III})$. 
Abundances of masses $49(\mathrm{Ti}), 50(\mathrm{Cr}, \mathrm{Ti}, \mathrm{V}), 51(\mathrm{~V}), 52(\mathrm{Cr}), 53(\mathrm{Cr}), 54(\mathrm{Cr}, \mathrm{Fe})$ and $56(\mathrm{Fe})$ in purified samples are detected in low resolution mode on the IsoProbe, a MC-ICP-MS featuring a hexapole collision cell capable of eliminating many polyatomic interferences. The machine is tuned such that the ratio of the $\mathrm{Cr}$ signal to the polyatomic sulfur signal is maximized. Once the true ${ }^{53} \mathrm{Cr} /{ }^{52} \mathrm{Cr}$ ratio of a sample is determined, it is compared to the ${ }^{53} \mathrm{Cr} /{ }^{52} \mathrm{Cr}$ ratio of standard reference material 979 (i.e. SRM 979) and relative deviations are reported as $\delta^{53} \mathrm{Cr}$ values in per mil (equation 1).

$$
\delta^{53} \operatorname{Cr}(\% 0)=\left(\frac{\left(\frac{{ }^{53} C r}{{ }^{52} C r}\right)_{\text {Sample }}}{\left(\frac{{ }^{53} C r}{{ }^{52} C r}\right)_{S R M 979}}-1\right) \times 1000
$$

When quantifying the magnitude of an isotope effect, we refer to fractionation factors $\alpha$, which compares the ${ }^{53} \mathrm{Cr} /{ }^{52} \mathrm{Cr}$ ratio of the product to that of the reactant (equation 2), and $\varepsilon$, compares the $\delta^{53} \mathrm{Cr}$ value of the product to that of the reactant (equation 3). The fractionation factors are approximately linked by equation 4 .

$$
\begin{gathered}
\alpha=\frac{\left(\frac{{ }^{53} \mathrm{Cr}}{{ }^{52} \mathrm{Cr}}\right)_{\text {Product }}}{\left(\frac{{ }^{53} \mathrm{Cr}}{{ }^{52} \mathrm{Cr}}\right)_{\text {Reactant }}} \\
\varepsilon(\% 0)=\delta^{53} \mathrm{Cr}_{\text {Product }}-\delta^{53} \mathrm{Cr}_{\text {Reactant }} \\
\varepsilon(\% 0) \approx 1000 \times \ln (\alpha) \approx 1000 \times(\alpha-1)
\end{gathered}
$$

\subsubsection{Other oceanographic parameters}

Mark Altabet (UMass Dartmouth) and Annie Bourbonnais (WHOI) measured nitrogen isotope signatures of nitrate at stations $2 \mathrm{~T}$ and $7 \mathrm{~T}$ in the ETNP. 


\subsection{Results and Discussion}

In order to directly compare the Cr data measured at the fully oxygenated SAFe station (chapter 2, figure 2.6) to the $\mathrm{Cr}$ data measured at the 3 stations featuring anoxic waters (i.e. 2T, 7T, Santa Barbara Basin), we correct for upwelling of water towards the coast using potential density expressed as $\sigma_{\theta}$ (figure 3.3). The $[\mathrm{Cr}]-\sigma_{\theta}$ relationship at $\mathrm{SAFe}$ can be approximated by a $4^{\text {th }}$-order polynomial (upper panel of figure 3.4). This relationship is applied to $\sigma_{\theta}$ of the 3 partly anoxic stations and results in the creation of an upwardly shifted and compressed SAFe Cr concentration profile. Likewise, the $\delta^{53} \mathrm{Cr}-\sigma_{\theta}$ relationship at $\mathrm{SAFe}$ can be approximated by a $4^{\text {th }}$-order polynomial (lower panel of figure 3.4), which is applied to $\sigma_{\theta}$ of the three partially oxygen deficient stations to give a $\sigma_{\theta}$ adjusted $\mathrm{SAFe} \mathrm{Cr}$ isotope ratio profile. Figures 3.5, 3.6 and 3.7 show the total $\mathrm{Cr}$ concentration and isotope ratios measured at 2T, 7T and at the Santa Barbara Basin site (blue dots) alongside the $\sigma_{\theta}$ adjusted SAFe profiles (orange lines).

\subsubsection{Station $2 \mathrm{~T}$ in the core of the ETNP's ODZ}

\subsubsection{Comparison between $\mathrm{Cr}$ data at $2 \mathrm{~T}$ and $\mathrm{SAFe}$ station}

At station $2 \mathrm{~T}$, oxygen concentrations are less than $1.6 \mu \mathrm{mol} / \mathrm{kg}$ between $130 \mathrm{~m}$ and $820 \mathrm{~m}$ depth (figure 3.5). Measured total $\mathrm{Cr}$ concentrations at this station are up to $0.84 \mathrm{nmol} / \mathrm{kg}$ lower relative to those at SAFe. The biggest [Cr] deficit is seen at 100m depth. Below 100m the [Cr] deficit becomes gradually smaller until $\mathrm{Cr}$ concentrations at $2 \mathrm{~T}$ and $\mathrm{SAFe}$ coincide at $800 \mathrm{~m}$. Between a depth range of $100 \mathrm{~m}$ to $600 \mathrm{~m}$, total measured $\mathrm{Cr}$ isotope signatures at $2 \mathrm{~T}$ are up to $0.17 \%$ o heavier compared those recorded at SAFe.

These observations are consistent with Cr reduction within the ODZ producing isotopically light, particle-reactive $\mathrm{Cr}(\mathrm{III})$, which is partially scavenged by particles and exported to depth. Isotopically heavy $\mathrm{Cr}(\mathrm{VI})$ is left behind in the upper water column. During remineralization of organic matter some of the previously scavenged light $\mathrm{Cr}$ (III) may be returned to the water column. Continuous remineralization of organic matter and thus release of light $\mathrm{Cr}$ below the depth of the 
onset of $\mathrm{Cr}$ reduction may explain why the total $\mathrm{Cr}$ concentration deficit and heavy $\mathrm{Cr}$ isotope anomaly becomes smaller with depth.

The fractionation factor $(\alpha)$, characterizing the observed $\mathrm{Cr}$ reduction at station 2T, can be found using the Rayleigh distillation equation (Rayleigh, 1896). This equation relates the initial $\mathrm{Cr}$ isotope ratio $\left(\delta^{53} \mathrm{Cr}_{\mathrm{O}}\right)$ and the transient $\mathrm{Cr}$ isotope ratio $\left(\delta^{53} \mathrm{Cr}_{\mathrm{t}}\right)$ of a system to the remaining $\mathrm{Cr}$ fraction (f) when $\mathrm{Cr}$ is removed with a constant fractionation factor $(\alpha)$.

$$
\begin{gathered}
\delta^{53} \mathrm{Cr}_{t}=\left(\delta^{53} \mathrm{Cr}_{O}+1000\right) \times f^{(\alpha-1)}-1000 \\
f=\frac{C_{t}}{C_{O}}
\end{gathered}
$$

The initial $\mathrm{Cr}$ isotope ratio and the initial $\mathrm{Cr}$ concentration $\left(\mathrm{C}_{\mathrm{O}}\right)$ can be extracted from the $\sigma$ adjusted $\mathrm{SAFe}$ profiles at $2 \mathrm{~T}$. The measured $\mathrm{Cr}$ concentration of seawater samples taken at station $2 \mathrm{~T}$ serves as the transient $\mathrm{Cr}$ concentration $\left(\mathrm{C}_{\mathrm{t}}\right)$. By choosing reasonable fractionation factors associated with $\mathrm{Cr}$ reduction, we can model the $\mathrm{Cr}$ isotope ratio of the residual $\mathrm{Cr}(\mathrm{VI})$ fraction (figure 3.8). A fractionation factor of $\alpha=0.99956$ (i.e. $\varepsilon=-0.44$ ) is able to mimic the $\mathrm{Cr}$ isotope profile observed at $2 \mathrm{~T}$ the best.

\subsubsection{Probable effect of analyzing unfiltered ODZ samples versus filtered ODZ samples}

Since this was a last-minute sampling effort, seawater samples at stations $2 \mathrm{~T}$ and $7 \mathrm{~T}$ were not filtered. As mentioned previously, up to $1.1 \mathrm{nmol} / \mathrm{kg}$ of particulate $\mathrm{Cr}$ has been measured in the ODZ of the ETNP (Murray et al., 1983). The particulate Cr fraction presumably consists of primarily particle-reactive isotopically light $\mathrm{Cr}$ (III). Consequently, if our samples had been filtered, we would expect to see a bigger $\mathrm{Cr}$ concentration deficit and a bigger anomaly of heavier $\delta^{53} \mathrm{Cr}$ within the ODZ. 


\subsubsection{Direct microbial reduction of $\mathrm{Cr}$ ?: $\delta^{53} \mathrm{Cr}-\delta^{15} \mathrm{~N}_{\mathrm{NO3}-}$ correlation}

For several decades, microbes were thought to break down organic matter using electron acceptors in a strict succession dictated by their free energy yields (Froelich et al., 1979). In this traditional view, the dissimilatory usage of electron acceptors with energy yields below that of the $\mathrm{NO}_{3}{ }^{-}-\mathrm{NO}_{2}{ }^{-}$ couple (such as the $\mathrm{CrO}_{4}{ }^{2-}-\mathrm{Cr}(\mathrm{OH})_{2}{ }^{+}$and the $\mathrm{SO}_{4}{ }^{2-}-\mathrm{HS}^{-}$couple), did not occur until nitrate concentrations were zero. In recent years, metagenomics techniques have revealed that nitrate and sulfate reduction can take place simultaneously (e.g. Canfield et al., 2010). Since chromate's reduction potential at seawater $\mathrm{pH}$ is only slightly lower than that of nitrate and higher than that of sulfate (Stumm and Morgan, 2012), it is conceivable that microbes directly reduce chromate in oxygen depleted waters.

The microbial reduction of nitrate leaves the residual $\mathrm{NO}_{3}{ }^{-}$enriched in ${ }^{15} \mathrm{~N}$, which results in an apparent isotope effect of 20\%o - 30\%o (e.g. Cline and Kaplan, 1975; Brandes et al., 1998; Voss et

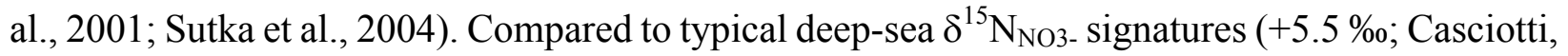
2016), all $\delta^{15} \mathrm{~N}_{\mathrm{NO} 3}$ - signatures recorded at station $2 \mathrm{~T}$ are heavy (figure 3.5 ) which indicates heterotrophic denitrification. In contrast, $\delta^{53} \mathrm{Cr}$ isotope signatures of $2 \mathrm{~T}$ at $600 \mathrm{~m}$ and $800 \mathrm{~m}$ depth were not heavy relative to those at SAFe. Nevertheless, when $\delta^{15} \mathrm{~N}_{\mathrm{NO} \text { - signatures are plotted }}$ against $\delta^{53} \mathrm{Cr}$ signatures at station 2T (figure 3.9), a strong correlation is observed. Excluding a single data point at $100 \mathrm{~m}, \mathrm{R}^{2}$ equals 0.91 (without exclusion, $\mathrm{R}^{2}=0.58$ ). This correlation supports the direct microbial reduction of $\mathrm{Cr}(\mathrm{VI})$ in the $\mathrm{ODZ}$ at station $2 \mathrm{~T}$. The fact that both nitrogen and chromium reduction are stronger in the upper portion of the ODZ would then be attributed to limitation of the process by the flux of sinking organic matter. A positive correlation between bulk

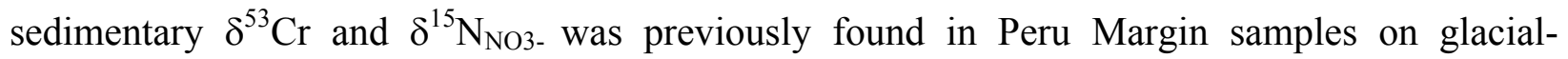
interglacial timescales (Gueguen et al., 2016).

\subsubsection{Reduction of $\mathrm{Cr}(\mathrm{VI})$ by $\mathrm{Fe}(\mathrm{II})$ ?}

Alternatively to direct microbial $\mathrm{Cr}$ reduction, $\mathrm{dFe}(\mathrm{II})$ may have acted as a reductant of $\mathrm{Cr}(\mathrm{VI})$ (Eary and Rai, 1988). Low oxygen shelf waters off Oregon and Washington have been observed to be sources of $\mathrm{dFe}(\mathrm{II})$ to the coastal upwelling region (Lohan and Bruland, 2008). Similarly, 
reducing continental-margin sediments were observed to be the source of $\mathrm{dFe}(\mathrm{II})$ to offshore waters of Peru (Chever et al., 2015; Hong and Kester, 1986). Analogously, Fe(III) may be reduced microbially in the anoxic pore waters of the Mexican shelf and subsequently transported offshore to station 2T. Furthermore, in-situ reduction of Fe in the ODZ cannot be excluded. Even though no direct $\mathrm{dFe}(\mathrm{II})$ measurements have been reported for the ODZ of the ETNP, total Fe concentrations have been shown to be unusually high here (up to $6 \mathrm{nmol} / \mathrm{kg}$ at $150 \mathrm{~m}, 18^{\circ} \mathrm{N} 108^{\circ} \mathrm{W}$, Landing and Bruland, 1987) and Fe(II) is likely to make up an significant fraction of total Fe.

\subsubsection{Station $7 T$ in the core of the ETNP's ODZ}

Station 7T is located closer to the Mexican coast compared to station 2T. Even though $\mathrm{O}_{2}$ levels are lower than $1.3 \mu \mathrm{mol} / \mathrm{kg}$ between $100 \mathrm{~m}$ and $800 \mathrm{~m}$ depth, no pronounced deficit in total $\mathrm{Cr}$ concentrations is seen relative to the $\sigma_{\theta}$ adjusted SAFe station (figure 3.6). Likewise, the total $\mathrm{Cr}$ isotope signatures coincide with those seen at $\mathrm{SAFe}$ apart from a slightly heavier $\delta^{53} \mathrm{Cr}$ signature at $600 \mathrm{~m}$. These observations imply that little or no $\mathrm{Cr}$ reduction and removal is taking place at station 7T despite the presence of anoxic conditions.

A peak in heavy $\delta^{15} \mathrm{~N}$ of $\mathrm{NO}_{3}{ }^{-}$was seen lower in the water column of this station $(400 \mathrm{~m}-500 \mathrm{~m})$, although all of the nitrate is heavier than typical deep ocean nitrate $(\sim+5.5 \%)$ (figure 3.6$)$. If $\mathrm{dFe}(\mathrm{II})$ originating from reducing continental-margin sediments was responsible for $\mathrm{Cr}(\mathrm{VI})$ reduction at station $2 \mathrm{~T}$, we would have expected to see the same or a higher extent of $\mathrm{Cr}$ reduction at station $7 \mathrm{~T}$ as it is located closer to the Mexican coast.

\subsubsection{Santa Barbara Basin}

\subsubsection{Patterns in dissolved $[\mathrm{Cr}]$ and $\delta^{53} \mathrm{Cr}$}

At the time of our sampling, very low oxygen $(1.47 \mu \mathrm{mol} / \mathrm{kg})$ and nitrate $(5.99 \mu \mathrm{mol} / \mathrm{kg})$ concentrations and a negative $\mathrm{N}^{*}$ of $-49 \mu \mathrm{mol} / \mathrm{kg}$ were observed in the bottom waters of the basin (figure 3.7). As anoxia and denitrification were well established, we can dismiss the potential occurrence of a flushing or turbidity current event immediately prior to sampling. Total $\mathrm{Cr}$ concentrations were steady over the upper $350 \mathrm{~m}$ at $\sim 3 \mathrm{nmol} / \mathrm{kg}$ except for a minor excursion to 
$2.78 \mathrm{nmol} / \mathrm{kg}$ at $100 \mathrm{~m}$. Over the same depth range $\delta^{53} \mathrm{Cr}$ isotope signatures were constant $(+1.00 \%$ - $+1.07 \%$ ) given the $2 \mathrm{SD}$ error bar on the measurement $( \pm 0.07 \%$ ). Both of these concentration and $\delta^{53} \mathrm{Cr}$ values agree well with our observations in the upper $350 \mathrm{~m}$ at $\mathrm{SAFe}([\mathrm{Cr}]=3.16-3.24$ $\mathrm{nmol} / \mathrm{kg}, \delta^{53} \mathrm{Cr}=+1.01 \%$ - $+1.11 \%$ ). At our Santa Barbara Basin site, nitrate concentrations increase in the upper $400 \mathrm{~m}$. The effects of denitrification manifest from $451 \mathrm{~m}$ downwards $\left(\left[\mathrm{O}_{2}\right] \leq\right.$ $10.85 \mu \mathrm{mol} / \mathrm{kg}$ ) with nitrate concentrations and $\mathrm{N}^{*}$ values decreasing. Simultaneously, total $\mathrm{Cr}$ concentrations decrease from at least $465 \mathrm{~m}$ onwards and reach a minimum concentration of 1.79 $\mathrm{nmol} / \mathrm{kg}$ at $570 \mathrm{~m}$. Cr isotopic signatures increase from $465 \mathrm{~m}$ onwards to a maximum $\delta^{53} \mathrm{Cr}$ value of $1.43 \%$ at $545 \mathrm{~m}$. Since the $\delta^{53} \mathrm{Cr}$ values at $545 \mathrm{~m}$ and at $570 \mathrm{~m}$ are only $0.09 \%$ apart (compared to an uncertainty of $\pm 0.07 \%$, $2 \mathrm{SD}$ ), we are unable to discern at which of these depths the true maximum $\delta^{53} \mathrm{Cr}$ value occurs.

Although the $\delta^{15} \mathrm{~N}_{\text {of }} \mathrm{NO}_{3}{ }^{-}$was not determined during our expedition, Sigman et al. (2003) saw a significant shift to heavier $\delta^{15} \mathrm{~N}$ of $\mathrm{NO}_{3}{ }^{-}$values between $500 \mathrm{~m}$ depth and the basin's bottom depth $(\sim 8.5 \%$ vs $\sim 12 \%)$. This was interpreted as a denitrification signal.

These observations are consistent with $\mathrm{Cr}$ reduction in anoxic waters producing isotopically light, particle-reactive $\mathrm{Cr}(\mathrm{III})$, which is partially scavenged by particles and exported to depth. Isotopically heavy $\mathrm{Cr}(\mathrm{VI})$ is left behind in the upper water column.

Analogous to the Rayleigh distillation calculations of station 2T, we can model the effect of different fractionation factors associated with the observed degree of Cr reduction in the Santa Barbara Basin (figure 3.10). A fractionation factor of $\alpha=0.99935$ (i.e. $\varepsilon=-0.65 \%$ ) is able to recreate the $\mathrm{Cr}$ isotope profile observed in the Santa Barbara Basin the best.

\subsubsection{Water column and sedimentary $\mathrm{Cr}$ reduction}

The Santa Barbara Basin is a site of intense denitrification. Taking advantage of the different $\mathrm{N}$ isotope effects that water column and sedimentary denitrification produce in the remaining $\mathrm{NO}_{3}{ }^{-}$, Sigman et al. (2003) attributed at least $76 \%$ of the observed nitrate loss to sedimentary denitrification. 
Likewise, $\mathrm{Cr}$ reduction may be occurring both in the anoxic water column and in the anoxic pore waters of the sediment. If $\mathrm{Cr}$ reduction is happening in the anoxic pore waters of the sediment, then there would be a steep $\mathrm{Cr}$ concentration gradient near the sediment-water interface (see section 3.4.3.4.). The transfer of $\mathrm{Cr}$ from the bottom waters into the sediments, would result in lower $\mathrm{Cr}$ concentrations in the bottom waters.

But a similar steep concentration gradient is known to occur for nitrate in the upper pore waters of reducing sediments, and evidence suggests that total diffusion of nitrate into the sedimentary denitrification zone produces a relatively minor nitrate $\delta^{15} \mathrm{~N}$ fractionation $(\sim 1.5 \%$; Brandes and Devol, 2002, 1997). In the absence of contrary information, we should expect a similar result for $\mathrm{Cr}$ isotope fractionation, hence although sedimentary $\mathrm{Cr}$ reduction is a plausible mechanism for reducing bottom water chromium concentrations and enriching the $\mathrm{Cr}$ concentration of reducing sediments, it would not appear to be a viable mechanism for the heavy $\mathrm{Cr}$ isotope enrichments that we observe.

\subsubsection{Potential mechanisms of $\mathrm{Cr}(\mathrm{VI})$ reduction}

As previously mentioned, dissolved Fe(II) is a potent reductant of Cr(VI) (Eary and Rai, 1988; Sedlak and Chan, 1997). Ample indirect evidence exists for the presence of high $\mathrm{dFe}(\mathrm{II})$ levels in the sediments and bottom waters. John et al. (2012) saw total Fe concentrations increase from 8.8 $\mathrm{nmol} / \mathrm{kg}$ above sill depth to $29.5 \mathrm{nmol} / \mathrm{kg}$ at $570 \mathrm{~m}$ depth within the anoxic bottom waters of the

Santa Barbara Basin. Simultaneously, Fe isotope ratios $\left(\delta^{56} \mathrm{Fe}\right)$ shifted to much lighter values within the bottom waters, which are typically produced by Fe(III) reduction to Fe(II). John et al. (2012) ascribed their observations to Fe reduction in the anoxic sediment pore waters and a subsequent flux of $\mathrm{Fe}(\mathrm{II})$ into the bottom waters. At the time our $\mathrm{Cr}$ profile was taken, total $\mathrm{Fe}$ concentrations reached up to $59.9 \mathrm{nmol} / \mathrm{kg}$ at $573 \mathrm{~m}$ depth (Jessica N. Fitzsimmons, personal communication) with $\mathrm{dFe}(\mathrm{II})$ likely accounting for the majority of it. 
In consequence, $\mathrm{dFe}(\mathrm{II})$ is a potential reductant of $\mathrm{Cr}(\mathrm{VI})$ in both the bottom waters and the sediment pore waters of the Santa Barbara Basin. Additionally, direct microbial Cr reduction may occur in both of these anoxic environments. Furthermore, Cr may be reduced by acid volatile sulfides in the anoxic sediment pore waters (Graham and Bouwer, 2010).

\subsubsection{Cr concentration gradient for the possibility of sedimentary $\mathrm{Cr}$ reduction}

Under the assumption that all observed Cr reduction occurs in the anoxic sediment pore waters of the Santa Barbara Basin, a pore water Cr concentration gradient can be calculated using Fick's first law of diffusion (Fick, 1855). Applying this law, the Cr removal flux over the Santa Barbara Basin's anoxic sediment area should equal the diffusion coefficient $(D)$ multiplied by the pore water $\mathrm{Cr}$ concentration gradient $(\Delta[C r] / \Delta z)$ (equation 7). In order to calculate the Cr removal flux over the basin's anoxic sediment area, we need to estimate how much total $\mathrm{Cr}$ is lost in the basin, and the time since the basin's bottom waters were last renewed (equation 8). The area of the anoxic sediment does not need to be estimated since this term will cancel out.

Cr removal flux over the SBB's anoxic sediment area $=D \times \frac{\Delta[C r]}{\Delta z}$

$\frac{\text { total } \mathrm{Cr} \text { lost in SBB }}{\text { anoxic sediment area of SBB } \times \text { time since last renewal of bottom waters }}=D \times \frac{\Delta[\mathrm{Cr}]}{\Delta \mathrm{z}}$

We roughly integrate the $\mathrm{Cr}$ lost in the basin by placing a triangle in the space between the $\mathrm{Cr}$ concentration profile of the adjusted SAFe station and that of our basin site $(=0.5 \times$ $\left.\left(3.00 \frac{\mathrm{nmol} \mathrm{Cr}}{\mathrm{kg}}-1.79 \frac{\mathrm{nmol} \mathrm{Cr}}{\mathrm{kg}}\right) \times(585 \mathrm{~m}-465 \mathrm{~m})\right)$ and multiplying it by the basin's anoxic sediment area. As this latter term appears in the denominator and the terms will cancel out.

On a quarterly basis, oxygen and nutrient concentrations in the water column of the Santa Barbara Basin are determined by the California Cooperative Oceanic Fisheries Investigations (CalCOFI). One CalCOFI occupation took place three days before our samples were taken and confirms that 
anoxia and denitrification were well-established in the bottom waters immediately prior to our sampling (figure 3.11). In contrast, CalCOFI data from April $13^{\text {th }}, 2014$ show higher $\mathrm{O}_{2}$ levels (up to $13 \mu \mathrm{mol} / \mathrm{kg}$ ) and nitrate concentrations are not substantially depleted relative to phosphate concentrations (figure 3.11). After a major flushing event, it takes $\sim 2$ months for anoxia and denitrification to manifest in the basin's bottom water (Sholkovitz and Gieskes, 1971). In consequence, the bottom waters of the Santa Barbara Basin were at least partially replaced sometime between mid-February and mid-April 2014. For our calculations, we estimate that the last renewal of the bottom waters occurred 4 months prior to sampling, which took place on July 24, 2014.

Using these estimates and a typically diffusion coefficient of $2.5 \times 10^{-5} \frac{\mathrm{cm}^{2}}{\mathrm{~s}}$, we arrive at a pore water $\mathrm{Cr}$ concentration gradient of $\sim 28 \frac{\mathrm{nM}}{\mathrm{cm}}$. Given that the bottom waters only hold $1.84 \mathrm{nM}$ of $\mathrm{Cr}$, $\mathrm{Cr}$ in sediment pore waters would get exhausted over $\sim 0.65 \mathrm{~mm}$.

\subsubsection{Cr data from ETNP (2T, 7T) and the Santa Barbara Basin on the global Cr array}

On a $\delta^{53} \mathrm{Cr}-\ln ([\mathrm{Cr}])$ plot (figure 3.12), the $\mathrm{Cr}$ data from stations 2T, 7T and from the Santa Barbara Basin site plot on the same Rayleigh-like fractionation line as published seawater data (Bonnand et al., 2013; Scheiderich et al., 2015) and SAFe station (chapter 2).

\subsection{Conclusions}

Our observations at station $2 \mathrm{~T}$ in the ETNP and at our Santa Barbara site are consistent with $\mathrm{Cr}$ reduction in anoxic waters producing isotopically light, particle-reactive $\mathrm{Cr}(\mathrm{III})$, which is partially scavenged by particles and exported to depth. Isotopically heavy $\mathrm{Cr}(\mathrm{VI})$ is left behind in the upper water column. Since seawater samples from station $2 \mathrm{~T}$ were not filtered, the magnitude of the $\mathrm{Cr}$ reduction signal may have been suppressed by the presence of isotopically light $\operatorname{Cr}(\mathrm{III})$ particles. 
At station 2T, the observed correlation of $\delta^{53} \mathrm{Cr}$ and $\delta^{15} \mathrm{~N}_{\mathrm{NO} \text { - }}$ suggests that $\mathrm{Cr}$ reduction may be microbially mediated instead of simply being a product of thermodynamic equilibrium. Alternatively, $\mathrm{Cr}(\mathrm{VI})$ may be reduced by $\mathrm{Fe}(\mathrm{II})$, which was generated in-situ by dissimilatory Fe reduction and/or was generated in the anoxic pore waters of the Mexican shelf by dissimilatory Fe reduction and subsequently transported offshore to station $2 \mathrm{~T}$.

In the Santa Barbara Basin, Cr reduction may take place via the same mechanisms in the anoxic bottom waters and/or in the anoxic sediment pore waters. Additionally, acid volatile sulfides may contribute to $\mathrm{Cr}(\mathrm{VI})$ reduction in the anoxic sediment pore waters. Although the sedimentary $\mathrm{Cr}$ reduction can contribute to lowering the $\mathrm{Cr}$ concentration of the bottom waters, it is unlikely to result in significant $\mathrm{Cr}$ isotope fractionation. If all of the observed $\mathrm{Cr}$ reduction took place in the basin's sediment, $\mathrm{Cr}$ in the pore waters would get depleted over a depth range of several millimeters. This narrow depth range would make any $\mathrm{Cr}$ analysis in such pore waters extremely challenging.

Is the SAFe station a suitable, fully oxic water column counterpart? The peak in heavy $\mathrm{Cr}$ and a subtle decrease in Cr concentrations at SAFe (at 200m depth) are located along the same isopycnal as the biggest total $\mathrm{Cr}$ deficit and heaviest $\mathrm{Cr}$ anomaly at station $2 \mathrm{~T}$ (at 100m depth). This point is best illustrated by comparing the $\mathrm{Cr}$ profiles of $2 \mathrm{~T}$ and the $\sigma_{\theta}$ adjusted $\mathrm{SAFe}$ station at $100 \mathrm{~m}$ (figure $3.5)$. It is conceivable that a signal of $\mathrm{Cr}$ reduction (=lower $[\mathrm{Cr}]$, heavier $\delta^{53} \mathrm{Cr}$ ) generated within the ODZ of the ETNP at station 2T can advect or diffuse to the SAFe station. In that case, a direct comparison between the two stations may underestimate the magnitude of Cr reduction occurring within the ODZ. To verify this hypothesis a transect from the ODZ into oxic waters of the North Pacific is required. Alternatively, a more remote station in the North Pacific such as Station ALOHA $\left(22.75^{\circ} \mathrm{N}, 158^{\circ} \mathrm{W}\right)$ could be analyzed with the hope that it is minimally impacted by transport of a $\mathrm{Cr}$ reduction signal out of the ODZ. 


\subsection{References}

Ball, J.W., Bassett, R.L., 2000. Ion exchange separation of chromium from natural water matrix for stable isotope mass spectrometric analysis. Chem. Geol. 168, 123-134. doi:http://dx.doi.org/10.1016/S0009-2541(00)00189-3

Basu, A., Johnson, T.M., 2012. Determination of Hexavalent Chromium Reduction Using Cr Stable Isotopes: Isotopic Fractionation Factors for Permeable Reactive Barrier Materials. Environ. Sci. Technol. 46, 5353-5360. doi:10.1021/es204086y

Berna, E.C., Johnson, T.M., Makdisi, R.S., Basu, A., 2010. Cr Stable Isotopes As Indicators of $\mathrm{Cr}(\mathrm{VI})$ Reduction in Groundwater: A Detailed Time-Series Study of a Point-Source Plume. Environ. Sci. Technol. 44, 1043-1048. doi:10.1021/es902280s

Bograd, S.J., Schwing, F.B., Castro, C.G., Timothy, D.A., 2002. Bottom water renewal in the Santa Barbara Basin. J. Geophys. Res. Ocean. 107, 9-1-9-9. doi:10.1029/2001JC001291

Bonnand, P., James, R.H., Parkinson, I.J., Connelly, D.P., Fairchild, I.J., 2013. The chromium isotopic composition of seawater and marine carbonates. Earth Planet. Sci. Lett. 382, 10-20. doi:http://dx.doi.org/10.1016/j.eps1.2013.09.001

Brandes, J.A., Devol, A.H., 1997. Isotopic fractionation of oxygen and nitrogen in coastal marine sediments. Geochim. Cosmochim. Acta 61, 1793-1801. doi:10.1016/S00167037(97)00041-0

Brandes, J.A., Devol, A.H., 2002. A global marine-fixed nitrogen isotopic budget: Implications for Holocene nitrogen cycling. Global Biogeochem. Cycles 16, 67-1-67-14. doi:10.1029/2001GB001856

Brandes, J.A., Devol, A.H., Yoshinari, T., Jayakumar, D.A., Naqvi, S.W.A., 1998. Isotopic composition of nitrate in the central Arabian Sea and eastern tropical North Pacific: A tracer for mixing and nitrogen cycles. Limnol. Oceanogr. 43, 1680-1689. doi:10.4319/lo.1998.43.7.1680

Brzezinski, M.A., Washburn, L., 2011. Phytoplankton primary productivity in the Santa Barbara Channel: Effects of wind-driven upwelling and mesoscale eddies. J. Geophys. Res. 116, C12013. doi:10.1029/2011JC007397

Canfield, D.E., Stewart, F.J., Thamdrup, B., De Brabandere, L., Dalsgaard, T., Delong, E.F., Revsbech, N.P., Ulloa, O., 2010. A cryptic sulfur cycle in oxygen-minimum-zone waters off the Chilean coast. Science (80-. ). 330, 1375-8. doi:10.1126/science.1196889

Casciotti, K.L., 2016. Nitrogen and Oxygen Isotopic Studies of the Marine Nitrogen Cycle. Ann. Rev. Mar. Sci. 8, 379-407. doi:10.1146/annurev-marine-010213-135052

Chever, F., Rouxel, O.J., Croot, P.L., Ponzevera, E., Wuttig, K., Auro, M., 2015. Total dissolvable and dissolved iron isotopes in the water column of the Peru upwelling regime. Geochim. Cosmochim. Acta 162, 66-82. doi:10.1016/j.gca.2015.04.031

Cline, J.D., Kaplan, I.R., 1975. Isotopic fractionation of dissolved nitrate during denitrification in the eastern tropical north pacific ocean. Mar. Chem. 3, 271-299. doi:10.1016/03044203(75)90009-2

Døssing, L.N., Dideriksen, K., Stipp, S.L.S., Frei, R., 2011. Reduction of hexavalent chromium by ferrous iron: A process of chromium isotope fractionation and its relevance to natural environments. Chem. Geol. 285, 157-166. doi:http://dx.doi.org/10.1016/j.chemgeo.2011.04.005

Eary, L.E., Rai, D., 1988. Chromate removal from aqueous wastes by reduction with ferrous ion. Environ. Sci. Technol. 22, 972-977. 
Ellis, A.S., Johnson, T.M., Bullen, T.D., 2002. Chromium isotopes and the fate of hexavalent chromium in the environment. Science (80-. ). 295, 2060-2062.

Fick, A., 1855. V. On liquid diffusion. Philos. Mag. 10, 30-39. doi:10.1080/14786445508641925

Froelich, P.N., Klinkhammer, G.P., Bender, M.L., Luedtke, N.A., Heath, G.R., Cullen, D., Dauphin, P., Hammond, D., Hartman, B., Maynard, V., 1979. Early oxidation of organic matter in pelagic sediments of the eastern equatorial Atlantic: suboxic diagenesis. Geochim. Cosmochim. Acta 43, 1075-1090. doi:10.1016/0016-7037(79)90095-4

Götz, A., Heumann, K.G., 1988. Chromium trace determination in inorganic, organic and aqueous samples with isotope dilution mass spectrometry. Fresenius Zeitschrift für Anal. Chemie 331, 123-128.

Graham, A.M., Bouwer, E.J., 2010. Rates of Hexavalent Chromium Reduction in Anoxic Estuarine Sediments: $\mathrm{pH}$ Effects and the Role of Acid Volatile Sulfides. Environ. Sci. Technol. 44, 136-142. doi:10.1021/es9013882

Gueguen, B., Reinhard, C.T., Algeo, T.J., Peterson, L.C., Nielsen, S.G., Wang, X., Rowe, H., Planavsky, N.J., 2016. The chromium isotope composition of reducing and oxic marine sediments. Geochim. Cosmochim. Acta 184, 1-19. doi:10.1016/j.gca.2016.04.004

Hong, H., Kester, D.R., 1986. Redox state of iron in the offshore waters of Peru1. Limnol. Oceanogr. 31, 612-626. doi:10.4319/lo.1986.31.3.0612

Izbicki, J.A., Bullen, T.D., Martin, P., Schroth, B., 2012. Delta Chromium-53/52 isotopic composition of native and contaminated groundwater, Mojave Desert, USA. Appl. Geochemistry 27, 841-853. doi:10.1016/j.apgeochem.2011.12.019

John, S.G., Mendez, J., Moffett, J., Adkins, J., 2012. The flux of iron and iron isotopes from San Pedro Basin sediments. Geochim. Cosmochim. Acta 93, 14-29. doi:10.1016/j.gca.2012.06.003

Karstensen, J., Stramma, L., Visbeck, M., 2008. Oxygen minimum zones in the eastern tropical Atlantic and Pacific oceans. Prog. Oceanogr. 77, 331-350. doi:10.1016/j.pocean.2007.05.009

Kitchen, J.W., Johnson, T.M., Bullen, T.D., Zhu, J., Raddatz, A., 2012. Chromium isotope fractionation factors for reduction of $\mathrm{Cr}$ (VI) by aqueous $\mathrm{Fe}(\mathrm{II})$ and organic molecules. Geochim. Cosmochim. Acta 89, 190-201. doi:http://dx.doi.org/10.1016/j.gca.2012.04.049

Landing, W.M., Bruland, K.W., 1987. The contrasting biogeochemistry of iron and manganese in the Pacific Ocean. Geochim. Cosmochim. Acta 51, 29-43. doi:10.1016/00167037(87)90004-4

Lohan, M.C., Bruland, K.W., 2008. Elevated Fe(II) and Dissolved Fe in Hypoxic Shelf Waters off Oregon and Washington: An Enhanced Source of Iron to Coastal Upwelling Regimes. Environ. Sci. Technol. 42, 6462-6468. doi:10.1021/es800144j

Luyten, J.R., Pedlosky, J., Stommel, H., Luyten, J.R., Pedlosky, J., Stommel, H., 1983. The Ventilated Thermocline. J. Phys. Oceanogr. 13, 292-309. doi:10.1175/15200485(1983)013<0292:TVT>2.0.CO;2

Murray, J.W., Spell, B., Paul, B., 1983. The Contrasting Geochemistry of Manganese and Chromium in the Eastern Tropical Pacific Ocean, in: Wong, C.S., Boyle, E., Bruland, K.W., Burton, J.D., Goldberg, E.D. (Eds.), Trace Metals in Sea Water, NATO Conference Series. Springer US, pp. 643-669. doi:- 10.1007/978-1-4757-6864-0_37

Palme, H., 1920. Studien über die Zersetzung der Überschwefelsäure. Zeitschrift für Anorg. und Allg. Chemie 112, 97-130. doi:10.1002/zaac.19201120105 
Paulmier, A., Ruiz-Pino, D., 2009. Oxygen minimum zones (OMZs) in the modern ocean. Prog. Oceanogr. 80, 113-128. doi:http://dx.doi.org/10.1016/j.pocean.2008.08.001

Rayleigh, Lord, 1896. L. Theoretical considerations respecting the separation of gases by diffusion and similar processes. London, Edinburgh, Dublin Philos. Mag. J. Sci. 42, 493498.

Reid Jr, J.L., 1965. Intermediate waters of the Pacific Ocean. La Jolla CA.

Reimers, C.E., Lange, C.B., Tabak, M., Bernhard, J.M., 1990. Seasonal spillover and varve formation in the Santa Barbara Basin, California. Limnol. Oceanogr. 35, 1577-1585. doi:10.4319/lo.1990.35.7.1577

Rudge, J.F., Reynolds, B.C., Bourdon, B., 2009. The double spike toolbox. Chem. Geol. 265, 420-431. doi:http://dx.doi.org/10.1016/j.chemgeo.2009.05.010

Rue, E.L., Smith, G.J., Cutter, G.A., Bruland, K.W., 1997. The response of trace element redox couples to suboxic conditions in the water column. Deep Sea Res. Part I Oceanogr. Res. Pap. 44, 113-134. doi:http://dx.doi.org/10.1016/S0967-0637(96)00088-X

Scheiderich, K., Amini, M., Holmden, C., Francois, R., 2015. Global variability of chromium isotopes in seawater demonstrated by Pacific, Atlantic, and Arctic Ocean samples. Earth Planet. Sci. Lett. 423, 87-97. doi:10.1016/j.eps1.2015.04.030

Sedlak, D.L., Chan, P.G., 1997. Reduction of hexavalent chromium by ferrous iron. Geochim. Cosmochim. Acta 61, 2185-2192.

Semeniuk, D.M., Maldonado, M.T., Jaccard, S.L., 2016. Chromium uptake and adsorption in marine phytoplankton - Implications for the marine chromium cycle. Geochim. Cosmochim. Acta 184, 41-54. doi:10.1016/j.gca.2016.04.021

Sholkovitz, E., Soutar, A., 1975. Changes in the composition of the bottom water of the Santa Barbara Basin: effect of turbidity currents. Deep Sea Res. Oceanogr. Abstr. 22, 13-21. doi:10.1016/0011-7471(75)90014-5

Sholkovitz, E.R., Gieskes, J.M., 1971. A physical-chemical study of the flushing of the Santa Barbara Basin. Limnol. Oceanogr. 16, 479-489. doi:10.4319/1o.1971.16.3.0479

Sigman, D.M., Robinson, R., Knapp, A.N., van Geen, A., McCorkle, D.C., Brandes, J.A., Thunell, R.C., 2003. Distinguishing between water column and sedimentary denitrification in the Santa Barbara Basin using the stable isotopes of nitrate. Geochemistry, Geophys. Geosystems 4, n/a-n/a. doi:10.1029/2002GC000384

Sikora, E.R., Johnson, T.M., Bullen, T.D., 2008. Microbial mass-dependent fractionation of chromium isotopes. Geochim. Cosmochim. Acta 72, 3631-3641. doi:http://dx.doi.org/10.1016/j.gca.2008.05.051

Small, L.F., Knauer, G.A., Tuel, M.D., 1987. The role of sinking fecal pellets in stratified euphotic zones. Deep Sea Res. Part A. Oceanogr. Res. Pap. 34, 1705-1712. doi:10.1016/0198-0149(87)90019-7

Stumm, W., Morgan, J.J., 2012. Aquatic chemistry: chemical equilibria and rates in natural waters. Vol. 126. John Wiley \& Sons.

Sutka, R.L., Ostrom, N.E., Ostrom, P.H., Phanikumar, M.S., 2004. Stable nitrogen isotope dynamics of dissolved nitrate in a transect from the north Pacific subtropical gyre to the eastern tropical north Pacific. Geochim. Cosmochim. Acta 68, 517-527. doi:10.1016/S0016-7037(03)00483-6

Voss, M., Dippner, J.W., Montoya, J.P., 2001. Nitrogen isotope patterns in the oxygen-deficient waters of the Eastern Tropical North Pacific Ocean. Deep Sea Res. Part I Oceanogr. Res. Pap. 48, 1905-1921. doi:10.1016/S0967-0637(00)00110-2 
Yamakawa, A., Yamashita, K., Makishima, A., Nakamura, E., 2009. Chemical separation and mass spectrometry of $\mathrm{Cr}, \mathrm{Fe}, \mathrm{Ni}, \mathrm{Zn}$, and $\mathrm{Cu}$ in terrestrial and extraterrestrial materials using thermal ionization mass spectrometry. Anal. Chem. 81, 9787-94. doi:10.1021/ac901762a

Zink, S., Schoenberg, R., Staubwasser, M., 2010. Isotopic fractionation and reaction kinetics between $\mathrm{Cr}(\mathrm{III})$ and $\mathrm{Cr}(\mathrm{VI})$ in aqueous media. Geochim. Cosmochim. Acta 74, 5729-5745. doi:http://dx.doi.org/10.1016/j.gca.2010.07.015 
Tables for Chapter 3

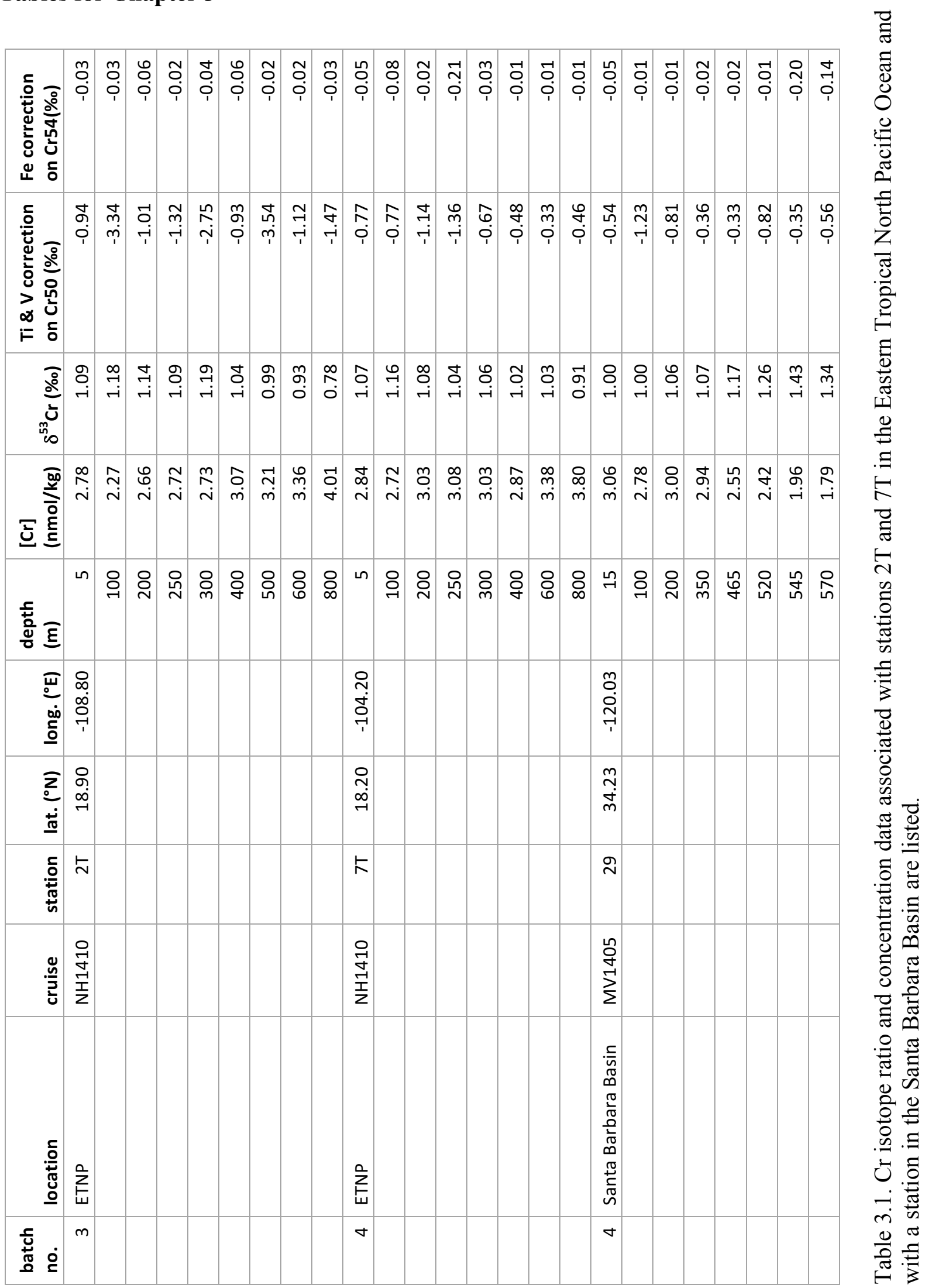


Figures for Chapter 3

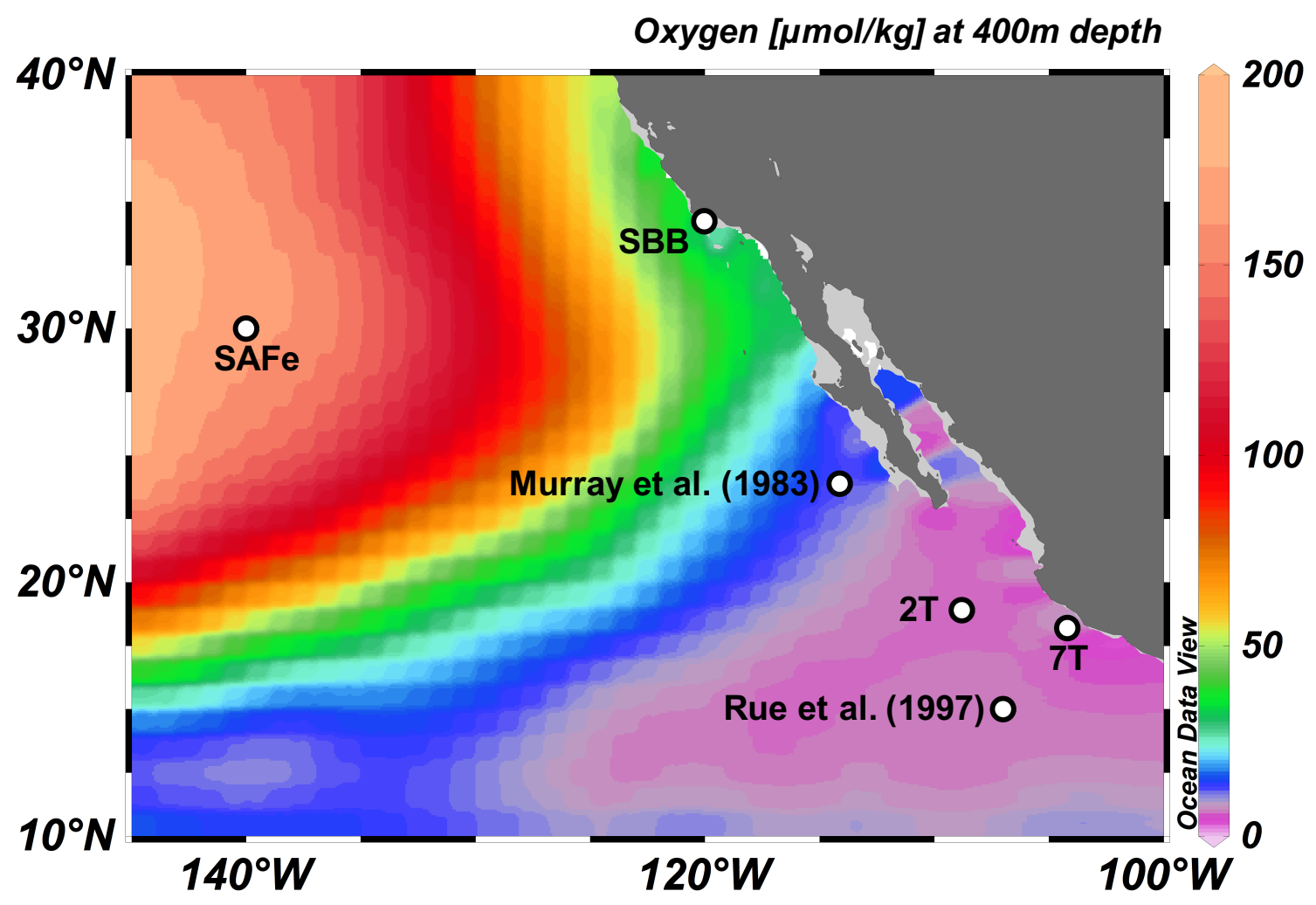

Figure 3.1. The sampling locations of stations 2T, 7T, SAFe and SBB (=Santa Barbara Basin) are superimposed onto the distribution of oxygen concentrations $(\mu \mathrm{mol} / \mathrm{kg})$ at $400 \mathrm{~m} \mathrm{depth}$. Annual oxygen data in $\mathrm{ml} / \mathrm{L}\left(1^{\circ}\right.$ grid) from the World Ocean Atlas 2009 (WOA09) served as a basis for this plot (Garcia et al., 2010). The original oxygen data was converted to $\mu \mathrm{mol} / \mathrm{kg}$ using an embedded function of Ocean Data View (Schlitzer, 2013). Ocean Data View was also used to make this map. Note that the lowest oxygen concentration at SAFe station is not found at $400 \mathrm{~m}$ but at $864 \mathrm{~m}$ with $13.2 \mu \mathrm{mol} / \mathrm{kg}$. The Santa Barbara Basin exhibits $\left[\mathrm{O}_{2}\right]<2.0 \mu \mathrm{mol} / \mathrm{kg}$ from 532 $\mathrm{m}$ to the bottom depth $(579 \mathrm{~m})$. 


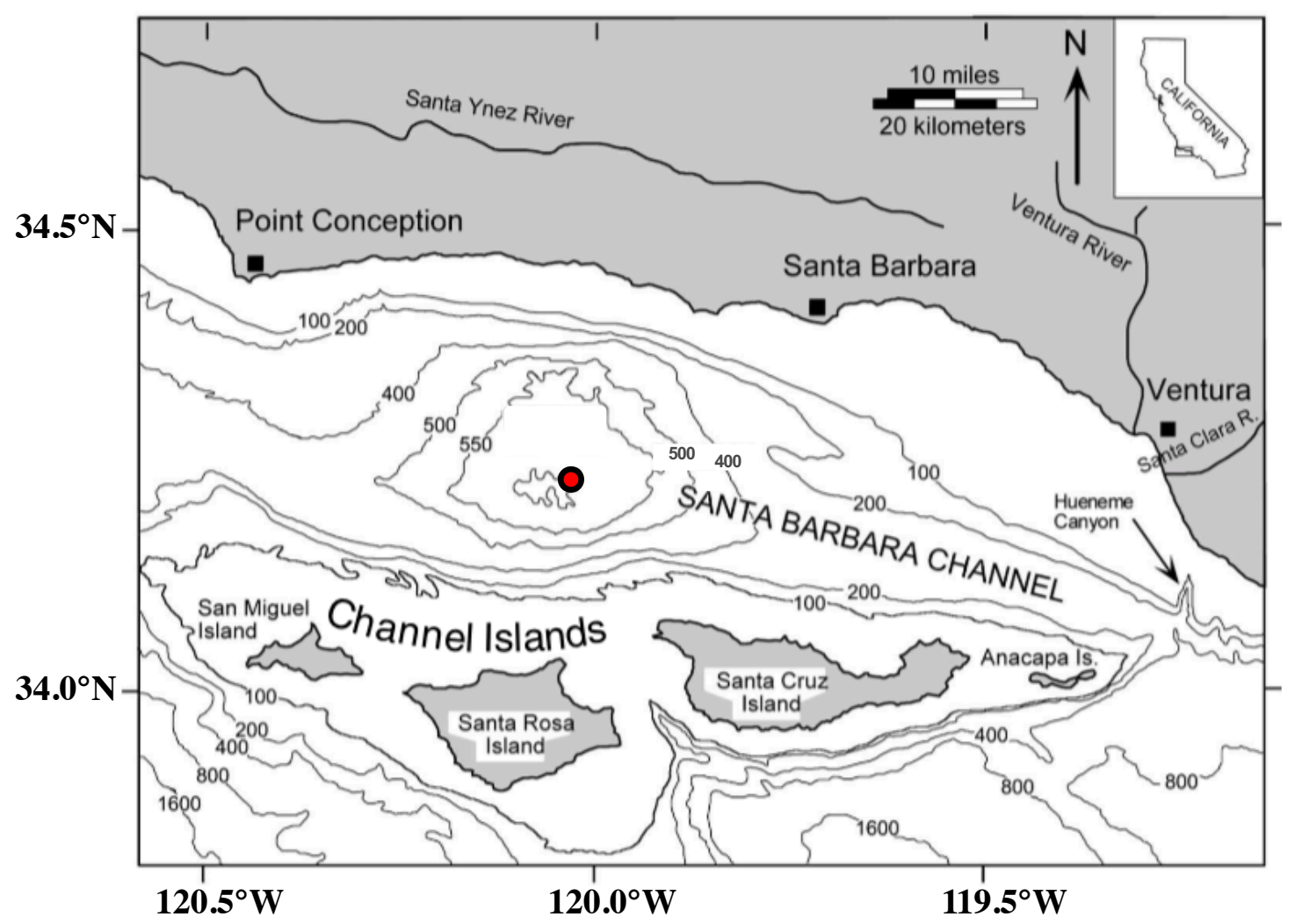

Figure 3.2. The bathymetry of the Santa Barbara Basin is shown. The red dot marks our sampling location. 


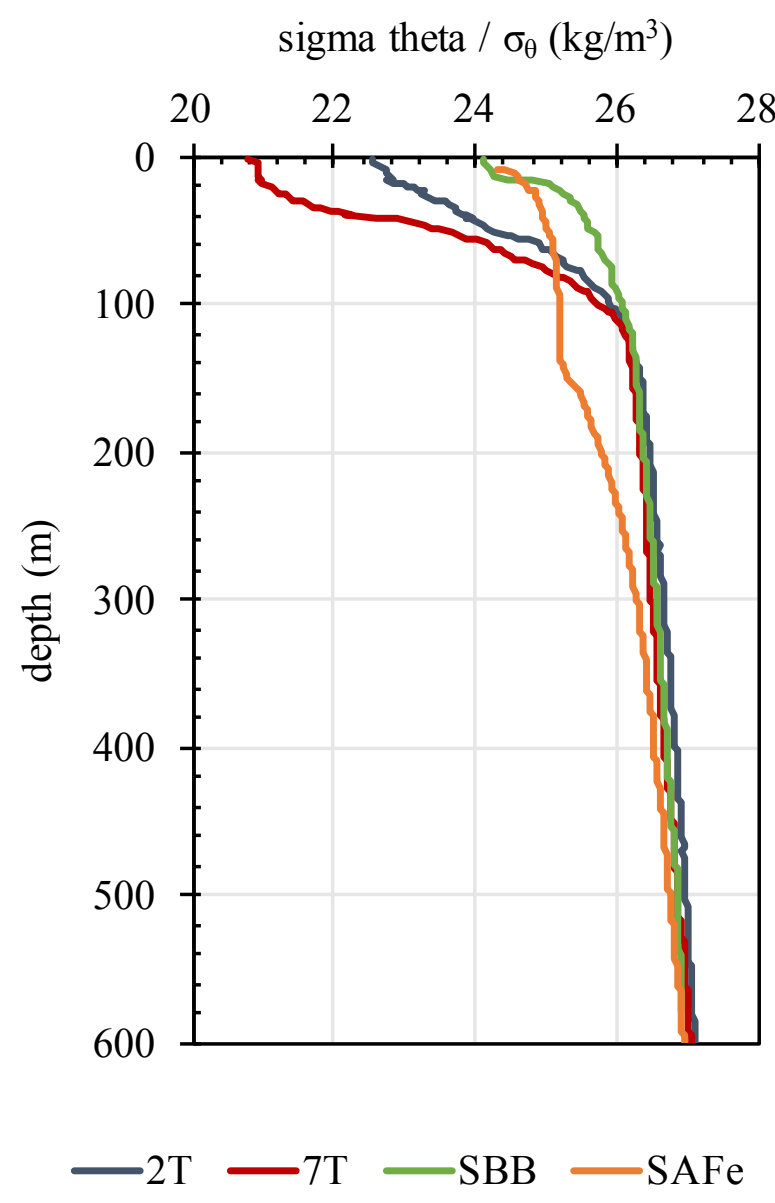

Figure 3.3. Upwelling of waters is observed towards the coast of Mexico and California. 

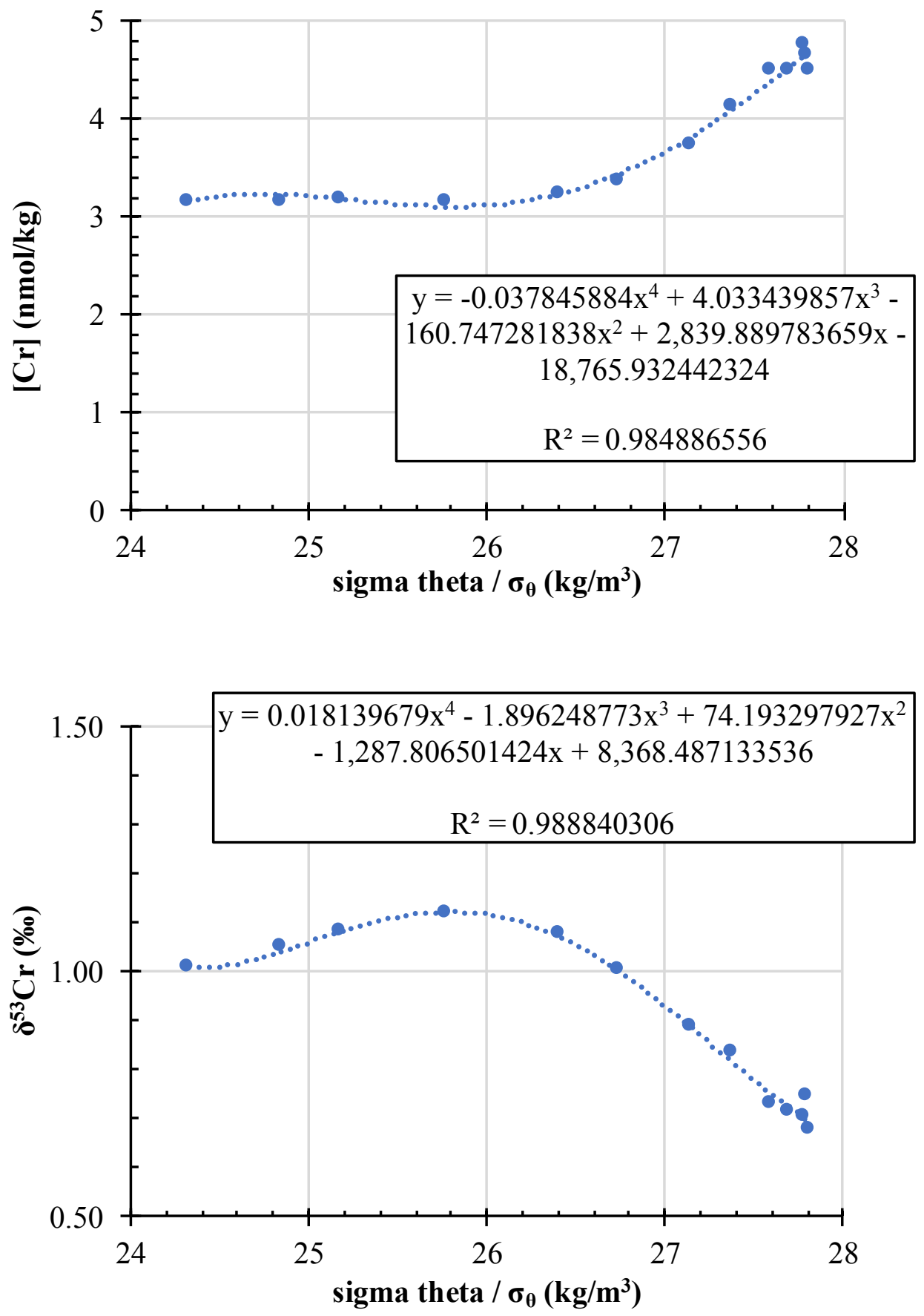

Figure 3.4. The $[\mathrm{Cr}]-\sigma_{\theta}$ relationship at $\mathrm{SAFe}$ is approximated by a $4^{\text {th }}$-order polynomial (upper panel). Likewise, the $\delta^{53} \mathrm{Cr}-\sigma_{\theta}$ relationship at SAFe is approximated by a $4^{\text {th }}$-order polynomial (lower panel). 

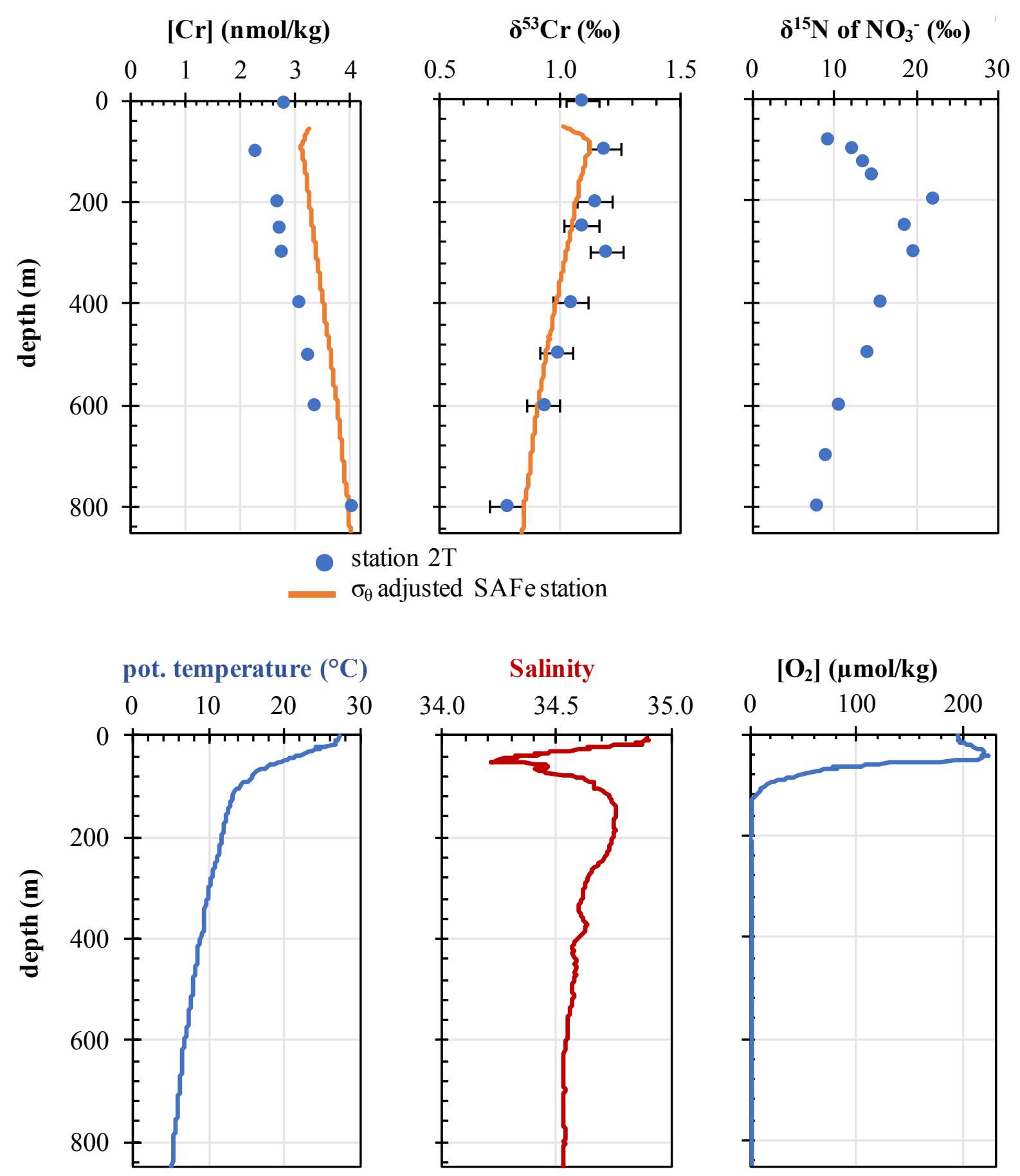

Figure 3.5. Full water column profiles are given for a suite of parameters at station $2 \mathrm{~T}$ which is located within the ODZ of the Eastern Tropical Pacific. Total Cr concentration and isotope ratios measured at $2 \mathrm{~T}$ (blue dots) are shown alongside the $\sigma_{\theta}$ adjusted $\mathrm{SAFe}$ profiles (orange lines). Mark Altabet (UMass Dartmouth) and Annie Bourbonnais (WHOI) measured nitrogen isotope signatures of nitrate. Error bars of $\mathrm{Cr}$ isotope ratios at 2SD. 

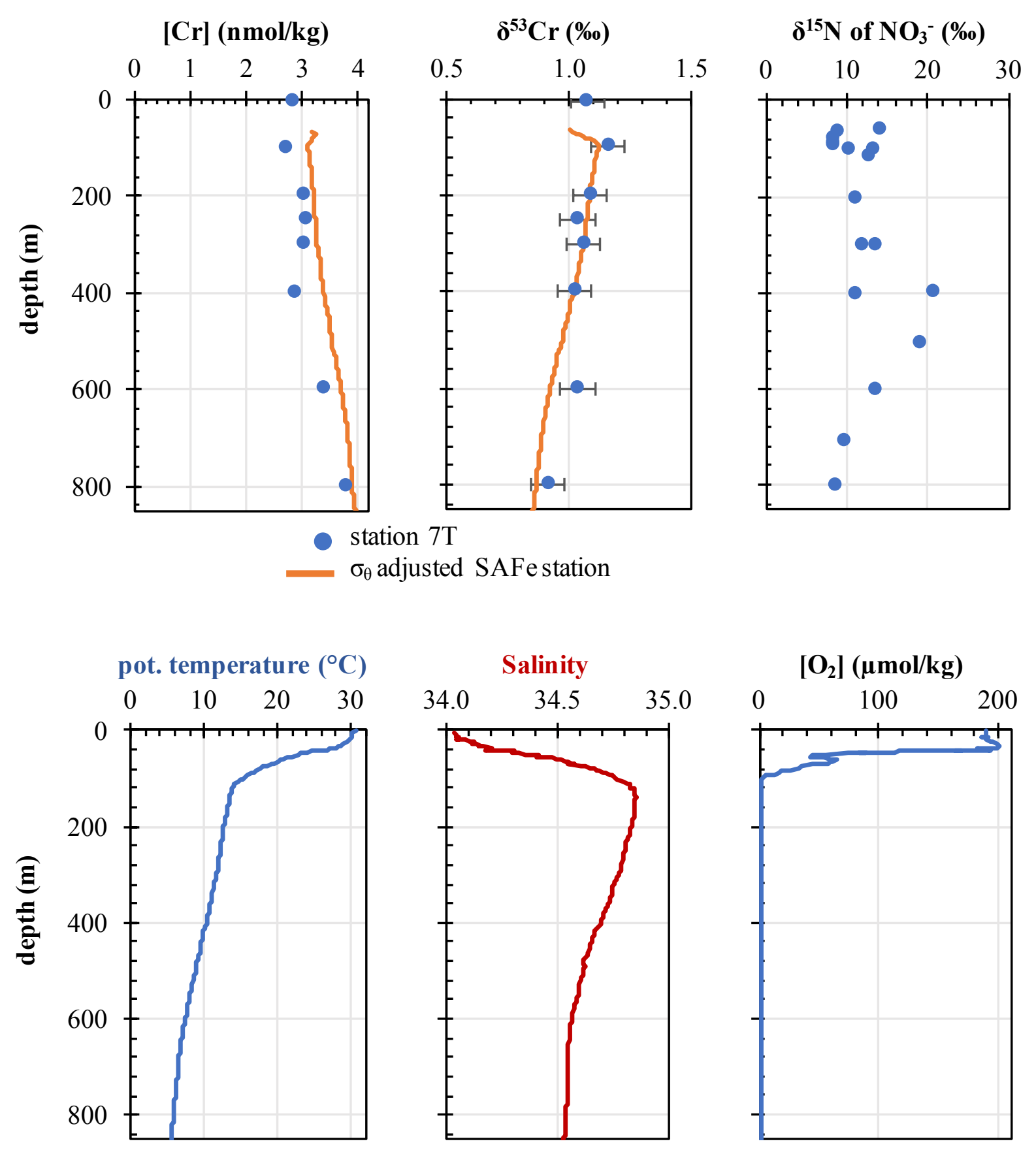

Figure 3.6. Full water column profiles are given for a suite of parameters at station 7T which is located within the ODZ of the Eastern Tropical Pacific. Total Cr concentration and isotope ratios measured at 7T (blue dots) are shown alongside the $\sigma_{\theta}$ adjusted SAFe profiles (orange lines). Mark Altabet (UMass Dartmouth) and Annie Bourbonnais (WHOI) measured nitrogen isotope signatures of nitrate. Error bars of $\mathrm{Cr}$ isotope ratios at 2SD. 


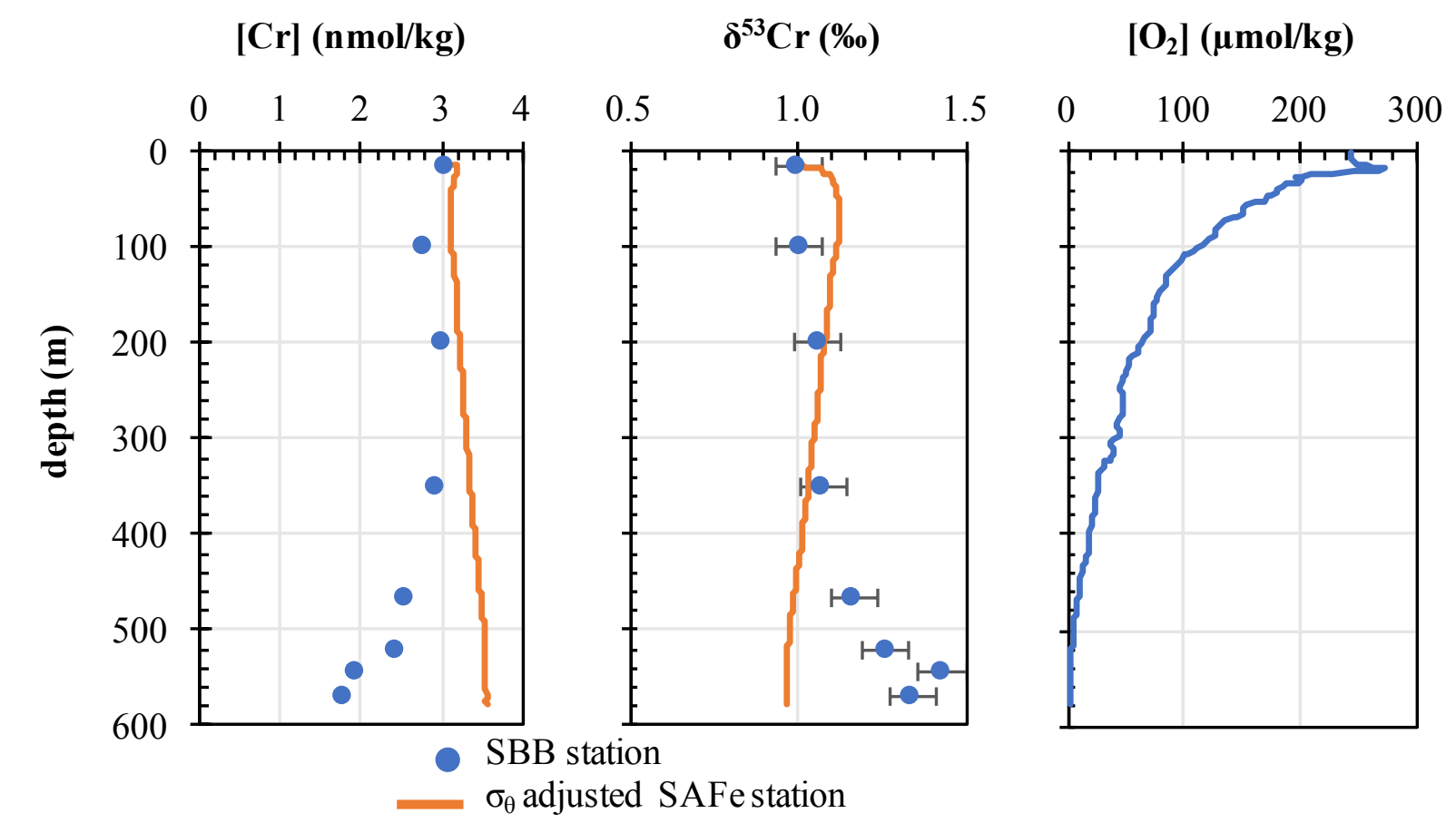

$\left[\mathrm{O}_{2}\right](\mu \mathrm{mol} / \mathrm{kg})$
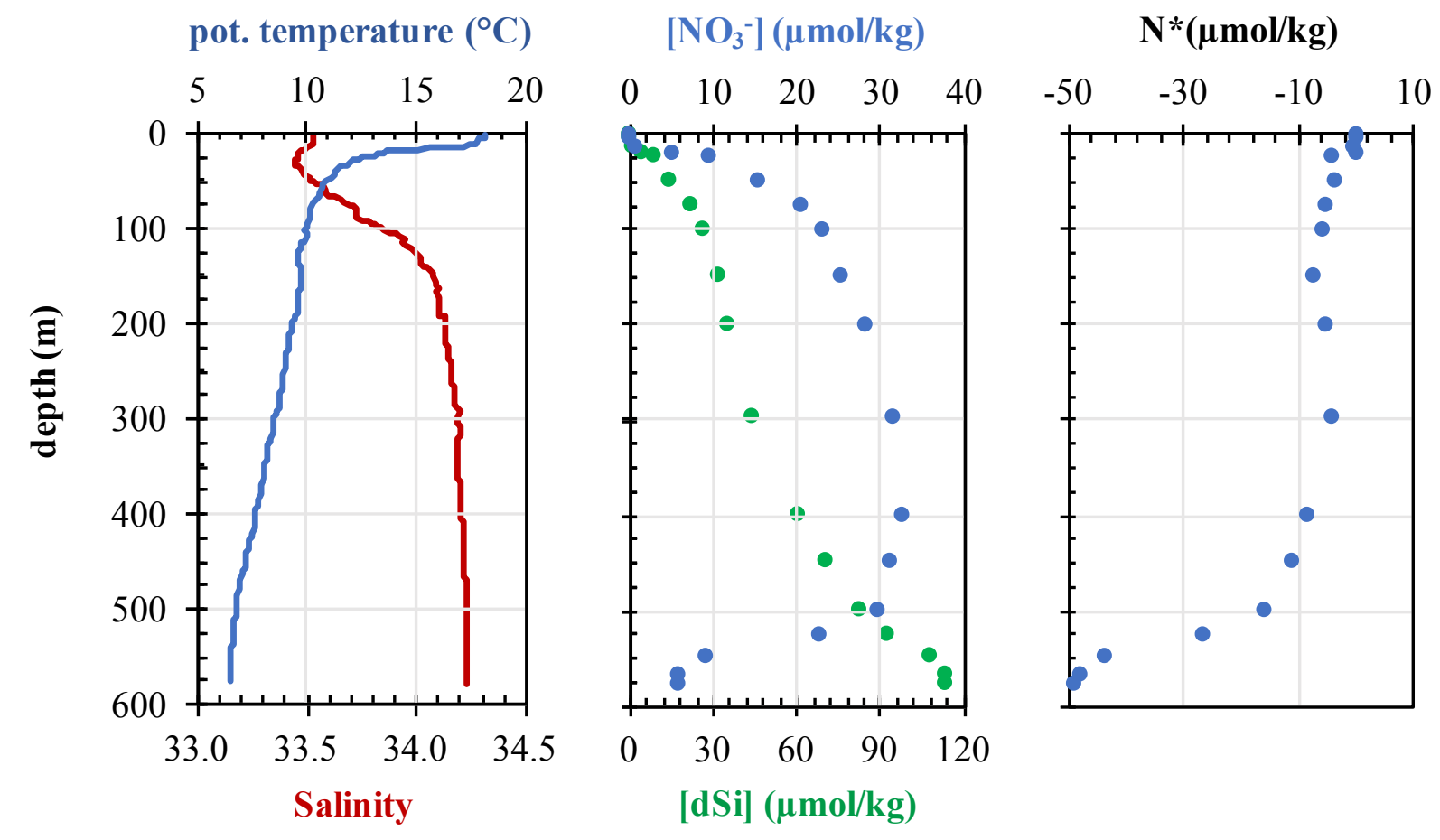

Figure 3.7. Chromium, oxygen, potential temperature, salinity, nitrate and $\mathrm{N}^{*}$ data is plotted for a water column profile taken in the center of the Santa Barbara Basin. Note that the depth of the western sill, that connects the Santa Barbara Basin to the North Pacific, is $475 \mathrm{~m}$. Nutrient data was kindly provided by Tyler Coale and Kenneth Bruland, who are both located at University of California, Santa Cruz. Error bars of $\mathrm{Cr}$ isotope ratios at 2SD. 
station $2 \mathrm{~T}$

$\sigma_{\theta}$ adjusted SAFe station
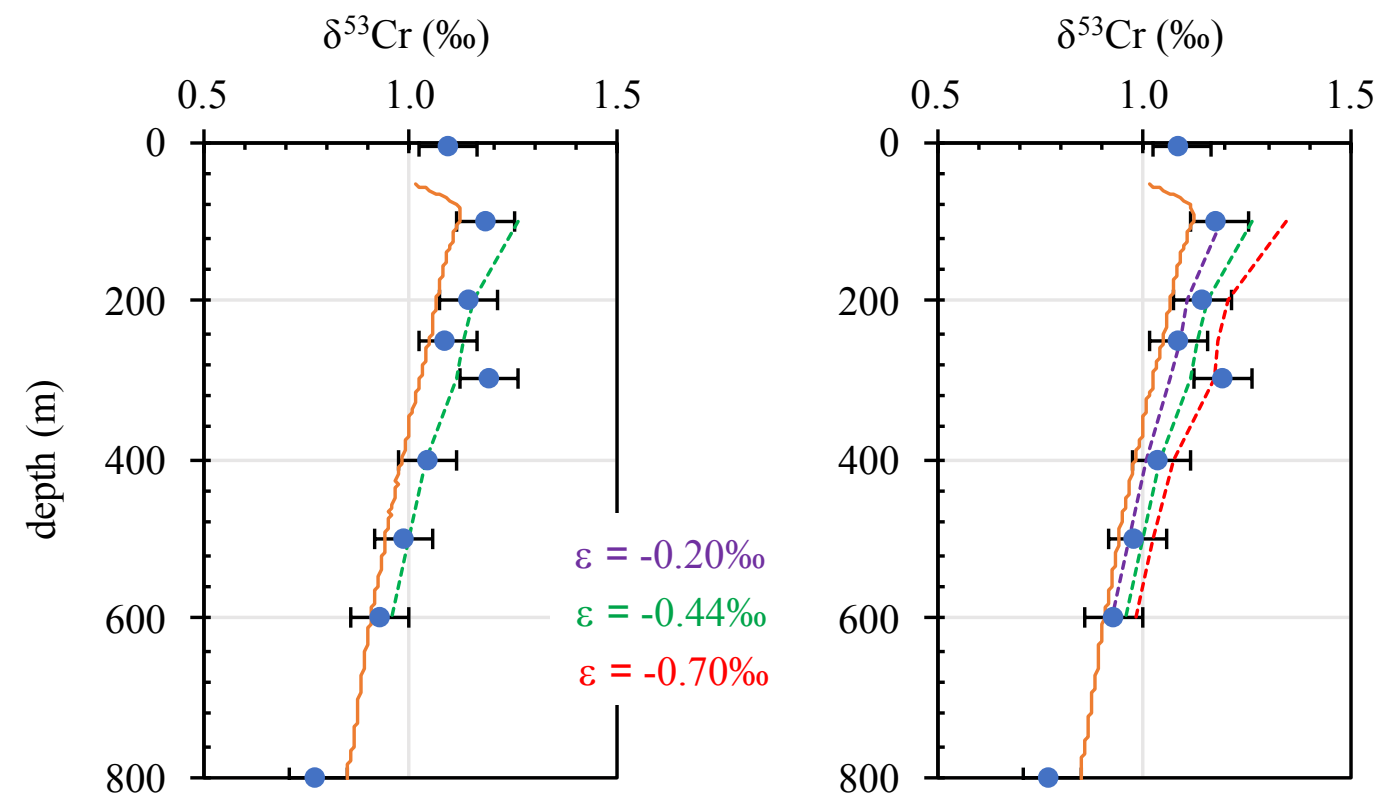

Figure 3.8. Using the Rayleigh distillation equation, we model the Cr isotope ratio of the residual $\mathrm{Cr}(\mathrm{VI})$ fraction after $\mathrm{Cr}$ reduction. For this purpose, three fractionation factors have been chosen. The fractionation factor listed in green font recreates the observed profiles at station $2 \mathrm{~T}$ best. 


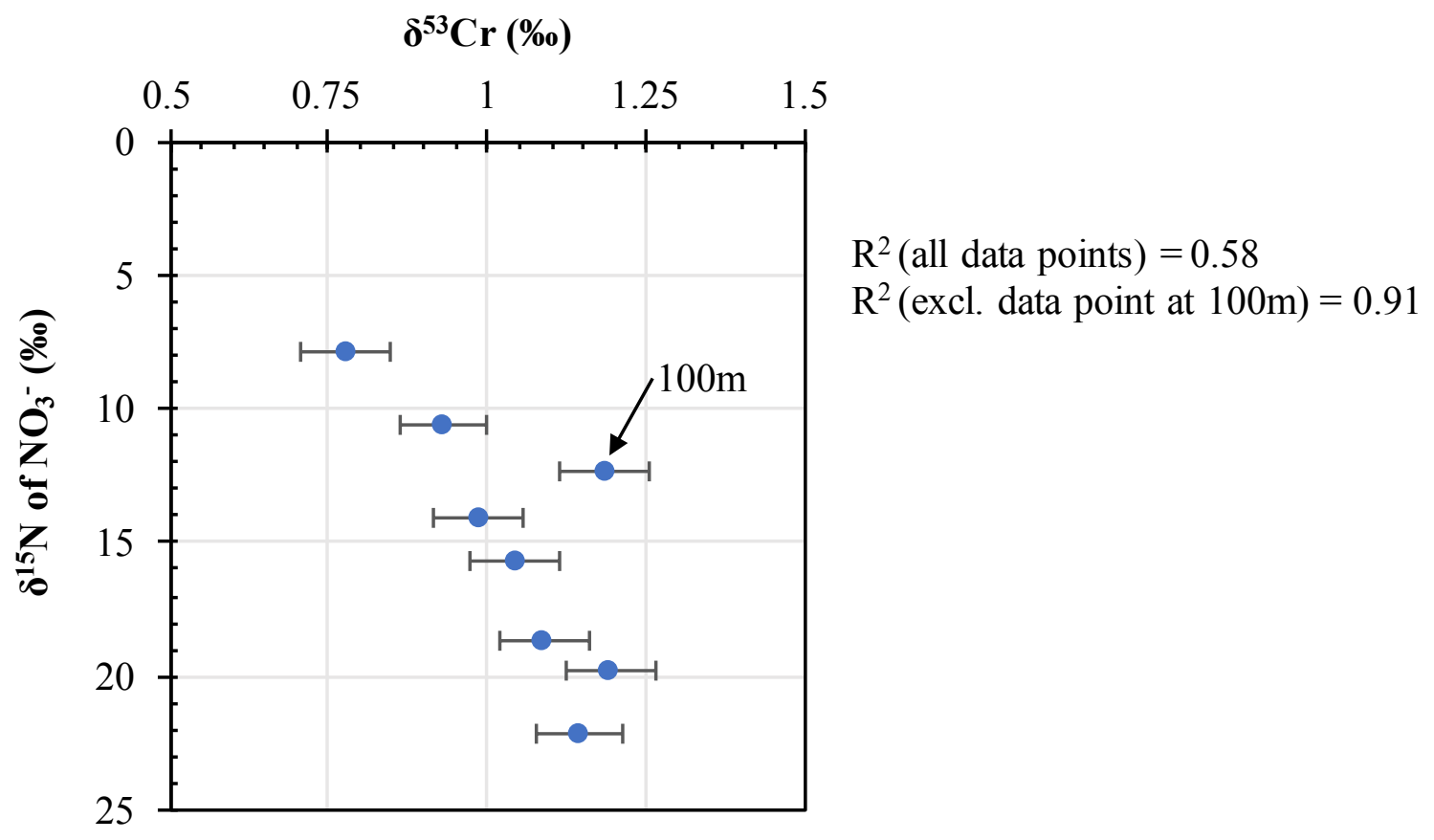

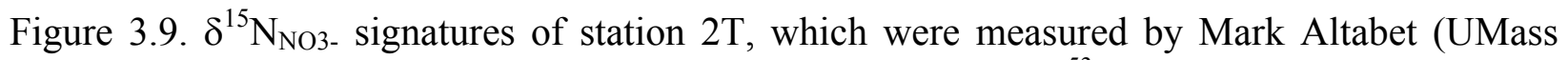
Dartmouth) and Annie Bourbonnais (WHOI), are plotted against $\delta^{53} \mathrm{Cr}$ signatures of station 2T. 
SBB station

$\sigma_{\theta}$ adjusted SAFe station
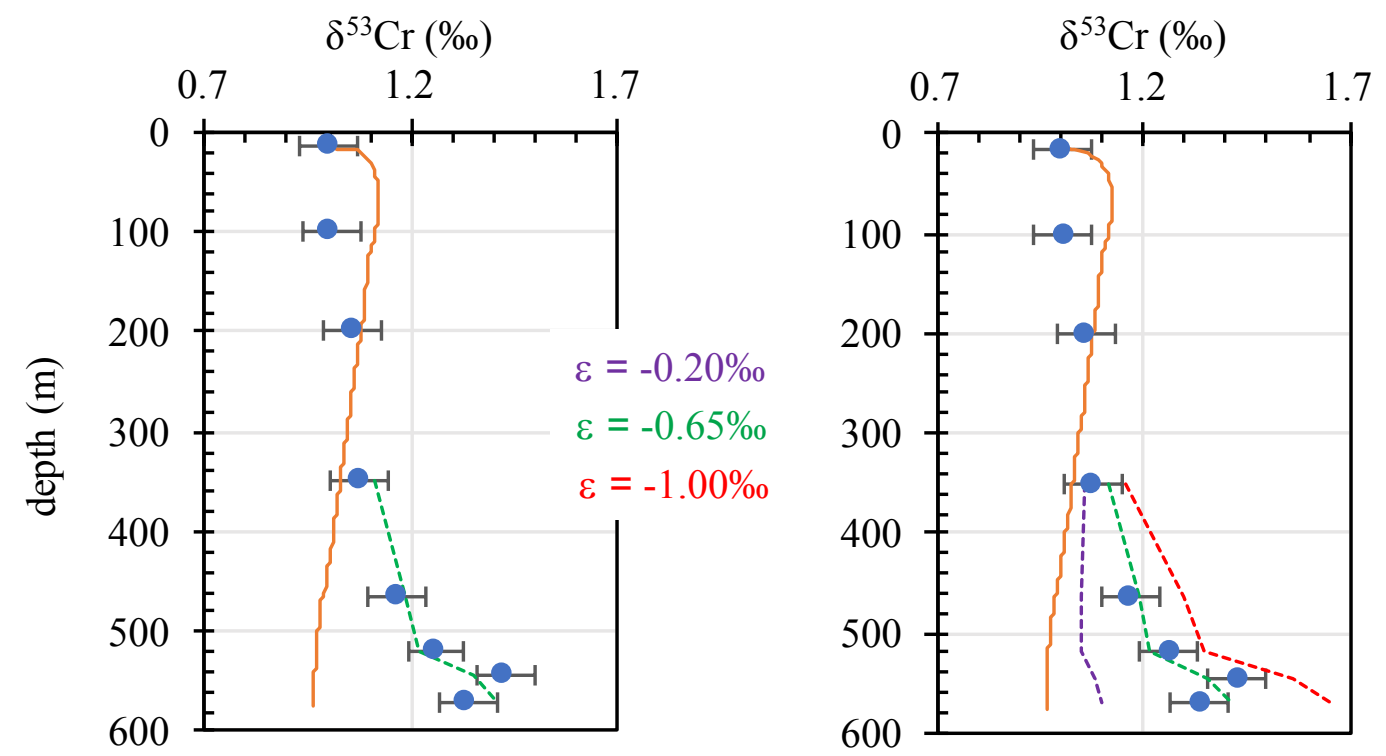

Figure 3.10. Using the Rayleigh distillation equation, we model the $\mathrm{Cr}$ isotope ratio of the residual $\mathrm{Cr}$ (VI) fraction after $\mathrm{Cr}$ reduction. For this purpose, three fractionation factors have been chosen. The fractionation factor listed in green font recreates the observed profiles at our Santa Barbara Basin best. 

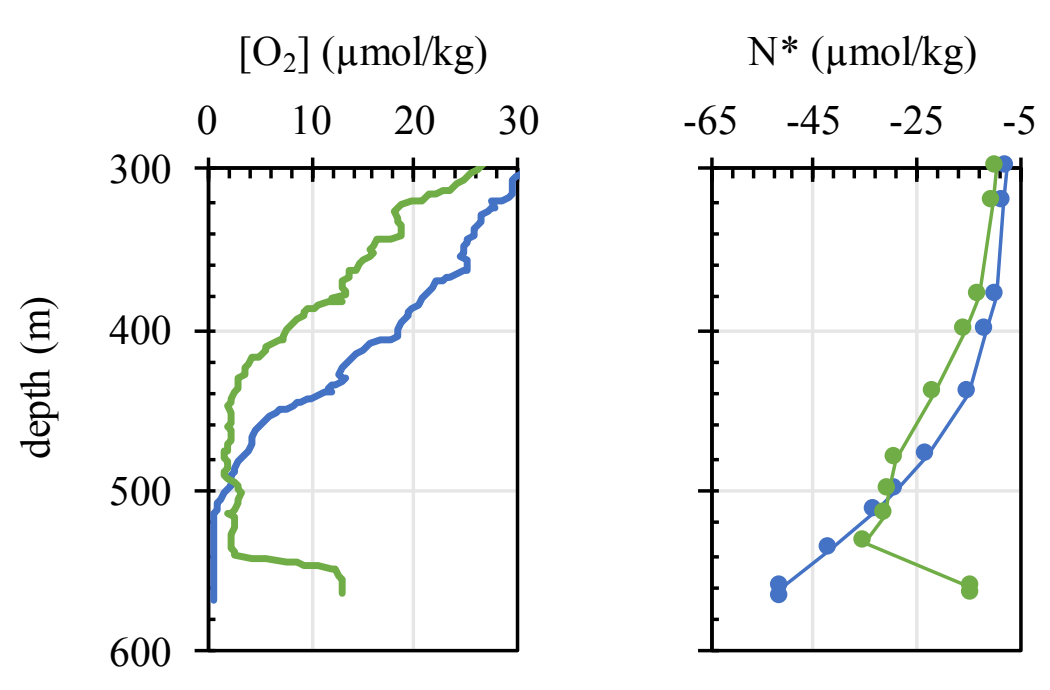

July 21, 2014

Aprill 13, 2014

Figure 3.11. Oxygen concentrations and $N^{*}$ data measured in the Santa Barbara Basin in April and July 2014 are shown. Oxygen and nutrient data, which were used to calculate $\mathrm{N}^{*}$, originate from quarterly expeditions that are conducted by the California Cooperative Oceanic Fisheries Investigations (CalCOFI). 


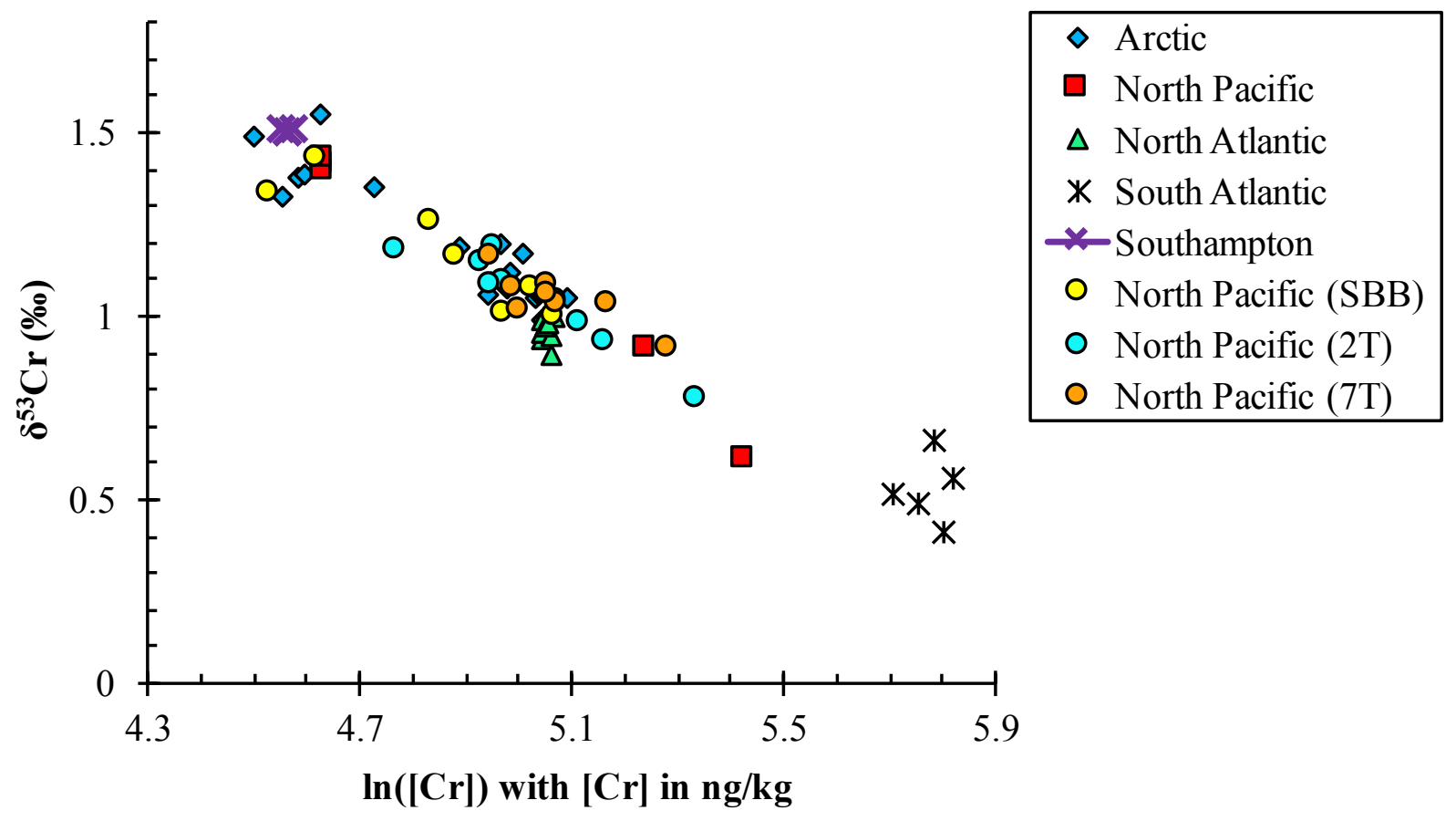

Figure 3.12. Samples from stations 2T, 7T and our Santa Barbara Basin site are plotted in $\delta^{53} \mathrm{Cr}$ $\ln ([\mathrm{Cr}])$ space alongside published seawater Cr isotope data (Bonnand et al., 2013; Scheiderich et al., 2015). 


\section{Chapter 4. Investigating Cr Cycling on the Arctic Chukchi Shelf and in the Central Artic Ocean using Cr Stable Isotopes}

\subsection{Introduction}

North Pacific surface waters at station PAPA $\left(50^{\circ} \mathrm{N} 145^{\circ} \mathrm{W}\right.$, Scheiderich et al., 2015) and at the SAFe station $\left(30^{\circ} \mathrm{N} 140^{\circ} \mathrm{W}\right.$, chapter 2 of this thesis) have higher $\mathrm{Cr}$ concentrations and lower $\mathrm{Cr}$ isotope ratios than the Pacific layer waters of Arctic stations (Scheiderich et al., 2015). This implies that $\mathrm{Cr}$ in Pacific waters is being modified during transport into the Arctic Ocean (Scheiderich et al., 2015).

Pacific inflow to the Arctic Ocean occurs through the Bering Strait via the highly productive surface waters of the Chukchi shelf. Scheiderich et al. (2015) suggested that the Cr modification of Pacific source waters occurs within the Chukchi shelf waters as biological productivity may promote $\mathrm{Cr}$ reduction (by an unspecified mechanism) followed by export of reduced $\mathrm{Cr}$ to the sediments.

The high primary productivity of the Chukchi Sea, ultimately leads to anoxia in the underlying sediments due to the respiration of high fluxes of exported organic matter. In the absence of oxygen, microbes break down organic matter using alternative electron acceptor such as nitrate. The reduction process of nitrate (=fixed nitrogen) to $\mathrm{N}_{2} \mathrm{O}$ and $\mathrm{N}_{2}$ gas is called denitrification. Several studies have observed high rates of denitrification in the anoxic sediments of the shallow Chukchi shelf (Chang and Devol, 2009; Devol et al., 1997; Mills et al., 2015). Nitrogen cycling on the Chukchi shelf is complex and more accurately described as a coupled partial nitrificationdenitrification (CPND) process (Granger et al., 2011; Mills et al., 2015). This process leads to traceable negative $\mathrm{N}^{*}$ values and to traceable ${ }^{15} \mathrm{~N}$-enriched and ${ }^{18} \mathrm{O}$-depleted isotope signatures of $\mathrm{NO}_{3}{ }^{-}$(Granger et al., 2011). Since the Chukchi shelf is very shallow $(\sim 50 \mathrm{~m})$, the denitrification signal can be transferred from the sediment - seawater interface to the entire water column. For example, brine rejection in the early winter leads to convective overturning and mixing of the shallow water column (Pickart et al., 2016). Since sedimentary denitrification rates do not vary 
with season (Chang and Devol, 2009), both PSW and PWW may carry this denitrification signal from the Chukchi shelf into the Canada Basin (Brown et al., 2015).

Since chromate's reduction potential at seawater $\mathrm{pH}$ is only slightly lower than that of nitrate and higher than that of sulfate (Stumm and Morgan, 2012), it is conceivable that microbes directly reduce chromate in the anoxic Chukchi shelf sediment. Additionally, potent $\mathrm{Cr}(\mathrm{VI})$ reductants such as $\mathrm{Fe}(\mathrm{II})$ and sulfide may be produced in and released from the anoxic sediments.

We had the opportunity to participate in the 2015 US Arctic GEOTRACES expedition which featured sampling stations in the North Pacific Ocean, the Bering Strait, on the Chukchi Shelf and in multiple basins of the Western Arctic Ocean (figure 4.1). Here, we present Cr concentration and $\mathrm{Cr}$ isotope data from a station on the shallow Chukchi shelf and from a central Arctic station.

\subsection{Seawater sampling and oceanographic setting}

A 23-depth water column profile was taken during the US Arctic GEOTRACES expedition aboard the U.S. Coast Guard Cutter Healy (HLY1502, GN01) at $85.1347^{\circ} \mathrm{N}$ and $150.0967^{\circ} \mathrm{W}$ (station 43, figure 4.1). This station is located on the Alpha ridge with the Canada basin to the south and the Makarov basin to the north. At the time of occupation (September $15^{\text {th }}$ and $16^{\text {th }} 2015$ ) surface waters were covered by thick ice floes.

A second water column profile was retrieved on the Chukchi shelf (station 61 , figure 4.1 ) at $72.8^{\circ} \mathrm{N}$ and $159.6^{\circ} \mathrm{W}$ on October $10^{\text {th }} 2015$. A bottom depth of $82 \mathrm{~m}$ was recorded at this station.

All seawater samples were collected with the US GEOTRACES Carousel, which contains 24 Teflon-coated 12-L GO-FLO bottles (Cutter and Bruland, 2012). On deck the GO-FLO bottles were removed from the rosette and transferred into a clean van for sampling. Within 2 hours of collection the seawater was filtered with either a pre-cleaned $0.2 \mu \mathrm{m}$ AcroPak Supor capsule or a pre-cleaned $25 \mathrm{~mm}$ membrane filter (Supor, $0.45 \mu \mathrm{m}$ ). The $2 \mathrm{~L}$ seawater samples were acidified to $\mathrm{pH} \sim 2$ with $4 \mathrm{ml}$ of $6 \mathrm{~N} \mathrm{HCl}$ in December 2015 and processed for total $\mathrm{Cr}$ isotope signatures in December 2016 (station 43) and in April 2017 (station 61). 


\subsection{Methods}

Total seawater $\mathrm{Cr}$ isotope signatures were determined via a procedure that has been presented in detail in thesis chapter 2. Here, an abbreviated version is given. First, all $\mathrm{Cr}$ in a given seawater sample is converted to the trivalent $\mathrm{Cr}$ form by acidification and prolonged storage at $\mathrm{pH} 2$ (Semeniuk et al., 2016). Subsequently, a ${ }^{50} \mathrm{Cr}-{ }^{54} \mathrm{Cr}$ double spike (also present as $\mathrm{Cr}(\mathrm{III})$ ) is equilibrated with the seawater sample over a 3-day time period. A double spike technique was chosen since it permits the correction of mass fractionations that occur during sample processing and instrumental analysis (Rudge et al., 2009). Total $\mathrm{Cr}$ is preconcentrated as $\mathrm{Cr}(\mathrm{III})$ by $\mathrm{Mg}(\mathrm{OH})_{2}$ coprecipitation (Semeniuk et al., 2016; $\mathrm{Wu}$ and Boyle, 1997). The resulting $\mathrm{Mg}(\mathrm{OH})_{2}$ pellet is dissolved slightly beyond the neutralization point using $\mathrm{HCl}$, such that $\mathrm{Cr}$ is present in a $0.02 \mathrm{M}$ $\mathrm{HCl}$ medium. $\mathrm{Cr}$ is separated from isobaric (i.e. Ti, V, Fe) and polyatomic interferences (e.g. S) through a series of $3 \mathrm{AG} 1-\mathrm{X} 8$ anion-exchange columns, the first of which requires Cr to be present in the oxidized form. Cr oxidation is performed using ammonium persulfate (Götz and Heumann, 1988) under carefully controlled $\mathrm{pH}$, temperature and time settings in order to prevent backreduction of $\mathrm{Cr}(\mathrm{VI})$ due to $\mathrm{H}_{2} \mathrm{O}_{2}$ generation (Palme, 1920). Now that $\mathrm{Cr}$ is present as negatively charged $\mathrm{CrO}_{4}{ }^{2-}$, it sticks to the binding sites of the first anion exchange column, whereas the matrix cations (e.g. Mg, V, Ti, Fe) do not stick (Ball and Bassett, 2000). The second anion exchange column functions as a sulfur cleanup step with $\mathrm{SO}_{4}{ }^{2-}$ again binding to the resin, while positively charged $\mathrm{Cr}(\mathrm{III})$ ions pass through. A third column step eliminates Fe traces as Fe sticks to the resin as negatively charged $\mathrm{FeCl}_{4}{ }^{-}$complexes (Yamakawa et al., 2009) and positively charged $\mathrm{Cr}(\mathrm{III})$ ions do not. Mass abundances $(49,50,51,52,53,54,56)$ in the purified sample were detected on the IsoProbe. This MC-ICP-MS contains a hexapole collision chamber that removes many polyatomic interferences and thereby allows $\mathrm{Cr}$ isotope analysis in low resolution mode. During tuning of the IsoProbe the $\mathrm{Cr}$ signal is maximized relative to the polyatomic sulfur signal. Seawater isotopic signatures are reported as $\delta^{53} \mathrm{Cr}$ values in per mil by comparing the ${ }^{53} \mathrm{Cr} /{ }^{52} \mathrm{Cr}$ ratio of a sample to that of SRM979 (equation 1).

$$
\delta^{53} \operatorname{Cr}(\% 0)=\left(\frac{\left(\frac{{ }^{53} C r}{{ }^{52} C r}\right)_{\text {Sample }}}{\left(\frac{{ }^{53} C r}{{ }^{52} C r}\right)_{\text {SRM } 979}}-1\right) \times 1000
$$




\subsubsection{Other oceanographic parameters}

$\mathrm{Fe}(\mathrm{II})$ concentrations were determined immediately after sample retrieval by Maija I. Heller (Ifremer).

Salinity, temperature, and pressure were measured with the CTD sensors of the GEOTRACES carousel. Potential temperature was derived from this data using a MATLAB script that is based on the international thermodynamic equation of seawater (IOC et al., 2010) and provided by the Gibbs-SeaWater (GSW) Oceanographic Toolbox (McDougall and Barker, 2011).

Nutrient (i.e. $\left[\mathrm{NO}_{3}{ }^{-}\right],\left[\mathrm{PO}_{4}{ }^{3-}\right],[\mathrm{dSi}]$ ) and oxygen concentrations were measured by ODF scientists from UCSD/SIO under the leadership of James H. Swift.

The tracer $\mathrm{N}^{*}$ measures $\mathrm{NO}_{3}{ }^{-}$loss or gain relative to the Redfield $\left[\mathrm{NO}_{3}{ }^{-}\right]:\left[\mathrm{PO}_{4}{ }^{3-}\right]$ relationship (equation 2; Deutsch et al., 2001; Gruber and Sarmiento, 1997). Generally, negative N* values indicate $\mathrm{NO}_{3}{ }^{-}$loss due to denitrification, whereas positive $\mathrm{N}^{*}$ values indicate $\mathrm{NO}_{3}{ }^{-}$gain due to $\mathrm{N}_{2}$ fixation.

$$
N^{*}\left(\frac{\mu m o l}{k g}\right)=\left(\left[N O_{3}^{-}\right]+\left[N_{2}^{-}\right]+\left[N H_{4}^{+}\right]\right)-16 \times\left[\mathrm{PO}_{4}^{3-}\right]+2.9 \frac{\mu m o l}{k g}
$$

Taking advantage of the distinct nitrate : phosphate concentration ratios of Pacific and Atlantic waters, the fraction of Pacific water $\left(\mathrm{FRAC}_{P W}\right)$ in a given Arctic Ocean sample was calculated (Jones et al., 2003, 1998). While the slope of the $\mathrm{N}: \mathrm{P}$ line exhibited by the pure endmembers is anchored in the Redfield ratio (Redfield, 1958) and therefore similar, the lines themselves are offset. At the same phosphate concentration, Pacific water contains less nitrate than Atlantic water due to denitrification within the basin. In making this comparison, we are aware of nitrate $\delta^{18} \mathrm{O}$ data indicating that the inflowing Pacific nitrate is completely recycled over the shelf (Granger et al., 2011); we simply note that both nitrate and phosphate are both largely remineralized, hence retaining the Pacific N:P relationship. Following the example of Jones et al. (1998), we plot nitrate and phosphate data taken within the Arctic Ocean (Station 7 - Station 48) during the 2015 US 
GEOTRACES Arctic expedition (figure 4.2). Linear regression (courtesy of James H. Swift, SIO) is used to arrive at equations 3 and 4 which describe the two endmembers:

$$
\begin{gathered}
\mathrm{PO}_{A W}=\left(0.0792 \times \mathrm{NO}_{O B S}\right)-0.135 \\
\mathrm{PO}_{P W}=\left(0.0711 \times \mathrm{NO}_{O B S}\right)+0.720
\end{gathered}
$$

$\mathrm{PO}_{A W}$ refers to the phosphate concentration the pure Atlantic water endmember would have at the observed nitrate concentration $\left(=\mathrm{NO} 3_{O B S}\right)$ of a given sample. Similarly, $\mathrm{PO} 4_{P W}$ refers to the

phosphate concentration the pure Pacific water endmember would have at the observed nitrate concentration $\left(=\mathrm{NO} 3_{O B S}\right)$ of a given sample. Comparing the observed phosphate concentration of the sample in question $\left(\mathrm{PO}_{O B S}\right)$ to the calculated phosphate concentration of the pure endmembers, allows us to quantify the fraction of Pacific water $\left(\mathrm{FRAC}_{P W}\right)$ in the sample:

$$
\mathrm{FRAC}_{P W}=\frac{\mathrm{PO}_{O B S}-\mathrm{PO}_{A W}}{\mathrm{PO}_{P W}-\mathrm{PO}_{A W}}
$$

\subsection{Results and Discussion}

\subsubsection{Shallow Chukchi Shelf (Station 61)}

The properties of the Pacific inflow to the Arctic Ocean vary seasonally, giving rise to Pacific Winter Water (PWW) and Pacific Summer Water (PSW). Looking at the water column of station 61 on the shallow Chukchi shelf, the upper 40m are occupied by PSW, whereas PWW resides in the bottom water (figure 4.3). PWW is characterized by decreased (but still fully oxic) $\mathrm{O}_{2}$ levels, lower temperatures, higher salinity and higher dissolved silicate levels. Most strikingly, the bottom waters are characterized by very negative $\mathrm{N}^{*}$ values, which indicate denitrification.

At station $61, \mathrm{Cr}$ isotope ratios shift dramatically from $\sim 1.40 \%$ in the upper $20 \mathrm{~m}$ to $3.85 \%$ and 4.15\% below 50m depth (figure 4.4). These are, by far, the heaviest seawater $\mathrm{Cr}$ isotope signatures 
measured within this thesis, as well as reported in the seawater $\mathrm{Cr}$ isotope literature (Bonnand et al., 2013; Scheiderich et al., 2015). At the same time, Cr concentrations first increase slightly between the surface and $20 \mathrm{~m}$ depth $(1.63 \mathrm{nmol} / \mathrm{kg}$ to $1.95 \mathrm{nmol} / \mathrm{kg})$ before dropping to 1.52 $\mathrm{nmol} / \mathrm{kg}$ below $50 \mathrm{~m}$. These observations are consistent with $\mathrm{Cr}$ reduction, which results in lower [Cr] and heavier $\delta^{53} \mathrm{Cr}$. However, the magnitude of this $\delta^{53} \mathrm{Cr}$ increase is in the upper range of observed isotope effects in laboratory experiments and field data (e.g. Ellis et al., 2002).

\subsubsection{1. $\delta^{53} \mathrm{Cr}-\ln ([\mathrm{Cr}])$ plot}

In $\delta^{53} \mathrm{Cr}-\ln ([\mathrm{Cr}])$ space, the Chukchi shelf samples taken at $55 \mathrm{~m}$ and $80 \mathrm{~m}$ depth plot far from the Rayleigh-like fractionation line, that was previously observed for samples presented by Bonnand et al. (2013), Scheiderich et al. (2015), and in chapters 2 and 3 of this thesis (figure 4.5). This implies a much higher fractionation factor than the average $\varepsilon=0.80 \%$ previously observed for the global Cr array (Scheiderich et al., 2015) and perhaps a novel isotope fractionation process at work. In $\delta^{53} \mathrm{Cr}-\ln ([\mathrm{Cr}])$ space, the Chukchi shelf samples taken in the upper $20 \mathrm{~m}$ coincide with Arctic surface mixed layer samples analyzed by Scheiderich et al. (2015).

We proceed by discussing potential Cr reduction mechanisms that may occur in the oxic bottom waters and in the anoxic sediment pore waters of the Chukchi shelf.

\subsubsection{2. $\mathrm{Cr}$ (VI) reduction by $\mathrm{Fe}(\mathrm{II})$ in the oxic bottom waters}

By far the highest dFe(II) concentrations of the entire US Arctic Ocean expedition were detected at station 61 , at depths of $55 \mathrm{~m}(\sim 0.1 \mathrm{nM})$ and $80 \mathrm{~m}(\sim 0.5 \mathrm{nM})$ (figure 4.4; Maija I. Heller, personal communication). The only viable source of this reduced Fe species are the underlying anoxic sediments, where concentrations can be expected to be even higher than in the bottom waters. Dissolved Fe(II) is a potent reductant of Cr(VI), with the reaction occurring on the order of minutes at micromolar concentrations in the laboratory (Eary and Rai, 1988).

$$
3 \mathrm{Fe}^{2+}+\mathrm{CrO}_{4}^{2-}+16 \mathrm{H}^{+}=3 \mathrm{Fe}^{3+}+\mathrm{Cr}^{3+}+8 \mathrm{H}_{2} \mathrm{O}
$$


$\mathrm{Cr}$ reduction by $\mathrm{Fe}$ (II) would likely generate isotopically light $\mathrm{Cr}$ (III), which is particle-reactive. $\mathrm{Cr}(\mathrm{III})$ would presumably be scavenged by particles, and residual heavy $\mathrm{Cr}(\mathrm{VI})$ would remain in the lower water column.

Sedlak and Chan (1997) investigated the kinetics of this reaction and found that it was first order with respect to both $\mathrm{Fe}(\mathrm{II})$ and $\mathrm{Cr}(\mathrm{VI})$. Under the room temperature laboratory conditions of $\sim 1$ $\mu \mathrm{M} \mathrm{Fe}(\mathrm{II})$, the $\mathrm{Cr}(\mathrm{VI})$ half-life was a few minutes. With $\mathrm{Fe}(\mathrm{II})$ concentrations $\sim 20000 \mathrm{x}$ lower and at $4{ }^{\circ} \mathrm{C}$, the $\mathrm{Cr}(\mathrm{VI})$ half-life would be about two - three months.

\subsubsection{3. $\mathrm{Cr}$ (VI) reduction in the anoxic sediment pore waters}

$\mathrm{Cr}$ is observed to be enriched in reducing sediments (Reinhard et al., 2014). If $\mathrm{Cr}$ reduction is happening in the anoxic pore waters of the sediment, then there would be a steep $\mathrm{Cr}$ concentration gradient near the sediment-water interface (see section 4.4.1.5). The transfer of $\mathrm{Cr}$ from the bottom waters into the sediments, would result in lower $\mathrm{Cr}$ concentrations in the bottom waters.

But a similar steep concentration gradient is known to occur for nitrate in the upper pore waters of reducing sediments, and evidence suggests that total diffusion of nitrate into the sedimentary denitrification zone produces a relatively minor nitrate $\delta{ }^{15} \mathrm{~N}$ fractionation $(\sim 1.5 \%$; Brandes and Devol, 2002, 1997). In the absence of contrary information, we should expect a similar result for $\mathrm{Cr}$ isotope fractionation, hence although sedimentary $\mathrm{Cr}$ reduction is a plausible mechanism for reducing bottom water chromium concentrations and enriching the $\mathrm{Cr}$ concentration of reducing sediments, it would not appear to be a viable mechanism for the heavy $\mathrm{Cr}$ isotope enrichments that we observe.

There is very little published pore water data for chromium. Brumsack and Gieskes (1983) generally observed an increase of total $\mathrm{Cr}$ concentrations with depth in sediment pore waters in the oxygen minimum zone of the Gulf of California. As this increase in [Cr] was correlated to an increase in 'a yellow substance', which they classified as organic matter, they attributed it to remineralization of $\mathrm{Cr}$ rich organic matter. Shaw et al. (1990) observed a peak in $\mathrm{Cr}$ concentrations at the oxic/suboxic pore water interface which they ascribed to a recent deepening of the oxic zone, 
triggering oxidative release of $\mathrm{Cr}(\mathrm{III})$ from minerals and particle surfaces. $\mathrm{Cr}$ concentrations in pore waters fell within the suboxic zone indicating $\mathrm{Cr}$ removal via reduction.

\subsubsection{4. $\mathrm{Cr}(\mathrm{VI})$ reduction mechanisms in the anoxic sediment pore waters}

In the anoxic sediment zone, $\mathrm{Fe}(\mathrm{III})$ in Fe(III)hydroxides can be reduced to dFe(II) by microbes. Shewanella is such a bacterium capable of dissimilatory Fe(III) reduction (Caccavo et al., 1992; Wielinga et al., 2001). The produced dFe(II) can swiftly reduce $\mathrm{Cr}(\mathrm{VI})$ with reaction times on the order of minutes (Eary and Rai, 1988). In this process dFe(II) is oxidized to dFe(III), which is a highly insoluble species that will likely precipitate again as $\mathrm{Fe}(\mathrm{III})$ hydroxides. The produced $\mathrm{Cr}$ (III) may be immobilized by incorporation into Fe(III)hydroxides, and by scavenging onto the surface of $\mathrm{Fe}(\mathrm{III})$ hydroxide minerals or other particles in the sediment. As previously mentioned, high levels of $\mathrm{dFe}(\mathrm{II})$ were detected in the bottom waters at station 61 (figure 4.4; Maija I. Heller, personal communication). This serves as indirect evidence for the presence of high concentrations of $\mathrm{dFe}(\mathrm{II})$ in the underlying sediments, so it is likely that some significant $\mathrm{Cr}$ reduction is occurring within them.

Additionally, acid volatile sulfides (AVS) have been recognized as potent reductants of $\mathrm{Cr}$ in sediments (Graham and Bouwer, 2010; Pettine et al., 1994). AVS is an operational measurement that includes multiple dissolved sulfide reductants (e.g. $\mathrm{H}_{2} \mathrm{~S}, \mathrm{HS}^{-}$, polysulfides) and mineral sulfide reductants (e.g. FeS, $\mathrm{Fe}_{3} \mathrm{~S}_{4}$ ).

Furthermore, $\mathrm{Cr}(\mathrm{VI})$ may itself be used directly as an electron acceptor during anaerobic respiration by microbes. Several studies have observed high rates of denitrification in the anoxic sediments of the shallow Chukchi shelf (Chang and Devol, 2009; Devol et al., 1997; Mills et al., 2015 ) and the energy gain for the $\mathrm{Cr}(\mathrm{VI})-\mathrm{Cr}(\mathrm{III})$ redox couple is only slightly lower than that of the $\mathrm{NO}_{3}{ }^{-}-\mathrm{NO}_{2}{ }^{-}$redox couple (Stumm and Morgan, 2012).

Fendorf et al. (2000) compared $\mathrm{Cr}(\mathrm{VI})$ reduction rates for $\mathrm{dFe}(\mathrm{II})$, dS(-II) and direct microbial reduction. At a $\mathrm{pH}$ of $\sim 8$, which we assume to prevail in the sediment pore waters, reduction rates 
for Fe(II) far exceed those of sulfide and microbial reduction. This makes Fe(II) the most likely reductant in the anoxic sediments of the Chukchi shelf.

\subsubsection{Cr concentration gradient for the possibility of sedimentary $\mathrm{Cr}$ reduction}

Following the assumption that all observed $\mathrm{Cr}$ reduction occurs in the anoxic sediment pore waters of the Chukchi shelf, a pore water $\mathrm{Cr}$ concentration gradient can be calculated using Fick's first law of diffusion (Fick, 1855). Applying this law, the Cr removal flux over the Chukchi shelf's anoxic sediment area should equal the diffusion coefficient $(D)$ multiplied by the pore water $\mathrm{Cr}$ concentration gradient $(\Delta[C r] / \Delta z$ ) (equation 7). In order to calculate the $\mathrm{Cr}$ removal flux over the shelf's anoxic sediment area (equation 8), we need to estimate three terms: the difference in $\mathrm{Cr}$ concentration of the incoming Pacific waters (SAFe station, $[\mathrm{Cr}]=3.16 \mathrm{nmol} / \mathrm{kg}$, chapter 2) and the bottom waters of station $61([\mathrm{Cr}]=1.52 \mathrm{nmol} / \mathrm{kg})$, the Pacific inflow through the Bering Strait $\left(0.8 \times 10^{6} \frac{\mathrm{m}^{3}}{\mathrm{~s}}\right.$, Beszczynska-Möller et al. (2011)), and the area that the shallow Chukchi shelf spans $\left(3.54 \times 10^{11} \mathrm{~m}^{2}\right)$.

$$
\begin{aligned}
& \text { Cr removal flux over the Chukchi shelf's anoxic sediment area }=D \times \frac{\Delta[\mathrm{Cr}]}{\Delta z} \\
& \frac{\Delta[\mathrm{Cr}]_{\text {Pacific-Arctic }} \times \text { Pacific inflow through the Bering Strait }}{\text { shallow Chukchi shelf area }}=D \times \frac{\Delta[\mathrm{Cr}]}{\Delta z}
\end{aligned}
$$

Using these estimates and a typically diffusion coefficient of $2.5 \times 10^{-5} \frac{\mathrm{cm}^{2}}{\mathrm{~s}}$, we arrive at a pore water Cr concentration gradient of $\sim 15 \frac{\mathrm{nM}}{\mathrm{cm}}$. Given that the bottom waters only hold $1.56 \mathrm{nM}$ of Cr, $\mathrm{Cr}$ in sediment pore waters would get exhausted over $\sim 1 \mathrm{~mm}$.

However, as noted above, sedimentary $\mathrm{Cr}$ reduction should not be expected to contribute much to the observed bottom water $\mathrm{Cr}$ isotope fractionation. Although the sedimentary sink could be a significant source of $\mathrm{Cr}$ loss to the sediments, there must be a comparably significant mechanism that can produce a $\mathrm{Cr}$ isotope signal. As noted above, we suggest that $\mathrm{Fe}(\mathrm{II})$ diffusion from the sediments into the oxic bottom water - followed by $\mathrm{Cr}(\mathrm{VI})$ reduction to $\operatorname{Cr}(\mathrm{III})$ - may be this 
mechanism. This is supported by the observed high bottom water Fe(II) concentrations and the kinetics of the reaction.

\subsubsection{Central Arctic (Station 43)}

The water column at station 43 above the Alpha Ridge is composed of both Pacific and Atlantic waters. When the fraction of Pacific water in each sample at station 43 is calculated using equations 3 - 5 (figure 4.6), it becomes evident that the upper 100m predominantly contain Pacific water (e.g. 97\%-76\%, generally decreasing with depth). Below $100 \mathrm{~m}$, Pacific water is no longer the dominant water mass and is completely absent below $\sim 250 \mathrm{~m}$ depth.

Considering figures 4.6 and 4.7 in tandem, we attempt to identify water masses. A first temperature maximum between $35 \mathrm{~m}$ and $54 \mathrm{~m}$ indicates the presence of PSW, whereas a temperature minimum between $74 \mathrm{~m}$ and $99 \mathrm{~m}$ indicates the presence of PWW. Furthermore, the highest silicate and phosphate concentrations, relatively high nitrate and relatively low oxygen concentrations, and the most negative $\mathrm{N}^{*}$ values are all recorded at a depth of $99 \mathrm{~m}$ and match commonly accepted characteristics of PWW (Jones and Anderson, 1986; Woodgate et al., 2005). Fram Strait Branch Waters (FSBW) give rise to a temperature maximum (Rudels et al., 2013), which occurs at 329m at station 43. Beneath this maximum, an inflection point occurs in potential temperature - salinity space at $\sim 700 \mathrm{~m}$ depth, where colder Barents Sea Branch Water (BSBW) becomes dominant (Rudels et al., 2013). Bottom waters with relatively lower oxygen concentrations are located below the BSBW (below $\sim 1200 \mathrm{~m}$ depth).

At station 43, a general increase of chromium concentrations and a general decrease of $\mathrm{Cr}$ isotopic signatures occurs synchronously with depth (figure 4.6). An analogous 'mirror image' of $\mathrm{Cr}$ concentration and $\mathrm{Cr}$ isotope profiles was previously observed by Scheiderich et al. (2015) in the Canadian basin (figure 4.1). At station 43, both the Cr concentration and isotope profile develop proportionally to the fraction of Pacific water. Consequently, we can infer that the mixing of Pacific water (lower [Cr], heavier $\delta^{53} \mathrm{Cr}$ ) and Atlantic water (higher $[\mathrm{Cr}]$, lighter $\delta^{53} \mathrm{Cr}$ ) gives rise to the overall shape of the Cr profiles. We proceed to describe the $\mathrm{Cr}$ profiles in greater detail. 
The lowest total chromium concentration $(1.62 \mathrm{nmol} / \mathrm{kg})$ at station 43 is found at $\sim 19 \mathrm{~m}$ depth (figure 4.6). Concentrations increase generally over the upper $\sim 224 \mathrm{~m}$ to $2.58 \mathrm{nmol} / \mathrm{kg}$ and are maintained through $\sim 1000 \mathrm{~m}$. Over the same depth span, the $\delta^{53} \mathrm{Cr}$ isotope signatures drop from $+1.65 \%$ to $+0.87 \%$. The presence of PWW at depth $99.6 \mathrm{~m}$ is reflected as an indentation towards slightly lower $\mathrm{Cr}$ concentrations and slightly heavier $\mathrm{Cr}$ isotope ratios.

Both $\mathrm{Cr}$ concentration and $\mathrm{Cr}$ isotope profiles show fluctuations that exceed analytical uncertainties at intermediate depths. While the variations in $\delta^{53} \mathrm{Cr}$ are marginally significant when considering that each measurement has an uncertainty of at least $\pm 0.07 \%$ ( $2 \mathrm{SD}$ ), the variations in $[\mathrm{Cr}]$ are significant (precision for reference sample: $[\mathrm{Cr}]=3.30 \pm 0.01 \mathrm{nmol} / \mathrm{kg}(2 \mathrm{SD}), \mathrm{n}=3)$. A possible explanation is 'the existence of several cyclonic circulation cells at intermediate depths, closely linked to topography' (J. H. Swift, personal communication), which have been confirmed by cruise data. Specifically, the circulation of older and colder Atlantic water was observed above the Alpha Ridge (J. H. Swift, personal communication), where our station is located. In general, a certain degree of interweaving of waters from the Makarov Basin and the Canadian Basin can be expected as station 43 sits on a ridge between the two basins.

Within the bottom waters (starting at $\sim 1200 \mathrm{~m}$ depth with declining $\left[\mathrm{O}_{2}\right]$ ), both $\mathrm{Cr}$ concentrations and $\mathrm{Cr}$ isotope signatures become much more stable than in the overlying Atlantic water masses. $\mathrm{Cr}$ in the bottom waters appears to be isotopically lighter than $\mathrm{Cr}$ in the above Barents Sea Branch Waters and Fram Strait Branch Waters $\left(\delta^{53} \mathrm{Cr}_{\text {bottom water }}=0.80 \pm 0.05 \%\right.$, $\delta^{53} \mathrm{Cr}_{\mathrm{BSBW}}=0.93 \pm 0.01 \%$, $\delta^{53} \mathrm{Cr}_{\mathrm{FSBW}}=0.93 \pm 0.17 \%$; $2 \mathrm{SE}$ for all). On the other hand, the mean $\mathrm{Cr}$ concentrations of these 3 water masses are not significantly different $\left([\mathrm{Cr}]_{\text {bottom water }}=2.65 \pm 0.07 \mathrm{nmol} / \mathrm{kg},[\mathrm{Cr}]_{\mathrm{BSBW}}=\right.$ $2.63 \pm 0.18 \mathrm{nmol} / \mathrm{kg},[\mathrm{Cr}]_{\mathrm{FSBW}}=2.57 \pm 0.11 \mathrm{nmol} / \mathrm{kg} ; 2 \mathrm{SE}$ for all).

Five meters above the seafloor, the $\delta^{53} \mathrm{Cr}$ signature of seawater shifts to a significantly more positive value $(+1.00 \%)$, while the [Cr] increases only slightly from $2.69 \mathrm{nmol} / \mathrm{kg}$ to $2.73 \mathrm{nmol} / \mathrm{kg}$.

In the above discussion, the sample at $1600 \mathrm{~m}$ depth with a much higher $\mathrm{Cr}$ concentration of 3.46 $\mathrm{nmol} / \mathrm{kg}$ (in brackets, figure 4.6) is excluded due to likely contamination. 


\subsubsection{Cr data from station 43 above the Alpha Ridge on a $\delta^{53} \mathrm{Cr}-\ln ([\mathrm{Cr}])$ plot}

In $\delta^{53} \mathrm{Cr}-\ln ([\mathrm{Cr}])$ space, $\mathrm{Cr}$ in the Pacific water mass at station 43 falls on the previously observed Rayleigh-like fractionation line (figure 4.8). This implies that the extreme $\mathrm{Cr}$ isotope fractionation signal, that was imprinted onto the Chukchi shelf samples at $55 \mathrm{~m}$ and $80 \mathrm{~m}$ depth and resulted in them falling off the previously observed Rayleigh-like fractionation line, is not transported to station 43 within the Pacific water layer.

In contrast to $\mathrm{Cr}$ in the Pacific water mass, $\mathrm{Cr}$ in the Atlantic and bottom water masses at station 43 plots below the previously observed Rayleigh-like fractionation line (figure 4.8). Out of all samples, the 4 bottom water samples plot furthest below the line. This is a first indication that $\mathrm{Cr}$ isotope signatures in the Atlantic and bottom water masses are shaped by processes distinct from those shaping $\mathrm{Cr}$ isotope signatures of samples which fall onto the Rayleigh-like fractionation line. At this point, these processes are unknown.

\subsection{Conclusions}

Cr gets progressively lower in concentration and heavier in isotope signature as Pacific water flows from the SAFe station in the North Pacific to our central Arctic station (SAFe: $[\mathrm{Cr}]=3.16 \mathrm{nmol} / \mathrm{kg}$,

$\delta^{53} \mathrm{Cr}=1.01 \%$; Station 61: $[\mathrm{Cr}]=1.63 \mathrm{nmol} / \mathrm{kg}, \delta^{53} \mathrm{Cr}=1.43 \%$; Station $43:[\mathrm{Cr}]=1.62 \mathrm{nmol} / \mathrm{kg}$, $\delta^{53} \mathrm{Cr}=1.56 \%$ ). This may be due to biological uptake of light $\mathrm{Cr}$ followed by export to depth (Scheiderich et al., 2015; Semeniuk et al., 2016). More stations need to be analyzed between SAFe station and our central Arctic station to understand how significant the role of the highly productive Chukchi waters is in this removal and fractionation of $\mathrm{Cr}$.

In the bottom waters of the shallow Chukchi shelf, we observed a shift to the heaviest Cr isotope signatures for seawater reported to date $\left(\delta^{53} \mathrm{Cr}=3.85 \%\right.$, $4.15 \%$ ), while $\mathrm{Cr}$ concentrations decreased. This isotope signal is consistent with $\mathrm{Cr}$ reduction which takes place in the oxic bottom waters due to the release of a potent $\mathrm{Cr}(\mathrm{VI})$ reductant such as ferrous iron from the anoxic sediments of the Chukchi shelf. Additionally, Cr reduction (e.g. by Fe(II) or acid volatile sulfides, direct dissimilatory $\mathrm{Cr}(\mathrm{VI})$ reduction) will likely occur within the anoxic sediments, but is expected to 
create very little isotope fractionation into the bottom water. In $\delta^{53} \mathrm{Cr}-\ln ([\mathrm{Cr}])$ space, the Chukchi bottom water samples plot far from the Rayleigh-like fractionation line, that was previously observed for samples presented by Bonnand et al. (2013), Scheiderich et al. (2015), and in chapters 2 and 3 of this thesis. This implies a much higher fractionation factor than the average $\varepsilon=0.80 \%$ o previously observed for the global Cr array (Scheiderich et al., 2015) and perhaps a novel isotope fractionation process at work.

A full water column profile taken at $85^{\circ} \mathrm{N}$ was analyzed. In general, $\mathrm{Cr}$ profiles at this station reflect the mixing of modified Pacific water (lower [Cr], heavier $\delta^{53} \mathrm{Cr}$ ) and Atlantic water (higher $[\mathrm{Cr}]$, lighter $\delta^{53} \mathrm{Cr}$ ). The extreme $\mathrm{Cr}$ isotope fractionation signal, that was imprinted onto the Chukchi shelf samples at $55 \mathrm{~m}$ and $80 \mathrm{~m}$ depth, is not reflected in the Pacific water layer of station 43. In contrast to $\mathrm{Cr}$ in the Pacific water mass, $\mathrm{Cr}$ in the Atlantic and bottom water masses at station 43 plots below the previously observed Rayleigh-like fractionation line. This is a first indication that $\mathrm{Cr}$ isotope signatures in the Atlantic and bottom water masses are shaped by processes distinct from those shaping Cr isotope signatures of samples which fall onto the Rayleigh-like fractionation line. At this point, these processes are unknown. 


\subsection{References}

Ball, J.W., Bassett, R.L., 2000. Ion exchange separation of chromium from natural water matrix for stable isotope mass spectrometric analysis. Chem. Geol. 168, 123-134. doi:http://dx.doi.org/10.1016/S0009-2541(00)00189-3

Beszczynska-Möller, A., Woodgate, R.A., Lee, C., Melling, H., Karcher, M., 2011. A Synthesis of Exchanges Through the Main Oceanic Gateways to the Arctic Ocean. Oceanography 24, 82-99. doi:10.2307/24861302

Bonnand, P., James, R.H., Parkinson, I.J., Connelly, D.P., Fairchild, I.J., 2013. The chromium isotopic composition of seawater and marine carbonates. Earth Planet. Sci. Lett. 382, 10-20. doi:http://dx.doi.org/10.1016/j.eps1.2013.09.001

Brandes, J.A., Devol, A.H., 1997. Isotopic fractionation of oxygen and nitrogen in coastal marine sediments. Geochim. Cosmochim. Acta 61, 1793-1801. doi:10.1016/S00167037(97)00041-0

Brandes, J.A., Devol, A.H., 2002. A global marine-fixed nitrogen isotopic budget: Implications for Holocene nitrogen cycling. Global Biogeochem. Cycles 16, 67-1-67-14. doi:10.1029/2001GB001856

Brown, Z.W., Casciotti, K.L., Pickart, R.S., Swift, J.H., 2015. Aspects of the marine nitrogen cycle of the Chukchi Sea shelf and Canada Basin. Deep Sea Res. Part II Top. Stud. Oceanogr. 118, 73-87. doi:10.1016/j.dsr2.2015.02.009

Brumsack, H.J., Gieskes, J.M., 1983. Interstitial water trace-metal chemistry of laminated sediments from the Gulf of California, Mexico. Mar. Chem. 14, 89-106. doi:10.1016/03044203(83)90072-5

Caccavo, F., Blakemore, R.P., Lovley, D.R., 1992. A Hydrogen-Oxidizing, Fe(III)-Reducing Microorganism from the Great Bay Estuary, New Hampshire. Appl. Environ. Microbiol. 58, $3211-6$.

Chang, B.X., Devol, A.H., 2009. Seasonal and spatial patterns of sedimentary denitrification rates in the Chukchi sea. Deep Sea Res. Part II Top. Stud. Oceanogr. 56, 1339-1350. doi:10.1016/j.dsr2.2008.10.024

Cutter, G.A., Bruland, K.W., 2012. Rapid and noncontaminating sampling system for trace elements in global ocean surveys. Limnol. Oceanogr. Methods 10, 425-436. doi:10.4319/lom.2012.10.425

Deutsch, C., Gruber, N., Key, R.M., Sarmiento, J.L., Ganachaud, A., 2001. Denitrification and N2 fixation in the Pacific Ocean. Global Biogeochem. Cycles 15, 483-506. doi:10.1029/2000GB001291

Devol, A.H., Codispoti, L.A., Christensen, J.P., 1997. Summer and winter denitrification rates in western Arctic shelf sediments. Devol, A.H., Codispoti, L.A., Christ. J.P., 1997. Summer winter denitrification rates West. Arct. shelf sediments. Cont. Shelf Res. 17, 1029-1050. doi10.1016/S0278-4343(97)00003-4Continental Shelf Res. 17, 1029-1050. doi:10.1016/S0278-4343(97)00003-4

Eary, L.E., Rai, D., 1988. Chromate removal from aqueous wastes by reduction with ferrous ion. Environ. Sci. Technol. 22, 972-977.

Ellis, A.S., Johnson, T.M., Bullen, T.D., 2002. Chromium isotopes and the fate of hexavalent chromium in the environment. Science (80-. ). 295, 2060-2062.

Fendorf, S., Wielinga, B.W., Hansel, C.M., 2000. Chromium Transformations in Natural Environments: The Role of Biological and Abiological Processes in Chromium(VI) 
Reduction. Int. Geol. Rev. 42, 691-701. doi:10.1080/00206810009465107

Fick, A., 1855. V. On liquid diffusion. Philos. Mag. 10, 30-39.

doi:10.1080/14786445508641925

Götz, A., Heumann, K.G., 1988. Chromium trace determination in inorganic, organic and aqueous samples with isotope dilution mass spectrometry. Fresenius Zeitschrift für Anal. Chemie 331, 123-128.

Graham, A.M., Bouwer, E.J., 2010. Rates of Hexavalent Chromium Reduction in Anoxic Estuarine Sediments: pH Effects and the Role of Acid Volatile Sulfides. Environ. Sci. Technol. 44, 136-142. doi:10.1021/es9013882

Granger, J., Prokopenko, M.G., Sigman, D.M., Mordy, C.W., Morse, Z.M., Morales, L. V., Sambrotto, R.N., Plessen, B., 2011. Coupled nitrification-denitrification in sediment of the eastern Bering Sea shelf leads to $15 \mathrm{~N}$ enrichment of fixed N in shelf waters. J. Geophys. Res. 116, C11006. doi:10.1029/2010JC006751

Gruber, N., Sarmiento, J.L., 1997. Global patterns of marine nitrogen fixation and denitrification. Global Biogeochem. Cycles 11, 235-266. doi:10.1029/97GB00077

IOC, SCOR, IAPSO, 2010. The International thermodynamic equation of seawater - 2010: calculation and use of thermodynamic properties. [includes corrections up to 31 st October 2015]. 196.

Jones, E.P., Anderson, L.G., 1986. On the origin of the chemical properties of the Arctic Ocean halocline. J. Geophys. Res. 91, 10759. doi:10.1029/JC091iC09p10759

Jones, E.P., Anderson, L.G., Swift, J.H., 1998. Distribution of Atlantic and Pacific waters in the upper Arctic Ocean: Implications for circulation. Geophys. Res. Lett. 25, 765-768. doi:10.1029/98GL00464

Jones, E.P., Swift, J.H., Anderson, L.G., Lipizer, M., Civitarese, G., Falkner, K.K., Kattner, G., McLaughlin, F., 2003. Tracing Pacific water in the North Atlantic Ocean. J. Geophys. Res. 108, 3116. doi:10.1029/2001JC001141

McDougall, T.J., Barker, P.M., 2011. Getting started with TEOS-10 and the Gibbs Seawater (GSW) Oceanographic Toolbox,. SCOR/IAPSO WG127.

Mills, M.M., Brown, Z.W., Lowry, K.E., van Dijken, G.L., Becker, S., Pal, S., Benitez-Nelson, C.R., Downer, M.M., Strong, A.L., Swift, J.H., Pickart, R.S., Arrigo, K.R., 2015. Impacts of low phytoplankton NO3-:PO43- utilization ratios over the Chukchi Shelf, Arctic Ocean. Deep Sea Res. Part II Top. Stud. Oceanogr. 118, 105-121. doi:10.1016/j.dsr2.2015.02.007

Palme, H., 1920. Studien über die Zersetzung der Überschwefelsäure. Zeitschrift für Anorg. und Allg. Chemie 112, 97-130. doi:10.1002/zaac.19201120105

Pettine, M., Millero, F.J., Passino, R., 1994. Reduction of chromium (VI) with hydrogen sulfide in $\mathrm{NaCl}$ media. Mar. Chem. 46, 335-344.

Pickart, R.S., Moore, G.W.K., Mao, C., Bahr, F., Nobre, C., Weingartner, T.J., 2016. Circulation of winter water on the Chukchi shelf in early Summer. Deep Sea Res. Part II Top. Stud. Oceanogr. 130, 56-75. doi:10.1016/j.dsr2.2016.05.001

Redfield, A.C., 1958. The biological control of chemical factors in the environment. Am. Sci. 46, 230A, 205-221.

Reinhard, C.T., Planavsky, N.J., Wang, X., Fischer, W.W., Johnson, T.M., Lyons, T.W., 2014. The isotopic composition of authigenic chromium in anoxic marine sediments: A case study from the Cariaco Basin, Earth and Planetary Science Letters. doi:10.1016/j.epsl.2014.09.024

Rudels, B., Jones, E.P., Anderson, L.G., Kattner, G., 2013. On the Intermediate Depth Waters of 
the Arctic Ocean. American Geophysical Union, pp. 33-46. doi:10.1029/GM085p0033

Rudge, J.F., Reynolds, B.C., Bourdon, B., 2009. The double spike toolbox. Chem. Geol. 265, 420-431. doi:http://dx.doi.org/10.1016/j.chemgeo.2009.05.010

Scheiderich, K., Amini, M., Holmden, C., Francois, R., 2015. Global variability of chromium isotopes in seawater demonstrated by Pacific, Atlantic, and Arctic Ocean samples. Earth Planet. Sci. Lett. 423, 87-97. doi:10.1016/j.epsl.2015.04.030

Sedlak, D.L., Chan, P.G., 1997. Reduction of hexavalent chromium by ferrous iron. Geochim. Cosmochim. Acta 61, 2185-2192. doi:10.1016/S0016-7037(97)00077-X

Semeniuk, D.M., Maldonado, M.T., Jaccard, S.L., 2016. Chromium uptake and adsorption in marine phytoplankton - Implications for the marine chromium cycle. Geochim.

Cosmochim. Acta 184, 41-54. doi:10.1016/j.gca.2016.04.021

Shaw, T.J., Gieskes, J.M., Jahnke, R.A., 1990. Early diagenesis in differing depositional environments: The response of transition metals in pore water. Geochim. Cosmochim. Acta 54, 1233-1246. doi:10.1016/0016-7037(90)90149-F

Stumm, W., Morgan, J.J., 2012. Aquatic chemistry: chemical equilibria and rates in natural waters. Vol. 126. John Wiley \& Sons.

Wielinga, B., Mizuba, M.M., Hansel, C.M., Fendorf, S., 2001. Iron promoted reduction of chromate by dissimilatory iron-reducing bacteria. Environ. Sci. Technol. 35, 522-527.

Woodgate, R.A., Aagaard, K., Swift, J.H., Falkner, K.K., Smethie, W.M., 2005. Pacific ventilation of the Arctic Ocean's lower halocline by upwelling and diapycnal mixing over the continental margin. Geophys. Res. Lett. 32. doi:10.1029/2005GL023999

Wu, J., Boyle, E.A., 1997. Low blank preconcentration technique for the determination of lead, copper, and cadmium in small-volume seawater samples by isotope dilution ICPMS. Anal. Chem. 69, 2464-2470.

Yamakawa, A., Yamashita, K., Makishima, A., Nakamura, E., 2009. Chemical separation and mass spectrometry of $\mathrm{Cr}, \mathrm{Fe}, \mathrm{Ni}, \mathrm{Zn}$, and $\mathrm{Cu}$ in terrestrial and extraterrestrial materials using thermal ionization mass spectrometry. Anal. Chem. 81, 9787-94. doi:10.1021/ac901762a 
Tables for Chapter 4

\begin{tabular}{|c|c|c|c|c|c|c|c|c|c|c|c|c|c|c|c|c|c|c|c|c|c|c|c|c|c|c|}
\hline 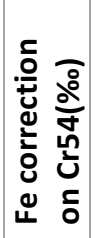 & $\begin{array}{l}\text { Oे } \\
0 \\
\end{array}$ & $\begin{array}{c}0 \\
\stackrel{9}{0} \\
0 \\
1\end{array}$ & $\begin{array}{l}20 \\
0 \\
0\end{array}$ & $\begin{array}{l}0 \\
\tilde{n} \\
\grave{1}\end{array}$ & \begin{tabular}{c}
2 \\
\hdashline \\
1
\end{tabular} & $\mid \begin{array}{l}n \\
0 \\
0 \\
1\end{array}$ & $\begin{array}{l}0 \\
0 \\
0 \\
1\end{array}$ & 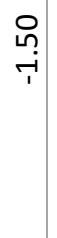 & $\begin{array}{l}-1 \\
0 \\
0 \\
\end{array}$ & $\begin{array}{l}8 \\
0 \\
0 \\
1\end{array}$ & $\begin{array}{l}8 \\
0 \\
0 \\
\end{array}$ & 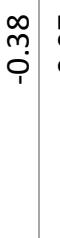 & 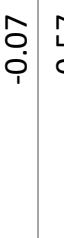 & 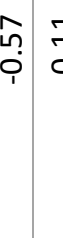 & 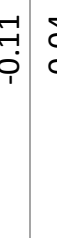 & $\begin{array}{l}\text { Ș } \\
\\
\end{array}$ & $\begin{array}{l}n \\
b \\
\vdots\end{array}$ & $b^{b}$ & $\begin{array}{l}0 \\
0 \\
0 \\
1\end{array}$ & $\begin{array}{l}\text { LO } \\
\text { Ọ. }\end{array}$ & $\begin{array}{l}\stackrel{n}{N} \\
\stackrel{1}{1}\end{array}$ & $\begin{array}{l}n \\
0 \\
\dot{1}\end{array}$ & $\begin{array}{l}\mathscr{0} \\
\dot{i}\end{array}$ & 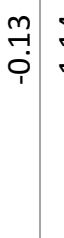 & 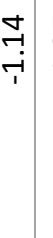 & 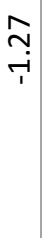 \\
\hline 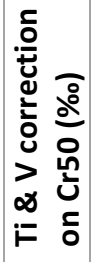 & 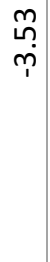 & 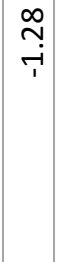 & $\stackrel{m}{m}$ & $\begin{array}{c}\hat{\sigma} \\
0 \\
1\end{array}$ & $\begin{array}{l}0 \\
0 \\
0 \\
1\end{array}$ & น̊ & $\begin{array}{l}0 \\
\overrightarrow{1} \\
\rightarrow\end{array}$ & $\stackrel{\stackrel{\sim}{m}}{\stackrel{T}{i}}$ & 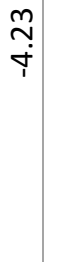 & $\begin{array}{l}\stackrel{2}{2} \\
\text { ̣. } \\
1\end{array}$ & $\begin{array}{c}0 \\
\text { ก } \\
i \\
\end{array}$ & $\begin{array}{l}0 \\
+ \\
0 \\
\end{array}$ & \begin{tabular}{l}
8 \\
$\stackrel{0}{0}$ \\
\hdashline \\
\end{tabular} & \begin{tabular}{l|l}
$\vec{f}$ & \multicolumn{1}{c}{} \\
& \multicolumn{1}{c}{}
\end{tabular} & 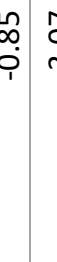 & 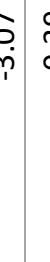 & 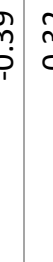 & $\begin{array}{l}\bar{c} \\
b \\
b\end{array}$ & $\begin{array}{l}\overrightarrow{7} \\
\stackrel{7}{i}\end{array}$ & $\begin{array}{l}\stackrel{\mathscr{\Omega}}{\sigma} \\
\dot{T}\end{array}$ & นึ̂ & $\begin{array}{l}m \\
\hat{0} \\
\dot{1}\end{array}$ & $\begin{array}{l}\text { ơ } \\
\text { ì }\end{array}$ & $\begin{array}{ll}\infty & \\
\stackrel{2}{0} & \\
& \end{array}$ & $\begin{array}{l}\underset{-}{ت} \\
\vec{i} \\
-\end{array}$ & 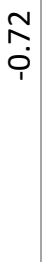 \\
\hline 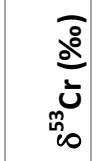 & 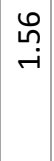 & $\stackrel{m}{m}$ & $\stackrel{-1}{-}$ & 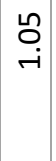 & $\begin{array}{l}-1 \\
0 \\
0\end{array}$ & $\begin{array}{l}0 \\
\infty \\
0 \\
0\end{array}$ & $\begin{array}{l}\text { ô. } \\
\text { o }\end{array}$ & $\begin{array}{l}\text { बे } \\
0\end{array}$ & $\begin{array}{l}\hat{\imath} \\
\vdots\end{array}$ & $\begin{array}{l}0 \\
\infty \\
0 \\
0\end{array}$ & , & $\stackrel{m}{m}$ & 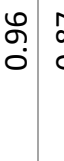 & $\begin{array}{c}c \\
\infty \\
0 \\
0\end{array}$ & $\begin{array}{c}8 \\
\end{array}$ & $\begin{array}{r}n \\
S \\
S\end{array}$ & 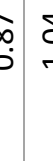 & 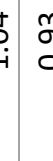 & 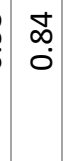 & $\stackrel{\infty}{\stackrel{\infty}{0}}$ & $\begin{array}{l}\stackrel{0}{\infty} \\
0 \\
0\end{array}$ & $\underset{-}{\stackrel{8}{-}}$ & 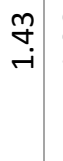 & 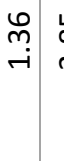 & $\begin{array}{l}\stackrel{n}{\infty} \\
\dot{m}\end{array}$ & $\stackrel{\sim}{\stackrel{\sim}{\sim}} \stackrel{-}{+}$ \\
\hline 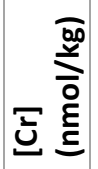 & 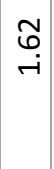 & $\begin{array}{c}\tilde{N} \\
\stackrel{0}{-} \\
-i\end{array}$ & 요 & 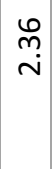 & 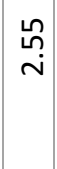 & $\begin{array}{l}\mathfrak{w} \\
\stackrel{i}{*}\end{array}$ & 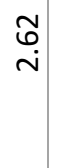 & 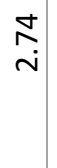 & $\begin{array}{l}\stackrel{O}{0} \\
\stackrel{i}{ }\end{array}$ & $\begin{array}{l}\stackrel{0}{0} \\
i \\
\sim\end{array}$ & , & $\begin{array}{c}\infty \\
\infty \\
\infty \\
-i\end{array}$ & 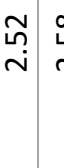 & 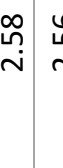 & 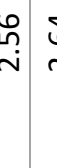 & \begin{tabular}{l|l}
0 \\
\multirow{2}{*}{}
\end{tabular} & $\begin{array}{l}\infty \\
\\
\end{array}$ & $\begin{array}{l}0 \\
0 \\
j \\
j\end{array}$ & $\begin{array}{l}\tilde{n} \\
i \\
ن\end{array}$ & $\begin{array}{l}\dot{0} \\
\dot{m} \\
m\end{array}$ & $\begin{array}{l}\stackrel{\bullet}{0} \\
\stackrel{i}{u}\end{array}$ & $\stackrel{m}{i}$ & $\begin{array}{l}n \\
\stackrel{n}{0} \\
i\end{array}$ & $\begin{array}{ll}\stackrel{n}{n} & \vdots \\
\rightarrow & \end{array}$ & in & ָָ \\
\hline 竞 & $\stackrel{m}{\stackrel{n}{-}}$ & $\begin{array}{l}\stackrel{9}{1} \\
\dot{n}\end{array}$ & gr & $\begin{array}{l}\stackrel{\sigma}{ } \\
\infty \\
\stackrel{m}{\sim}\end{array}$ & $\begin{array}{l}\sim \\
\dot{\sigma} \\
\stackrel{+}{ }\end{array}$ & ने & $\begin{array}{l}0 \\
\infty \\
\vdots \\
\infty\end{array}$ & $\begin{array}{l}\infty \\
\infty \\
\stackrel{\infty}{-} \\
\stackrel{-}{-}\end{array}$ & $\begin{array}{l}0 \\
\\
\\
\text { N }\end{array}$ & $\begin{array}{l}\hat{n} \\
\stackrel{n}{n} \\
\end{array}$ & $\begin{array}{l}\mathscr{9} \\
\dot{m}\end{array}$ & $\begin{array}{l}\dot{0} \\
\dot{\delta}\end{array}$ & 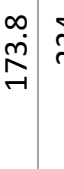 & $\stackrel{ \pm}{\star}$ & $\underset{N}{\stackrel{d}{N}}$ & $\underset{\forall}{\vec{f}}$ & 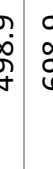 & $\begin{array}{ll}0 \\
\vdots \\
b \\
b & \alpha \\
0\end{array}$ & $\begin{array}{l}\sigma \\
\infty \\
\infty \\
m \\
\sim\end{array}$ & $\begin{array}{l}\sigma \\
\infty \\
o \\
\\
\rightarrow\end{array}$ & $\begin{array}{l}\infty \\
\infty \\
\infty \\
\stackrel{0}{\rightarrow} \\
\rightarrow\end{array}$ & 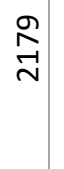 & $\stackrel{\circ}{\rightarrow}$ & 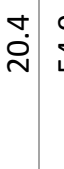 & $\begin{array}{l}\mathscr{g} \\
\dot{\sim}\end{array}$ & $\begin{array}{l}6 \\
\stackrel{0}{R}\end{array}$ \\
\hline 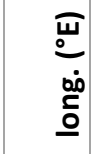 & 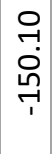 & & & & & & & & & & 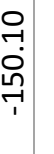 & & & & & & & & & & & & 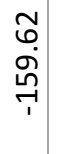 & & & \\
\hline $\begin{array}{l}\overline{\mathbf{z}} \\
\stackrel{+}{\mathbf{\pi}}\end{array}$ & $\underset{\substack{m \\
\infty}}{\stackrel{m}{0}}$ & & & & & & & & & & 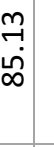 & & & & & & & & & & & & $\begin{array}{l}\infty \\
\stackrel{N}{N} \\
\stackrel{N}{n}\end{array}$ & & & \\
\hline 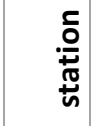 & $\stackrel{m}{q}$ & & & & & & & & & & $\stackrel{m}{q}$ & & & & & & & & & & & & $\overrightarrow{6}$ & & & \\
\hline$\frac{\mathscr{m}}{\frac{\mathscr{m}}{2}}$ & 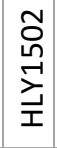 & & & & & & & & & & 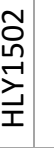 & & & & & & & & & & & & 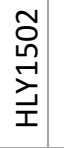 & & & \\
\hline 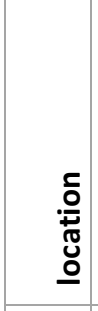 & 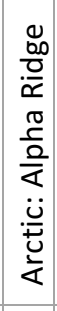 & & & & & & & & & & 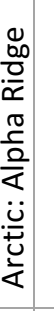 & & & & & & & & & & & & 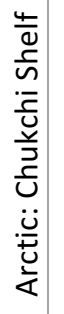 & & & \\
\hline 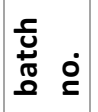 & -1 & & & & & & & & & & $v$ & & & & & & & & & & & & L & & & \\
\hline
\end{tabular}




\section{Figures for Chapter 4}

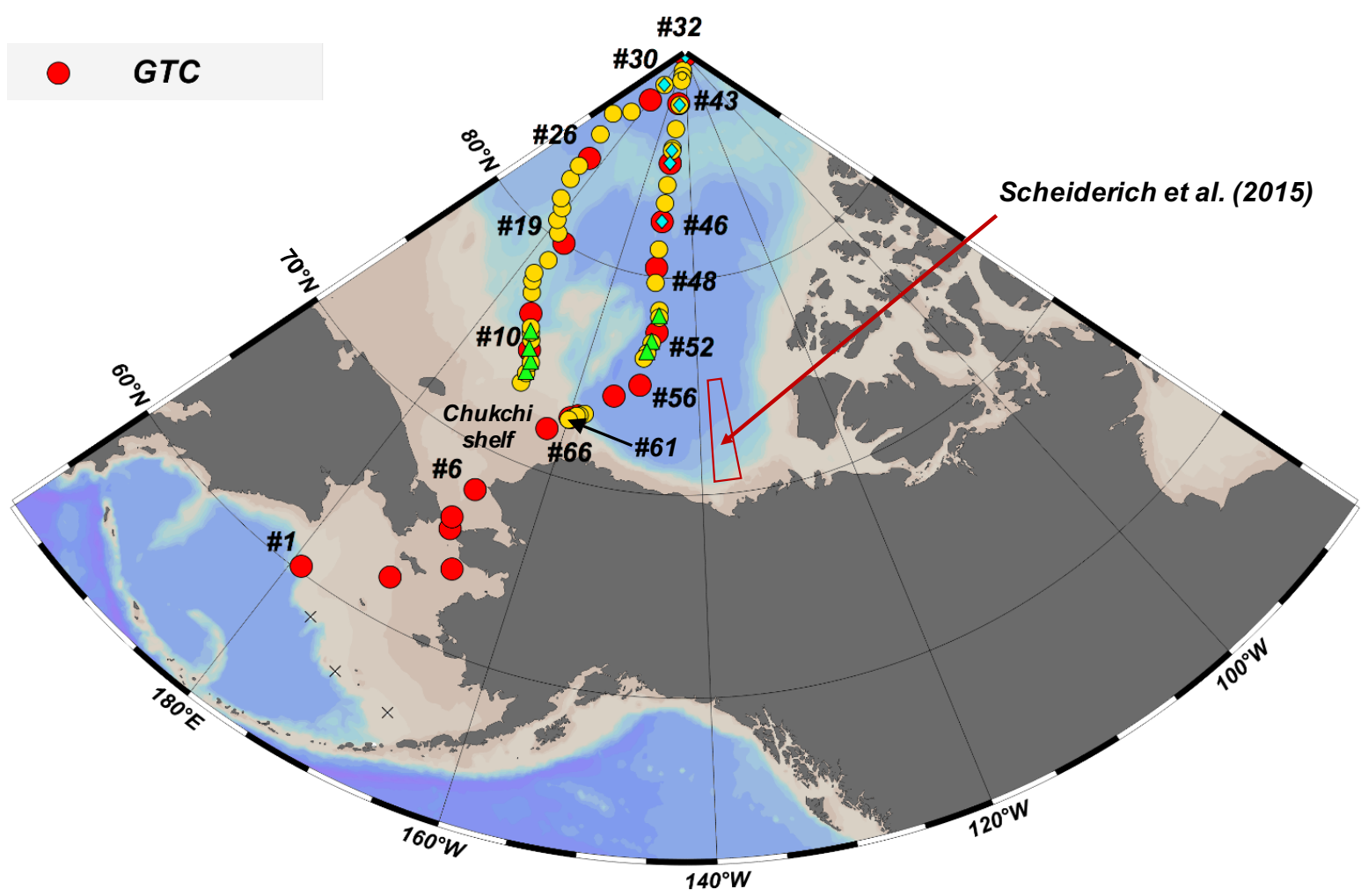

Figure 4.1. This map shows the sampling locations of the US Arctic GEOTRACES expedition (August to October 2015). We present Cr data from station 43, which is located on the Alpha Ridge with the Makarov Basin to the north and the Canada Basin to the south. Note the location of the Chukchi shelf between Russia and Alaska. Previously, Scheiderich et al. (2015) published Cr concentration and isotope ratio data of seawater samples which were taken in the Canada Basin (red trapezoid above marks their general sampling area). This map was made using Ocean Data View (Schlitzer, 2013). 


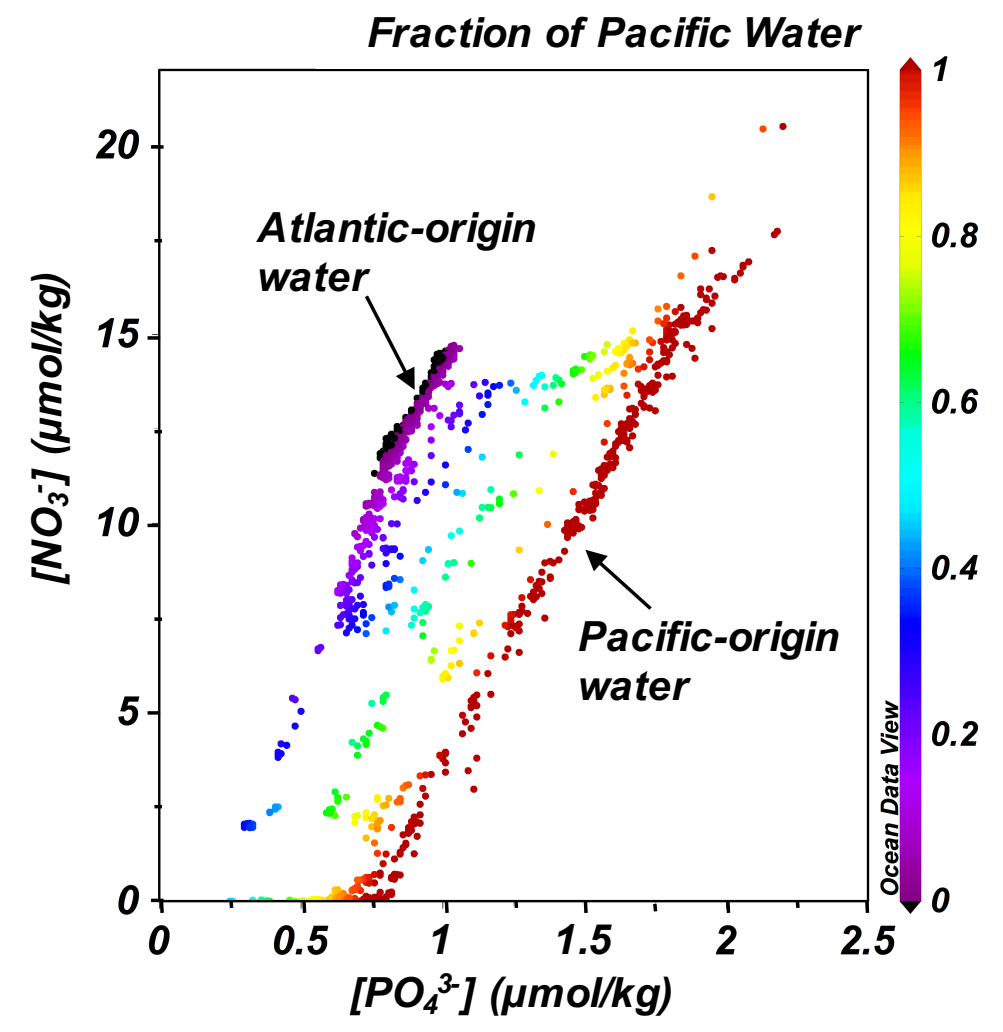

Figure 4.2. Phosphate and nitrate concentrations of seawater samples within the Arctic Ocean (stations 7 - 48) are plotted. Pure Atlantic-origin water (= black dots) and pure Pacific-origin water (= dark red dots) form 2 distinct lines on this plot. Data points in the middle of these two lines are a product of mixing between the two endmembers. Each sample's data point is colored according to the fraction of Pacific-origin water it contains. This plot was made using Ocean Data View (Schlitzer, 2013). 


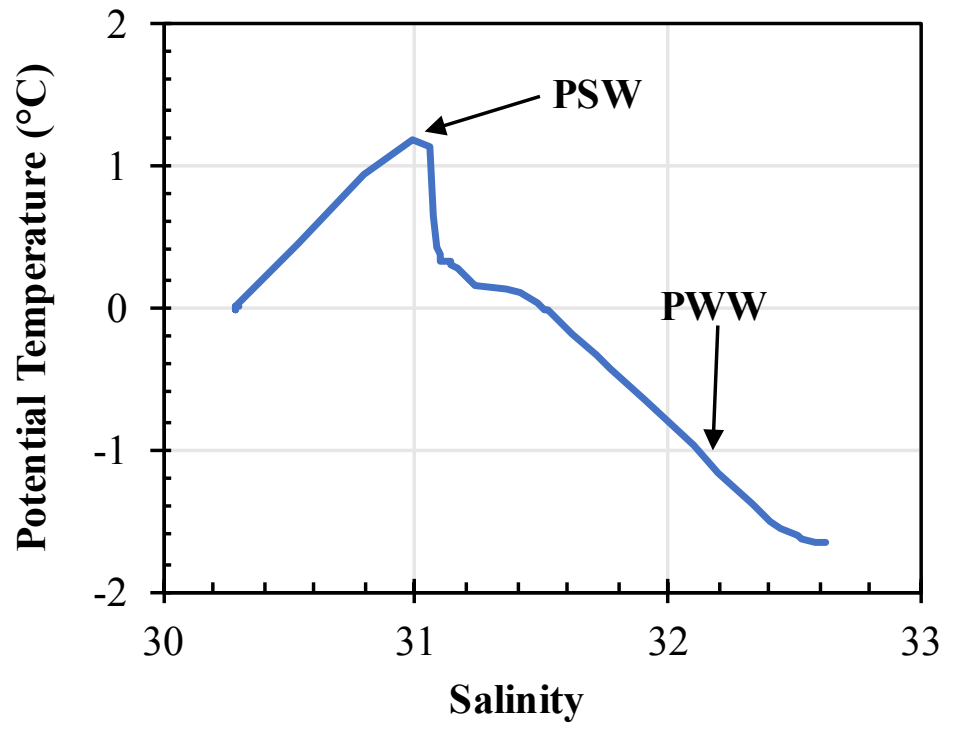

Figure 4.3. A potential temperature- salinity plot helps identify water masses at station 61 of the US Arctic GEOTRACES expedition: PSW = Pacific Summer Water, and PWW = Pacific Winter Water. 

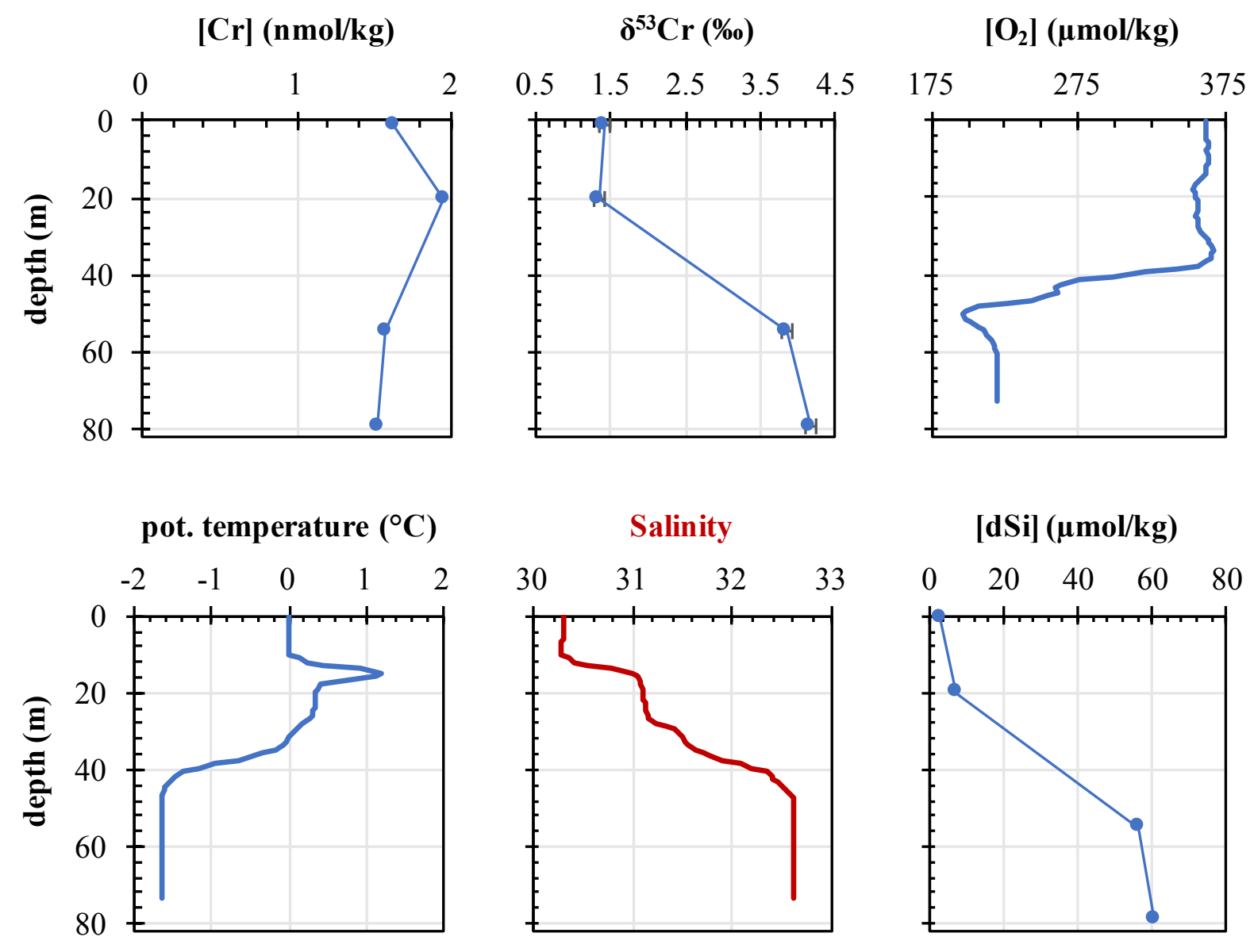

[dSi] $(\mu \mathrm{mol} / \mathbf{k g})$
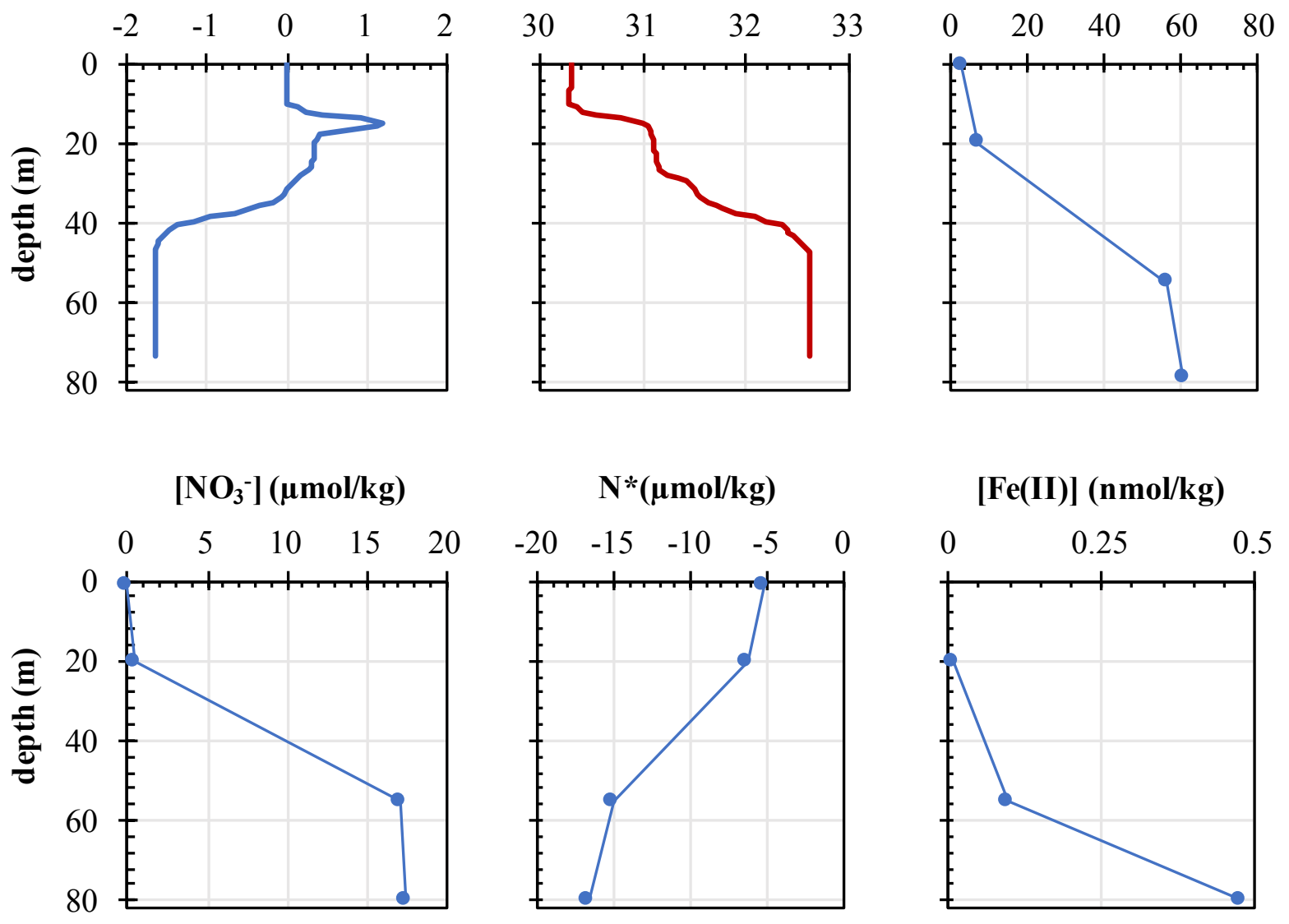

Figure 4.4. Full water column profiles are given for a suite of parameters at station 61 in the Arctic Ocean. Fe(II) concentrations were measured by Maija I. Heller. Cr isotope ratio error bars are $2 \mathrm{SD}$. 


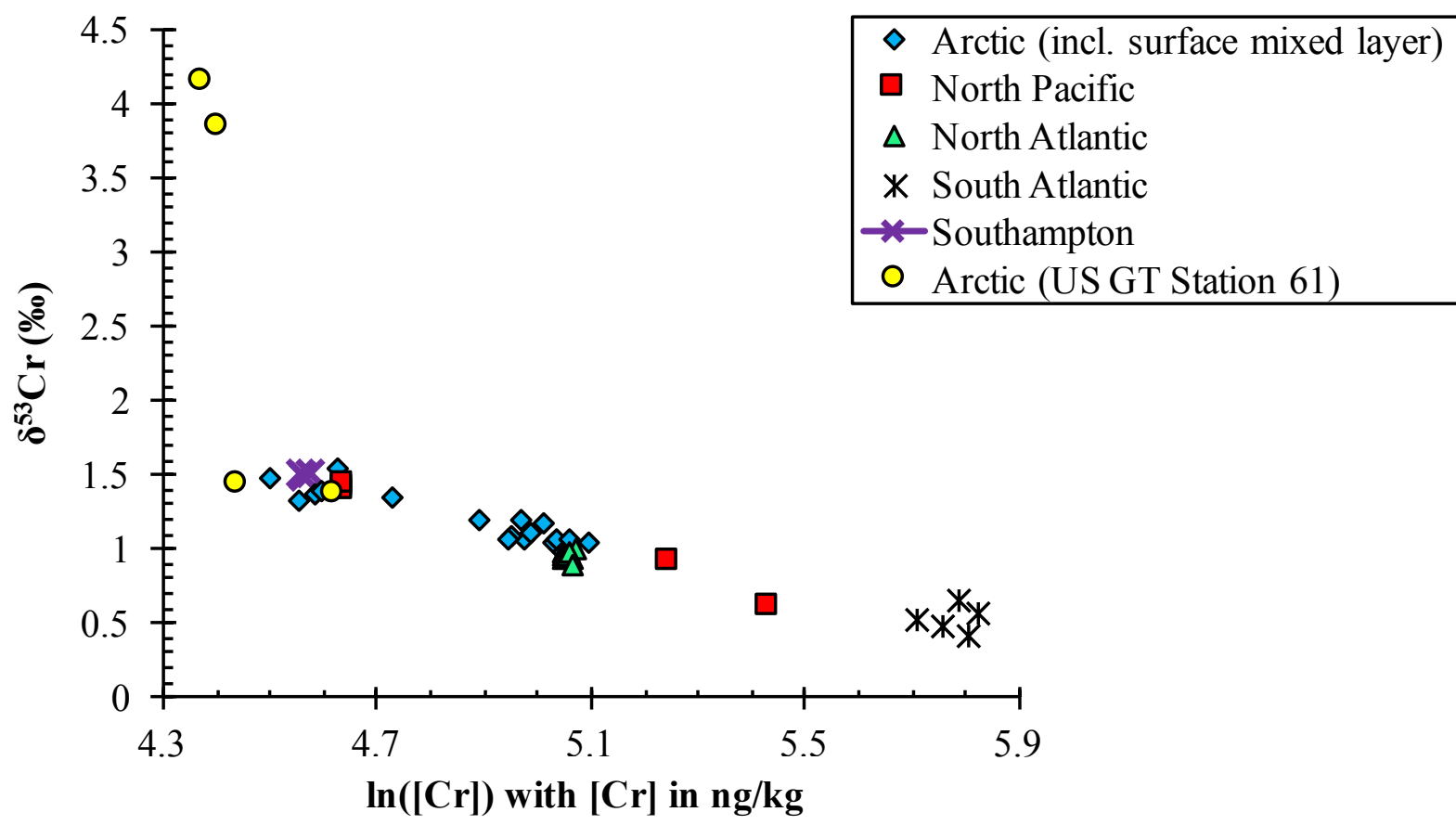

Figure 4.5. Samples from station 61 on the Chukchi shelf are plotted in $\delta^{53} \mathrm{Cr}-\ln ([\mathrm{Cr}])$ space alongside published seawater Cr isotope data (Bonnand et al., 2013; Scheiderich et al., 2015). 

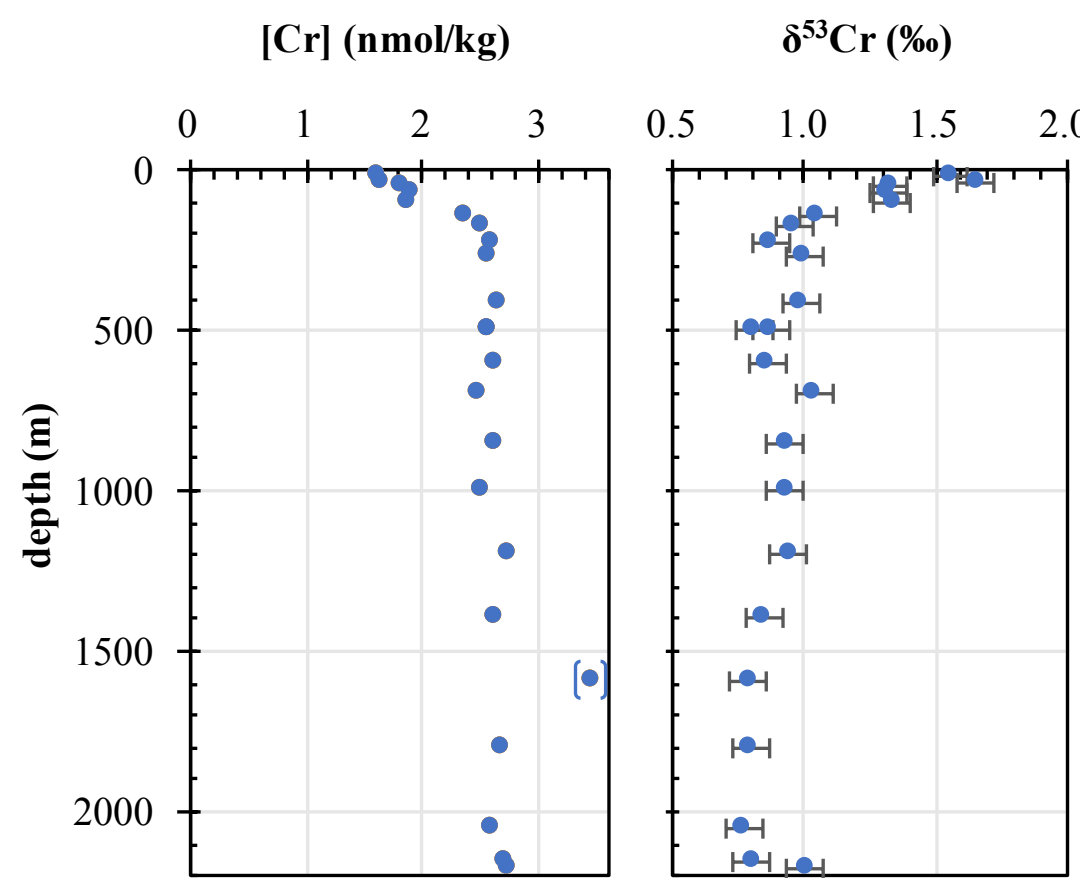

fraction of Pacific water
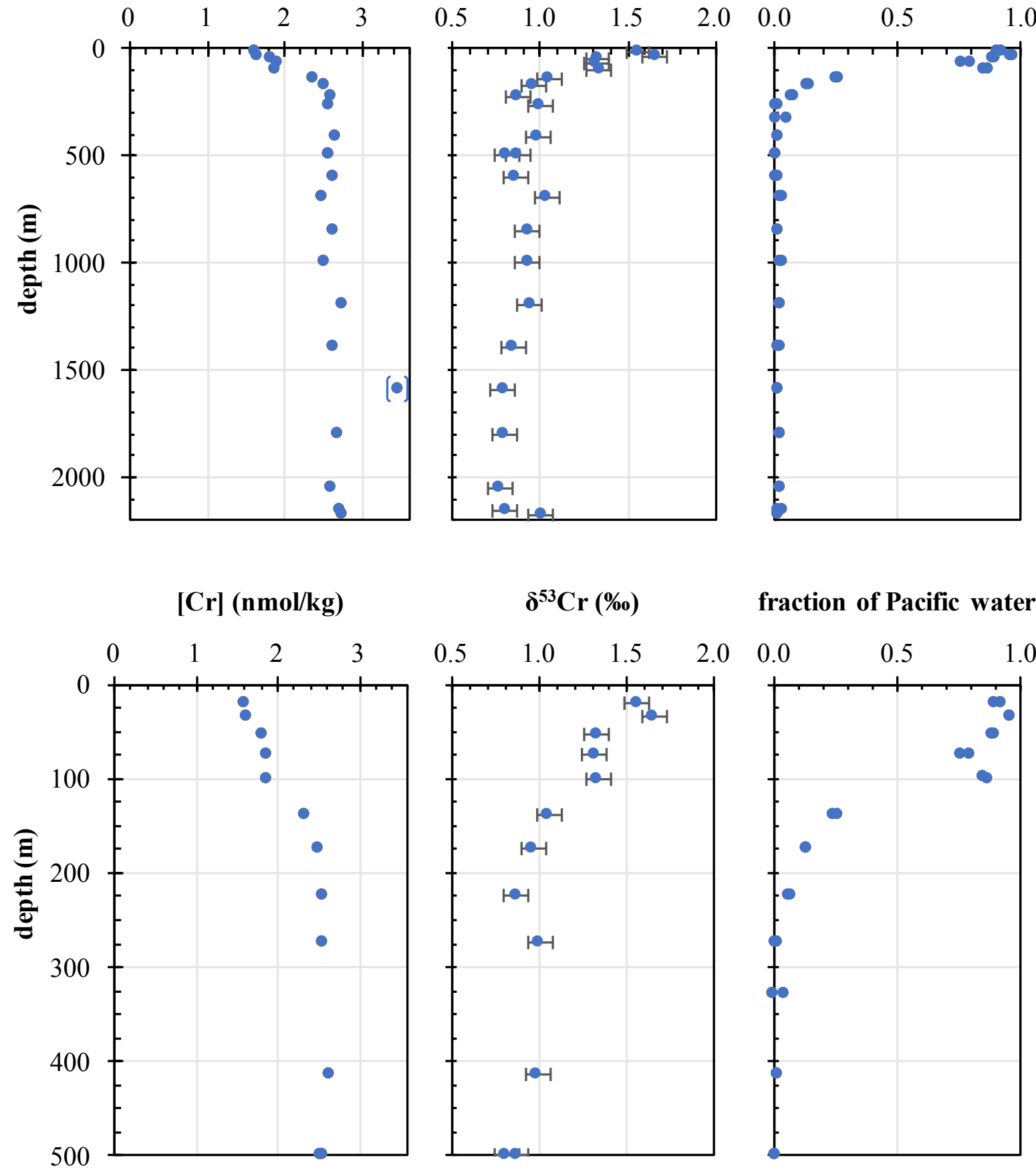

fraction of Pacific water

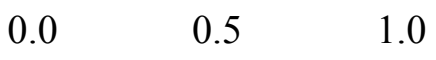

Figure 4.6. Full water column profiles ( $1^{\text {st }}$ row) and more detailed profiles of the upper $500 \mathrm{~m}$ $\left(2^{\text {nd }}\right.$ row) are given for a suite of parameters at station 43 in the Arctic Ocean. Cr isotope ratio error bars are 2SD. 

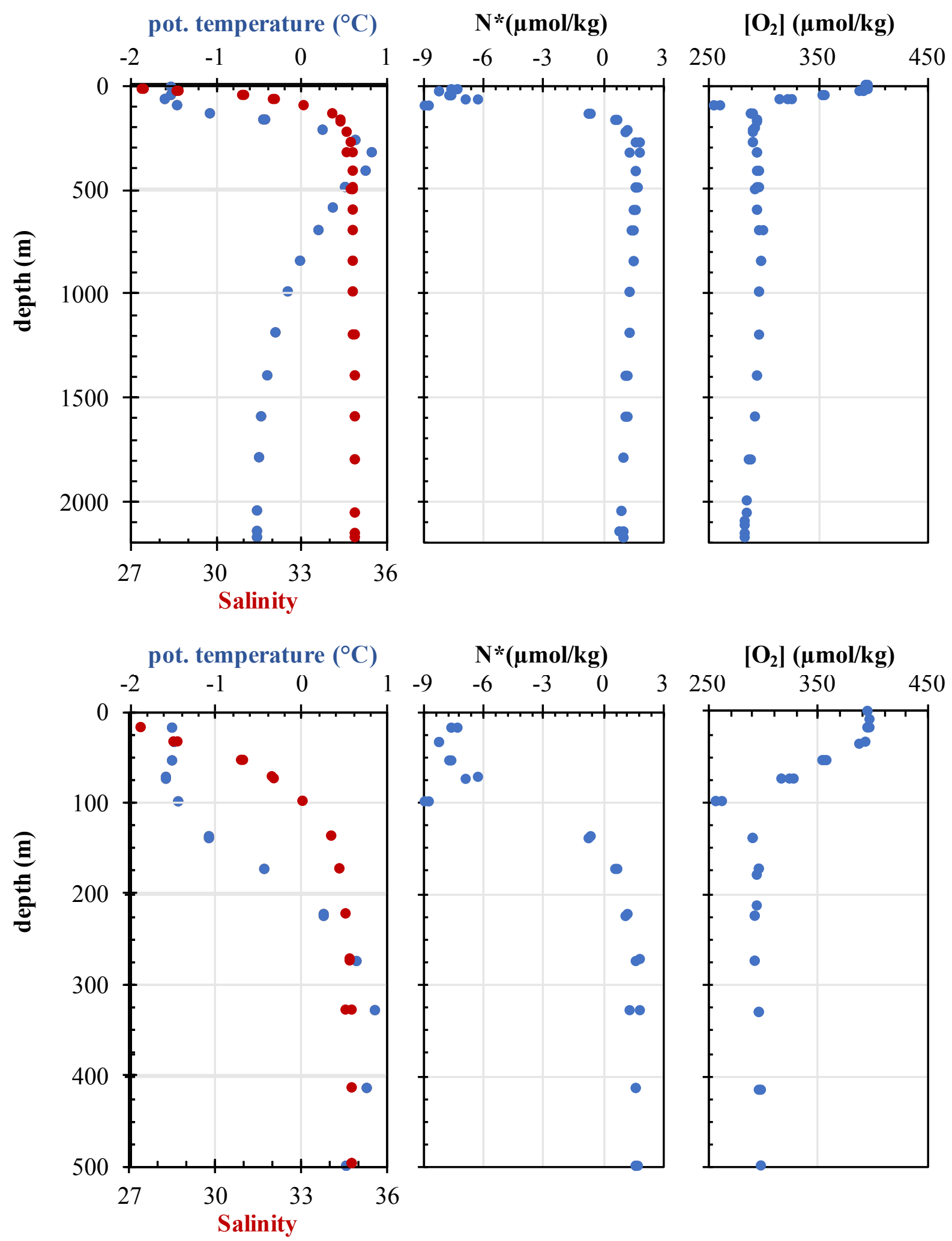

Figure 4.6 continued. Full water column profiles ( $1^{\text {st }}$ row) and more detailed profiles of the upper $500 \mathrm{~m}\left(2^{\text {nd }}\right.$ row $)$ are given for a suite of parameters at station 43 in the Arctic Ocean. 

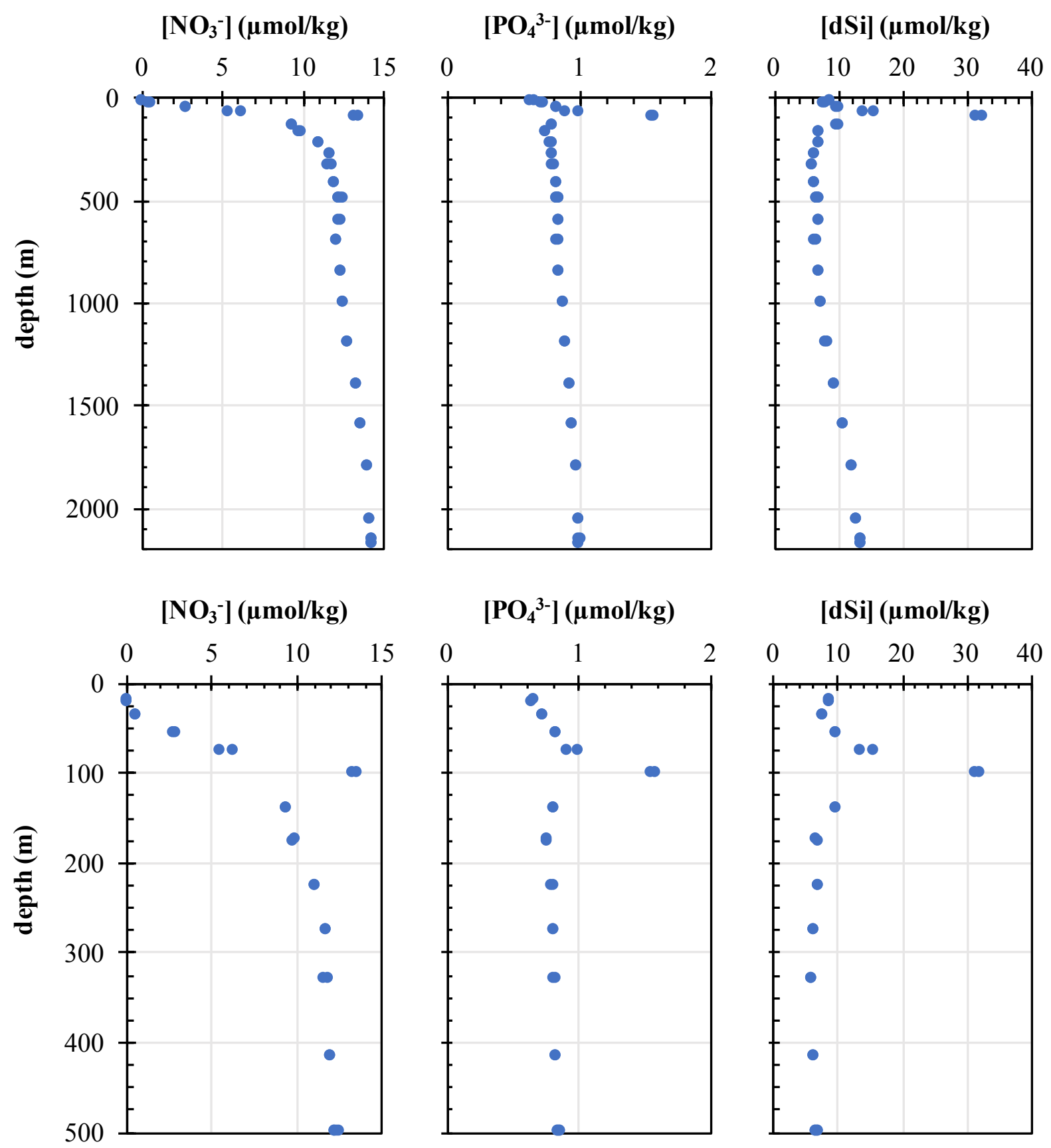

Figure 4.6 continued. Full water column profiles ( $1^{\text {st }}$ row) and more detailed profiles of the upper $500 \mathrm{~m}\left(2^{\text {nd }}\right.$ row $)$ are given for a suite of parameters at station 43 in the Arctic Ocean. 


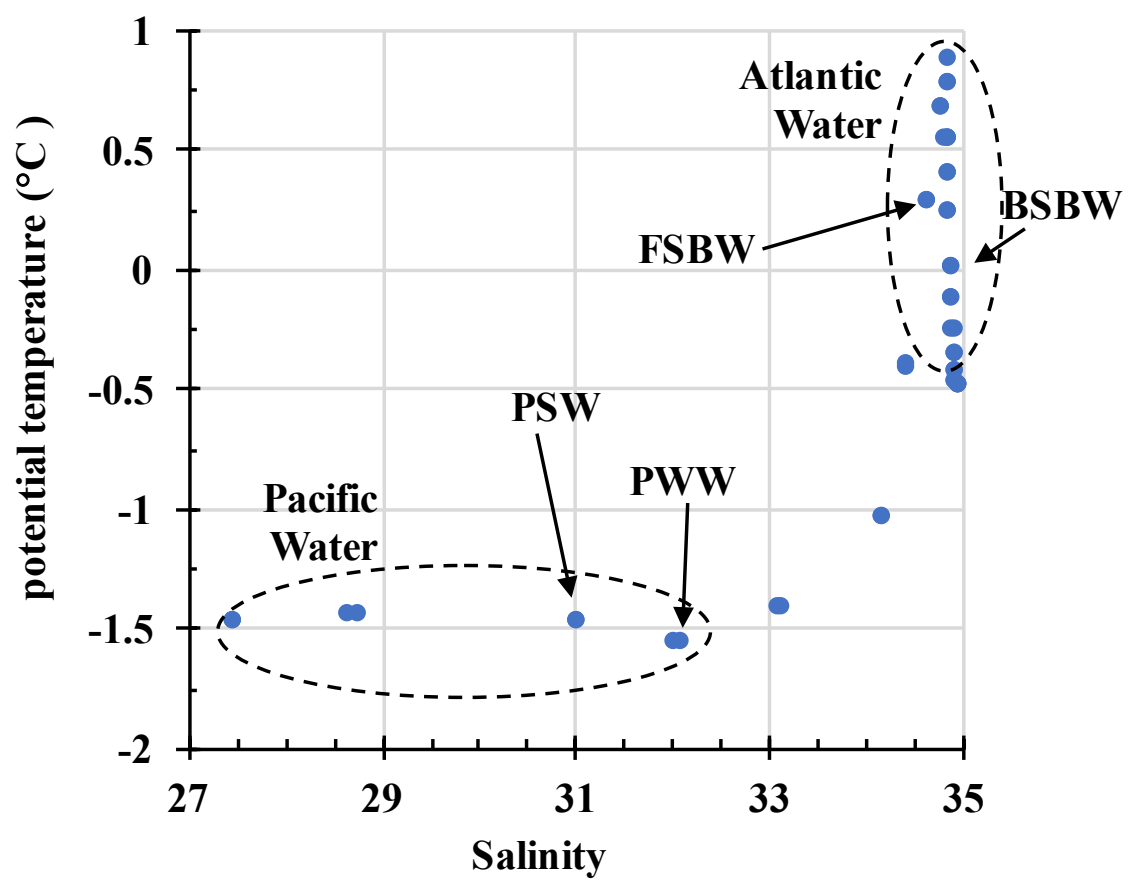

Figure 4.7. A potential temperature- salinity plot helps identify water masses at station 43 of the US Arctic GEOTRACES expedition: PSW = Pacific Summer Water, PWW = Pacific Winter Water, FSBW = Fram Strait Branch Water, and BSBW = Barents Sea Branch Water. 


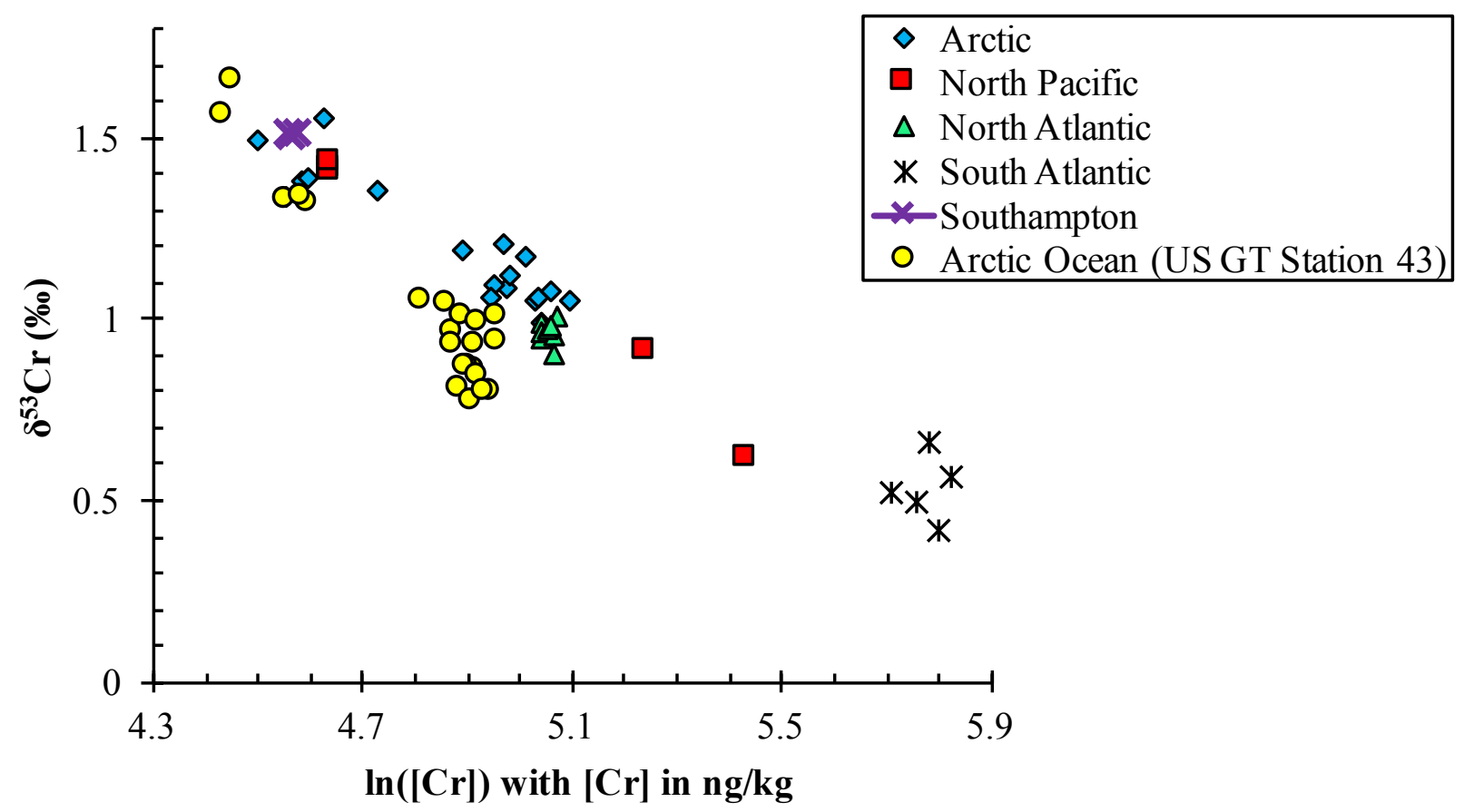

Figure 4.8. Samples from station 43 in the Central Arctic Ocean are plotted in $\delta^{53} \mathrm{Cr}-\ln ([\mathrm{Cr}])$ space alongside published seawater $\mathrm{Cr}$ isotope data (Bonnand et al., 2013; Scheiderich et al., 2015). 


\section{Chapter 5. Summary, Conclusions \& Outlook}

\subsection{Method for determination of accurate and precise $\mathrm{Cr}$ isotope ratios in seawater}

Within this $\mathrm{PhD}$ thesis, I developed a precise and accurate chromium isotope method for seawater samples. After acidification of seawater samples to $\mathrm{pH} 2, \mathrm{Cr}(\mathrm{VI})$ is converted to $\mathrm{Cr}(\mathrm{III})$ over the course of several months (Semeniuk et al., 2016). A ${ }^{50} \mathrm{Cr}^{54} \mathrm{Cr}$ double spike is added and allowed to equilibrate with the sample for 3 days. At this point, all chromium is present as trivalent $\mathrm{Cr}$ which can be preconcentrated with $\mathrm{Mg}(\mathrm{OH})_{2}$ coprecipitation ( $\mathrm{Wu}$ and Boyle, 1997; Semeniuk et al., 2016). $\mathrm{HCl}$ is added slightly beyond the neutralization point of the $\mathrm{Mg}(\mathrm{OH})_{2}$ pellet, such that $\mathrm{Cr}$ is present in a $0.02 \mathrm{M} \mathrm{HCl}$ solution. This is followed by a Cr oxidation step using ammonium persulfate which demands careful $\mathrm{pH}$ and temperature control. Although this oxidation step has been employed by several other non-seawater Cr isotope studies (e.g. Ball and Bassett, 2000; Frei et al., 2009; Schoenberg et al., 2008), none point out the pitfall of a back-reduction due to $\mathrm{H}_{2} \mathrm{O}_{2}$ generation (Palme, 1920). Additionally, the degree of APS decomposition during this step determines how much sulfur persists after the first anion-exchange column. Purification of the seawater matrix is achieved with a 3-anion exchange column scheme. The first column separates $\mathrm{Cr}$, which is present as the oxyanion $\mathrm{CrO}_{4}{ }^{2-}$, from the salt matrix (e.g. $\mathrm{Mg}$ ) and from isobaric interferences (i.e. V, Ti, Fe) (e.g. Ball and Bassett, 2000; Frei et al., 2009; Schoenberg et al., 2008). Sulfur species, which form polyatomics that interfere with accurate $\mathrm{Cr}$ analysis, are removed in a second column run for which $\mathrm{Cr}$ is present in the trivalent state. Traces of Fe are eliminated in a third column step with $\mathrm{Fe}$ present as $\mathrm{FeCl}_{4}{ }^{-}$and $\mathrm{Cr}$ present as positively charged $\mathrm{Cr}(\mathrm{III})$ (Yamakawa et al., 2009). Abundances of masses 49-56 of purified samples are detected in low resolution mode on the IsoProbe, a MC-ICP-MS featuring a hexapole collision cell capable of eliminating many polyatomic interferences. The machine is tuned such that the ratio of the $\mathrm{Cr}$

signal to the polyatomic sulfur signal is maximized. $\delta^{53} \mathrm{Cr}$ values of samples are calculated with respect to bracketing SRM-DS solutions.

Method adjustment for seawater $\mathrm{Cr}$ (III) isotope ratio measurements. Although only total $\mathrm{Cr}$ isotope signatures were determined here, the developed method can be used to measure $\mathrm{Cr}$ (III) 
isotope signatures of seawater samples. Samples need to be frozen and processed immediately upon thawing. In the case of $\mathrm{Cr}(\mathrm{III})$, a 3-day isotope equilibration period between sample and DS is not possible. Since the sample would need to remain at seawater $\mathrm{pH}$ for 3 days, $\mathrm{Cr}$ (III) would likely partially adsorb to the walls of the separatory funnels. Furthermore, over the course of 3 days uncontrolled changes in redox state may occur and artificially alter the seawater's original $\mathrm{Cr}(\mathrm{III})$ isotope signature. Tests during the method development stage indicated a $\mathrm{Cr}$ (III) recovery of $100 \%$ for the $\mathrm{Mg}(\mathrm{OH})_{2}$ coprecipitation step. This was independently verified by Davidson et al. (2017) and Semeniuk et al. (2016) using a Cr-51 radio tracer. Given a reliable $100 \%$ Cr recovery during the preconcentration step, isotope equilibration between the sample and the DS is not necessary and consequently, the $\mathrm{Mg}(\mathrm{OH})_{2}$ precipitation can be induced directly after adding the DS. A further option to separate $\mathrm{Cr}(\mathrm{III})$ from $\mathrm{Cr}(\mathrm{VI})$ is the addition of Chelex 100 resin to seawater immediately after sampling. At the $\mathrm{pH}$ of seawater, Chelex 100 resin binds $\geq 99 \%$ of $\mathrm{Cr}$ (III) but not $\mathrm{Cr}(\mathrm{VI})$ (Rue et al., 1997). So far, the Cr blank associated with this resin has been significant and may obstruct the precise determination of $\mathrm{Cr}$ (III) isotope ratios upon elution of $\mathrm{Cr}$ (III) from the resin beads. In contrast, the hexavalent fraction of $\mathrm{Cr}$ should not be affect by this resin blank. Once resin beads are filtered out of the seawater sample, it can be acidified to convert $\mathrm{Cr}$ (VI) to $\mathrm{Cr}(\mathrm{III})$ in solution and processing through the developed isotope method can start once conversion is complete.

\subsection{Interpretation of $\mathrm{Cr}$ isotope ratio data of analyzed seawater samples}

In this thesis, seawater samples from the Arctic Ocean, the open North Pacific Ocean (including from within the oxygen deficient zone of the Eastern Tropical North Pacific), and the Santa Barbara Basin were analyzed for total $\mathrm{Cr}$ isotope signatures $\left(\delta^{53} \mathrm{Cr}\right)$ and total $\mathrm{Cr}$ concentrations. Hereby, the number of reliable published $\mathrm{Cr}$ isotope data for seawater samples (Bonnand et al., 2013; Scheiderich et al., 2015) has been more than doubled. In all three investigated settings, a fraction of the $\mathrm{Cr}$ data indicated that in-situ $\mathrm{Cr}$ reduction was occurring. The reduction of soluble $\mathrm{Cr}(\mathrm{VI})$ results in the production of isotopically light, particle reactive $\mathrm{Cr}(\mathrm{III})$ (e.g. Ellis et al., 2002). Trivalent $\mathrm{Cr}$ is removed from the system by scavenging onto solid surfaces. The residual $\mathrm{Cr}$ becomes isotopically heavy (e.g. Ellis et al., 2002). 
Oligotrophic North Pacific. Here, we present the first full water column profile of $\mathrm{Cr}$ isotope ratios in the Pacific Ocean ( $\mathrm{SAFe}$ station). The profile is oceanographically consistent as $\mathrm{Cr}$ concentrations and isotope ratios develop gradually with water masses and the profile shapes are correlated with other oceanographic parameters. The correlation of the $\mathrm{Cr}$ and dissolved $\mathrm{Si}$ data is evident; the SAFe data on its own supports $\mathrm{Cr}$ being a nutrient-type element. However in the context of other published data, inconsistencies remain with regard to the potential biological control on Cr (Bonnand et al., 2013; Scheiderich et al., 2015; Sirinawin et al., 2000). Furthermore, we speculate that a heavy $\mathrm{Cr}$ isotope peak at $200 \mathrm{~m}$ at SAFe may originate from advection and diffusion of a $\mathrm{Cr}$ reduction signal out of the ODZ of the ETNP. In $\delta^{53} \mathrm{Cr}-\ln ([\mathrm{Cr}])$ space, the SAFe data and our internal reference sample (from 100m depth in the SPSG) fall on the same previously observed Rayleigh-like fractionation line (Scheiderich et al., 2015).

Eastern Tropical North Pacific (ETNP) and Santa Barbara Basin. We measured Cr isotope ratios and concentrations at two stations within the ODZ of the ETNP and at a station in the Santa Barbara Basin which features anoxic bottom waters. Cr profiles are compared to those available at the nearby SAFe station, which is characterized by a fully oxygenated water column.

Our observations at station $2 \mathrm{~T}$ in the ETNP and at our Santa Barbara site are consistent with $\mathrm{Cr}$ reduction in anoxic waters producing isotopically light, particle-reactive $\mathrm{Cr}(\mathrm{III})$, which is partially scavenged by particles and exported to depth. Isotopically heavy $\mathrm{Cr}(\mathrm{VI})$ is left behind in the upper water column. Since seawater samples from station $2 \mathrm{~T}$ were not filtered, the magnitude of the $\mathrm{Cr}$ reduction signal may have been suppressed by the presence of isotopically light $\mathrm{Cr}(\mathrm{III})$ particles.

At station 2T, the observed correlation of $\delta^{53} \mathrm{Cr}$ and $\delta^{15} \mathrm{~N}_{\mathrm{NO} \text { - }}$ suggests that $\mathrm{Cr}$ reduction may be microbially mediated instead of simply being a product of thermodynamic equilibrium. Alternatively, $\mathrm{Cr}(\mathrm{VI})$ may be reduced by $\mathrm{Fe}(\mathrm{II})$, which was generated in-situ by dissimilatory $\mathrm{Fe}$ reduction and/or was generated in the anoxic pore waters of the Mexican shelf by dissimilatory $\mathrm{Fe}$ reduction and subsequently transported offshore to station $2 \mathrm{~T}$.

In the Santa Barbara Basin, $\mathrm{Cr}$ reduction may take place via the same mechanisms in the anoxic bottom waters and/or in the anoxic sediment pore waters. Additionally, acid volatile sulfides may 
contribute to $\mathrm{Cr}(\mathrm{VI})$ reduction in the anoxic sediment pore waters. Although the sedimentary $\mathrm{Cr}$ reduction can contribute to lowering the $\mathrm{Cr}$ concentration of the bottom waters, it is unlikely to result in significant $\mathrm{Cr}$ isotope fractionation. If all of the observed $\mathrm{Cr}$ reduction took place in the basin's sediment, $\mathrm{Cr}$ in the pore waters would get depleted over a depth range of a millimeter. This narrow depth range would make any $\mathrm{Cr}$ analysis in such pore waters extremely challenging.

Is the SAFe station a suitable, fully oxic water column counterpart? The peak in heavy $\mathrm{Cr}$ and a subtle decrease in Cr concentrations at SAFe (at 200m depth) are located along the same isopycnal as the biggest total $\mathrm{Cr}$ deficit and heaviest $\mathrm{Cr}$ anomaly at station $2 \mathrm{~T}$ (at 100m depth). This point is best illustrated by comparing the Cr profiles of $2 \mathrm{~T}$ and the $\sigma_{\theta}$ adjusted SAFe station at $100 \mathrm{~m}$ (figure $3.5)$. It is conceivable that a signal of $\mathrm{Cr}$ reduction (=lower $[\mathrm{Cr}]$, heavier $\delta^{53} \mathrm{Cr}$ ) generated within the ODZ of the ETNP at station 2T can advect or diffuse to the SAFe station. In that case, a direct comparison between the two stations may underestimate the magnitude of Cr reduction occurring within the ODZ. To verify this hypothesis a transect from the ODZ into oxic waters of the North Pacific is required. Alternatively, a more remote station in the North Pacific such as Station ALOHA $\left(22.75^{\circ} \mathrm{N}, 158^{\circ} \mathrm{W}\right)$ could be analyzed with the hope that it is minimally impacted by transport of a $\mathrm{Cr}$ reduction signal out of the ODZ.

Arctic Ocean. Cr gets progressively lower in concentration and heavier in isotope signature as Pacific water flows from the SAFe station in the North Pacific to our central Arctic station (SAFe: $[\mathrm{Cr}]=3.16 \mathrm{nmol} / \mathrm{kg}, \delta^{53} \mathrm{Cr}=1.01 \%$; Station $61:[\mathrm{Cr}]=1.63 \mathrm{nmol} / \mathrm{kg}, \delta^{53} \mathrm{Cr}=1.43 \%$; Station 43 : $[\mathrm{Cr}]=1.62 \mathrm{nmol} / \mathrm{kg}, \delta^{53} \mathrm{Cr}=1.56 \%$ ). This may be due to biological uptake of light $\mathrm{Cr}$ followed by export to depth (Scheiderich et al., 2015; Semeniuk et al., 2016). More stations need to be analyzed between SAFe station and our central Arctic station to understand how significant the role of the highly productive Chukchi waters is in this removal and fractionation of $\mathrm{Cr}$.

In the bottom waters of the shallow Chukchi shelf, we observed a shift to the heaviest Cr isotope signatures for seawater reported to date $\left(\delta^{53} \mathrm{Cr}=3.85 \%\right.$, $4.15 \%$ ), while $\mathrm{Cr}$ concentrations decreased. This isotope signal is consistent with $\mathrm{Cr}$ reduction which takes place in the oxic bottom waters due to the release of a potent $\mathrm{Cr}(\mathrm{VI})$ reductant such as ferrous iron from the anoxic sediments of the Chukchi shelf. Additionally, Cr reduction (e.g. by $\mathrm{Fe}(\mathrm{II})$ or acid volatile sulfides, direct 
dissimilatory $\mathrm{Cr}(\mathrm{VI})$ reduction) will likely occur within the anoxic sediments, but is expected to create very little isotope fractionation into the bottom water. In $\delta^{53} \mathrm{Cr}-\ln ([\mathrm{Cr}])$ space, the Chukchi bottom water samples plot far from the Rayleigh-like fractionation line, that was previously observed for samples presented by Bonnand et al. (2013), Scheiderich et al. (2015), and in chapters 2 and 3 of this thesis. This implies a much higher fractionation factor than the average $\varepsilon=0.80 \%$ previously observed for the global $\mathrm{Cr}$ array (Scheiderich et al., 2015) and perhaps a novel isotope fractionation process at work.

A full water column profile taken at $85^{\circ} \mathrm{N}$ was analyzed. In general, $\mathrm{Cr}$ profiles at this station reflect the mixing of modified Pacific water (lower $[\mathrm{Cr}]$, heavier $\delta^{53} \mathrm{Cr}$ ) and Atlantic water (higher [Cr], lighter $\delta^{53} \mathrm{Cr}$ ). The extreme $\mathrm{Cr}$ isotope fractionation signal, that was imprinted onto the Chukchi shelf samples at $55 \mathrm{~m}$ and $80 \mathrm{~m}$ depth, is not reflected in the Pacific water layer of station 43. In contrast to $\mathrm{Cr}$ in the Pacific water mass, $\mathrm{Cr}$ in the Atlantic and bottom water masses at station 43 plots below the previously observed Rayleigh-like fractionation line. This is a first indication that $\mathrm{Cr}$ isotope signatures in the Atlantic and bottom water masses are shaped by processes distinct from those shaping $\mathrm{Cr}$ isotope signatures of samples which fall onto the Rayleigh-like fractionation line. At this point, these processes are unknown.

\subsection{Recommendations for future research}

Our data shows that changes in isotope signatures of total $\mathrm{Cr}$ (=dissolved $\mathrm{Cr}(\mathrm{III})+$ dissolved $\mathrm{Cr}(\mathrm{VI})$ ) in seawater can be detected in response to reduced, isotopically light $\mathrm{Cr}(\mathrm{III})$ being scavenged and exported from the system. These shifts in isotope signatures should be even more extreme for individual redox species (=dissolved $\mathrm{Cr}(\mathrm{III})$ versus dissolved $\mathrm{Cr}(\mathrm{VI})$ ). Therefore, future research aimed at studying $\mathrm{Cr}$ isotope effects produced by $\mathrm{Cr}$ reduction should characterize both $\mathrm{Cr}(\mathrm{III})$ and total $\mathrm{Cr}$ isotope signatures.

Even though particulate $\mathrm{Cr}$ will eventually be exported and removed from the water column, it can reach significant intermittent levels in anoxic zones (Murray et al., 1983). If no filtration is performed the presence of isotopically light particulate $\mathrm{Cr}(\mathrm{III})$ may mute the heavy $\delta^{53} \mathrm{Cr}$ anomaly of total $\mathrm{Cr}$ or $\mathrm{Cr}(\mathrm{VI})$. Sample filtration is thus imperative when wanting to study the fully 
articulated heavy $\delta^{53} \mathrm{Cr}$ anomaly of total $\mathrm{Cr}$ or $\mathrm{Cr}(\mathrm{VI})$ produced by $\mathrm{Cr}$ reduction. It would also make sense to deliberately sample the particulate $\mathrm{Cr}$ in the $\mathrm{ODZ}$ and measure its isotopic composition.

Future research aimed at studying $\mathrm{Cr}$ isotope effects produced by $\mathrm{Cr}$ reduction should focus on the following environments: (1) silled basins that develop an anoxic layer (e.g. the Black Sea, the Cariaco Basin, the Saanich Inlet, the Framvaren Fjord), (2) upwelling zones that display anoxia (e.g. the Benguela upwelling system off the coast of Namibia, the Chilean/ Peruvian shelf), (3) oxygen deficient zones of the open ocean (e.g. Arabian Sea, Eastern Tropical Southern and Northern Ocean), (4) oxic waters that receive potent $\mathrm{Cr}(\mathrm{VI})$ reductants such as ferrous iron from anoxic sediments, and (5) anoxic sediment pore waters. In general, $\mathrm{Cr}$ reduction is likely to occur in anoxic (or oxic waters) that exhibit strong signals of denitrification, and reduced species such as $\mathrm{dFe}(\mathrm{II})$.

Another potentially important process that has been suggested to control the distribution of $\mathrm{Cr}$ in the ocean remains to be tackled by future research: It has been proposed that significant $\mathrm{Cr}$ (III) levels can be produced in surface waters by photochemically and biologically mediated redox reactions and are subsequently stabilized by organic ligand complexation (e.g. Sander et al., 2003; Van Der Weijden and Reith, 1982). If this is the case, there is a potential for significant isotope fractionation between inorganic $\mathrm{Cr}(\mathrm{III})$, organically complexed $\mathrm{Cr}(\mathrm{III})$ and $\mathrm{Cr}(\mathrm{VI})$ in the surface waters. 


\subsection{References}

Ball, J.W., Bassett, R.L., 2000. Ion exchange separation of chromium from natural water matrix for stable isotope mass spectrometric analysis. Chem. Geol. 168, 123-134. doi:http://dx.doi.org/10.1016/S0009-2541(00)00189-3

Bonnand, P., James, R.H., Parkinson, I.J., Connelly, D.P., Fairchild, I.J., 2013. The chromium isotopic composition of seawater and marine carbonates. Earth Planet. Sci. Lett. 382, 10-20. doi:http://dx.doi.org/10.1016/j.eps1.2013.09.001

Davidson, A., Holmden, C., Francois, R., Crowe, S.A., 2017. Chromium Isotope Speciation in Seawater, in: Goldschmidt Abstracts.

Ellis, A.S., Johnson, T.M., Bullen, T.D., 2002. Chromium isotopes and the fate of hexavalent chromium in the environment. Science (80-. ). 295, 2060-2062.

Frei, R., Gaucher, C., Poulton, S.W., Canfield, D.E., 2009. Fluctuations in Precambrian atmospheric oxygenation recorded by chromium isotopes. Nature 461, 250-253.

Murray, J.W., Spell, B., Paul, B., 1983. The Contrasting Geochemistry of Manganese and Chromium in the Eastern Tropical Pacific Ocean, in: Wong, C.S., Boyle, E., Bruland, K.W., Burton, J.D., Goldberg, E.D. (Eds.), Trace Metals in Sea Water, NATO Conference Series. Springer US, pp. 643-669. doi:- 10.1007/978-1-4757-6864-0_37

Palme, H., 1920. Studien über die Zersetzung der Überschwefelsäure. Zeitschrift für Anorg. und Allg. Chemie 112, 97-130. doi:10.1002/zaac.19201120105

Rue, E.L., Smith, G.J., Cutter, G.A., Bruland, K.W., 1997. The response of trace element redox couples to suboxic conditions in the water column. Deep Sea Res. Part I Oceanogr. Res. Pap. 44, 113-134. doi:http://dx.doi.org/10.1016/S0967-0637(96)00088-X

Sander, S., Koschinsky, A., Halbach, P., 2003. Redox speciation of chromium in the oceanic water column of the Lesser Antilles and offshore Otago Peninsula, New Zealand. Mar. Freshw. Res. 54, 745-754.

Scheiderich, K., Amini, M., Holmden, C., Francois, R., 2015. Global variability of chromium isotopes in seawater demonstrated by Pacific, Atlantic, and Arctic Ocean samples. Earth Planet. Sci. Lett. 423, 87-97. doi:10.1016/j.eps1.2015.04.030

Schoenberg, R., Zink, S., Staubwasser, M., von Blanckenburg, F., 2008. The stable Cr isotope inventory of solid Earth reservoirs determined by double spike MC-ICP-MS. Chem. Geol. 249, 294-306. doi:http://dx.doi.org/10.1016/j.chemgeo.2008.01.009

Semeniuk, D.M., Maldonado, M.T., Jaccard, S.L., 2016. Chromium uptake and adsorption in marine phytoplankton - Implications for the marine chromium cycle. Geochim.

Cosmochim. Acta 184, 41-54. doi:10.1016/j.gca.2016.04.021

Sirinawin, W., Turner, D.R., Westerlund, S., 2000. Chromium (VI) distributions in the Arctic and the Atlantic Oceans and a reassessment of the oceanic Cr cycle. Mar. Chem. 71, 265282.

Van Der Weijden, C.H., Reith, M., 1982. Chromium(III) - chromium(VI) interconversions in seawater. Mar. Chem. 11, 565-572. doi:10.1016/0304-4203(82)90003-2

$\mathrm{Wu}$, J., Boyle, E.A., 1997. Low blank preconcentration technique for the determination of lead, copper, and cadmium in small-volume seawater samples by isotope dilution ICPMS. Anal. Chem. 69, 2464-2470.

Yamakawa, A., Yamashita, K., Makishima, A., Nakamura, E., 2009. Chemical separation and mass spectrometry of $\mathrm{Cr}, \mathrm{Fe}, \mathrm{Ni}, \mathrm{Zn}$, and $\mathrm{Cu}$ in terrestrial and extraterrestrial materials using thermal ionization mass spectrometry. Anal. Chem. 81, 9787-94. doi:10.1021/ac901762a 


\section{Appendix}

\section{Annual variability of total Cr concentrations of seawater samples taken at $40 \mathrm{~m}-47 \mathrm{~m}$ depth off of Bermuda}

Connelly et al. (2006) presented total Cr concentrations for the upper water column (down to 500m depth) at Hydrostation ' $\mathrm{S}$ ' located southeast of Bermuda. Based on their data, total $\mathrm{Cr}$ concentrations varied significantly over the year (sampling occurred in March, June, September, November, and January). Specifically, at a depth of $\sim 50 \mathrm{~m}$ total $\mathrm{Cr}$ concentrations ranged from $\sim 2$ $\mathrm{nmol} / \mathrm{kg}$ to $\sim 5 \mathrm{nmol} / \mathrm{kg}$.

Here, we present total $\mathrm{Cr}$ concentrations for seawater samples taken for $\sim 1$ year on a weekly basis between $40 \mathrm{~m}$ and $47 \mathrm{~m}$ depth at a site proximate to that sampled by Connelly et al. (2006). As part of the Bermuda Testbed Mooring (Dickey et al., 1998), which was situated $\sim 80 \mathrm{~km}$ southeast of Bermuda $\left(31.73^{\circ} \mathrm{N}, 61.17^{\circ} \mathrm{W}\right)$, an autonomous trace metal sampler was installed. This sampler called MITESS is described in detail by Bell et al. (2002). Samples presented here were taken between 11/18/1998 and 10/01/1999.

Total $\mathrm{Cr}$ concentrations were analyzed using a single isotope dilution method (sample volume of $\sim 12 \mathrm{~mL}$ ). Duplicates of each sample were processed (pooled standard deviation of $\pm 0.26 \mathrm{nmol} / \mathrm{kg}$, $2 \sigma)$.

Total Cr concentrations ranged between $2.38 \mathrm{nmol} / \mathrm{kg}$ and $2.97 \mathrm{nmol} / \mathrm{kg}$ (figure A.1, table A.1). A very subtle seasonal variability was detected with samples from the end of February to the end of June holding slightly less $\mathrm{Cr}$ (avg. $[\mathrm{Cr}]_{02 / 23 / 1999-06 / 30 / 1999}=2.51 \pm 0.11 \mathrm{nmol} / \mathrm{kg}$, avg. $[\mathrm{Cr}]_{\text {rest of the year }}=$ $2.75 \pm 0.22 \mathrm{nmol} / \mathrm{kg} ; \pm 2 \mathrm{SE}$ ). Therefore, our findings do not confirm the strong seasonal variations reported by Connelly et al. (2006). 


\section{References for Appendix}

Bell, J., Betts, J., Boyle, E., 2002. MITESS: a moored in situ trace element serial sampler for deep-sea moorings. Deep Sea Res. Part I Oceanogr. Res. Pap. 49, 2103-2118. doi:10.1016/S0967-0637(02)00126-7

Connelly, D.P., Statham, P.J., Knap, A.H., 2006. Seasonal changes in speciation of dissolved chromium in the surface Sargasso Sea. Deep Sea Res. Part I Oceanogr. Res. Pap. 53, 19751988. doi:http://dx.doi.org/10.1016/j.dsr.2006.09.005

Dickey, T., Frye, D., Jannasch, H., Boyle, E., Manov, D., Sigurdson, D., McNeil, J., Stramska, M., Michaels, A., Nelson, N., Siegel, D., Chang, G., Wu, J., Knap, A., 1998. Initial results from the Bermuda Testbed Mooring program. Deep Sea Res. Part I Oceanogr. Res. Pap. 45, 771-794. doi:10.1016/S0967-0637(97)00096-4 


\section{Tables for Appendix}

\begin{tabular}{|c|c|c|c|c|c|}
\hline $\begin{array}{r}\text { Sample ID } \\
\#\end{array}$ & Sampling date & $\begin{array}{r}\text { depth } \\
m\end{array}$ & $\begin{array}{r}\text { avg [total Cr] } \\
\mathrm{nmol} / \mathrm{kg}\end{array}$ & $\begin{array}{r}\text { rejected } \\
\text { avg [total } \mathrm{Cr}] \\
\mathrm{nmol} / \mathrm{kg}\end{array}$ & comments \\
\hline 90 & $11 / 18 / 98$ & 44 & 2.66 & & \\
\hline 92 & $11 / 24 / 98$ & 47 & 2.87 & & \\
\hline 93 & $11 / 30 / 98$ & 44 & 2.63 & & \\
\hline 96 & $12 / 12 / 98$ & 44 & 2.64 & & \\
\hline 97 & $12 / 18 / 98$ & 47 & 2.82 & & \\
\hline 98 & $12 / 24 / 98$ & 44 & 2.54 & & \\
\hline 99 & $12 / 30 / 98$ & 47 & 2.97 & & \\
\hline 100 & $01 / 05 / 99$ & 44 & 2.78 & & \\
\hline 101 & $01 / 11 / 99$ & 47 & 2.81 & & \\
\hline 102 & $01 / 17 / 99$ & 44 & 2.90 & & \\
\hline 103 & $01 / 23 / 99$ & 47 & 2.84 & & \\
\hline 104 & $01 / 29 / 99$ & 44 & & 2.26 & $\mathrm{pH} \sim 3.5$ \\
\hline 107 & 02/10/99 & 44 & 2.64 & & \\
\hline 108 & $02 / 11 / 99$ & 10 & 2.73 & & \\
\hline 109 & $02 / 16 / 99$ & 47 & 2.72 & & \\
\hline 110 & $02 / 22 / 99$ & 44 & & 3.34 & contaminated for $\mathrm{Pb}$ \\
\hline 111 & $02 / 23 / 99$ & 10 & 2.54 & & \\
\hline 113 & $02 / 28 / 99$ & 47 & 2.50 & & \\
\hline 114 & 03/07/99 & 44 & 2.55 & & \\
\hline 115 & $03 / 13 / 99$ & 47 & & 2.28 & $\mathrm{pH} \sim 3.5$ \\
\hline 117 & $04 / 02 / 99$ & 44 & 2.38 & & \\
\hline 120 & $04 / 14 / 99$ & 40 & 2.52 & & \\
\hline 121 & $04 / 20 / 99$ & 43 & 2.47 & & \\
\hline 123 & $04 / 26 / 99$ & 43 & 2.50 & & \\
\hline 130 & $05 / 24 / 99$ & 40 & 2.47 & & \\
\hline 131 & $05 / 30 / 99$ & 43 & 2.61 & & \\
\hline 134 & $06 / 06 / 99$ & 40 & 2.55 & & \\
\hline 137 & $06 / 24 / 99$ & 43 & 2.56 & & \\
\hline 138 & $06 / 30 / 99$ & 40 & 2.52 & & \\
\hline 140 & $07 / 05 / 99$ & 43 & 2.72 & & \\
\hline 153 & 08/27/99 & 43 & 2.76 & & \\
\hline 155 & 09/03/99 & 43 & 2.89 & & \\
\hline 156 & 09/10/99 & 43 & 2.64 & & \\
\hline 157 & 09/17/99 & 43 & & 2.39 & $\mathrm{pH} \sim 3.5$ \\
\hline 158 & $09 / 24 / 99$ & 40 & 2.76 & & \\
\hline 161 & $10 / 01 / 99$ & 43 & 2.65 & & \\
\hline
\end{tabular}

Table A.1. Total Cr concentrations between 40m - 47m depth off the coast of Bermuda are listed. 
Figures for Appendix

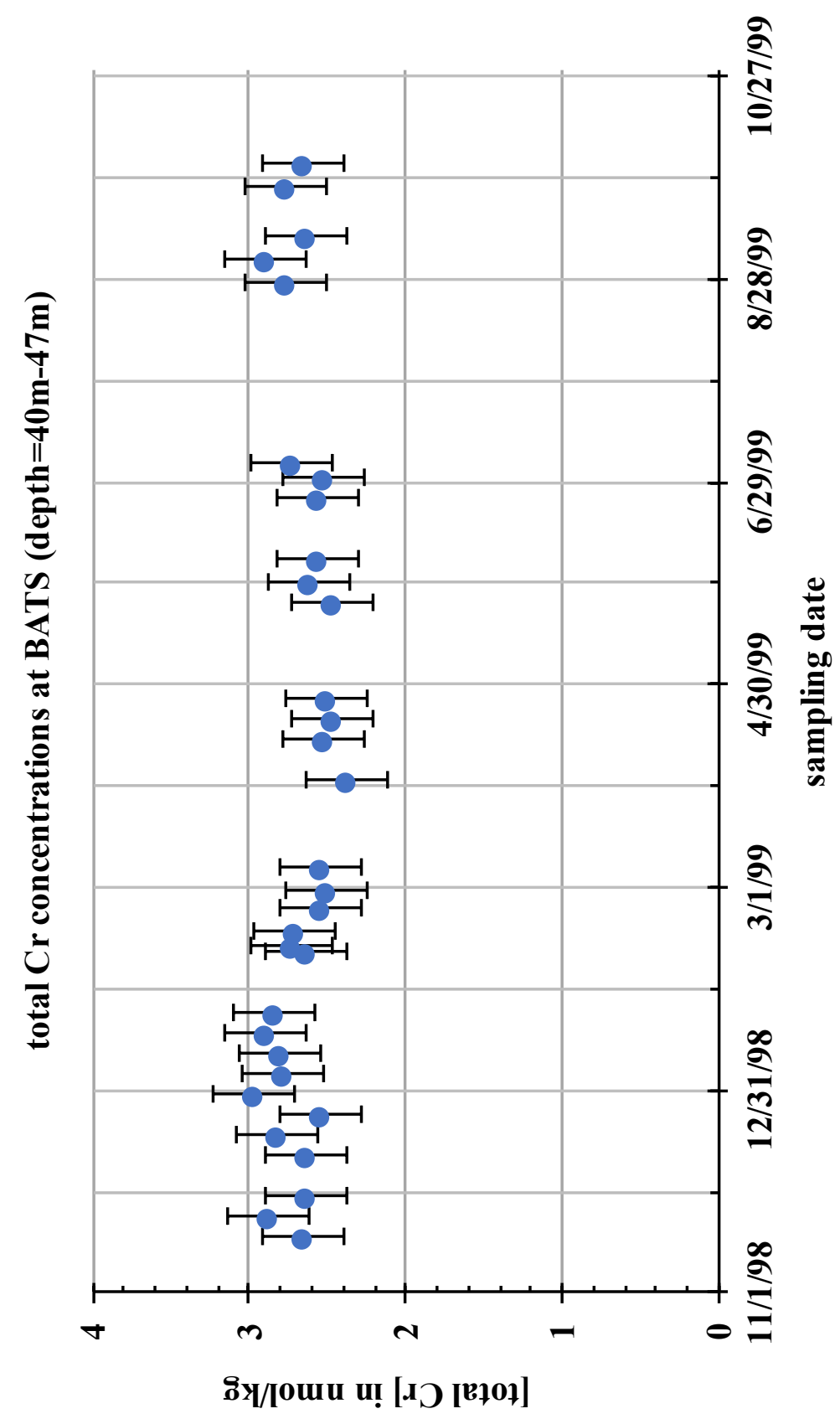

Figure A.1. Variations in total Cr concentrations of seawater samples taken between $40 \mathrm{~m}$ and $47 \mathrm{~m}$ depth off the coast of Bermuda are shown. 